\title{
Bioestratigrafía del Pérmico de la Sierra de Los Llanos, La Rioja (Cuenca Paganzo), sobre la base de la megaflora y su correlación con áreas relacionadas
}

\author{
Eliana Paula Coturel
}

Tesis para optar por el título de Doctor en Ciencias Naturales

Director: Dr. Pedro Raúl Gutiérrez

Codirector: Dr. Eduardo Morel

Facultad de Ciencias Naturales y Museo

Universidad Nacional de La Plata 
Quiero dedicar esta Tesis a mi mamá, Mónica Edith Emmerich. Creo que no hace falta dar razones de por qué una le dedica su Tesis a su Madre. Tampoco hay, en el rico idioma castellano, palabras suficientes para hacerlo.

Agradezco a todos los que hicieron posible el desarrollo de esta Tesis. A mis directores, los Dres. Pedro R. Gutiérrez y Eduardo M. Morel, por la confianza depositada y por permitirme trabajar y aprender bajo su ala. A mis compañeras de equipo, Lucía Balarino y Bárbara Cariglino, por la ayuda y el apoyo que me dieron en todos estos ańos (nota aquí: Bárbara escaneó las láminas de Glossopteris que usé en el capítulo de morfografía, es importante mencionarlo). Las quiero mucho. Y a Gustavo Correa, por el apoyo en el viaje de campo y el tiempo que compartimos en el Museo.

Lo normal sería ver aquí un listado de gente y miles de agradecimientos personales, pero a mí no me parece que sea el lugar (principalmente porque seguro que me olvido de alguien y queda muy feo al estar escrito!!). A cada persona que quiero, que aprecio, se lo hago saber (quizás no con palabras, pero sí con los gestos). Eso sí, les agradezco a todos en el MACN la compañía y los buenos momentos compartidos durante estos cinco años de Tesis, y los anteriores desde que empecé a trabajar, y a todos en la UNLP por lo mismo. Cada lugar deja una huella a su manera, espero haber aprendido de lo mejor de cada uno de ustedes.

Por último, a CONICET por las becas y proyectos que permitieron el desarrollo de esta Tesis, y a Agencia por los proyectos, y a la Facultad de Ciencias Naturales y Museo (UNLP) por ser mi segunda casa y permitirme hacer el Doctorado allí. 
Eliana Paula Coturel - Bioestratigrafía del Pérmico de la Sierra de los llanos...

¡Oid! pido a todas las estirpes divinas, grandes y pequeños, hijos de Heimdall; me pides, oh Valfödr, que te refiera las más viejas historias que yo pueda recordar

Völuspa, 1. 


\section{Índice}

Página

Resumen 1

$\begin{array}{ll}\text { Abstract } & 3\end{array}$

Capítulo I. Introducción $\quad 5$

$\begin{array}{lr}\text { Capítulo II. Antecedentes } & 12\end{array}$

$\begin{array}{ll}\text { Antecedentes Geológicos } & 16\end{array}$

$\begin{array}{ll}\text { Antecedentes Paleobotánicos } & 23\end{array}$

$\begin{array}{lr}\text { Capítulo III. Material y Métodos } & 29\end{array}$

Capítulo IV. Resultados 36

$\begin{array}{ll}\text { IV.1 Geología } & 37\end{array}$

IV.2 Paleobotánica $\quad 54$

IV.3 Análisis morfográfico de Glossopteris $\quad 115$

$\begin{array}{ll}\text { Capítulo V. Bioestratigrafía } & 131\end{array}$

$\begin{array}{lr}\text { Capítulo VI. Conclusiones } & 152\end{array}$

$\begin{array}{lr}\text { Bibliografía } & 155\end{array}$

$\begin{array}{lr}\text { Anexo } & 169\end{array}$ 


\section{RESUMEN}

Este trabajo comprende el estudio paleobotánico de los depósitos de edad pérmica que afloran en la sierra de Los Llanos, Provincia de La Rioja, y su propósito principal es ubicar estratigráficamente la flora en el contexto local y regional.

Se realizaron dos viajes de campo al conjunto de las sierras de Los Llanos y se reconocieron los sitios donde afloran las Formaciones Solca y Arroyo Totoral. Se hallaron cinco localidades fosiliferas para la Formación Arroyo Totoral en la pampa de Anzulón, entre las que se incluyen aquellas mencionadas en la literatura y una nueva localidad. Se levantaron perfiles geológicos en cuatro localidades de la pampa de Anzulón, donde fueron detallados los niveles fosilíferos. Los perfiles y niveles fosilíferos fueron correlacionados con el perfil tipo de la Formación Arroyo Totoral. Se obtuvieron cerca de mil ejemplares de plantas fosilizadas como impresiones-compresiones.

Los estudios sedimentológicos realizados confirman que la Formación Arroyo Totoral consiste de una secuencia fluvio-lacustre, que inicia con facies de abanico aluvial proximal medio, las cuales retrogradan hasta la generación de un sistema lacustre somero. Posteriormente aparecen barras de desembocadura y se desarrolla un sistema fluvial entrelazado distal, el que pasa en transición a un sistema fluvial meandriforme y culmina en un sistema lacustre somero. La secuencia estudiada comienza por el primer evento lacustre somero, el cual prograda a varios ciclos de sistema fluvial entrelazado. Hacia el Norte, mientras se genera el sistema fluvial mencionado, se desarrolla un sistema fluvial meandriforme con eventos lacustres, donde aparecen los niveles fosilíferos del tope de la secuencia. Esto permite verificar las hipótesis sobre la evolución de la sedimentación en la pampa de Anzulón durante el Pérmico.

Se reconocieron nueve niveles fosilíferos repartidos en cinco localidades, tres de los cuales permitieron la integración de los perfiles de las distintas localidades y de éstas con el perfil tipo. El estudio sistemático de la flora permitió identificar 21 taxones. Casi todos los 
grupos mencionados previamente para la Formación Arroyo Totoral mostraron mayor diversidad que la previamente conocida. A nivel específico, es la primera mención de Paracalamites cf. frigidus, Cruciaetheca patagónica y Arberia cf. madagascariensis. Se describe material que resultará en nuevos taxones, dentro de Asterothecaceae, Glossopteridales y Ferugliocladaceae, y se presentan las bases para la reasignación genérica de Bumbudendron versiforme. Se presenta un análisis preliminar de agrupación basado en la morfografía del género Glossopteris, haciendo hincapié en las características de la venación secundaria. Se presenta una variante en la descripción de las venas secundarias, cuantificando su recorrido a través de una función polinómica. Sobre ésta, se realiza un cluster analysis para verificar si forman grupos. Como resultado, se caracterizan varios grupos morfológicos y se discute la posibilidad de continuar usando esta metodología para clasificar en morfotipos.

Para el análisis bioestratigráfico se comparó el contenido paleoflorístico de la Formación Arroyo Totoral con el presente en otras Formaciones de la Cuenca Paganzo, en otras cuencas pérmicas de Argentina, y con los registros en Brasil, Uruguay y el resto de Gondwana. Se tuvieron en consideración las hipótesis de cambio climático postuladas para el Pérmico, y las dataciones radimétricas más recientes. Se pudo correlacionar la flora de Sierra de los Llanos con otras unidades coetáneas de la Cuenca Paganzo. Se ajustó la correlación de la Zona Gangamopteris inferior con la Zona Ginkgoites eximia de la Cuenca Tepuel Genoa, y con la Formación Melo de Uruguay. Se plantean hipótesis de correlación con la Cuenca Paraná de Brasil. Estas comparaciones permiten considerar a la Formación Arroyo Totoral como de edad asseliana $\mathrm{o}$ asseliana-sakmariana inferior. 


\section{ABSTRACT}

This work comprises the study of the fossil flora of Permian deposits that outcrop in Sierra de los Llanos, and its main purpose is to locate stratigraphically this flora, in the local and regional context.

During the two field trips made, outcrops sites of the Solca Formation and Arroyo Totoral Formation were recognized. Five localities from Arroyo Totoral Formation were recognized. Some of the localities were previously described and a new locality was found. Sedimentological profiles were logged at four localities to precise the position of the fosiliferous levels. Altogether, almost 1000 specimens of impression-compressions were obtained.

The sedimentological studies confirm that Arroyo Totoral Formation comprises a fluvial-lacustrine sequence, which starts with facies of a half proximal alluvial fan, which regress and become a shallow lake system. Subsequently, the system develops as a braided river system, which starts with mouth bars. Then becomes a meandering river system and culminates in a shallow lake system. The sequence recognized begins with the first shallow lacustrine event, which prograde to several cycles of a braided river system. At north a meandering river system with lacustrine events develops. Fossiliferous strata belonging to both lacustrine events were found. This allowed to test the hypotheses about the evolution of sedimentation in this site during the Permian.

Nine fosiliferous strata in five localities were recognized, three of them allowed to make a correlation between localities. The systematic study of the paleoflora allowed identifying 21 taxa. Almost every previously described group showed more diversity. At species level, it is the

first appointment of Paracalamites cf. frigidus, Cruciaetheca patagónica and Arberia cf. madagascariensis. New taxa belonging to Asterothecaceae, Glossopteridales and Ferugliocladaceae is described. The reassignment to new genera of Bumbudendron versiforme is suggested. A preliminar cluster analysis based on morphographical characters of the Glossopteris 
leaf is presented. A change in the description way of the secondary venation is proposed, taking the vein as a whole and describing its path with a function. As a result, morphogroups are described and there is a discussion about the possibility of the establishment of a morphological systematic in Glossopteris.

Biostratigraphic analysis consisted in the comparison of the paleoflora with other Formations of the Paganzo Basin, close related basins, Tepuel Genoa Basin and the coetaneous flora of Uruguay, Brazil and the rest of Gondwana. Recently postulated climate change scenarios for the Permian of western Gondwana were took into account, and also the latest published radiometric data. The general correlation within Paganzo Basin is ratified, and the existence of the Gangamopteris Biozone. Correlation with Tepuel Genoa Basin was adjusted, resulting in the correlation between lower Gangamopteris Biozone and Ginkgoites eximia Biozone of Tepuel Genoa Basin. A new element to correlate Gangamopteris Zone with Melo Formation in Uruguay is presented. Correlation hypotheses with Paraná Basin in Brazil are presented. The whole comparisons and radiometric data allowed constraining the Gangamopteris Biozone to Asselian or Asselian-Lower Sakmarian age. 
Eliana Paula Coturel - Bioestratigrafía del Pérmico de la Sierra de los llanos...

\section{CAPÍTULO I. INTRODUCCIÓN}


El Paleozoico es la primera división de tiempo dentro del Eón Fanerozoico, y transcurrió desde los 540 hasta los 251 millones de años atrás. Dentro de esta Era, los períodos Carbonífero y Pérmico conforman el denominado Neopaleozoico, o Paleozoico superior, abarcando el intervalo de tiempo desde los 359 hasta 251 Millones de años atrás (IUGS, 2013).

Durante el Paleozoico superior se sucedieron los procesos tectónicos que culminaron en la conformación de la Pangea mesozoica. Hacia el inicio del Carbonífero, se reconocen los paleocontinentes de Angara (en el Hemisferio Norte), Euramérica y Cathaysia en posición septentrional a paleoecuatorial y Gondwana en el hemisferio meridional, estando conformado este último supercontinente por África, Antártida, Australia, India, América del Sur y el Sur de China. Durante el Carbonífero y Pérmico el continente de Gondwana sufrió una rotación y traslación causadas por la tectónica global, que produjo el desplazamiento sobre su superficie del polo Sur, desde África hasta la Antártida, y consecuentemente el cambio latitudinal de los continentes. Actualmente, con mejores dataciones y datos de paleomagnetismo, se está refinando la trayectoria del polo magnético, lo que permitirá precisar la paleogeografía global (Figura I.a, López-Gamundi y Buatois, 2010; Domeier et al 2011, Isbell et al 2012).

Durante el Neopaleozoico, en un período que abarca unos 100 millones de años y comienza en el Viseano, se reconoce la existencia de una serie de glaciaciones que afectaron principalmente a Gondwana. Durante este tiempo, conocido como la "Edad del Hielo del Paleozoico tardío" (Late Paleozoic Ice Age, LPIA), se emplazaron núcleos glaciales sobre la superficie emergida, los cuales fueron avanzando y retrocediendo sobre continente en forma diacrónica (Isbell et al. 2012). En la Figura I.b, se pueden observar cuatro reconstrucciones paleogeográficas que abarcan el intervalo Carbonífero superior - Pérmico, donde se señala la posición de Argentina, y a la derecha se grafica la latitud que alcanzaron los hielos continentales (en color más oscuro, las glaciaciones registradas en Argentina). Tradicionalmente se representaba la influencia glacial con una capa masiva de hielo, que crecía y decrecía, pero trabajos más recientes han detectado centros glaciales de crecimiento individual, durante varios períodos glaciales que habrían durado de 1 a 8 millones de años. Este modelo, donde se 
alternan períodos de alta y baja temperatura, es comparable a las glaciaciones que afectaron al Cenozoico. Los efectos de estas glaciaciones fueron variando por el crecimiento y disminución de la superficie que ocupaban los glaciares, la traslación y rotación continental debida a la tectónica global y por el aumento de temperatura que se observa desde mediados hasta fines del Pérmico (Fig. I.b). Así, las variaciones climáticas condicionaron el desarrollo de los ambientes depositacionales y la evolución de la biota, promoviendo el endemismo y la diferenciación entre la flora y fauna gondwánica y aquella de los sectores paleoecuatoriales. Este aspecto dificulta la correlación entre las secuencias, dado que los patrones mundiales fueron definidos para el sector paleoecuatorial: de este modo, la ubicación estratigráfica de las secuencias gondwánicas es imprecisa.

América del Sur formó el margen occidental de Gondwana durante el Neopaleozoico, y se desarrollaron grandes cuencas sedimentarias en toda su extensión (Fig. I.c). De éstas, históricamente las más estudiadas han sido aquellas de Argentina, Brasil y Uruguay. Los depósitos sedimentarios poseen un importante desarrollo estratigráfico, facial y un abundante contenido paleontológico, lo cual redunda en el registro de una gran diversidad de ambientes sedimentarios: son por ende herramientas clave para la realización de reconstrucciones climáticas y ambientales, y un importante aporte para conocer los detalles locales en las reconstrucciones paleogeográficas. Debido a la estrecha relación entre las cuencas que se desarrollaron sobre la superficie de Gondwana, el estudio de las secuencias sudamericanas y sus fósiles es fundamental para interpretar la evolución del Hemisferio Sur.

En este marco, las secuencias sedimentarias neopaleozoicas de la Argentina se manifiestan como una buena alternativa para poder obtener información que nos permita establecer un esquema estratigráfico para el Pérmico dentro del Gondwana. Estas secuencias afloran en el Oeste argentino, en Patagonia y en Buenos Aires, y además aparecen en el subsuelo de las cuencas Claromecó-Colorado y Chacoparaná.

La Cuenca Paganzo (Azcuy y Morelli, 1970) se sitúa en el sector centro-oeste de la Argentina, en las actuales provincias de Catamarca, La Rioja, San Juan, Córdoba y San Luis. 
Cubre una superficie aproximada de $140.000 \mathrm{~km}^{2}$, y el contenido megaflorístico de esta cuenca es uno de los mejores conocidos para el país (véase Archangelsky y Cúneo, 1984, 1991; Archangelsky, 1987, 1996; Gutiérrez et al., 2006). Se encuentra limitada por el Arco de Pie de Palo al sur, las Sierras Pampeanas al Este y el Arco del Famatina al Norte, y se reconocen dos sectores: oriental y occidental, diferenciándose éstos por su dominio continental y marino respectivamente.

Dentro de esta cuenca, las sedimentitas pérmicas muestran una menor extensión que las sucesiones carboníferas. Los afloramientos principales para este período se localizan en el sector Oriental, en San Luis (Bajo de Véliz), Córdoba (Tasa Cuna) y La Rioja (Sierra de los Llanos Sierra de Maz). La secuencia de Sierra de los Llanos se destaca por exhibir depósitos formados desde el Pennsylvaniano hasta el inicio del Pérmico tardío, y ha suministrado abundantes restos fósiles, los cuales han sido estudiados desde fines del siglo XIX.

Los esquemas bioestratigráficos definidos para el Centro-Oeste de Argentina poseen una deficiencia causada por la escasa integración de la información disponible de las floras, en un marco litoestratigráfico y paleoambiental. A partir de las características que presenta (génesis, historia geológica, evolución tectónica, importante desarrollo vertical y areal de las sedimentitas contenidas), se proyecta el análisis de las floras pérmicas de la sierra de Los Llanos (Cuenca Paganzo) para salvar esta deficiencia.

Se formulan entonces dos hipótesis:

- La megaflora de la Sierra de los Llanos respondería al mismo esquema bioestratigráfico que el resto de la Cuenca Paganzo.

- La megaflora que se recupere y sus cambios son un reflejo de las adaptaciones a las variaciones paleoclimáticas, paleobiogeográficas y paleoambientales que se sucedieron a lo largo del lapso de tiempo y área considerados.

Para la verificación de estas hipótesis, los objetivos de este trabajo de Tesis incluyen la realización de estudios paleontológico-sistemáticos, sedimentológicos y bioestratigráficos. 
El estudio paleobotánico de la sección pennsylvaniana-pérmica de la Sierra de Los Llanos intentará resolver cuestiones sistemáticas de los taxones que se presentan en esta flora. La información sobre las condiciones paleoambientales que proveerá el análisis sedimentológico, en conjunción con los resultados de los estudios sistemáticos y paleofitoecológicos, permitirá una lectura integrada de la evolución de la flora y los ecosistemas estudiados, y la ulterior comparación con las floras de localidades vecinas y de sectores más alejados permitirá descubrir similitudes y diferencias que podrán ser aprovechados en pos del análisis bioestratigráfico, posibilitando el ajuste de los esquemas existentes hasta el momento en nuestro país, y su correlación entre ellos y con los propuestos para áreas vecinas. 


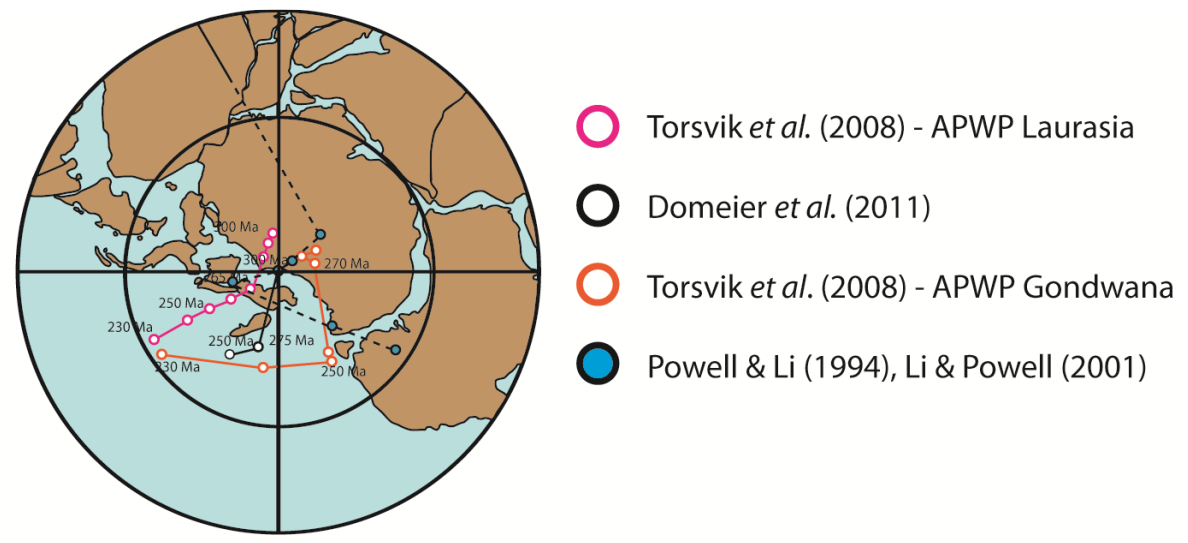

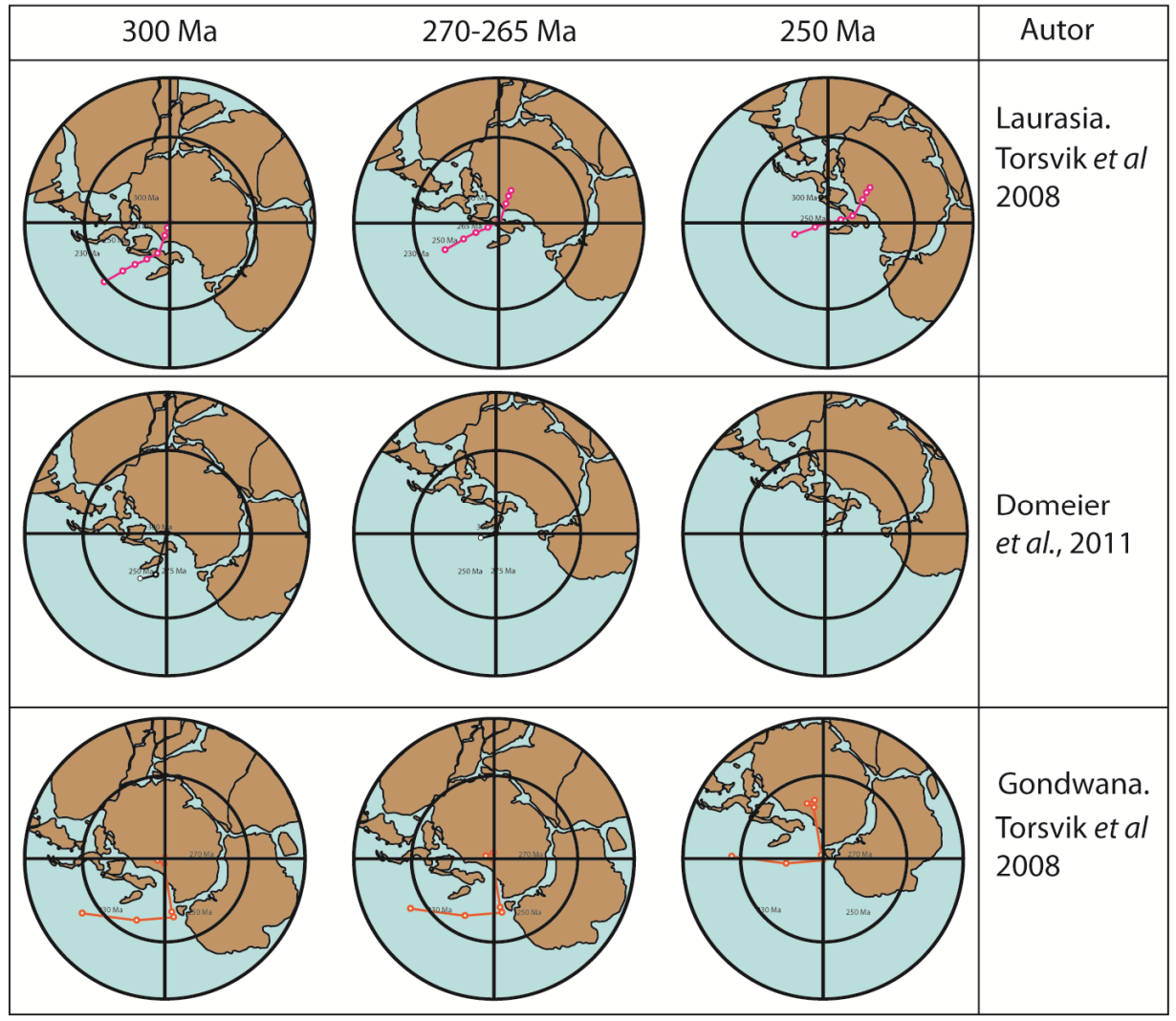

Fig. I.a. a. Vista polar de la tierra hace $300 \mathrm{Ma}$, desde el polo Sur, donde se observan las rutas de deriva polar de Domeier et al. (2011), Powell and Li (1994), Li and Powell (2001), y Torsvik et al. (2008) para Laurasia y Gondwana. Modificado de Isbell et al. (2012) b. Deriva continental de acuerdo a los movimientos en el polo magnético, para el inicio del Pérmico, mediados de éste y para el Límite Permo-triásico. 

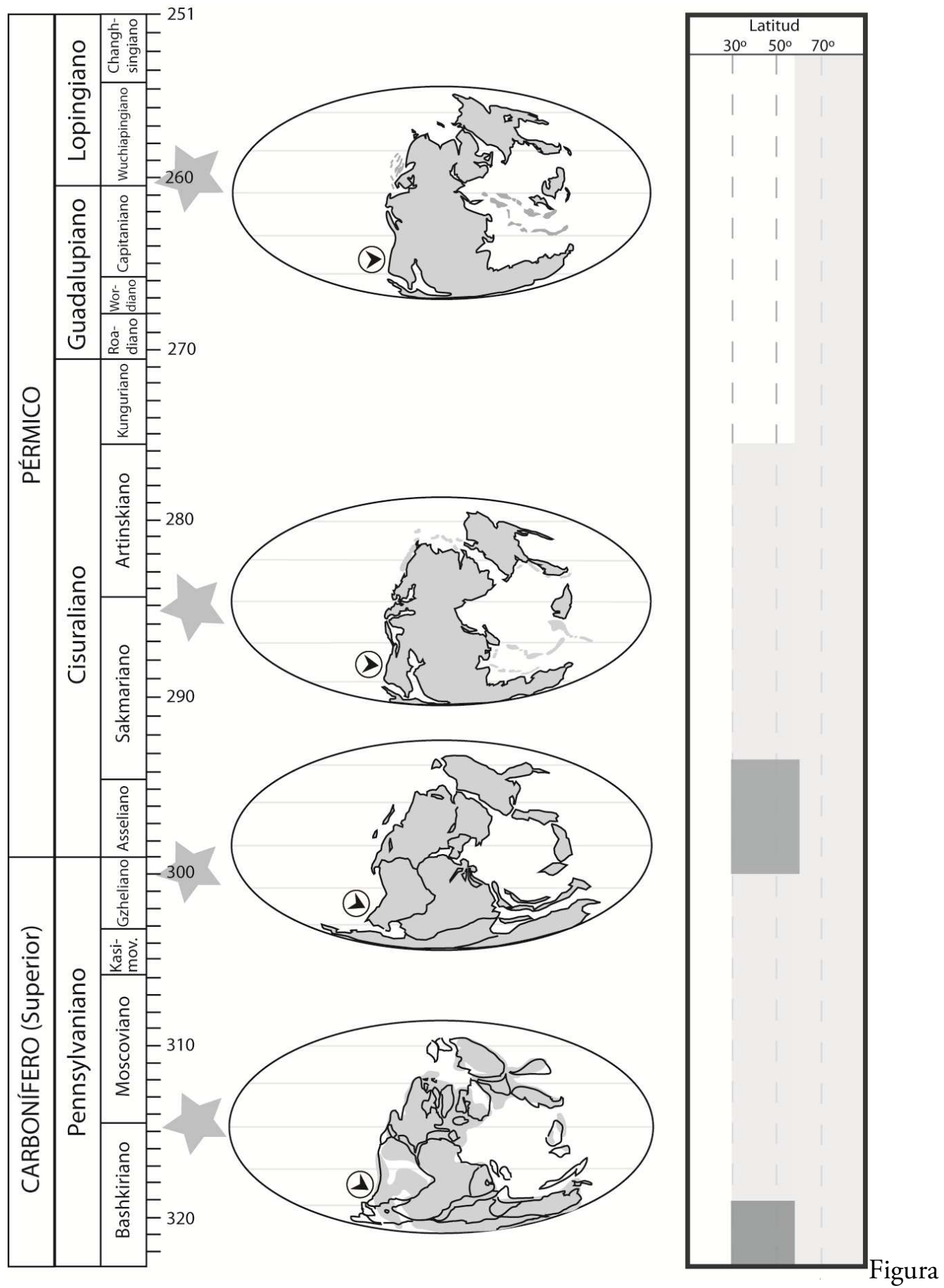

I.b. Rotación y movimiento hacia el Norte de Gondwana y Pangea en el Neopaleozoico. Se señala con una estrella la edad de las reconstrucciones paleogeográficas (modificadas de Scotese). A la derecha, se señala la latitud que alcanza el casquete glacial (gris claro) y los emplazamientos glaciales conocidos (gris oscuro). Basado en Césari et al. (2013). 
Eliana Paula Coturel - Bioestratigrafía del Pérmico de la Sierra de los llanos...

\section{CAPÍTULO II. ANTECEDENTES}




\section{Estudios geológicos y paleontológicos en Argentina.}

En la reseńa presentada en el Sistema Carbonífero (Archangelsky, 1987), se reconoce una sucesión de tres etapas en el desarrollo histórico de las investigaciones del Carbonífero y Pérmico inferior de nuestro país.

- Etapa de los pioneros (1883-1921)

- Etapa de Investigadores extranjeros (1941-1960)

- Etapa de los investigadores argentinos (1960 en adelante)

Fue durante la presidencia de Domingo F. Sarmiento, mediante la insistencia de Germán Burmeister, que se dio el primer gran impulso a las Ciencias Naturales en Argentina, con la contratación de investigadores europeos, principalmente alemanes, para promover la formación de profesores y la investigación en ciencias sobre nuestro territorio. Se eligió como sede de las investigaciones en esta temática a la Universidad Nacional de Córdoba, ciudad donde se funda la Academia Nacional de Ciencias, la cual previo a su oficialización comenzó a traer a los geólogos de la denominada "Escuela Geológica Alemana". Entre ellos, se destacan los nombres de Stelzner, Brackebush, Bodenbender, y más adelante Stappenbeck, Keidel, Penck, von Freyberg, Geinitz y Berg.

Alfredo Stelzner se desempeñó entre 1871 y 1874 como profesor de Mineralogía y Geología en la Universidad de Córdoba, realizando exploraciones por Córdoba, San Juan y Mendoza, finalmente retornando a Alemania en 1875, donde publicaría la obra Beiträge zur Geologie und Paläontologie der Argentinischen Republik entre 1876 y 1885.

Luis Brackebusch tomó su lugar entre 1875 y 1888, dirigiendo el Museo de Mineralogía y enseñando en la Cátedra de Mineralogía. Entre sus viajes de campo, podemos mencionar una primera expedición a la Sierra de Córdoba y a la Sierra de San Luis (1876), Catamarca (1878), La Rioja y San Juan (1881), Jujuy (1883), Salta, Catamarca, San Juan y La 
Rioja (1887) y finalmente San Juan y Mendoza (1888). A su regreso a Alemania publica el Mapa Geológico de la Argentina.

Guillermo Bodenbender llegó al país en 1885 como ayudante de Brackebusch, reemplazándolo en la Cátedra de Mineralogía de la Universidad de Córdoba cuando éste retornó a Alemania. A diferencia de sus antecesores, permaneció en nuestro país hasta su fallecimiento en 1941. Después de una serie de campañas a la Patagonia, donde comenzó su colaboración con el paleobotánico alemán Federico Kurtz, quien estaba a cargo de la Cátedra de Botánica de esta misma Universidad, exploró la Precordillera de La Rioja, San Juan y Mendoza, reconociendo las unidades marinas silúrico-devónicas y enviando el contenido fosilífero (invertebrados) a Alemania para su estudio. En el sector más oriental de la Precordillera descubrió los niveles fosilíferos del Paleozoico Superior, importante colección paleobotánica que estudió Kurtz, y fue depositada en la Universidad de Córdoba, hallándose colecciones menores en la Universidad Nacional de La Plata y en Alemania (Archangelsky y Arrondo, 1974). Sus investigaciones en la Provincia de La Rioja, especialmente en la Sierra de los Llanos y el Nevado de Famatina, fueron la base de los estudios del Neopaleozoico, obras consultadas hasta hoy día, donde define los Estratos de Paganzo.

Los autores del Sistema Carbonífero determinan el cierre de este primer ciclo en 1921, con la publicación del Atlas de Plantas Fósiles de la República Argentina de Federico Kurtz.

Entre 1921 y 1941, aparecieron trabajos aislados, destacando aquí los trabajos de von Freyberg (1927), Gothan (1927) y los más generales de Gerth (1932), Du Toit (1927), Groeber $(1937,1939,1940)$. Además, Bodenbender publicó las traducciones de trabajos previos de Stelzner y Geinitz entre otros (Hünicken, 2004).

Inician la segunda etapa los primeros trabajos de Frenguelli, y es el incremento de las publicaciones de investigadores argentinos lo que determina la transición a la siguiente etapa, en 1960. 
Joaquín Frenguelli fue un médico y naturalista italiano, que llegó a Argentina en 1911 para visitar a sus familiares, y permaneció en el país hasta su fallecimiento, en 1958. Vivió en el Litoral hasta 1934, cuando comienza su actividad en el Museo de La Plata, donde publicó la mayor parte de su obra: habiendo estudiado fósiles en todas las ramas de la paleontología, se destaca su contribución a la paleobotánica en general y especialmente del Paleozoico superior, y también a la estratigrafía, como en sus extensos Apuntes acerca del Paleozoico superior del Noroeste argentino.

Otros investigadores extranjeros fueron Fossa-Mancini, Keidel, Heim, Feruglio, Piatnitzky, Groeber y Polanski, y se debe destacar a los argentinos Bracaccini, Riggi, Mésigos y Amos.

Osvaldo Bracaccini realizó importantes contribuciones al estudio de los Estratos de Paganzo de Bodenbender, y su trabajo sigue tomándose como referencia para la interpretación de las relaciones entre las unidades que componen el Grupo Paganzo. (Azcuy, Net, Limarino, etc).

La etapa denominada "De los investigadores argentinos" comienza en 1960, y en el sentido literal de su nombre continúa hasta la actualidad, aunque durante los 50 años que transcurrieron desde su inicio se puede observar variación en la intensidad y los tipos de trabajos publicados.

En sus inicios, la mayoría de los investigadores se encontraban relacionados a la entonces División de Minas, Geología e Hidrología, a los Yacimientos Petrolíferos Fiscales, y a las Universidades Nacionales: con el tiempo, el CONICET fue tomando importancia en las Ciencias de la Tierra en general, y en el estudio del Neopaleozoico en particular a partir de la creación del Comité Argentino del Programa Internacional de Correlación Geológica, organizado entre otros para el Proyecto 42 - Upper Paleozoic of South America, auspiciado por UNESCO e IUGS en 1975. 
Acompañando a la labor geológica, se propagó la la labor en paleobotánica, con cada vez mayor cantidad de investigadores en este ámbito, además de en las otras ramas de la paleontología. Así, a fines de los años '70 e inicios de los '80 se realizaron diversos trabajos sistemáticos, paleoecológicos y estratigráficos, como el extenso y minucioso El paleovalle de Malanzán: nuevos criterios para la estratigrafía del Neopaleozoico de la Sierra de los Llanos (Andreis et. al. 1984). Más adelante aparecen diversas síntesis del conocimiento paleobotánico para nuestro país. A fines de esta década, se publica el tomo del Sistema Carbonifero en la República Argentina, mientras que a pesar de la merma en la cantidad de publicaciones durante la década del '90, fue publicado El Sistema Pérmico en la República Argentina y en la República Oriental del Uruguay, completándose así la síntesis del conocimiento geológico y paleontológico del Neopaleozoico en Argentina.

En el actual siglo XXI se observa un auge en los trabajos de vertiente paleopalinológica, y la posibilidad de acceder a herramientas de datación absoluta permite precisar la edad de las formaciones y de su contenido fosilífero, resolviendo problemas de correlación local y regional, y exacerbando el rigor en el análisis de los datos, promoviendo así un nuevo ciclo de trabajos de síntesis regional de la información.

\section{Los “Estratos de Paganzo" en la Sierra de los Llanos.}

En sus obras de 1894 y 1896 "Sobre la edad de algunas formaciones carboníferas de la República Argentina“ y “Devono y Gondwana en la República Argentina” Bodenbender constata la presencia de Gondwana inferior en nuestro país y de una flora de Glossopteris en la Pampa de Ansulón (sic). En el segundo trabajo reitera que los estratos fosilíferos, que ocurren en discordancia sobre las "pizarras arcaicas" (basamento cristalino?) y sobre los niveles silúricos y devónicos deben ser unidos bajo una expresión (Permo-Carbón). La equivalencia de las secuencias aflorantes en el noroeste de nuestro país con aquellas de la India ofrecía un nuevo 
argumento a favor del continente de Gondwana, llevando al autor a postular un "GondwanaArgentina", previo a las hipótesis de Wegener y du Toit.

Es en su obra de 1911 donde define los "Estratos de Paganzo", denominando así a los terrenos Carbonífero, Pérmico y Triásico -excluyendo al Rético-. Acusa una serie de estratos de entre 800 y 1500 metros de espesor, dispuestos de forma concordante, compuestos en la parte inferior por conglomerados y arcosas gris amarillento, esquistos carboníferos con plantas fósiles y culminando en areniscas coloradas. Pese a referir que se hallan en transición, distingue tres pisos: es notable señalar que los describe en dos secciones, "Piso I" y "Piso II y III".

En el Piso I reúne a las sedimentitas carboníferas, refiriendo una secuencia que comienza con conglomerados gris amarillentos, que aparecen especialmente en la sierra de los Llanos, sucedidos por arcosas, vaques y esquistos carboníferos con plantas. Este piso alcanza su mayor desarrollo vertical en nuestra área de estudio, en la zona de Malanzán-Loma Larga, mientras que en otros sectores puede desaparecer, apoyando el Piso II directamente sobre el basamento. El Piso II se distingue, según sus propias palabras, del Piso I por la predominancia de estratos finos arcillosos o cuarzosos de color rojo, y del Piso III por el alto contenido de caliza. La concentración de caliza es tal, que puede formar concreciones o bancos. Los estratos arcillosos y calcáreos pueden presentar silicificación parcial. Por último, el Piso III se diferencia por su color rojizo más oscuro, la falta de sedimentos calcáreos y que su material areniscoso es más grueso: petrográficamente es similar a los otros dos pisos.

von Freyberg, en 1927, publica un extenso estudio geológico de la Sierra de los Llanos. En la sección "Das Tal des Río Anzulón zwischen Río Anacates und Arroyo Totoral” realiza una descripción y serie de perfiles geológicos, definiendo las "Capas de Catuna” (die CatunaSchichten) como un cuerpo de roca que yace discordantemente sobre el basamento, sea este gneis, granito o capas paleozoicas que sufrieron metamorfismo de contacto. Las "capas de Catuna" comienzan con un conglomerado y arenisca de color rojizo oscuro, con estratificación cruzada, al que se superponen unos 10 metros de "pizarras arenosas y esquistos" con plantas fósiles, y sobre éstos aparecen areniscas rojas y conglomerados. Para estos últimos señala que se 
habrían depositado en un ambiente fluvial, y que "las morrenas son bastante escasas". Toda la flora extraída de esta sección pertenece al mismo nivel, y al comparar con la flora del Piso I de Bodenbender, a la que asigna edad pérmica inferior (“unteres Perm”), da a la flora de Catuna (que no es más que la del Arroyo Totoral) una edad pérmica superior (oberes Perm). En la zona de Olpa y Pampa de Anzulón señala también la presencia de las “capas de Catuna”. Hacia el Oeste, en "Solca - Paß nach Malanzan" describe la zona del "Violettes Konglomerat" o Conglomerado Violeta, las cuales se encuentran entre el "unteres Perm”, y el Triásico: las dos opciones de edad que estima son Pérmico inferior, o corresponder a una variación de facies de las "capas de Catuna", y ser por ende de edad pérmica superior, hipótesis que, a su criterio, es más plausible que la primera. Entre su Pérmico inferior, Pérmico superior y Triásico, reconoce contactos discordantes, debidos a que se superpone también sobre basamento cristalino (en el caso del contacto entre el Pérmico inferior y el superior), y a fallas y pliegues en la base del Trias.

Bracaccini (1946) realiza un minucioso estudio y de los estratos de Paganzo en la Sierra de los Llanos, y determina que en este conjunto de serranías afloran sólo los pisos I y II, descartando la presencia del Piso III. Estos pisos rellenan la cuenca de Solca y sus ramificaciones. Confirma a Bodenbender al rechazar la existencia de una discordancia entre los Pisos I y II, describiendo una transición paulatina entre ambos. La disposición “pseudotransgresiva” de las capas sobre el basamento se explica, según sus palabras, por el “progresivo relleno de la cubeta sin participación de movimientos relativos de las áreas de acumulación y deposición”.

El Piso I tendría un espesor variable, de acuerdo a su disposición central o marginal en la cubeta, y observa la mayor potencia en la zona entre Malanzán y Loma Larga, donde reconoce cinco unidades:

- Conglomerado basal $(200 \mathrm{~m})$ de color grisáceo a verdoso, pobremente estratificado, integrado por bloques mal seleccionados de granito en matriz arcósica; 
- Grupo de la Divisoria (ca. $800 \mathrm{~m}$ ) con dos secciones: la inferior dominada por arcillas y areniscas amarillentas finamente estratificadas, con abundantes restos de plantas, y la superior arenosa, de arcosas macizas o con estratificación entrecruzada. Su potencia sería de $400-450$ y $300-350$ m respectivamente;

- Conglomerado Intermedio $(5-10 \mathrm{~m})$, compuesto por rodados graníticos y con algunas lentes de areniscas amarillentas;

- Complejo de Esquistos Carbonosos $(80 \mathrm{~m})$ formado por arcillitas carbonosas de color negro intenso;

- Conglomerado Amarillo-Verdoso hasta Violado (270m), compuesto por bancos lenticulares de conglomerados medianos y areniscas gruesas, con lentes y capas delgadas de areniscas micáceas con restos de plantas hacia la parte superior; el color dominante es gris blanquecino en los tres cuartos inferiores, volviéndose rojo hacia el techo. Incluiría este piso al "Violetten Konglomerat" de von Freyberg. Entre el Complejo de Esquistos Carbonosos y el Conglomerado Amarillo Verdoso hasta Violado existiría una relación discordante, hallándose en este último rodados del nivel infrayacente.

El "Piso II" de Bodenbender fue denominado "Capas Rojas", apoyaría en forma concordante sobre el Piso I (tal como señala Bodenbender 1911) y en él se suceden un "Conglomerado Rojo", el "Nivel del Arroyo Totoral" -caracterizado por una sucesión de areniscas conglomerádicas, conglomerados finos y arenosos, arcosas, margas, arcillitas con restos de plantas y calizas arenosas de color rojo- y por encima otro conjunto, también de color rojo, compuesto por areniscas finas, calizas y fangositas arenosas. Bracaccini reconoció tres estratos plantíferos, siendo aquel del "Nivel del Arroyo Totoral" el superior, asignándole edad carbonífera tardía o pérmica más baja (apoyándose para ésto en Frenguelli (1926)).

Furque (1968) es quien otorga el nombre de Formación Malanzán a las unidades en las que Bracaccini divide al Piso I. 
Di Paola (1972) correlaciona los afloramientos de este conjunto serrano con los de la Sierra de Paganzo y Sierra Brava. Para esto, utiliza argumentos sedimentológicos, petrológicos y paleoambientales.

Azcuy (1975) reconoce tres miembros en la Formación Malanzán: Divisoria, Estratos Carbonosos y Conglomerado Amarillo Verdoso a Violado: incluye el Conglomerado Basal en el miembro Divisoria, y el Conglomerado Intermedio en los Estratos Carbonosos. Señala que los miembros inferiores podrían corresponder a una misma Formación, separados del Conglomerado Amarillo Verdoso a Violado, por la relación pseudoconcordante entre ellos. En concordancia y mediante un pasaje transicional se apoya la Formación La Colina, la cual es subdividida en dos miembros: un miembro inferior $(45 \mathrm{~m})$ donde alternan conglomerados gruesos, bancos lenticulares de sabulitas y areniscas medianas, y un miembro superior (de más de $50 \mathrm{~m}$ ) compuesto por areniscas finas y limolitas de color rojo. Describió esta unidad apoyándose en concordancia, en forma transicional, sobre el intervalo estratigráfico que el autor identificara como Formación Malanzán.

Un grupo de geólogos y paleobotánicos, liderado por el Dr. R. Andreis, publicó en la década del '80 una serie de trabajos tendiente a concluir la estratigrafía y paleoambientes de toda la sucesión neopaleozoica de la sierra de los Llanos, en el marco del Proyecto 211 IGCP "Paleozoico superior de Sudamérica". La primera de las publicaciones (Andreis et al, 1984) consiste en la definición formal de la Formación Arroyo Totoral. Aquí, se presentó una columna estratigráfica integrada (Fig. 3, Capítulo IV.1) del Pérmico temprano de la sierra de Los Llanos, consistente en las formaciones Arroyo Totoral y La Colina, superpuesta la segunda en concordancia sobre la primera. El análisis de facies realizado permitió la interpretación paleoambiental y la reconstrucción paleogeográfica de la sucesión. La Formación Arroyo Totoral, caracterizada por su color gris verdoso, se depositó en una secuencia ambiental de abanicos aluviales, sistemas fluviales entrelazados proximal y lacustre somero: esta última asociación de facies contiene los niveles fosilíferos. La Formación La Colina representa un sistema fluvial entrelazado distal, se distingue por sus colores rojizos, y carece de fósiles. 
Andreis et al. (1986), reconocieron cuatro unidades formacionales en el sector Malanzán-Loma Larga, esquema estratigráfico que se extendió hacia el área comprendida por Loma Larga-OltaDique de Anzulón. Allí fueron descriptas las formaciones Malanzán, Loma Larga, Solca y La Colina. Para las formaciones Solca y La Colina, la transición fue descripta como aquella entre Arroyo Totoral y La Colina. Culminan esta serie de trabajos los estudios paleofitoecológicos de Cúneo (1984) y Cúneo y Archangelsky (1996), que serán tratados en la sección de paleobotánica.

En 1998, Net reinterpreta los depósitos del Conglomerado Amarillo Verdoso hasta Violado de Bracaccini, considerando que la discordancia ubicada en su base (local, según Bracaccini) se trataría "de una fuerte discordancia erosiva especialmente visible en sectores del borde de la cuenca neopaleozoica", y que se habría originado en los movimientos de finales del Carbonífero, responsables entonces de los depósitos de abanicos aluviales observados en la zona, siendo visible como discontinuidades menores o paraconcordancias hacia el centro de la cuenca. De este modo, el Conglomerado Amarillo Verdoso a Violado es incluido en la Formación Solca, y la discordancia se localiza, no entre ciclos de la Formación Loma Larga, sino como contacto entre ambas formaciones. Además, se asigna a las formaciones Solca y Arroyo Totoral edad pérmica inferior (Figura II.a).

En 1999, Net y Limarino presentan una interpretación de la evolución paleogeográfica de los depósitos de la Sierra de Los Llanos para el Paleozoico Superior en esta región. Reconocen tres intervalos de depositación: Namuriano-Westfaliano, con restricción a los paleovalles de Malanzán-Solca y Olta; Estefaniano-Pérmico, ampliándose la cuenca hacia los sectores de Anzulón y Olpas (depositación de las formaciones Solca y Arroyo Totoral), y a partir del Pérmico inferior, una extensión de los depósitos hacia el área más oriental de las sierras. En la primera etapa, las Formaciones Malanzán y Loma Larga se desarrollaron como sistemas fluvio-deltaicos en condiciones de alta subsidencia local. En la segunda etapa, cuyo origen sería una serie de movimientos tectónicos que ampliaron la cuenca, se desarrollaron sistemas fluviales y secuencias de abanicos aluviales. Por último, la Formación La Colina 
correspondería a una expansión lenta del área depositacional, solapándose las secuencias fluviales sobre el basamento y los depósitos de las etapas anteriores.

Además, definen horizontes guías y realizan una correlación estratigráfica con los perfiles de otras dos localidades, Paganzo y Huaco, que se encuentran en el ámbito oriental y occidental de la cuenca respectivamente. El sector de Sierra de los Llanos se correspondería así al borde oriental de la cuenca de Paganzo. De esta manera, explican la diferencia en el relleno sedimentario de toda la región.

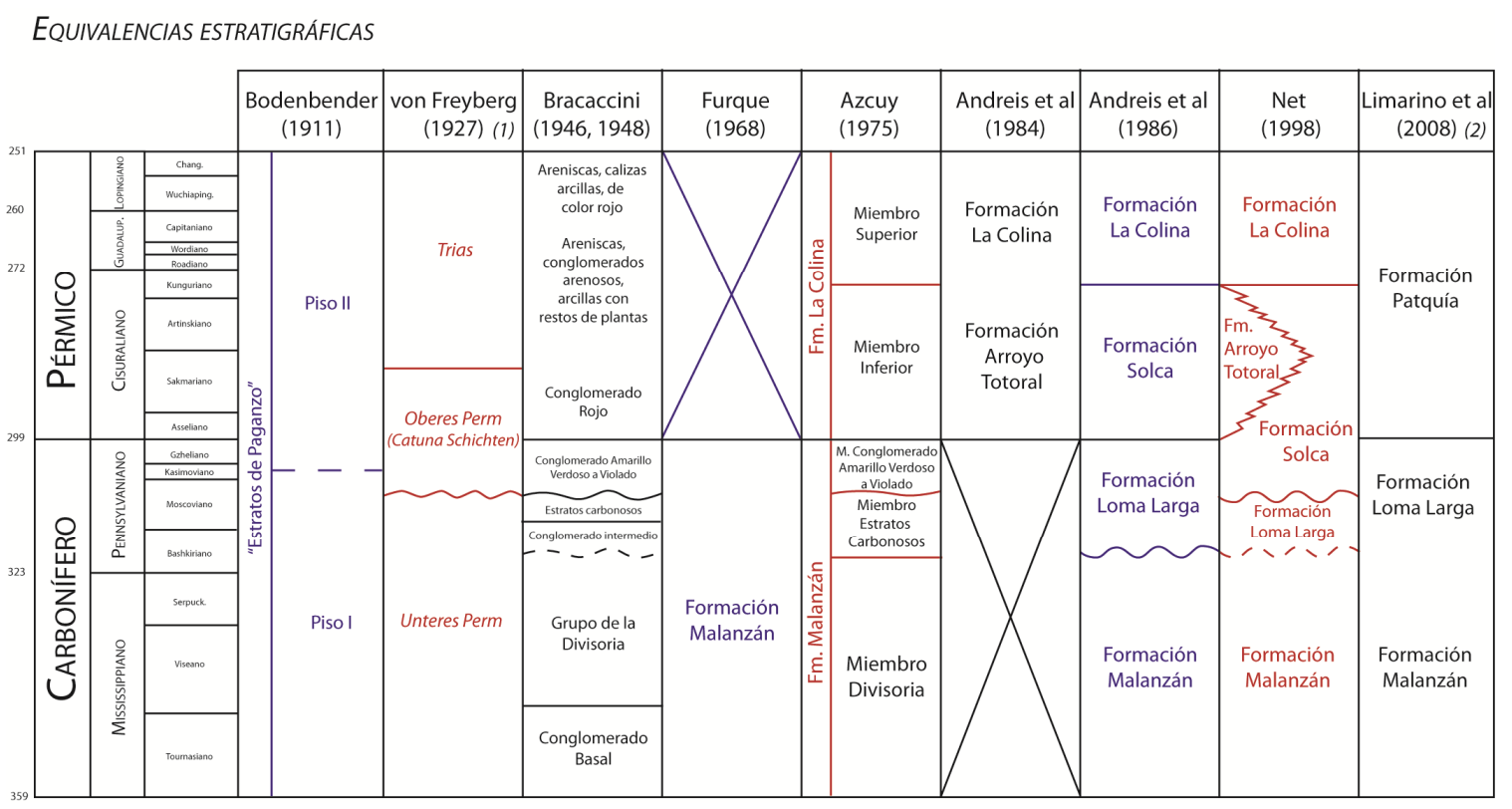

Figura II.a. Equivalencias estratigráficas. Basado en Net y Limarino (1999). Referencias: (1) Oberes Perm (Pérmico superior) incluye al O y N, en la Cuenca de Solca, el Conglomerado Violeta. von Freyberg señala que quizás puede ser Unteres Perm. Al Sur, incluye conglomerados rojos oscuros. En la Pampa de Anzulón incluye la sucesión del Arroyo Totoral (base de conglomerados rojos y areniscas, pelitas arenosas grises con plantas fósiles y techo de conglomerado rojo y areniscas). En Olta, incluye conglomerados rojos oscuros. (2) En el texto de la hoja Chamical, Limarino et al (2008) citan a la formación Solca en el sentido de Andreis et al. (1986), por lo tanto el Conglomerado Amarillo Verdoso a Violadovuelve a incluirse en la Formación Loma Larga (a diferencia de Net, 1998, y Net y Limarino, 1999) 
Limarino et al. (2008), en la página 31 de la Hoja Geológica 3166-I Chamical señalan que los depósitos de las formaciones Solca, Arroyo Totoral y La Colina sensu Andreis et al. (1986) “no resultan mapeables a escala 1:250.000” y que estos depósitos constituirían "intervalos estratigráficos pequeños, comparables a miembros", que pueden ser comparados en otros sectores de la cuenca con facies de la propia Formación Patquía, nombre que dan a todo el conjunto sedimentario pérmico de la Sierra de los Llanos. Asimismo, respecto de la Formación Arroyo Totoral, detallan que su escasa extensión areal los lleva a considerarla "una facies lacustre dentro de la Formación Patquía”.

\section{La tafoflora Pérmica de Sierra de Los Llanos}

En esta sección se tratarán los hallazgos de flora fósil en los "Estratos de Paganzo" en Sierra de los Llanos, con énfasis en los Niveles del Arroyo Totoral, y prestando atención a la flora de la Formación Solca. En la Tabla xxiv se presentará el listado del material mencionado.

Fue Bodenbender, en 1895, quien dio la primera referencia a una flora fósil comparable a la flora del Bajo de Véliz en el sector que nos ocupa en esta Tesis, publicando una lista de plantas originarias de la Pampa de Anzulón en 1912. Este material fue determinado por Kurtz. Las plantas proceden de dos niveles separados geográficamente. El primero de ellos se localiza poco arriba de la desembocadura del Arroyo Totoral en el Río Anzulón (= Río Solca), caracterizado como esquistos arcillosos gris-amarillentos. El segundo nivel se ubica $350 \mathrm{~m}$ al Sur del Arroyo Totoral, al E del camino que va a Peña: un banco de margas grises o negras cubierta de conglomerados y areniscas. En ellos reconocen Neuropteridium validum Feistm. Var argentinae Kurtz, Pachypteris riojana Kurtz, Glossopteris retifera Feistm., Glossopteris indica Schimp. (G. comunis Feistm.), Phyllotheca deliquescens (Goepp.) Schmalh., Phyllotheca leptophylla Kurtz, Annularia argentina Kurtz, Noeggerathiopsis hislopi Feistm. Et var. cuneifolia Kurtz, Cyclopitys dichotoma Feistm., Cladophlebis mesozoica Kurtz (=Pecopteris sp.) y Walchia sp. 
Bodenbender considera que ambos niveles son equivalentes, diferenciándose en dos taxones citados sólo para el segundo horizonte (Pecopteris sp. y Walchia sp.). En la continuación de los depósitos al norte, río arriba, entre Unquillar y Arado, y en la quebrada de Olta entre Agua Negra y Chimenea se halló Neuropteridium validum. También en los alrededores de Olta se hallaron troncos permineralizados.

En la zona de Aguadita-Chamical refiere la presencia de una flora compuesta por Lepidodendron y Noeggerathiopsis hislopi. En el extremo sur de la Sierra de Chepes registró una flórula mal conservada donde se reconocen Noeggerathiopsis y Equisetites.

Kurtz (1921), en su Atlas, ilustra en las láminas VIII a XIII el lote de plantas colectado por Bodenbender, y que conforma la tafoflora de la Sierra de los Llanos. Ésta está compuesta por Pecopteris sp., Glossopteris browniana, Gondwanidium (Neuropteridium) validum var. argentina, Noeggerathiopsis hislopi, Noeggerathiopsis sp., Cyclopitys dichotoma, Aphlebia sp., Phyllotheca leptophylla, Annularia argentinae, Walchia sp. Se describe para esta localidad Neuropteridium validum Fst. y $N$. validum var. argentina: todas las otras determinaciones carecen de comentarios o descripciones en el texto.

von Freyberg (1927) expone un breve listado de plantas determinadas por Gothan para Aguadita y Arroyo Totoral: para la primera localidad, Noeggerathiopsis hislopi, Gondwanidium("Neuropteridium") validum var argentina y restos indeterminables, y para la segunda localidad Linguifolium aregentinum, que refiere afin a Glossopteris indica. Lista también los ejemplares de la Colección de Bodenbender. Realiza una discusión sobre los géneros citados, y referente a la edad, dentro del Pérmico se inclina hacia un Pérmico superior, aunque nunca Triásico, debido al hallazgo de formas permocarboníferas referido por Keidel (1922).

Bracaccini (1946), en su detallado estudio geológico, define dos horizontes plantíferos para el Piso I. El horizonte inferior, en el Grupo la Divisoria, cerca de Aguadita, contiene Lepidodendron (dos especies), Gondwanidium sp. y Noeggerathiopsis sp.; las mismas formas aparecen nuevamente en el Conglomerado Amarillo-Verdoso hasta Violado. Para los niveles de Arroyo Totoral, menciona que la flora es congruente con los listados taxonómicos de 
Bodenbender y Kurtz. Recalca que esta flora se encuentra a unos 450-500 m que los niveles plantíferos de la Divisoria, y a unos $300 \mathrm{~m}$ del nivel localizado en el Conglomerado, y localiza a los niveles del Arroyo Totoral en el Piso II, por su vinculación con las capas rojas. Asimismo, compara esta flora con la del Bajo de Véliz, de edad Pérmica inferior, y aduce que teniendo tal edad, el Piso II no podría llegar a un Triásico (como señalaban autores anteriores) sino que correspondería al último período del Paleozoico.

En 1949, Frenguelli describe una flora proveniente de dos nuevos niveles de los Estratos del Arroyo Totoral, precisando la ubicación de los mismos. El primer nivel, el más antiguo, se encuentra un kilómetro al Noroeste del pueblo de Solca, y consiste de una toba arcillosa gris clara con improntas vegetales: destacan aquí la presencia de Calamites sp., Gondwanidium plantianum, Cyclopteris sp,. y Gangamopteris cyclopteroides. El segundo nivel se halla próximo al pueblo de Unquillal, al SO del camino y a un kilómetro del vado del torrente. Consiste en un "esquisto arcilloso compacto, gris", donde menciona la presencia de Gondwanidium argentinum, Noeggerathiopsis hislopi, Odontopteris sp., Barakaria dichotoma y Walchia kurtzi. Ambos niveles corresponderían a los Estratos del Arroyo Totoral, y la presencia de Barakaria dichotoma favorece la asignación de las capas al Pérmico inferior.

Archangelsky y Arrondo (1973) en ocasión de realizar una revisión del material ilustrado por Kurtz, hallaron una porción de la colección original de Bodenbender en el repositorio del Museo de La Plata (Facultad de Ciencias Naturales y Museo, Universidad Nacional de La Plata), añadiéndola a las piezas más conocidas, depositadas en la Cátedra de Paleontología de la Facultad de Ciencias Exactas, Físicas y Naturales de la Universidad de Córdoba. Realizan las siguientes determinaciones: Phyllotheca leptohylla Kurtz, Asterotheca feruglioi Frenguelli, Sphenopteris sp., Glossopteris occidentalis White, Gangamopteris obovata (Carr.) White, Cordaites hislopi (Bunbury), Paranocladus? fallax Florin, Samaropsis sp., Arberia cf. minasica White, Botrychiopsis plantiaza (Carr) Archangelsky y Arrondo, (Rhodea) criciumana Rigby. 
Archangelsky y Arrondo (1974) describen dos especies de Gingkgoales, dentro de la flora de Kurtz: Ginkgophyllum diazii y Ginkgophyllum criciumensis. Bernardes de Oliveira (1977) cambia la asignación genérica de esta segunda especie, combinándola como Notoangaridium criciumensis (Rigby) Bernardes de Oliveira.

Andreis et al (1984), en la definición de la Formación Arroyo Totoral, añaden a la lista de Archangelsky y Arrondo (1973, 1974) a ?Buriadia isophylla Guerra Sommer y Bortoluzzi, Eucerospermum sp., Glossopteris wilsonii (Seward) Archangelsky et al. (1981), Ginkgophyllum sp.

Cúneo (1984) y Cúneo y Archangelsky (1996) realizaron estudios fitopaleoecológicos en la Formación Arroyo Totoral. Cúneo (1984) menciona la presencia de Phyllotheca sp., Botrychiopsis plantiana, Cordaites sp., Ginkgophyllum, Glossopteris wilsonii, Paranocladus, mientras que en el siguiente trabajo se agrega la presencia de "semillas" y Samaropsis.

Limarino y Césari (1984) reportan el primer hallazgo de flora fósil para la Formación La Colina, la cual incluye una asociación de indudable edad pérmica: Cordaites cf. hislopi (Bunbury) Seward y Leslie, Euryphyllum whittianum Feistmantel, Gangamopteris spp., Glossopteris cf. wilsonii (Seward) Archangelsky, Archangelsky y Cúneo, ?Rhabdotaenia sp. y Paracalamites australis Rigby. Esta flora fue descripta en detalle por Césari (1987).

Andreis et al (1986), en su detallado trabajo sobre las secuencias aflorantes en el valle de Malanzán, refieren para la Formación Solca un nivel fosilífero portador de licófitas de mediano porte fértiles, Botrychiopsis cf. Plantiana, Cordaites sp., Cordaicarpus sp., Ginkgophyllum sp., y coníferas. Cúneo (1987) actualiza este listado, asignando las licófitas al género Brasilodendron, y sugiriendo para las coníferas el género Paranocladus. En la localidad de "El Loro", siempre dentro de la Formación Solca, añade al registro de Ginkgophyllum una flora más completa, identificando Dicranophyllum sp., Botrychiopsis plantiana, Paranocladus sp., Pecopteris sp., Alloiopteris sp., y abundantes semillas. Para la Formación La Colina reconoce, en la localidad de Tacopayana, una tafoflora similar a la de Arroyo Totoral, aunque en facies diferente, compuesta por Ferugliocladus? Riojanum, Botrychiopsis plantiana, Samaropsis sp., Phyllotheca sp., Cordaites sp. y Euryphyllum sp.. Postula a su vez que los "Estratos rojos" de la base de la 
Formación La Colina no estarían vinculados a un a condición de aridización general, sino que su coloración correspondería a cambios diagenéticos.

Álvarez y Fernández Seveso (1987) para los depósitos que refieren a la Formación Arroyo Totoral en el Cerro Horcobola, mencionan una flora compuesta por Phyllotheca leptophylla, Paracalamites australis, Botrychiopsis plantiana, Gangamopteris obovata, Cordaites hislopi, Genoites cf. patagonica, Paranocladus sp. y Cordaicarpus sp. A.

A partir de los estudios de Barreda (1985, inédito) se realizaron dos publicaciones sobre los niveles fosilíferos presentes en la ladera oriental de la Sierra de los Llanos. La secuencia neopaleozoica se puede estudiar en dos localidades, La Huerta (ya mencionada por Bracaccini en 1946) y Santa Bárbara, ambas al Norte de la ciudad de Olta, camino de Chamical. En 1994, Barreda y Césari describen para el nivel fosilífero superior de La Huerta Glossopteris wilsonii, Gangamopteris obovata, Ottokaria sp. y Cordaicarpus sp. En 2007, Coturel et al describen los materiales hallados por Barreda en las capas inferiores de las dos localidades, que referirían estos niveles a una edad Pennsylvaniana. La flora del Nivel Inferior en La Huerta está compuesta por Paranocladus? fallax Florin, Samaropsis nunezi García, Eucerospermun nitens Feruglio, Cordaites hislopi (Bunbury) Seward, cf. Bumbudendron versiforme Gutiérrez et al. y cf. Eusphenopteris sp., mientras que el nivel de Santa Bárbara presenta sólo cf. Bumbudendron versiforme. La referencia litoestratigráfica dada por Barreda et al. (1984) no fue muy clara, pero el contenido florístico descripto por Barreda y Césari (1994) les permitió correlacionarlo con la flora de la Formación Arroyo Totoral. Por las características litológicas y las estructuras sedimentarias presentes en la secuencia que incluye al nivel con Glossopteridales, este es referible a la Formación Arroyo Totoral, mientras que la sección inferior del perfil de La Huerta es referido por Coturel et al (2007) a la Formación Solca, y en el caso de la secuencia de Santa Bárbara, que porta solo licófitas, Coturel et al (2007) la refieren a la Formación Loma Larga.

Archangelsky et al (1996) realizan un sumario de las especies en las distintas cuencas y unidades litoestratigráficas. Para la Formación Arroyo Totoral, citan Asterotheca feruglioi Frenguelli, Paracalamites australis Rigby, Phyllotheca leptophylla Kurtz, Phyllotheca sp., 
Botrychiopsis plantiana, Sphenopteris sp., Cordaites hislopi, Ferugliocladus riojanum Arch. y Cúneo, Paranocladus (?) fallax, Ginkgophyllum sp., Arberia cf. minasica, Gangamopteris obovata (Carruthers) D. White, Glossopteris cf. occidentalis White, Glossopteris wilsonii, Cordaicarpus sp., Samaropsis kurtzii Leguizamón, Samaropsis sp. Para la Formación Solca reconocen Brasilodendron sp., Paracalamites australis, Cordaicarpus acuminatus, Cordaicarpus cesariae, Cordaicarpus sp., Cordaites sp., Ginkgophyllum diazii, Ginkgophyllum sp., Paranocladus sp., Samaropsis nunezii. Para La Colina, menciona los taxones ya referidos por Limarino y Césari (1984): Paracalamites australis, Euryphyllum whittianum Feistmantel, Ginkgophyllum sp., Glossopteris cf. occidentalis, Glossopteris wilsonii y Samaropsis sp.

Austin, Escapa y Cúneo (2008) mencionan la presencia de Cruciaetheca, Botrychiopsis plantiana, Ginkgophyllum criciumensis y Buriadia? en distintas localidades de la Formación Arroyo Totoral. Crisafulli y Herbst (2008) describen para la Formación Solca cinco especies de leños permineralizados: Agathoxylon kumarpurensis (Bajpai y Singh) Crisafulli y Herbst, Agathoxylon ningahense (Maheshwari) Crisafulli y Herbst, Podocarpoxylon indicum (Bhardwaj) Bose y Maheshwari, Chapmanoxylon jamuriense Pant y Singh, Chapmanoxylon oltaense Crisafulli y Herbst. Reafirman allí la edad pérmica inferior para la Formación Solca, dadas las características de los leños estudiados, y la ocurrencia de estos géneros en otras localidades pérmicas del resto del mundo. 
Eliana Paula Coturel - Bioestratigrafía del Pérmico de la Sierra de los llanos...

\section{CAPÍTULO III. MateriaLES Y MÉTODOS}




\section{I. Área de estudio}

La Sierra de los Llanos se encuentra ubicada al SE de la Provincia de La Rioja (Figura III.a), al sur de la ciudad de Chamical, y a $150 \mathrm{~km}$ aproximadamente de la Ciudad de La Rioja, en su extremo septentrional. Se desarrolla dentro de un conjunto montañoso, denominado "Sierras de los Llanos", formado también por las sierras de Malanzán, Chepes y Ulapes.

Este conjunto de serranías está comprendido dentro del área abarcada por la Hoja Chamical (provincias de La Rioja y San Juan), 3166-I (Escala 1:250.000). En la Fig. III.b se presenta un detalle de la hoja geológica. La Sierra de los Llanos se localiza en el sector Austral de la faja oriental de las Sierras Pampeanas Noroccidentales, constituyendo el bloque de menor latitud del grupo (Caminos, 1979). Se encuentra limitada por fallas inversas, que le otorgan un diseño triangular y perfil asimétrico (pendiente oriental escarpada, occidental tendida). La localidad de Punta de Los Llanos, al Norte, indica su inicio, y su altitud incrementa hacia el sur, donde sus máximas elevaciones fueron medidas en el cerro Pelado y en la sierra de La Huerta (superando los 1500 metros de altura). Limita al oeste con la Sierra de Malanzán, estando ambas separadas por el valle de Tasquín: esta última sierra presenta igual diseño y perfil. El sector sur de esta serranía, separado de las dos sierras más septentrionales por los valles de Malanzán y Olta, se descompone en las sierras del Porongo, de Abajo y de los Luján en estricto sentido oeste a este. Los valles penetran los macizos montańosos, son generalmente estrechos y están controlados por lineamientos estructurales (Limarino et al. 2008).

Las unidades neopaleozoicas reconocidas en la Sierra de los Llanos son las Formaciones Malanzán, Loma Larga, Solca, Arroyo Totoral y La Colina. Las primeras tres comprenden el intervalo Pennsylvaniano, mientras que las últimas dos son de edad Pérmica.

Son objeto de estudio de esta tesis los afloramientos pérmicos hallados en el valle de Anzulón, en el área comprendida entre los paralelos $30^{\circ} 47^{\prime}$ y $30^{\circ} 52^{\prime}$ de latitud Sur, y los meridianos de 66 $16^{\prime}$ y $66^{\circ} 19^{\prime}$ de longitud Oeste, en el Departamento de General Ocampo 
(Provincia de La Rioja). Se analizaron las rocas provenientes de la Formación Arroyo Totoral (sensu Andreis et. al. 1984) y las plantas fósiles contenidas en ellas.

\section{Trabajos de campo}

Se realizaron dos viajes de campo al área estudiada (3 al 10 de Octubre de 2010, 3 al 10 de Mayo de 2012), donde se exploró la zona para localizar los sitios de exposición de la Formación Arroyo Totoral en los alrededores del Río Anzulón, precisándose su ubicación geográfica mediante instrumental de GPS.

Se reconocieron y muestrearon los fósiles de cinco localidades (Fig. III.c):

\begin{tabular}{lll}
\hline \hline Localidad & Latitud & Longitud \\
\hline Localidad 1 & $30^{\circ} 48^{\prime} 29.70^{\prime \prime S}$ & $66^{\circ} 18^{\prime} 23.91^{\prime \prime O}$ \\
\hline Localidad 2 & $30^{\circ} 48^{\prime} 35^{\prime \prime} \mathrm{S}$ & $66^{\circ} 18^{\prime} 23.63^{\prime \prime} \mathrm{O}$ \\
\hline Localidad 3 & $30^{\circ} 48^{\prime} 33.70^{\prime \prime} \mathrm{S}$ & $66^{\circ} 18^{\prime} 19.45^{\prime \prime} \mathrm{O}$ \\
\hline Localidad 4 & $30^{\circ} 49^{\prime} 31.32^{\prime \prime} \mathrm{S}$ & $66^{\circ} 17^{\prime} 22.26^{\prime \prime} \mathrm{O}$ \\
\hline Localidad 5 & $30^{\circ} 50^{\prime} 17.02^{\prime \prime S}$ & $66^{\circ} 16^{\prime} 47.39^{\prime \prime} \mathrm{O}$
\end{tabular}

Se levantaron perfiles sedimentológicos de detalle en tres de las localidades (1, 2 y 5$)$, donde se consideró la granulometría, color, composición y estructura de las sedimentitas, y la geometría de los cuerpos que las contienen. Asimismo, se reconocieron niveles portadores de plantas fósiles en las cinco localidades, identificándose aquellos de trabajos previos (Andreis et al. 1984; Cúneo 1984, Cúneo y Archangelsky, 1996, entre otros), y se los muestreó para el desarrollo de estudios sistemáticos y estadísticos. 
En total se obtuvieron 946 ejemplares de plantas preservadas como impresióncompresión. Se realizó muestreo para estudios palinológicos.

\section{Trabajo de gabinete}

El material fue preparado para su determinación limpiando el sedimento que cubría los fósiles y, en los casos en que la roca lo permitía, se removieron capas finas de sedimentitas para localizar nuevos taxones. Para su ilustración se utilizó una cámara Canon Powershot S5IS y los detalles fueron tomados bajo lupa binocular Nikon SM2800 con cámara Nikon DS-Fi1-U2.

Los materiales serán depositados en el Centro Regional de Investigaciones La Rioja (CRILAR) bajo las siglas CRILAR Pb.

La descripción se realizó utilizando la terminología brindada por el diccionario Font Quer (1982). Se midieron usando reglas y calibre Vernier.

El tratamiento nomenclatural se realizó siguiendo el International Code of Botanical Nomenclature (Vienna Code, McNeill et al., 2006). Para la asignación supragenérica, se siguieron los criterios de Archangelsky (1970), Stewart y Rothwell (1993), Kenrick y Crane (1997), Taylor et al. (2009).

Para el análisis del género Glossopteris se utilizaron los programas PAST (Hammer et al. 2001) y Mesquite (Maddison y Maddison, 2011). 


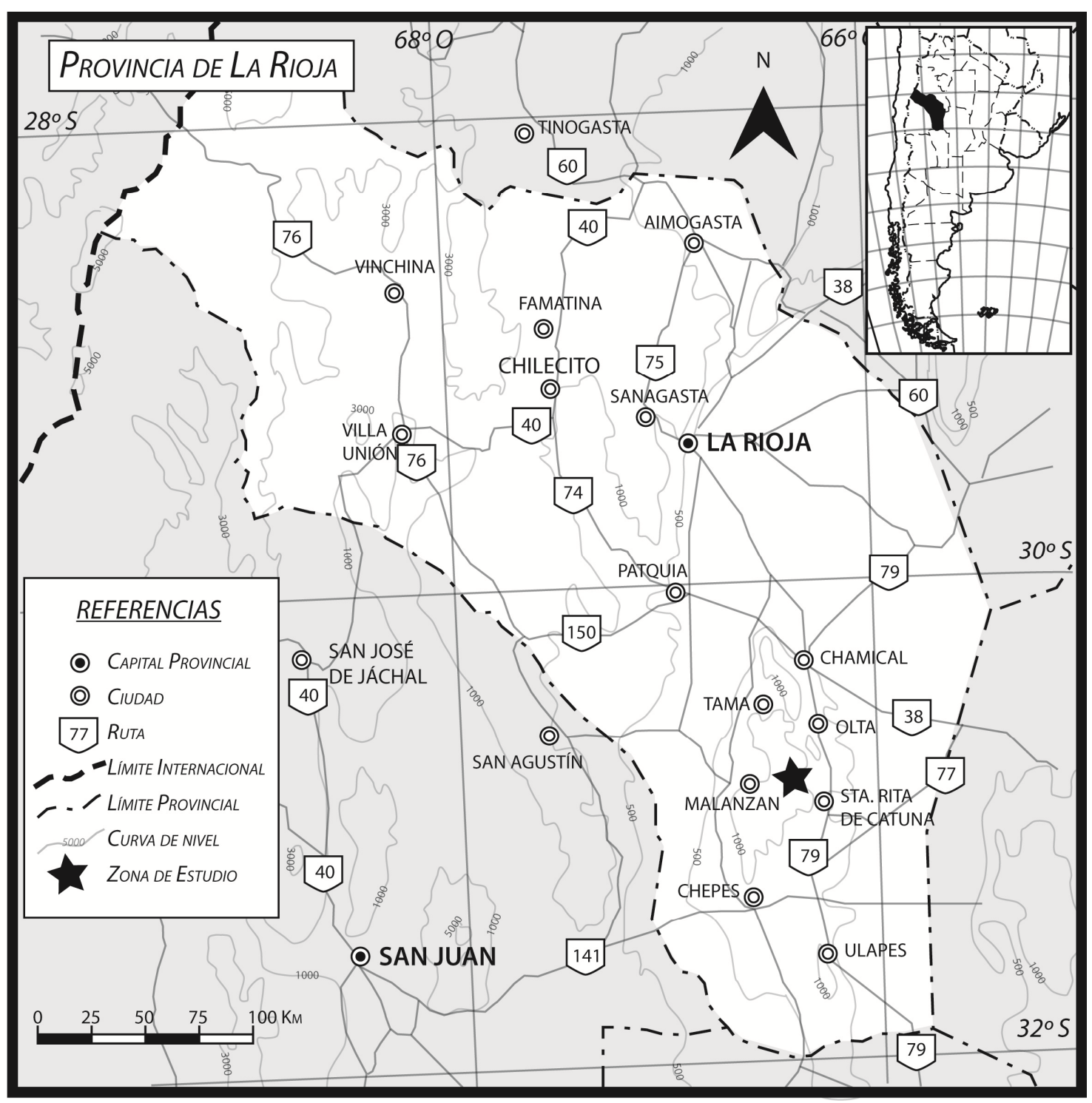

Figura III.a. Provincia de La Rioja y Zona de Estudio. 


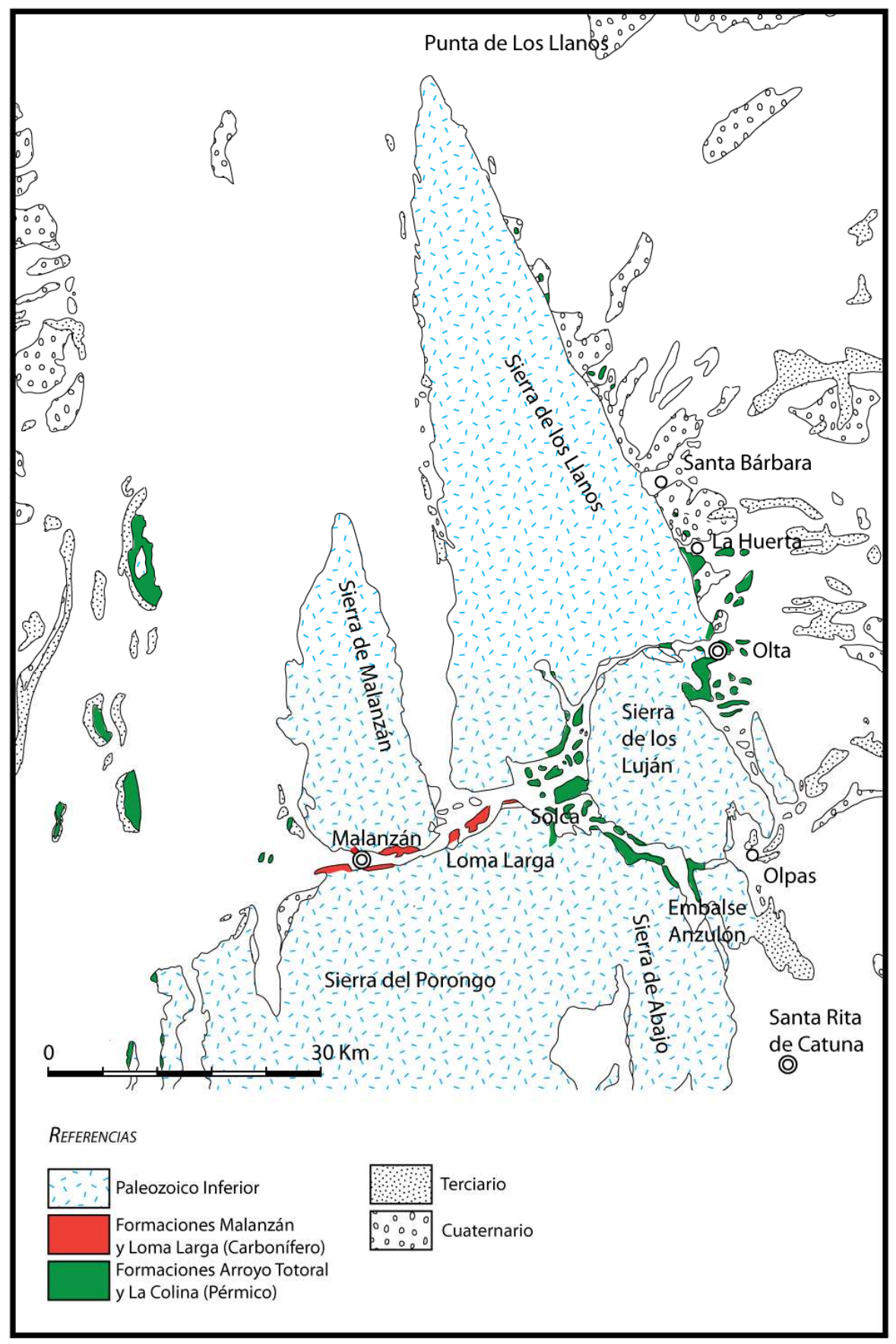

Figura III.b. Sector de Sierra de los Llanos, modificado de la Hoja Geológica 3166-I Chamical (Limarino et al., 2008) 


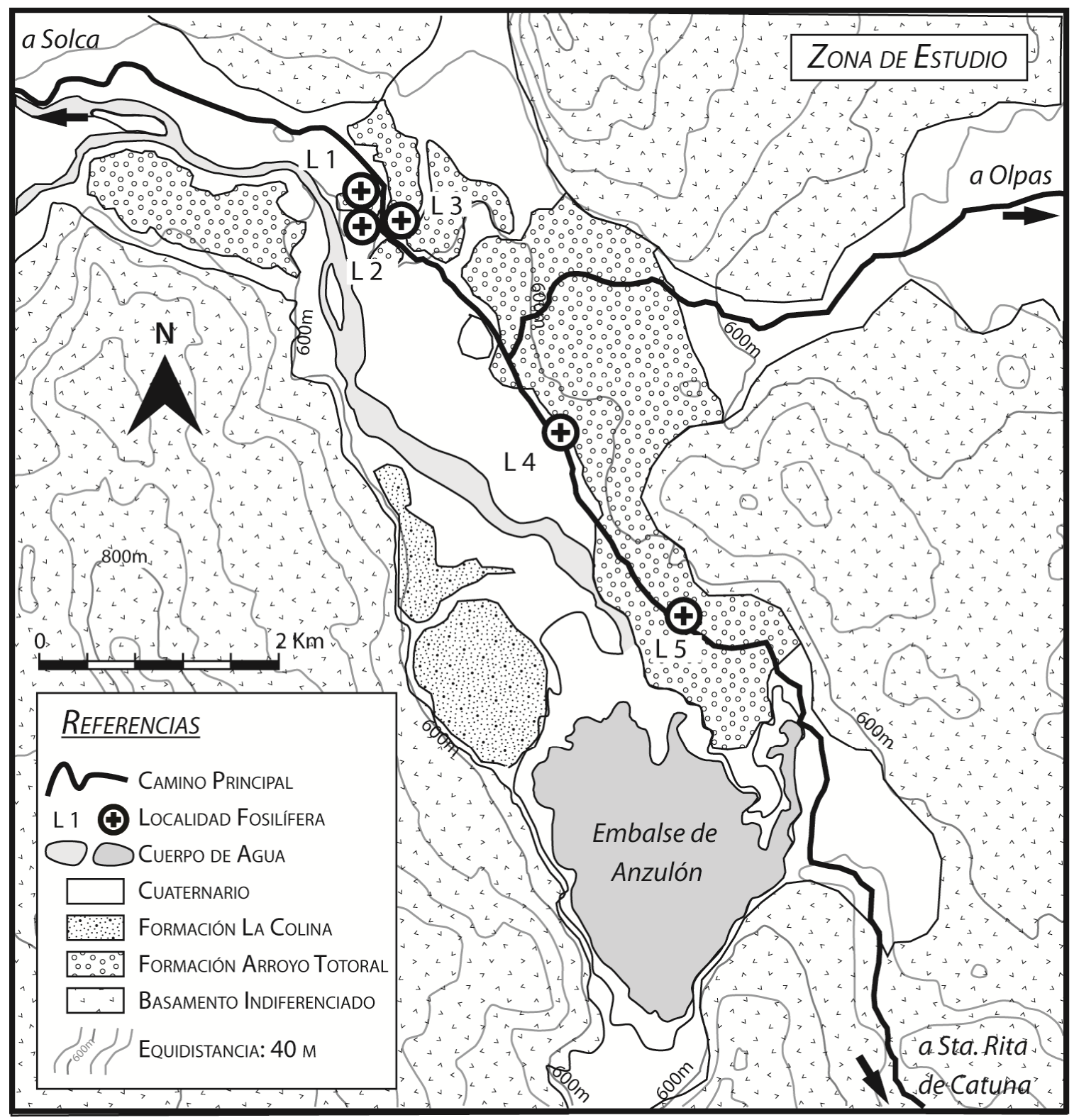

Figura III.c. Localidades fosiliferas estudiadas. 
Eliana Paula Coturel - Bioestratigrafía del Pérmico de la Sierra de los llanos...

\section{CAPÍTULO IV. RESULTADOS}




\section{IV.1 GEOLOGíA}

La Cuenca Paganzo es pericratónica y se halla limitada al E y NE por las Sierras Pampeanas, al S por la sierra de San Luis y los Arcos de Zonda y Pie de Palo. Su límite occidental es incierto, y se supone que durante el Pérmico habría estado conectada con las de Calingasta-Uspallata y Río Blanco (Archangelsky et al., 1996a). Las características paleogeográficas llevaron a determinar dos dominios, Oriental y Occidental (Figura IV.1.a). Limarino et al. (1996), reconocen tres ambientes depositacionales según el emplazamiento paleogeográfico y la litología: ambiente marginal oriental, ambiente central y ambiente precordillerano u occidental. El sector de la Sierra de los Llanos fue adscripto, dentro del Dominio Oriental, al ambiente central (Limarino et al., 1996) o al ambiente oriental de margen de cuenca (Net y Limarino, 1998).

En el sector de Sierra de Los Llanos, las secuencias neopaleozoicas se desarrollan de O a E, de Carbonífero a Pérmico. Las Formaciones Malanzán, Loma Larga y Solca representan los depósitos del Carbonífero, apareciendo en el valle de Malanzán, y hasta la vuelta de Solca, mientras que las Formaciones Arroyo Totoral y La Colina engloban los depósitos pérmicos, teniendo mayor desarrollo en la zona de Anzulón y en la ladera oriental de la Sierra de los Llanos.

\section{Formación Arroyo Totoral}

La Formación Arroyo Totoral (Andreis et al., 1984), se apoya en discordancia sobre el basamento cristalino, y está cubierta por la Formación La Colina en forma concordante. Fue definida y estudiada con rigurosidad por Andreis et al. (1984). Es una sucesión epiclástica, de tonalidades predominantemente grises, gris verdosas y amarillentas, aparte de los tonos castaños y negro. Los estratos son mayormente finos, con contactos de tipo planar (nítidos o 
transicionales). El análisis de facies realizado por los mencionados autores concluyó que la secuencia comprende una sucesión de abanicos aluviales, sistemas fluviales entrelazados y sistemas lacustres someros. En este último ambiente es donde se registra la mayor abundancia de niveles fosilíferos.

\section{Mapeo de la Formación Arroyo Totoral}

Andreis et al (1984) realizaron un mapa geológico del valle de Río Anzulón entre Los Mistoles y el Dique de Anzulón, a partir de una corrida de fotos aéreas (IFTA, $\quad$ corridas 2882002/2004/2006), y en él apuntaron ocho sitios (Figura IV.1.b, Localidades Fosilíferas I a VIII), donde colectaron flora fósil y a partir de los cuales realizaron la columna geológica y el estudio de los paleoambientes sedimentarios de la Formación Arroyo Totoral (Figura IV.1.c). La colección de la flora durante el estudio geológico se realizó mediante una metodología especial, orientada al análisis fitopaleoecológico (Cúneo, 1987; Cúneo y Archangelsky, 1995).

Para la presente Tesis se realizó un mapa de la zona (Figura II.c - Materiales y Métodos) utilizando como base las fotos aéreas y satelitales y los datos geográficos proporcionados por 
Google Maps. Los contactos entre secuencias se determinaron a partir de los cambios de coloración en las fotografías. Se comparó con el mapa publicado en Andreis et al. (1984), Cúneo (1984) y Cúneo y Archangelsky (1996), a partir de los mapas publicados y con las fotografías provistas por Google $\operatorname{Maps}^{\oplus}$ y Earth $^{\oplus}$. La ausencia de puntos GPS para los puntos Fosilíferos I a VIII, lleva a la posible equivalencia de localidades que se presenta en el Cuadro IV.1.a.

Para la localización de los niveles fosilíferos se realizaron perfiles de las localidades 1, 2, 3 y 5. Posteriormente, se correlacionaron las columnas y se ubicó la sección dentro de la columna estratigráfica integrada de Andreis et al. (1984).

\section{Descripción de los perfiles sedimentológicos}

Las localidades se nombraron de 1 a 5 . Los niveles fosilíferos se nombran con el nombre de la Localidad y luego, como inferior, medio o superior de acuerdo a su posición relativa en la secuencia. De esta manera, el nivel "L1Ninf" es el Nivel inferior del perfil de la localidad 1, exceptuando en la Localidad 3, donde hay un solo nivel fosilífero y se denomina L3Nfos. Los perfiles se presentan en la Figura IV.1.d.

\section{Localidad 1 (Cuadro IV.1.b)}

En la Localidad $1\left(30^{\circ} 48^{\prime} 29.70^{\prime \prime S}-66^{\circ} 18^{\prime} 23.91^{\prime \prime O}\right)$ se realizó un perfil de 30,1 m de espesor, donde se observa una secuencia progradante. La columna comienza con unos $5 \mathrm{~m}$ de estratos finos, laminados o masivos, de coloración grisverdosa a negra. Son abundantes los niveles con briznas y tallos, y se identificó el Nivel Inferior (L1Ninf). Lo sucede un nivel con briznas y luego una lente de areniscas medianas a gruesas ( $1 \mathrm{~m}$ de espesor). Se desarrollan a continuación $9 \mathrm{~m}$ de niveles limolíticos estériles, grises a grisverdosos. Luego aparece un banco tabular ( $4 \mathrm{~m}$ de espesor) de areniscas limosas, con fósiles reconocibles (L1Nsup). Sobre éste se 
desarrolla un banco pelítico de $3 \mathrm{~m}$ de espesor, y coronan la secuencia 3 lentes de areniscas.

Espesor Descripción

-- $\quad$ Base oculta

$1,5 \mathrm{~m}$ Pelitas grisverdosas, oscuras, con laminación ondulada a plano paralela. Pelitas negras planoparalelas.

0,2 m Pelitas a limolitas arenosas gris verdosas, con briznas y tallos.

0,4 $\mathrm{m} \quad$ Banco de pelitas más oscuras, sin laminación.

$2 \mathrm{~m} \quad$ Hacia el techo, bancos delgados de limolitas gris verdosas con tallos indeterminados.

2,2 m Pelitas gris verdosas oscuras y negras con laminación ondulítica. Con niveles de carbones muy delgados.

$1 \mathrm{~m} \quad$ Lente de arenisca mediana a gruesa, cuarzosa. Gris medio. $4 \mathrm{~m}$ de largo.

0,5 m Limolita gris verdosa clara, micácea, con laminación plano paralela.

0,3 m Limolita arenosa, gris verdosa clara, micácea, con laminación ondulítica. Con lentes irregulares de arenisca margosa oscura.

$8 \mathrm{~m}$ Pelita gris verdosa oscura con laminación. Hacia el techo, bancos de pelitas gris oscuras laminadas.

$4 \mathrm{~m} \quad$ Arenisca limosa, gris verdosa, clara, con laminación ondulítica. Se intercalan areniscas finas y margosas, delgadas.

$3 \mathrm{~m} \quad$ Pelitas gris oscuras con laminación plano paralela. Con bancos de limolitas gris verdosas claras con laminación ondulítica.

$1 \mathrm{~m} \quad$ Areniscas grises, medianas a gruesas, con estratificación entrecruzada planar. Aparece en lentes, que se yuxtaponen.

$5 \mathrm{~m} \quad$ Areniscas limosas, grises verdosas claras, micáceos, laminados, que alternan con escasas pelitas gris oscuras laminadas.

$1 \mathrm{~m} \quad$ Areniscas grises medianas a gruesas, con laminación entrecruzada planar, en lente.
Contenido Fósil

Briznas, tallos.

Tallos.

L1 Nivel

Inferior.

Briznas

$--$

$-$

L1 Nivel

Superior

$-$

$--$

$-$

$--$

Cuadro IV.1.b. Perfil Localidad 1 
En el nivel fosilífero inferior (L1Ninf) se determinó la presencia de: esfenofitas, Botrychiopsis plantiana, hojas de Glossopteridales, Arberia spp., Cordaites hislopi, Ferugliocladus riojanum.

En el nivel fosilifero superior (L1Nsup) se hallaron esfenofitas, B. plantiana, hojas de Glossopteridales, Cordaites hislopi.

\section{Localidad 2 (Cuadro IV.1.c)}

En la Localidad $2\left(30^{\circ} 48^{\prime} 35^{\prime \prime} \mathrm{S}-66^{\circ} 18^{\prime} 23.63^{\prime \prime} \mathrm{O}\right)$ aflora una secuencia de $19,7 \mathrm{~m}$ de espesor, donde se observa una alternancia entre niveles finos (pelitas y limolitas gris-verdosas, laminadas) y medianos (areniscas limosas, laminadas). El contenido fosilífero se halla en un estrato de 4 a $5 \mathrm{~m}$ de espesor, que contiene bancos de arenitas limosas con laminación

\begin{tabular}{lll}
\hline \hline Espesor & Descripción & Contenido Fósil \\
\hline-- & Base oculta & -- \\
$4 \mathrm{~m}$ & Pelitas gris verdosas, claras, con laminación ondulítica. & - \\
$0,2 \mathrm{~m}$ & Areniscas margosas grisverdosas, con laminación ondulítica. & -- \\
$2,5 \mathrm{~m}$ & Limolitas gris verdosas claras & -- \\
$0,5 \mathrm{~m}$ & Areniscas limosas, gris claras, con laminación ondulítica. & -- \\
$6 \mathrm{~m}$ & Pelitas gris verdosas con laminación. Hay lentes de pelitas & Briznas en la base \\
& carbonosas. & \\
$4-5 \mathrm{~m}$ & Bancos de areniscas limosas con laminación ondulítica, & L2 Nivel inferior (en la \\
& afinándose hacia el techo. & base) \\
& & L2 Nivel superior (en \\
& & el techo) \\
\hline \hline
\end{tabular}

Cuadro IV.1.c Perfil Localidad 2.

ondulítica. En la parte inferior y superior del estrato se hallan niveles con fósiles reconocibles (L2Ninf y L2Nsup), en el resto aparecen briznas. 
En el nivel inferior (L2Ninf) se hallaron tallos flotados de esfenofitas, B. plantiana, hojas de Glossopteridales, Arberia spp., Cordaites hislopi.

En el nivel superior (L2Nsup) se determinó la presencia de restos de tallos y hojas de esfenofitas, hojas de glossopteridales, Arberia spp., Cordaites hislopi, Ferugliocladus riojanum, y una gran abundancia de semillas y óvulos dispersos.

\section{Localidad 3 (Cuadro IV.1.d)}

En esta localidad (Localidad 3; 3048'33.70"S - 66²18'19.45"O), se realizó un perfil de $8,35 \mathrm{~m}$ de espesor. Éste presenta un nivel pelítico en la base, donde se hallaron restos vegetales muy bien preservados (L3Nfos). Sobre éste, alternan lentes de areniscas gruesas a medianas en la base, con pelitas grisverdosas y en la parte superior dos bancos de areniscas finas que retrogradan a limolitas arenosas.

\begin{tabular}{lll}
\hline \hline \multicolumn{1}{c}{ Espesor } & Descripción & Contenido Fósil \\
\hline-- & Base oculta & -- \\
$+1 \mathrm{~m}$ & Pelitas grisverdosas con laminación paralela. Briznas y plantas. & L3 Nivel \\
& Areniscas sabulíticas, gris blanquecina, con laminación & fosilífero \\
$1,7 \mathrm{~m}$ & entrecruzada. En Lente. & -- \\
& Areniscas medianas, gris amarillenta, con estratificación plano & \\
$2 \mathrm{~m}$ & paralela. Con lente de areniscas, entrecruzadas en la parte & -- \\
& superior. En lente. & \\
& Pelitas - limolitas gris verdosas con laminación paralela. \\
$1,5 \mathrm{~m}$ & Areniscas finas en la base, transición a limolitas arenosas verdes & -- \\
$1 \mathrm{~m}$ & en el techo. Laminación plano paralela. & -- \\
& Areniscas finas en la base, transición a limolitas arenosas verdes & \\
$0,5 \mathrm{~m}$ & en el techo. Laminación plano paralela. & - \\
$0,65 \mathrm{~m}$ & Areniscas color ocre. & - \\
\hline- & Cubierto. & \\
\hline \hline
\end{tabular}

Cuadro IV.1.d. Perfil Localidad 3. 
En esta localidad se identificaron restos de esfenófitas, Asterothecaceae, Eusphenopteris, hojas de Glossopteridales, Arberia spp., Cordaites hislopi, Ferugliocladus riojanum y semillas dispersas.

\section{Localidad 5 (Cuadro IV.1.e)}

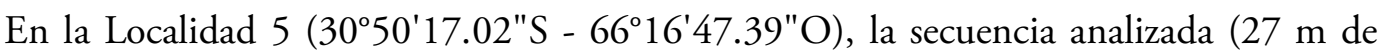
potencia) exhibe varios niveles fosilíferos. La secuencia se inicia con niveles finos (limolitas y arcillitas muy carbonosas), donde se localiza el nivel fosilífero inferior (L5Ninf). Continúan limolitas con laminación ondulítica, y luego se desarrollan pequeños lentes de areniscas finas. Por sobre éstas, aparecen areniscas finas planares y en lente con tallos. A continuación se desarrollan $2 \mathrm{~m}$ de limolitas gris verdosas, estériles. Sobre éste nivel se desarrolla otro, también con limolitas verdosas claras, el cual presenta abundancia de fósiles. En la base se reconoce el nivel medio (L5Nmed) y hacia el techo, el nivel superior (L5Nsup). Sobre este nivel se presenta otro nivel de pelitas, con abundantes briznas, y coronan la secuencia en el punto de inicio dos niveles de arenas medias a gruesas, en lente o en estratificación planar. El perfil se continúa cruzando el camino, donde se presentan, en primer lugar, $13 \mathrm{~m}$ de arenisca gruesa, con estratificación entrecruzada en artesa y planar, lentes de conglomerados finos. Esto se repite, con mayor proporción de arenas, en canales y estructura en artesa y culmina la sección con una nueva secuencia de grano fino, con arenas en artesas y en canal. 
Eliana Paula Coturel - Bioestratigrafía del Pérmico de la Sierra de los llanos...

\begin{tabular}{|c|c|c|}
\hline Espesor & Descripción & Contenido Fósil \\
\hline -- & Base oculta & -- \\
\hline $4 \mathrm{~m}$ & Limolitas gris verdosas, claras. Con laminación ondulítica. & Briznas \\
\hline $1,7 \mathrm{~m}$ & $\begin{array}{l}\text { Arcillitas carbonosas negras, de laminación plano paralela, que } \\
\text { alternan con limolitas gris verdosas claras con laminación ondulítica. }\end{array}$ & L5 Nivel Inferior \\
\hline & Limolitas gris verdosas, claras, con laminación ondulítica. Lentes de & \\
\hline $0,6 \mathrm{~m}$ & areniscas finas, pequeños. & -- \\
\hline $0,2 \mathrm{~m}$ & Areniscas finas gris claras con estratificación planar fina. & -- \\
\hline $0,7 \mathrm{~m}$ & $\begin{array}{l}\text { Areniscas medianas a gruesas, gris medio con estratificación } \\
\text { entrecruzada planar (lente) y laminación ondulítica hacia el techo. } \\
\text { Limolitas gris verdosas, claras, planas en la base y ondulíticas hacia el } \\
\text { techo. }\end{array}$ & Tallos \\
\hline $2 \mathrm{~m}$ & Limolitas verdosas claras con laminación ondulítica. & -- \\
\hline $1,8 \mathrm{~m}$ & & L5 Nivel medio (base) \\
\hline & Pelitas gris verdosas oscuras, ondulíticas. & $\begin{array}{l}\text { L5 Nivel superior } \\
\text { (techo) }\end{array}$ \\
\hline $1 \mathrm{~m}$ & $\begin{array}{l}\text { Lente de areniscas medianas a gruesas, grises. } \\
\text { Arenisca media, gris. Estratificación planar. }\end{array}$ & Abundantes briznas \\
\hline $0,5 \mathrm{~m}$ & Arenisca gruesa a sabulita, con estratificación entrecruzada en artesa y & - \\
\hline $\begin{array}{l}1,5 \mathrm{~m} \\
13 \mathrm{~m}\end{array}$ & $\begin{array}{l}\text { planar. Lentes de conglomerados finos. Hacia el techo, sabulita más } \\
\text { clara. }\end{array}$ & - \\
\hline
\end{tabular}

\section{Cuadro IV.1.e. Perfil Localidad 5}

En el nivel fosilífero inferior (L5Ninf) hay abundante materia carbonosa, indeterminable. Asimismo, se determinó la presencia de esfenófitas, hojas de Glossopteridales y ramas de coníferas. 
En el nivel fosilífero intermedio (L5Nmed) se registran esfenófitas, hojas fragmentadas de glossopteridales, y hojas asignables a Cordaites sp. El nivel fosilífero superior (L5Nsup) una flora monótona compuesta por Phyllotheca (esfenofita).

\section{Correlaciones}

En las secuencias que afloran en las localidades 1, 2, 3 y 5, las capas presentan un buzamiento general hacia el $\mathrm{N}$. Las localidades 1,2 y 3 se hallan muy cercanas entre sí (a menos de 400 metros entre ellas), y habrían pertenecido a la misma secuencia de depositación. La Localidad 4 se halla a 2,13 $\mathrm{km}$ al SE de la Localidad 3, y la Localidad 5 se encuentra a 1,8 km al S de la Localidad 4. La correlación entre los perfiles se presenta en la Figura IV.1.e.

La correlación entre los perfiles de las localidades 1, 2 y 3 se observa en el campo. La parte inferior de la secuencia está representada por el perfil de la Localidad 3. Éste presenta la base oculta, y niveles finos portadores de flora, sobre los que se disponen lentes de areniscas. Luego se presenta otra secuencia progradante, con limolitas que pasan en transición a areniscas finas a medias hacia el tope, el cual está cubierto. Lo sigue la secuencia de la Localidad 1. Su base está oculta, y predominan los elementos finos, pelíticos, de profundidad, pero durante la secuencia se observa un aumento en la proporción de areniscas, las cuales aparecen como lentes y estratos tabulares. Sobre ésta, continúa la secuencia de la Localidad 2. Como en los casos anteriores, se trata de una secuencia progradante, que comienza con bancos de limolitas entre los que intercalan pequeños niveles de arenas finas, y hacia el tope de la secuencia sólo presenta areniscas, de disposición tabular, y culmina con una lente de conglomerados finos. En esta secuencia integrada, se observan al menos tres ciclos de progradación.

La localidad 5 comienza con capas finas, entre las que intercalan lentes de areniscas finas, y en la parte superior se desarrolla un sistema fluvial entrelazado, caracterizado por los canales de areniscas con estructura en artesa. Estratigráficamente, se encuentra por debajo de la 
Localidad 3. La Localidad 4 correspondería a un punto intermedio entre las Localidades 3 y 5. Se caracteriza por poseer sedimentos finos (limolitas grisverdosas con laminación paralela).

La correlación presentada produce la siguiente disposición de los niveles fosilíferos (de techo a base):

- Localidad 2 Nivel superior

- Localidad 2 Nivel inferior

- Localidad 1 Nivel superior

- Localidad 1 Nivel inferior

- Localidad 3 Nivel fosilífero / Localidad 4 Nivel fosilífero / Localidad 5 Nivel superior?

- Localidad 5 Nivel medio

- Localidad 5 Nivel inferior

\section{Paleoambientes sedimentarios}

Habiéndose trabajado en la zona tipo de la Formación Arroyo Totoral, se han reconocido características litofaciales similares a las definidas por Andreis et. al. (1984). Los perfiles y su interpretación ambiental pueden analizarse con aquel estudio. Se definen allí las siguientes facies:

Facies psefíticas: en general fueron depositadas por corrientes ácueas fluidas, traccionales, bajo régimen de flujo superior (migración de barras longitudinales en canales de un río entrelazado, con disminución de energía si presenta agradación positiva) o inferior (migración de barras transversales y linguoidales o lobuladas, con flujo rápido, fijo).

Facies psamíticas: presentan variedad de facies según su estructura. 
- laminadas: de grano fino a medio, se depositaron por corrientes traccionales bajo condiciones de régimen de flujo inferior, en fase de lecho plano.

- ondulíticas: formada en psamitas de grano fino a medio. Se interpreta como producida en medio ácueo, por corrientes traccionales fluidas, en fase de óndula y régimen de flujo inferior. Correspondería a aguas someras.

- con estructuras entrecruzadas planares: representan la formación y migración de barras transversales, bajo régimen de flujo inferior (fase de duna) en canales fluviales.

- con estructuras entrecruzadas en artesa: formadas en condiciones similares a la facies anterior, pero a mayor profundidad.

Facies pelíticas, como las psamitas presentan variedad de facies según la estructura.

- laminadas o macizas, en estratos tabulares, con contactos planos, son las que contienen los fósiles (desde briznas hasta órganos bien preservados). Fueron depositadas por suspensión, las más gruesas pueden haber sido depositadas como flujo laminar.

- ondulíticas, son escasas y representan facies similares a las de arenas ondulíticas, pero a menor velocidad.

- con raíces, se trata de horizontes con raíces o paleosuelos, indicadores de alta colonización de los márgenes de lagos.

- arcillitas carbonosas y carbón, se interpretan como depositada en pantanos drenados o mal drenados.

Andreis et al. (1984) reconoce dos asociaciones de facies:

1) facies de grano grueso a medio, componen ciclos granodecrecientes, en cuerpos de geometría de canal, comienzan y terminan con diastema. Estos ciclos, dentro de un sistema fluvial entrelazado, representan la migración lateral de barras o la acción de corrientes fuertes que sufren un descenso de energía. 
2) facies de grano fino (pelitas y psamitas finas a medias), pueden representar depósitos de planicies aluviales arenosas, inundadas por cuerpos lacustres someros; depósitos de abanicos aluviales aportados durante períodos de lluvias abundantes, o depósitos de albardón o crevasse splay, asociados a canales meandriformes. Los depósitos de carbón se consideran de ambientes palustres o asociados a paleosuelos.

En el perfil integrado (Figura IV.1.c), se detalla la sucesión de paleoambientes referida para la Formación Arroyo Totoral. La secuencia comienza con facies de abanico aluvial proximal medio, las cuales retrogradan hasta la generación de un sistema lacustre somero. Posteriormente aparecen barras de desembocadura y se desarrolla un sistema fluvial entrelazado distal, que pasa en transición a un sistema fluvial meandriforme y por último un sistema lacustre somero. La secuencia aquí estudiada comenzaría por el primer evento lacustre somero, en la Localidad 5, que progradaría a varios ciclos de sistema fluvial entrelazado. Hacia el Norte, mientras se generaba el sistema fluvial en la Localidad 5, comenzaba la sedimentación en un sistema fluvial meandriforme con eventos lacustres en las localidades 1, 2 y 3.

Esto es coherente con la evolución paleogeográfica propuesta por Net y Limarino (1999). Allí, se presenta un modelo de evolución paleogeográfica para la secuencia completa (Formaciones Malanzán, Loma Larga, Solca, Arroyo Totoral y La Colina). La depositación de las unidades inferiores (Formaciones Malanzán y Loma Larga) habría ocupado los valles de Malanzán-Solca y parte del paleovalle de Olta. La cuenca paleozoica se amplió posteriormente hacia el Este, depositándose las Formaciones Solca y Arroyo Totoral en los valles de Solca y Anzulón, respectivamente. Luego de la colmatación de esta cuenca, se produce una extensión suave y se deposita la Formación La Colina. 

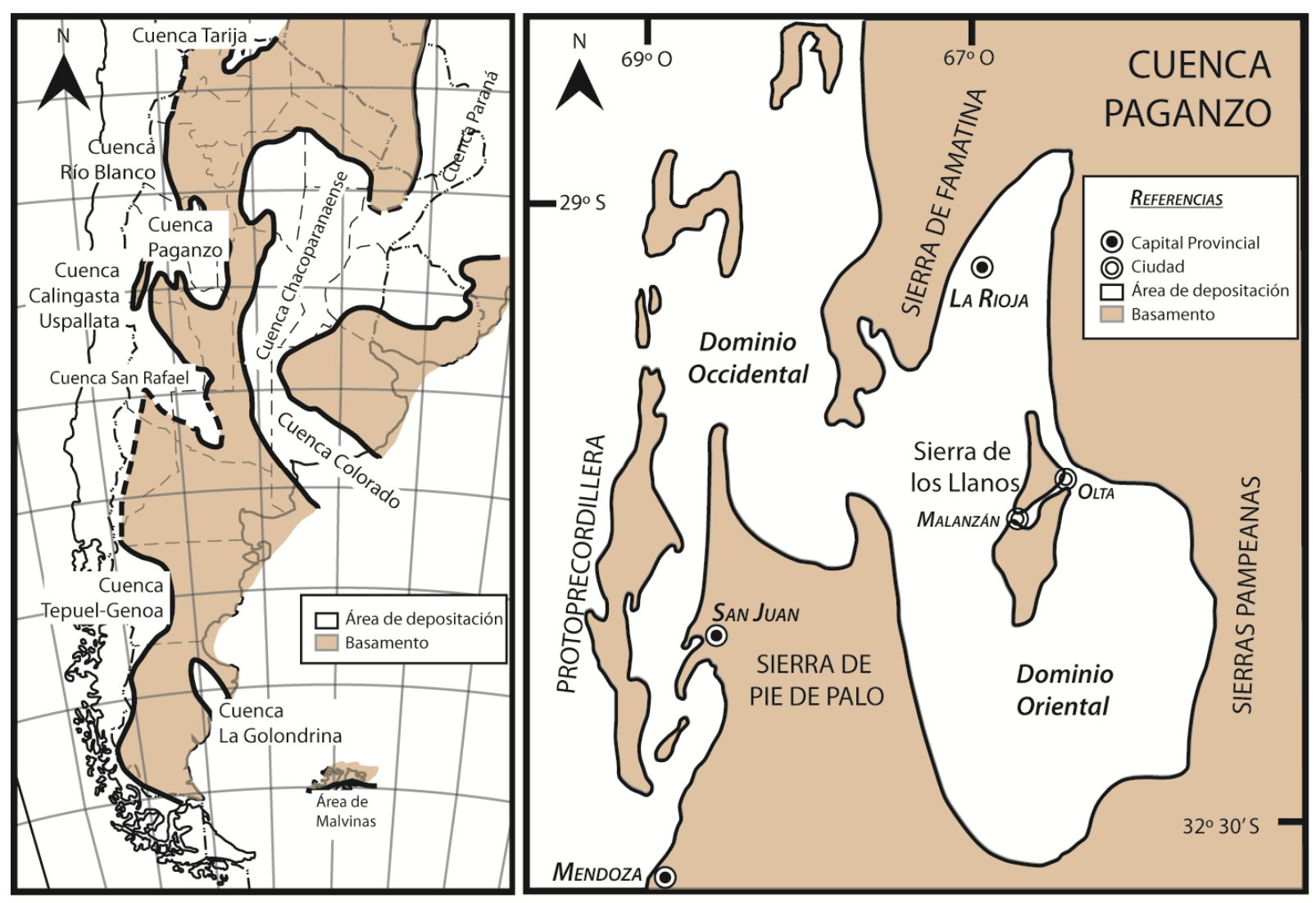

Figura IV.1.a. Cuencas Neopaleozoicas de Argentina, y detalle de la Cuenca Paganzo. Basado en Cuerda (1996) y Limarino et al. (1996) 


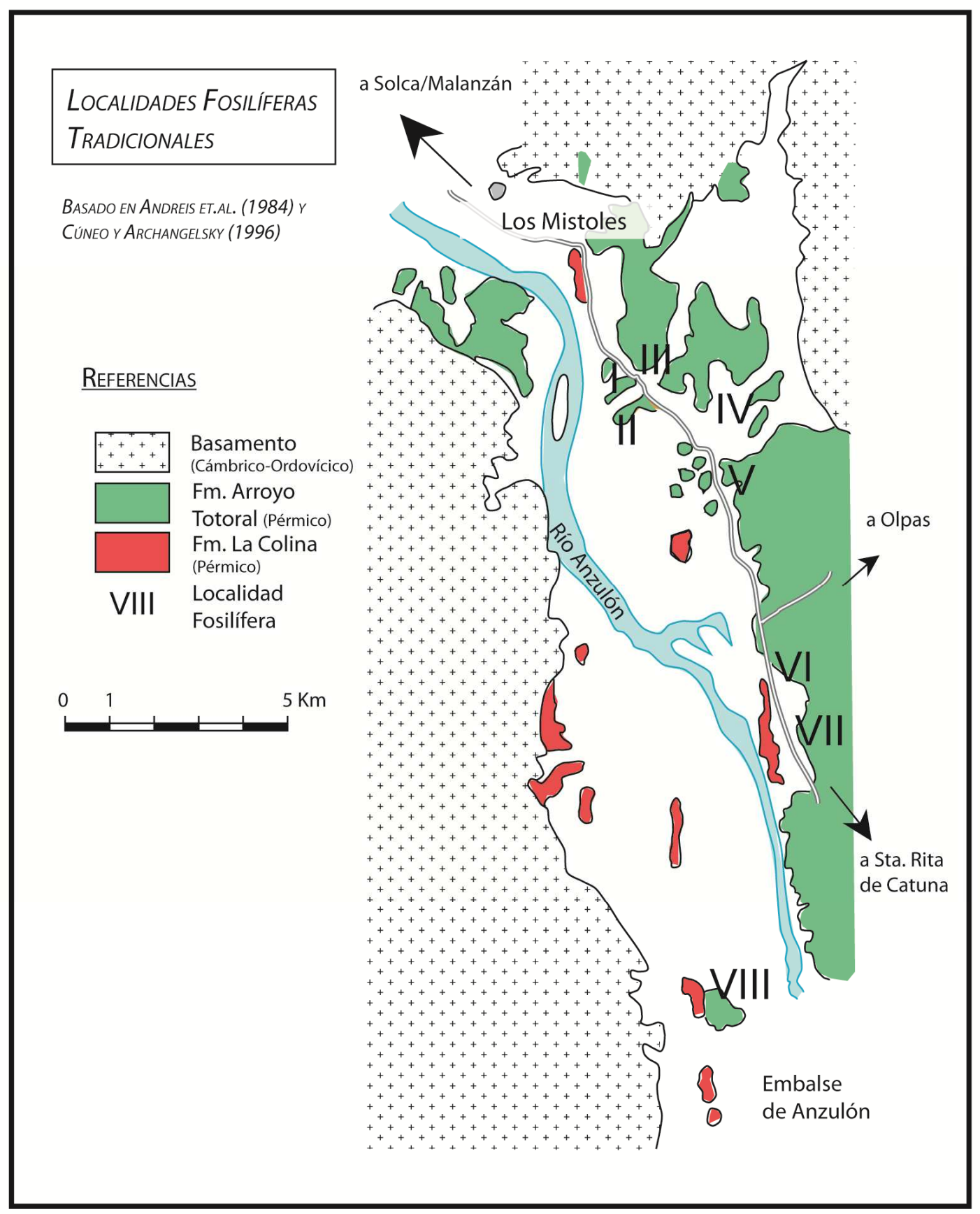

Figura IV.1.b. Mapa y localidades de Andreis et al. (1984) 
Figura IV.1.c. Perfil general de la Formación Arroyo Totoral, basado en Andreis et al. (1984)
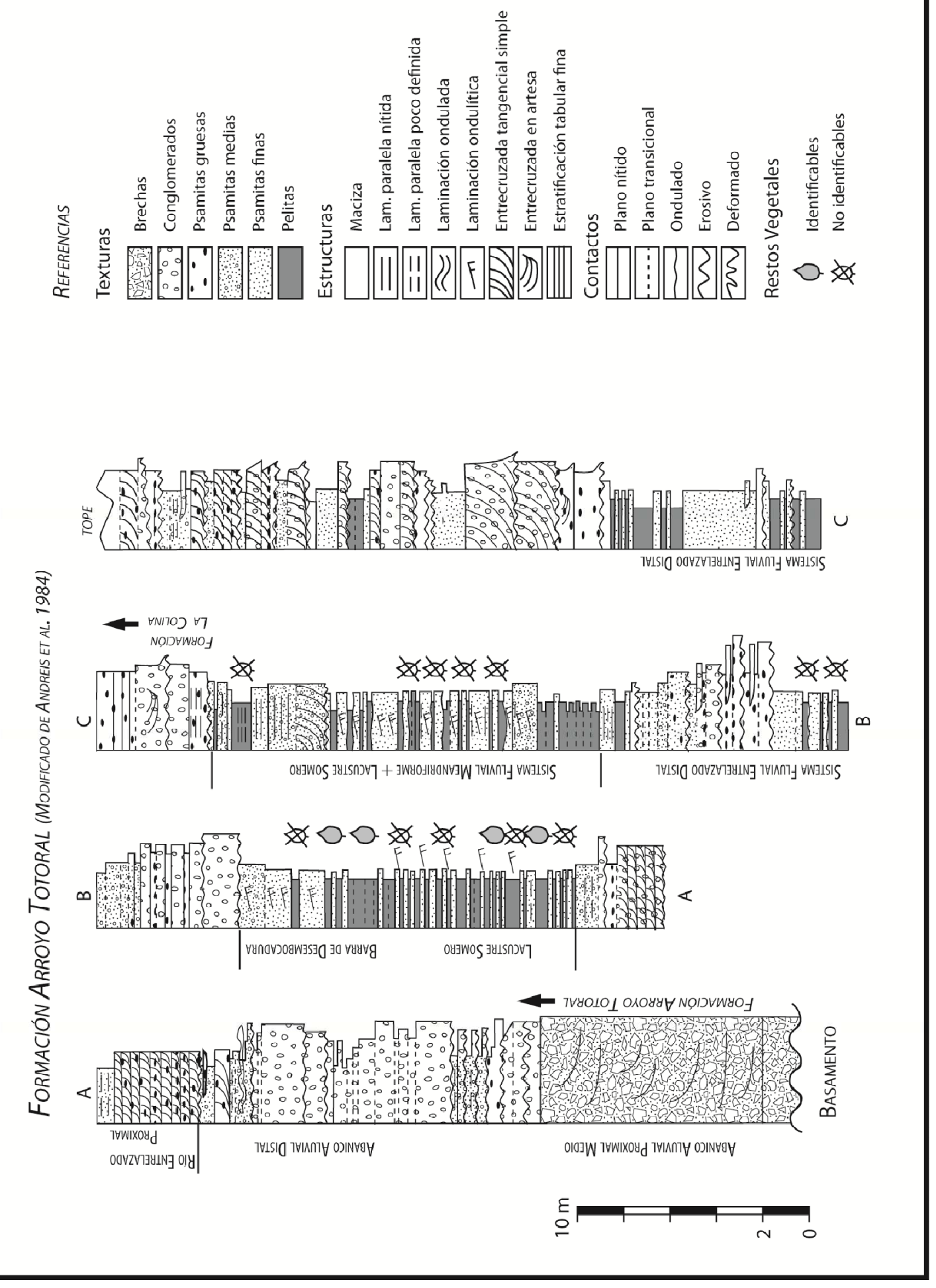
Eliana Paula Coturel - Bioestratigrafía del Pérmico de la Sierra de los llanos...

Figura IV.1.d. Perfiles de las localidades estudiadas en esta Tesis.

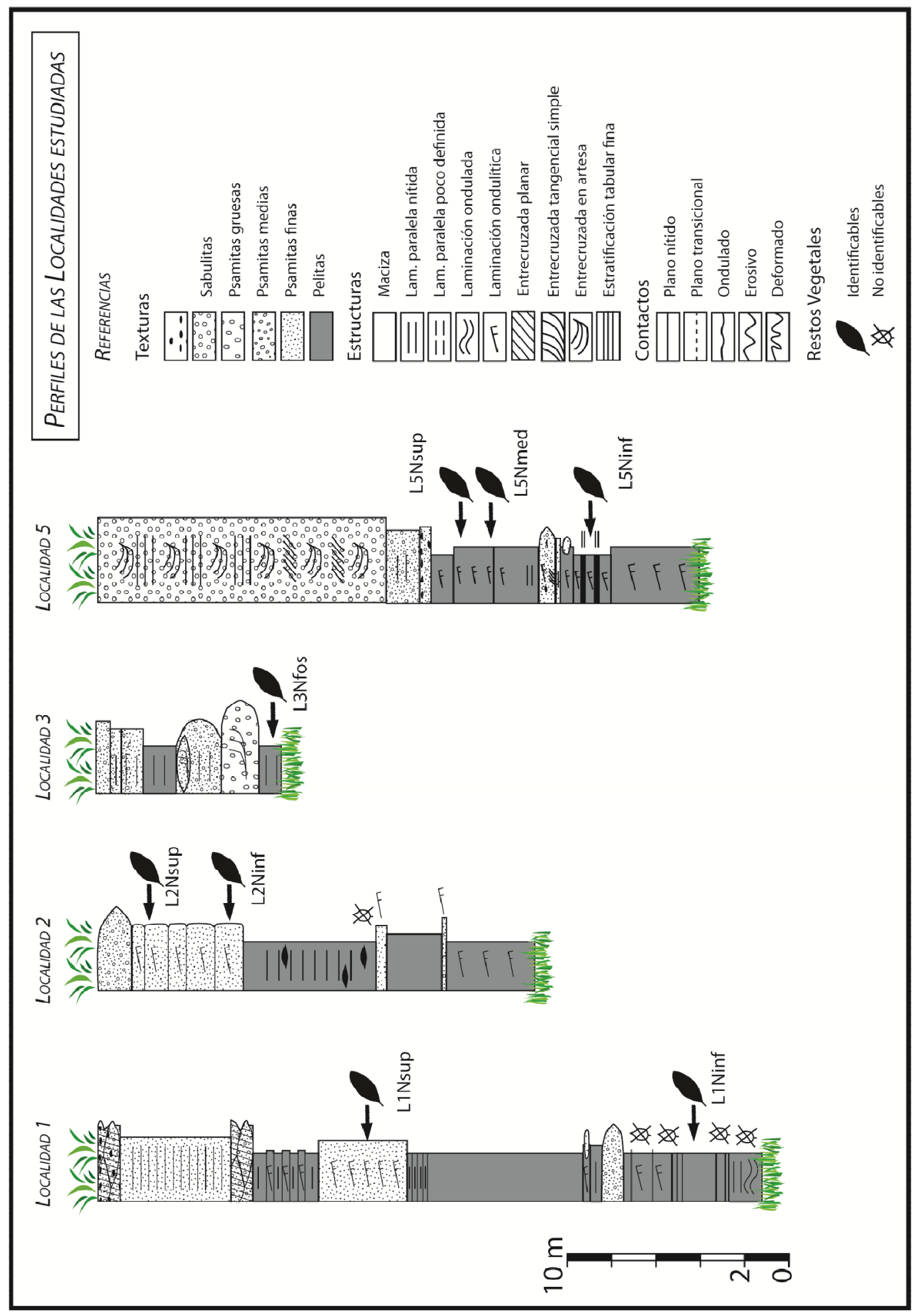


Eliana Paula Coturel - Bioestratigrafía del Pérmico de la Sierra de Los llanos...

Figura IV.1.e. Correlación entre las localidades.

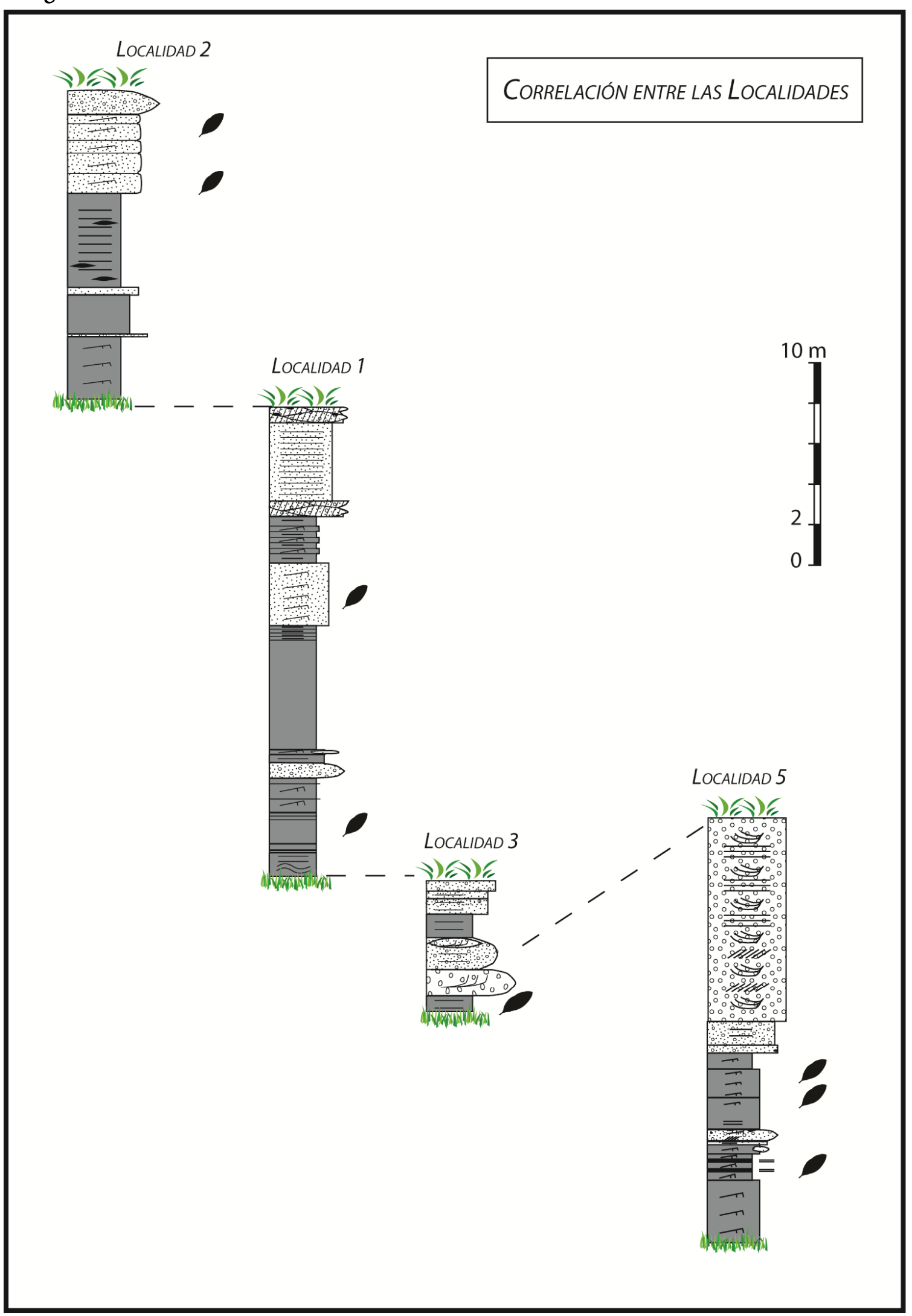

$\sim 53 \sim$ 


\section{IV.2. PALEOBOTÁNICA}

\section{Introducción}

La flora de la localidad clásica del Arroyo Totoral y de la Formación homónima, fue ilustrada y descripta por primera vez por Kurtz (1921), y luego fue revisada y publicada por Archangelsky y Arrondo (1973). Estudios posteriores en la Pampa de Anzulón hallaron nuevas localidades fosilíferas (Andreis et al., 1984) en las cuales se llevaron a cabo análisis fitopaleoecológicos (Cúneo, 1984; Cúneo y Archangelsky, 1996).

En este Capítulo se incluye descripción y ubicación sistemática de los taxones hallados en los trabajos de campo realizados. Para cada taxón se indica la localidad y nivel (Procedencia) del que fue extraído. Las localidades fosilíferas pertenecen enteramente a la Formación Arroyo Totoral. En la Formación Solca solo se halló un nivel fosilífero, compuesto enteramente por Cordaites spp.

La sistemática de los fósiles colectados presenta como complicación la utilización del concepto "morfogéneros" (=taxones utilizados para describir tipos morfológicos cuya ubicación sistemática está determinada en forma parcial). En este Capítulo, para ordenar el estudio y no confundir al lector, dentro de un Orden los morfogéneros se describen antes que las especies que pueden ubicarse en las Familias.

El material fue descripto en base a características cualitativas y cuantitativas. Las medidas se dan en centímetros, salvo que se indique lo contrario. Todo el material de la Tesis se presenta con números provisionales. Será depositado en el Centro Regional de Investigaciones La Rioja (CRILAR) bajo las siglas CRILAR Pb. 


\title{
Sistemática Paleobotánica
}

\author{
División TRACHEOPHYTA Sinnott ex Cavalier-Smith 1998 \\ Subdivisión LYCOPODIOPHYTINA Typpo ex Reveal 1996 \\ Clase ISOETOPSIDA Rolle 1885 \\ Orden LEPIDODENDRALES Boureau 1964
}

Lycophyta sp. A

Material: NF1: CIRGEO Pb: 565, 566, 578a/b, 579-584, 586a, 831; NF: 824-830

Procedencia: NF1 La Huerta, Formación Solca; NF Santa Bárbara, Formación Loma Larga.

Descripción: en Coturel et al. (2009)

Comentarios: El estudio del material tipo de Bumbudendron versiforme Gutiérrez, Césari y Limarino 1986 reveló la presencia de foseta ligular. Dado que en la diagnosis del género Bumbudendron Archangelsky, Azcuy y Wagner se hace referencia a la ausencia de esta estructura, esta especie debe ser combinada a un nuevo género. El material de Sierra de los Llanos posee foseta ligular (Figura 4H, Coturel et al. 2009), y será recombinado junto al material tipo. La presencia de foseta ligular permite asignar también a Lycophyta sp. de la Formación Melo del Pérmico de Uruguay (Gutiérrez y Herbst, 1994) a esta futura especie.

Subdivisión EUPHYLLOPHYTINA Kenrick et Crane 1997 MONILOPHYTA

Clase EQUISETOPSIDA Agardh 1825

Orden EQUISETALES Dumortier 1829

Morfogénero Paracalamites Zalessky 1927

Especie tipo: Paracalamites striatus (Schmalhausen 1879) Zalessky, 1927 
Comentarios. Se incluyen en este morfogénero todos los tallos de articuladas representados como ejes enteros o fragmentarios, sin evidencia de hojas o estructuras reproductivas.

\section{Paracalamites australis Rigby 1966}

\section{Lámina IV.2.1 Figuras A-E}

Material: L1Ninf: 31, 36, 65, 86, 109, 116, 134, 138; L1Nsup: 203, 208; L2Ninf: 211, 224, 228, 236, 258, 274, 280, 281, 290, 299, 343, 344; L3: 511, 520, 622, 624; L4: 771, 783, 788, 796; L5Ninf: 809, 828; L5Nmed: 837, 838.

Procedencia: Localidad 1, nivel inferior, nivel superior; Localidad 2, nivel inferior; Localidad 3, Localidad 4; Localidad 5, nivel inferior, nivel medio.

Descripción: Moldes de tallos articulados, de hasta $26 \mathrm{~cm}$ de largo, con nudos y entrenudos. Los entrenudos poseen un largo que oscila entre 0,2 y 3,67 $\mathrm{cm}$ y un ancho de entre 0,64 y 4,15 $\mathrm{cm}$. Los entrenudos son más largos que el ancho del eje. Poseen carenas, en número que varía entre 3 y 26, opuestas a la altura del nudo, raras veces alternas. Pueden presentar ramificaciones (ejemplar 290) que parten en un ángulo de $65^{\circ}$. En ellas se observa un incremento rápido del ancho del tallo desde el punto de inserción hacia las porciones más distales. No presentan verticilos foliares ni estructuras reproductivas en conexión.

Paracalamites sp. cf. P. frigidus Neuburg 1970

Lámina IV.2.2 Figuras A-D

Material: L1Ninf: 58, 70, 74, 97, 111, 112; L1Nsup:182; L2Ninf: 223, 234, 301, 308, 341; L3: 570, 588, 610 .

Procedencia: Localidad 1, nivel inferior, nivel superior; Localidad 2, nivel inferior; Localidad 3.

Descripción: El material estudiado se compone de fragmentos de tallos articulados preservados como moldes, con nudos y entrenudos, donde los entrenudos son sustancialmente más 
alongados que el ancho del eje. Pueden presentar ramas en conexión, pero en aquellos casos donde no hay ramificación, tampoco se observan tubérculos a la altura del nudo. No se observan verticilos foliares ni estructuras reproductivas en conexión. Las carenas pueden oponerse o alternarse a la altura de los nudos y presentar finas estrías. Se hallan aquí ejes de diferente porte, de al menos dos órdenes distintos, discriminables por el ancho del tallo.

Los ejes poseen un largo máximo medido de $17,5 \mathrm{~cm}$, y un ancho máximo de $3,7 \mathrm{~cm}$. En general poseen un ancho que varía entre 0,2 y $3,7 \mathrm{~cm}$, y una longitud de entrenudo que oscila entre 0,8 y 4,15 cm. En todos los casos, el entrenudo es más largo que el ancho a la altura del nudo. El número de carenas oscila entre 4 en las ramas de último orden, y 26 en las de mayor ancho.

Material de similares características, del cual no se posee información cuantitativa acerca de la relación morfométrica Longitud Entrenudo/Ancho, se asigna también a esta especie. En estos ejemplares, la ausencia del dato morfométrico se debe a la presencia de un solo nudo, pero la longitud incompleta de los entrenudos es mayor al ancho observado. El ancho oscila entre 0,2 y 3,67 cm, y el número de carenas lo hace entre 4 y 26 .

Comentarios: La proporción entre la longitud del entrenudo y el ancho fue utilizada por Zampirolli y Oliveira (2000) como referente para la identificación de especies de Paracalamites. Estos autores encontraron que, para las tres especies de Paracalamites (P. australis, P. levis Rigby 1966, P. montemorensis Millan 1977) presentes en el Carbonífero de Itapeva, era la relación morfométrica el carácter más constante y que podía diferenciar los taxones. De estas tres especies, el material de Sierra de los Llanos se diferencia por la presencia de algunas alternancias en las carenas a nivel del nudo, no debidas a un cambio en el número de carenas. Paracalamites montemorensis se asemeja a $P$. australis en poseer una longitud del entrenudo mayor al ancho, y en general posee menor porte que $P$. levis. Además, tiene carenas estriadas. Parte del material aquí descripto comparte con la especie de Millan la proporción (entre 1 y 2) y el porte, pero no presenta estrías en las carenas.

Rigby (1966) refiere un ancho de al menos $1,5 \mathrm{~cm}$ y un mayor número de carenas (al menos 13) para $P$. australis, difiere también esta especie en la alternancia de las carenas a nivel 
del nudo. Es remarcable que el material aquí estudiado comparte con $P$. australis que el entrenudo es más largo que el ancho del eje. Esta última característica lo diferencia de Paracalamites levis. Rigby (1966) mencionó que en los tallos de $P$. frigidus hay alternancia de las carenas en los nodos, y que sería la especie más relacionable con los restos ilustrados por Kurtz (1921) para Sierra de los Llanos. También comparten el porte y que los entrenudos son más largos que el ancho del eje. Paracalamites frigidus es un taxón descripto únicamente en el territorio de Angara, por esta razón se mantienen las reservas respecto de la asignación específica.

\title{
Familia PHYLLOTHECACEAE Brongniart 1828 \\ Género Phyllotheca Brongniart 1828 \\ Especie tipo: Phyllotheca australis Brongniart 1828.
}

\author{
Phyllotheca leptophylla (Kurtz) Archangelsky et Arrondo 1973 \\ Lámina IV.2.3 Figuras A-E
}

Material: L2Ninf: 258; L4: 771; L5Nmed: 891; L5Nsup: 895, 897, 898, 900, 901, 902, 903, 904, 905, 906, 907, 908, 909, 911, 912, 913, 918, 919, 920, 921, 922, 923, 924, 928, 929, 930, 931, 932, 934, 936, 938, 939, 940, 941, 942, 945.

Procedencia. Localidad 2, nivel inferior; Localidad 4; Localidad 5, nivel medio, nivel superior. Descripción: tallos articulados, de entre 0,76 y 9,55 cm de largo, y 0,2 a 3,82 cm de ancho a nivel del nudo. Los entrenudos son en general más grandes que el ancho del nudo, y miden entre 0,76 y 3,97 cm de largo. Poseen entre 5 y 21 carenas, dependiendo del ancho del tallo. Presentan hojas en los nudos. Las hojas poseen la porción basal fusionada, formando vainas envolventes, y se curvan en dirección adaxial. La vaina mide hasta $1 \mathrm{~cm}$ de largo, y la porción libre mide también hasta $1 \mathrm{~cm}$ de largo. Se contaron hasta 22 hojas libres.

Comentarios. Los ejemplares estudiados responden a la diagnosis brindada en Archangelsky y Arrondo (1973). Archangelsky y Arrondo (1973) indican que existe material en Brasil que 
pudiera ser asignado a $P$. leptophylla. Durante la revisión bibliográfica se observó que $P$. leptophylla fue utilizada únicamente para restos de esfenofitas en el sector de la Sierra de Los Llanos, y que en general se denominan $P$. australis y $P$. griesbachii Zeiller 1902 las Phyllothecaceae pérmicas de Sudamérica.

\section{Incertae sedis}

Género Cruciaetheca Cúneo et Escapa 2006

Especie tipo: Cruciaetheca patagonica Cúneo et Escapa 2006

Cruciaetheca patagonica Cúneo et Escapa 2006

\section{Lámina IV.2.4 Figuras A-I}

Material: BAPB 519, 538, 1082, 1091, 1095, 1105, 1106, 1107, 1116.

Localidad: VIII, Niveles fosilíferos 1, 4 y 5 (Figura 3) de Cúneo y Archangelsky (1996).

Descripción. Moldes de tallos articulados, donde se diferencian nudos y entrenudos. Los ejes de anteúltimo orden miden entre 1,2 y 1,85 cm de ancho y 3,5 - 8,7 de largo. Poseen carenas rectas, continuas al atravesar el nodo. Se observan hasta 12 carenas en el entrenudo más ancho. Estos ejes no portan hojas, pero sí portan ejes de último orden.

Los ejes de último orden miden entre 0,15 y $0,7 \mathrm{~cm}$ de ancho y al menos $9 \mathrm{~cm}$ de largo, se disponen en verticilos, en ángulo agudo respecto de los ejes de anteúltimo orden. Los nudos son atravesados por 2 a 4 carenas, dependiendo del ancho del tallo. Los entrenudos miden hasta $2 \mathrm{~cm}$ de largo. Estos ejes portan verticilos de hojas en los nudos. Hojas acintadas, uninervias, fusionadas en la parte basal. Las hojas miden al menos $3,7 \mathrm{~cm}$ de largo y $0,2 \mathrm{~cm}$ de ancho. La porción basal fusionada mide 0,3-0,4 cm. Cada verticilo tiene entre 6 y 15 hojas, dependiendo del ancho del eje. La relación entre la longitud de la hoja y la porción fusionada es 10. 
El ejemplar BAPB 1106 posee internodos con verticilos de esporangióforos. Las ramas de último orden poseen los internodos proximales fértiles y los distales estériles. Se reconoce un verticilo de esporangióforos en el internodo, debajo del verticilo foliar (Lámina 4 Figuras E-F). Los esporangióforos son cruciados y miden $2 \mathrm{~mm}$ de largo. Portan esporangios ovalados a piriformes, de $0,5 \mathrm{~mm}$ de largo.

El ejemplar BAPB 591 (Lámina 4 Figura I) presenta un verticilo foliar, en vista transversal, y esporangióforos dispersos. Los esporangióforos son cruciados y portan tres o cuatro esporangios globosos a subtriangulares.

Comparaciones. Del material presente en Arroyo Totoral se recuperaron tanto partes vegetativas como estructuras reproductivas. Las partes vegetativas son similares a las que presenta el género Phyllotheca, destacándose la fusión de los verticilos de hojas en su parte basal. Los esporangióforos son simples, en forma de cruz (=cruciados), en contraposición a los esporangióforos de Phyllotheca, que están dos veces ramificados, en ramas primarias de 2 a 3 $\mathrm{mm}$ de largo y secundarias de 1 a $2 \mathrm{~mm}$ de largo, éstas últimas portan, cada una, cuatro esporangios anátropos, ovales, en su extremo (Boureau, 1964).

Dentro de las Equisetales se han descripto esporangióforos cruciados para los géneros, Pothocites Paterson, Stephanophyllites Millan y Dolianiti y Cruciaetheca Cúneo y Escapa. Las comparaciones realizadas por Cúneo y Escapa (2006) son también válidas para el material aquí estudiado: la posición de los esporangióforos y la forma foliar de tipo Phyllotheca sustentan la asignación del material de Sierra de los Llanos dentro del género Cruciaetheca. Este género fue propuesto por Cúneo y Escapa (2006) para incluir restos de equisetales de esporangióforo simple y hojas con la base en vaina, halladas en el Pérmico de la Cuenca Tepuel Genoa (Chubut). Dentro de este género reconocieron 3 especies, basándose en caracteres vegetativos (características foliares) y reproductivos (número de verticilos de esporangióforos, posición, tamaño y forma de los esporangios), resumidos en el Cuadro 1. Allí se compara el material descripto en este trabajo para Sierra de Los Llanos con los caracteres de las especies creadas por Cúneo y Escapa (2006). En lo que respecta a los caracteres vegetativos, el material de Arroyo 
Totoral comparte con Cruciaetheca patagonica Cúneo y Escapa el ancho del eje, la longitud del entrenudo, ancho y largo de la hoja, el radio hoja/vaina, la cantidad de hojas por verticilo y radio entrenudo/hoja. En una comparación visual (Figs. 2.A-E; Fig. 3A; de Cúneo y Escapa, 2006) la similitud se torna aún más evidente. El material aquí estudiado presenta un porte mayor que las otras dos especies, las hojas son varias veces más largas que la vaina foliar, y la porción libre de las hojas es de mayor longitud que en $C$. feruglioi Cúneo y Escapa y en $C$. genoensis Cúneo y Escapa.

Los esporangióforos descriptos para el material de Arroyo Totoral son cruciados, y los esporangios, donde pueden observarse, son piriformes. Los esporangióforos son de menor tamaño que en $C$. patagónica y se sitúan en verticilos en los entrenudos. C. patagonica presenta de 2 a 4 verticilos por entrenudo. Los verticilos se hallan en la parte superior del entrenudo, y los entrenudos fértiles se encuentran en la porción superior del eje, reconociéndose entrenudos estériles en la porción proximal de éste (Fig. 2.A, Cúneo y Escapa, 2006). En el material que asignamos a esta especie, en cambio, se reconocen al menos 2 verticilos de esporangióforos en la porción media a distal del entrenudo (Lámina 4 Figuras E-F) y la zona fértil se halla en los entrenudos de la porción inferior del eje. Phyllotheca deliquescens (Goeppert) Schmalhausen, fue mencionada para Arroyo Totoral. Esta especie es similar a Cruciaetheca patagonica en sus hojas, pero difiere porque sus esporangióforos son peltados y no cruciados (Boureau, 1964, pág. 398, Fig. 362). Phyllotheca longifolia Roesler \& Iannuzzi 2012 presenta también similitud a nivel vegetativo, y es comparada con $P$. deliquescens por los autores, pero éste taxón no posee preservación de sus estructuras reproductivas. La Figura 4.D de Roessler \& Iannuzzi (2012) muestra una gran similitud con $C$. patagonica. Se requeriría una revisión del material tipo y otro material de la misma localidad, para determinar la naturaleza de las estructuras reproductivas.

Durán et al. (1994) describieron para la Formación Bajo de Véliz (niveles comparables a los de Arroyo Totoral en Cuenca de Paganzo) Phyllotheca sp. cf. P. indica Pant y Kidwai 1968 y Giridia sp. cf. G. indica Pant, Nautiyal y Lata Misra 1981, sugiriendo que ambos taxones pertenecen a la misma entidad biológica. En la descripción de Giridia sp. cf. G. indica 
mencionan que "la masa de órganos fértiles está fuertemente incarbonada y sus detalles finos no se distinguen; a pesar de ello fue posible observar algunas marcas redondeadas dejadas por los esporangios". No fue posible hacer una comparación con las ilustraciones. Las partes vegetativas, aunque similares en la forma general de las hojas, se diferencian porque en el material de Arroyo Totoral las vainas son mayores y las hojas no se bifurcan en su porción libre.

\begin{tabular}{|c|c|c|c|c|}
\hline \multicolumn{5}{|c|}{ Comparación de caracteres morfológicos entre especies de Cruciaetheca } \\
\hline Caracteres & Arroyo Totoral & C. patagonica ${ }^{1}$ & C. genoensis ${ }^{1}$ & C. feruglioi ${ }^{1}$ \\
\hline \multicolumn{5}{|l|}{ Ejes con hojas } \\
\hline Ancho & Hasta $0,7 \mathrm{~cm}$ & Hasta $0,7 \mathrm{~cm}$ & Hasta $0,6 \mathrm{~cm}$ & Hasta $0,12 \mathrm{~cm}$ \\
\hline Long. entrenudo & Hasta $2 \mathrm{~cm}$ & Hasta $2,4 \mathrm{~cm}$ & Hasta $2 \mathrm{~cm}$ & Hasta $0,1 \mathrm{~cm}$ \\
\hline Long. hoja & $\mathrm{Al}$ menos $3,7 \mathrm{~cm}$ & $\mathrm{Al} \mathrm{menos} 6 \mathrm{~cm}$ & $1,6-2,4 \mathrm{~cm}$ & Ca. $1 \mathrm{~cm}$ \\
\hline Ancho hoja & $0,2 \mathrm{~cm}$ & $0,15-0,24 \mathrm{~cm}$ & Ca. $0,15 \mathrm{~cm}$ & Ca. $0,17 \mathrm{~cm}$ \\
\hline Largo vaina & $0,3-0,4 \mathrm{~cm}$ & hasta $0,5 \mathrm{~cm}$ & $0,3-0,5 \mathrm{~cm}$ & $0,32-0,56 \mathrm{~cm}$ \\
\hline Radio Hoja/vaina & Ca. 10 & Ca. 10 & Ca. 5 & Ca. 2 \\
\hline No hojas por verticilo & $6-15$ & $14-15$ & $9-12$ & $22-24$ \\
\hline Radio entrenudo/hoja & $1 / 2$ & $2 / 5$ & $5 / 6$ & -1 \\
\hline \multicolumn{5}{|l|}{ Esporangióforos } \\
\hline Tipo & Cruciado & Cruciado & Cruciado & Cruciado \\
\hline Ancho & Ca. $0,1 \mathrm{~cm}$ & Ca. $0,22 \mathrm{~cm}$ & Ca. $0,15 \mathrm{~cm}$ & Ca. $0,1 \mathrm{~cm}$ \\
\hline Largo & Ca. $0,1 \mathrm{~cm}$ & Ca. $0,17 \mathrm{~cm}$ & Ca. $0,15 \mathrm{~cm}$ & Ca. $0,2-0,3 \mathrm{~cm}$ \\
\hline \multicolumn{5}{|l|}{ Esporangio } \\
\hline $\begin{array}{l}\text { Tamańo } \\
\text { Forma }\end{array}$ & & $\begin{array}{l}0,9 \mathrm{~mm} \times 0,6 \mathrm{~mm} \\
\text { ancho, piriforme }\end{array}$ & $\begin{array}{l}0,65 \mathrm{~mm} \times \\
0,5 \mathrm{~mm} \\
\text { ancho, } \\
\text { piriforme }\end{array}$ & $\begin{array}{l}0,8 \mathrm{~mm} \times 0,6 \\
\mathrm{~mm} \\
\text { ancho, oval }\end{array}$ \\
\hline
\end{tabular}

${ }^{1}$ Tomado de Cúneo y Escapa (2006)

Cuadro IV.2.a. Comparación del material de Arroyo Totoral con las especies de Cruciaetheca 
Eliana Paula Coturel - Bioestratigrafía del Pérmico de la Sierra de los llanos...

Clase MARATTIOPSIDA Doweld 2001

Orden MARATTIALES Link 1833

Familia ASTEROTHECACEAE Boureau et Doubinger 1975

Género Asterotheca Presl

Especie tipo: Asterotheca sternbergii (Goeppert) Presl en Corda 1845

Asterotheca feruglioi Frenguelli 1953

Lámina IV.2.5 Figuras. A-C, E

Material: 564, 565, 570.

Procedencia: Localidad 3.

Descripción: fragmentos de frondes bipinnadas, con pínnulas pecopterídeas: ápice redondeado, márgenes paralelos y en la base el acroscópico es constricto y el basiscópico es levemente decurrente. Poseen una vena media, que se dicotomiza cerca del ápice, y venas secundarias que se bifurcan al menos una vez antes de alcanzar el margen. Raquis principal de hasta 1,6 $\mathrm{mm}$ de ancho, raquis de pinna alrededor de $1 \mathrm{~mm}$ de ancho. El largo de las pínnulas oscila entre 4,2 y 8,5 mm, el ancho entre 0,2 y 4,8 mm. El ejemplar 564 (Lámina 5, Fig. A) comprende impronta y contra-impronta de fronde fértil, pudiéndose distinguir los ápices agudos de los esporangios piriformes, agrupados en número de 3 o 4, posiblemente fusionados en la base.

Comentarios: los fragmentos de frondes comparten las características del material estudiado por Archangelsky y Arrondo (1973).

\section{Asterotheca sp.}

Lámina IV.2.5, Figuras F-G

Material: L2Nsup: 384; L3: 554, 566.

Procedencia: Localidad 2, nivel superior; Localidad 3. 
Descripción. Fragmentos de fronde de helecho monopinnada de margen lobulado a bipinnatifida, de hasta $61 \mathrm{~mm}$ de largo y $22 \mathrm{~mm}$ de ancho máximo. El raquis de pinna (de hasta $2 \mathrm{~mm}$ de ancho) emite una vena para cada lóbulo, que se divide anisotómicamente.

El ejemplar 384 muestra un fragmento de pinna de $13,7 \mathrm{~mm}$ de largo y $5,5 \mathrm{~mm}$ de ancho, con un raquis de $11 \mathrm{~mm}$ de ancho, y lámina lobulada a pinnatifida. En cada lóbulo ingresa una vena, que se divide en la base.

El ejemplar 554 comprende impronta y contraimpronta de cuatro pinnas consecutivas, de la misma fronde. El largo máximo observado es de $24 \mathrm{~mm}$, y el ancho de las pinnas es de 4,8 $\mathrm{mm}$. El raquis de la pinna mide $0,4 \mathrm{~mm}$ de ancho. Los lóbulos miden 1,7 $\mathrm{mm}$ de largo por 2,2 mm de ancho.

El ejemplar 566 corresponde a una impronta y contraimpronta de una fronde donde se preservan raquis principal y 4 pinnas de un lado. El largo total del ejemplar es de $61 \mathrm{~mm}$ y el ancho (de media fronde) de 21,5 $\mathrm{mm}$. El raquis mide 1,3 $\mathrm{mm}$ de ancho. Las pinnas se insertan con un ángulo de $60-70^{\circ}$ al raquis. La pinna de mayor tamaño mide $15,3 \mathrm{~mm}$ de largo (incompleto) y 5,2 $\mathrm{mm}$ de ancho. La lámina presentaría estructuras reproductivas, puesto que no se puede discernir la venación con claridad. Éstas comprenderían sinangios compuestos por esporangios fusiformes, con la base fusionada y libres en la parte apical.

Comentarios. Este material es comparable a Asterotheca golondrinensis Herbst por el grado de fusión de las pínulas, las características de la venación, y la posible presencia de sinangios con esporangios fusionados en la base. 
Eliana Paula Coturel - Bioestratigrafía del Pérmico de la Sierra de los llanos...

Clase SPERMATOPSIDA Serbet et Rothwell 1995

Orden INCERTAE SEDIS

Género Botrychiopsis (Kurtz) Archangelsky y Arrondo 1971

Especie tipo: Botrychiopsis weissiana (Kurtz) Archangelsky y Arrondo 1971.

Botrychiopsis plantiana (Carruthers) Archangelsky y Arrondo 1971

Lámina IV.2.6 Figuras A-F

Material: L1Ninf: 1, 2, 3, 4, 5, 6 ,7, 8, 9, 10, 11, 12 ,13, 14, 15, 16, 17, 18, 19, 20, 21, 22, $23,24,26,27,28,29,30,33,35,37,39,40,41,42,43,44,47,48,49,50,51,52,53,54$, $55,56,57,73,81,83,85,98,99,115,117,118,121,122,123,124,125,126,127,129$, 135, 136, 137, 142, 143, 144, 147; L1Nsup: 151, 153, 156, 158, 163, 164, 166, 167, 168, 169, 170, 171, 174, 177, 181, 175, 185, 191, 199, 201, 202, 204, 207; L2Ninf: 254, 268.

Procedencia: Localidad 1, nivel inferior, nivel superior; Localidad 2, nivel inferior.

Comentarios: Se preservan mayormente pinnas sueltas de la zona media a distal. Por sus características son referibles sin dudas a Botrychiopsis plantiana.

Género Eusphenopteris Novik 1947

Especie tipo: Eusphenopteris obtusiloba (Brongniart) Novik, 1947.

Eusphenopteris sp.

Lámina IV.2.6 Figuras G-I

Sinonimia. 1973. Sphenopteris sp. Archangelsky y Arrondo (1974), p. 213, lám. III, fig. 1.

Material: L2Nsup: 492, 505; L3: 630.

Procedencia: Localidad 2, Nivel superior. Localidad 3.

Descripción: fronde bipinnada, fragmentos de hasta $2,9 \mathrm{~cm}$ de largo y $2 \mathrm{~cm}$ de ancho (hemifronde), con pinnas alternas, que se insertan con un ángulo de $45^{\circ}$ al raquis. Pinnulas pequeñas, de entre 0,5 y $1,8 \mathrm{~cm}$ de largo y 0,1 a $0,45 \mathrm{~cm}$ de ancho, alternas, de base catadrómica decurrente, contorno aovado y margen muy lobado. La venación está compuesta 
por escasas venas, una vena media de igual calibre que las venas secundarias, las cuales se dicotomizan en los lóbulos.

Comentarios: el material estudiado es igual al descripto por Archangelsky y Arrondo (1973). La ausencia de estructuras reproductivas y/o de frondes de mayor tamańo impide la asignación específica. Este material es similar a Alloiopteris sp. (Taylor et al., 2009) porque son frondes tripinnadas, con las pinnulas lobuladas de tipo esfenopterídeo, que se caracterizan por su escasa venación, la cual es dicotómica y ocupa todos los lóbulos de las pinnulas.

\section{Orden GLOSSOPTERIDALES}

Género Gangamopteris McCoy 1847

Especie tipo: Cyclopteris angustifolia McCoy, 1847

Gangamopteris obovata (Carruthers) White 1908

Lámina IV.2.7 Figuras 1, 2, 4, 5, 7

Material: L1Ninf:131, 141; L2Ninf: 278, 279, 314, 332; L2Nsup: 454; L4: 749; L5Nmed: 844,884 .

Procedencia: Localidad 1, nivel inferior; Localidad 2, nivel inferior, nivel superior; Localidad 4; Localidad 5, nivel medio.

Descripción: hojas obovadas a espatuladas, de 3 a $7 \mathrm{~cm}$ de largo y 2 a $4 \mathrm{~cm}$ de ancho. Zona media a veces diferenciada con venas paralelas, adelgazándose hacia el ápice. Venas secundarias se arquean suavemente y llegan al margen formando un ángulo de entre 50 y $60^{\circ}$. Anastomosis más frecuentes en zona media.

Comentarios: por las características de la venación secundaria, Gangamopteris obovata puede confundirse con Glossopteris wilsonii (Seward). En esta última la vena media es más conspicua.

Género Glossopteris Brongniart 1828

Especie tipo: Glossopteris browniana Brongniart 1831.

Glossopteris occidentalis (White) Tybusch et Iannuzzi 2010 


\section{Lámina IV.2.8 Figuras 1-7, 9}

Material: L1Ninf: 67, 68, 104, 110, 133, 148; L2Ninf: 265, 283, 287; L2Nsup: 453, 456, 457, 466, 485; L3: 651, 659, 663; L4: 750, 751, 763; L5Nmed: 846, 847, 851, 855, 865, 880, 881.

Procedencia: Localidad 1, nivel inferior; Localidad 2, nivel inferior, nivel superior; Localidad 3, Localidad 4, Localidad 5, nivel medio.

Descripción: Hoja oblanceolada, de margen entero, con ápice agudo (a veces redondeado), de más de $5 \mathrm{~cm}$ de largo y hasta $6 \mathrm{~cm}$ de ancho. Vena media ancha, compuesta de varias venas paralelas, gruesas, bien definidas, que se afinan hacia el ápice y se interconectan mediante venas oblicuas. Las venas secundarias emergen de la vena media en ángulos de $15-39^{\circ}$, y se curvan pronunciadamente, luego siguen un curso recto y paralelo en un ángulo casi recto respecto de margen y bordes, donde antes de llegar se arquea distalmente, alcanzando el margen con un ángulo de $60-79^{\circ}$. La venación tiene una densidad uniforme a lo largo de la hoja: 36-55 venas por $\mathrm{cm}$. La venación secundaria se anastomosa, principalmente cerca de la vena media.

Comentarios: las hojas responden al patrón general de venación de Glossopteris occidentalis, pero presentan menor cantidad de aréolas.

Glossopteris wilsonii (Seward) Archangelsky, Archangelksy y Cúneo 1982 Lámina IV.2.7 Figuras 3-4; Lámina IV.2.8 Figura 8; Lámina IV.2.9 Figuras 1-8

Material: L1Ninf: 60, 62, 63, 64, 77, 113, 119, 132; L1Nsup: 195; L2Ninf: 217, 228, 231, 243, 244, 245, 247, 253, 272, 273, 274, 285, 286, 294, 301, 302, 312, 313, 316, 322, 323, 326, 327, 328, 335, 342; L2Nsup: 387, 389, 390, 452, 455, 482, 489, 495, 496, 505; L3: 661, 665, 673, 678, 680, 689, 690; L4: 752, 754, 755, 761; L5Nmed: 764, 830, 859, 863, 864.

Procedencia: Localidad 1, nivel inferior, nivel superior; Localidad 2, nivel inferior, nivel superior; Localidad 3; Localidad 4; Localidad 5, nivel medio. 
Descripción: Hoja obovada a lanceolada, a veces espatulada, de ápice agudo a obtuso. Las hojas miden entre 2 y más de $8 \mathrm{~cm}$ de largo y entre 1 y $3 \mathrm{~cm}$ de ancho. Vena media conspicua, de ancho variable. En la base y sector medio está formada por varias venas del mismo calibre que las laterales, sobresaliendo a veces del nivel general de la lámina. Venas laterales decurrentes, presentan un arco ancho y llegan paralelas al borde de la lámina. Escasas bifurcaciones, raras anastomosis. Concentración de venas por centímetro de 15 a 35 de acuerdo al tamaño de la hoja. Aréolas presentes en el sector decurrente cercano a la vena media, formadas por venas dicotomizadas o con conexiones transversales.

\section{$\underline{\text { Estructuras reproductivas }}$}

Familia ARBERIACEAE sensu Adendorff 2005

Género Arberia White 1908 emend. Adendorff 2005. Especie tipo: Arberia minasica White 1908 emend. Rigby 1972.

Arberia sp. cf. A. minasica White 1908 emend. Rigby 1972

Lámina IV.2.10 Figuras A, B, E, F, H-J, L, M

Material: L1Ninf: 105; L2Ninf: 304, 307, 334, 337, 338, 340; L3: 566, 670, 692; L4: 784.

Procedencia: Localidad 1, nivel inferior; Localidad 2, nivel inferior; Localidad 3; Localidad 4. Descripción: Polisperma de hasta $2 \mathrm{~cm}$ de largo y 1,6 cm de ancho, compuesta por un eje primario laminar, con ramificación dicótoma a irregular. Eje primario con estrías longitudinales, las cuales son continuas en las ramas laterales. Los ejes secundarios miden alrededor de $1 \mathrm{~cm}$ y rematan en expansiones escuamiformes, de 0,33 cm de largo y 0,24 cm de ancho, con el punto de inserción del óvulo en la base de la escama. El eje primario planado es bifacial en algunos casos, con ramas laterales surgiendo de la cara que se corresponde con la superficie fértil de las terminaciones marginales de la rama. 


\title{
Arberia sp. cf. A. madagascariensis
}

Lámina IV.2.10, C, G, K

Material: L1Ninf: 145; L2Ninf: 268, 271; L2Nsup: 470, 500.

Procedencia: Localidad 1 (nivel inferior); Localidad 2 (nivel inferior, nivel superior).

Descripción: Estructura reproductiva con eje primario laminar, de forma triangular o en abanico, con un pedicelo basal de 0,8 cm de largo y $0,35 \mathrm{~cm}$ de ancho. Se divide en dos sectores, que luego se ramifican, presentando de tres a cinco ramas, cuyo largo oscila entre 0,28 y $0,9 \mathrm{~cm}$, y el ancho entre 0,17 y $0,36 \mathrm{~cm}$. El eje es estriado. Las ramas secundarias poseen terminaciones agudas, en algunos casos (Ejemplar 470) se interpreta la presencia de óvulos, de $0,4 \mathrm{~cm}$ de largo y $0,25 \mathrm{~cm}$ de ancho.

El ejemplar 268 (Lámina 10 Figura K) comprende impronta y contraimpronta de la parte basal de una hoja de Glossopteris wilsonii, que lleva en conexión a la altura del pecíolo un receptáculo alargado, de $2 \mathrm{~cm}$ de largo hasta una constricción y que continúa. Posteriormente a la constricción, se inserta una polisperma tipo Arberia. El material, fragmentario, no permite discernir si se insertaría otra polisperma sobre el mismo receptáculo, distalmente a la que se observa en la figura.

\author{
Orden CORDAITALES \\ Género Cordaites Unger 1850 \\ Especie tipo: Cordaites borassifolia (Sternberg) Unger 1850. \\ Cordaites hislopi (Bunbury) Seward \& Leslie 1908 \\ Lámina IV.2.11 Figuras A-E
}

Material: L1Ninf: 33, 45, 61, 69, 86, 88, 89, 90, 91, 93, 96, 100, 106, 107, 119, 120;

L1Nsup: 186; L2Ninf: 226, 229, 230, 232, 233, 235, 237, 238, 239, 240, 246, 248, 266, 267, 284, 289, 291, 292, 298, 300, 316, 335, 336; L2Nsup: 467, 468, 470, 487; L3: 529, 
532, 541, 548, 566, 571, 596, 607, 612, 629, 637, 647, 686; L4: 724, 744; L5med: 831, 834, $836,837,840,854,856,860,861,878,890$.

Procedencia: Localidad 1, nivel inferior, nivel superior; Localidad 2, nivel inferior, nivel superior; Localidad 3; Localidad 4; Localidad 5, nivel medio.

Descripción: Gran parte de los ejemplares estudiados son fragmentarios, presentando ápice y base truncados. Hojas sésiles, variables en tamaño (largo observado: 2,3 a 12,7 cm; ancho 0,7 a 3,5 cm), lineares, de márgenes enteros, subparalelos, con el ancho máximo cerca del ápice y angostándose hacia la base. Venación paralela a subparalela que se dicotomiza en forma aguda, con una densidad de entre 8 y 18 venas por centímetro. En algunos casos pueden observarse estrías longitudinales. Varios ejemplares muestran marcas de interacciones con insectos.

\section{Orden GINKGOALES Gorožankin 1904}

Género Ginkgophyllum Saporta 1875 emend. Neuburg 1948

Especie tipo: Ginkgophyllum grasseti Saporta, 1875.

\section{Ginkgophyllum sp.}

Material: 819, 821.

Procedencia: Localidad 5, nivel inferior.

Descripción: fragmentos de hojas en forma de abanico. Los fragmentos corresponden a sectores de la lámina que presentan incisiones pronunciadas, venas paralelas a veces dicotomizadas, y venación abierta. El largo máximo observado es de 6,6 cm, y el ancho de uno de los segmentos, de $0,8 \mathrm{~cm}$.

Comentarios: se incluyen en esta especie hojas segmentadas, referibles al género Ginkgophyllum pero cuyo grado de fragmentación no permite realizar asignación específica. Para Sierra de Los Llanos, Archangelsky y Arrondo (1974) identificaron la presencia de G. criciumensis (Rigby ) Archangelsky y Arrondo 1974, del cual Frenguelli (1949) (refiriéndose a éste como Barakaria dichotoma (Feistmantel) Seward y Sahni 1920) señaló que es uno de los dos taxones más abundantes. 


\author{
CONIFEROPSIDA \\ Familia FERUGLIOCLADACEAE Archangelsky y Cúneo 1987 \\ Género Ferugliocladus Archangelsky y Cúneo 1987 \\ Especie tipo: Ferugliocladus riojanum Archangelsky y Cúneo 1987. \\ Ferugliocladus riojanum Archangelsky y Cúneo 1987 \\ Lámina IV.2.12 Figuras A-H
}

Material: L1Ninf: 103; L2Nsup: 365, 367, 368, 369, 371, 372, 374, 375, 376, 377, 378, 427 , 438, 439, 445, 446, 447, 448, 449, 450, 451, 458, 459, 461, 462, 463, 464, 465, 472, 473, 475, 483, 488, 490, 491, 493, 494, 498, 501, 502, 506, 507; L3: 510, 514, 516, 517, 518, $521,522,524,525,527,528,529,530,532,533,534,535,536,537,538,540,543,546$, $547,549,551,552,556,557,558,559,562,569,584,585,586,593,594,596,597$; L4: 725, 729, 736, 757, 762, 770, 777, 779, 787, 790, 791, 794, 795, 800.

Procedencia: Localidad 1 (nivel inferior); Localidad 2 (nivel superior); Localidad 3; Localidad 4

Descripción: Ramas de hasta tercer orden, cuyas medidas varían de acuerdo al orden de ramificación. En las ramificaciones de antepenúltimo orden la longitud alcanza los $10 \mathrm{~cm}$ y el ancho oscila entre 0,6 y 2,7 cm. Estas ramas son áfilas. Las ramas de penúltimo y último orden poseen un largo de entre 0,8 y $8,52 \mathrm{~cm}$, y un ancho que varía entre 0,2 y 1,65 cm. Ramas cubiertas de hojas pequeñas, de disposición helicoidal, levemente superpuestas, adpresas en la base y con la parte libre suavemente curvada hacia el eje. Escuamiformes o lanceoladas. El largo de las hojas oscila entre 0,3 y $0,95 \mathrm{~cm}$, poseen un ancho de entre 0,09 y $0,17 \mathrm{~cm}$.

Se hallan conos en asociación recurrente y en conexión orgánica. Éstos tienen contorno triangular, y miden entre 6 y $36 \mathrm{~mm}$ de largo, con un ancho que varía entre 2 y16 mm. Se observan distintas preservaciones, sean superficiales, donde se ve la parte externa del cono, o secciones internas, donde se observa el eje principal, de alrededor de $5 \mathrm{~mm}$ de ancho, y los esporofilos. Los conos se componen de un eje principal que porta esporofilos con filotaxis 
helicoidal. Los esporofilos llevan óvulos en su cara adaxial. Los esporofilos miden de 4 a 7,4 mm de largo, y de 2,4 a 1,6 mm de ancho.

\author{
Género Genoites (Feruglio) Cúneo 1985 \\ Especie tipo: Genoites patagonica Feruglio
}

Genoites nov. sp.

\title{
Lámina IV.2.13 Figuras A-F
}

Material: 801, 802, 803, 804, 805, 806, 807, 808, 810, 811, 812, 813, 814, 815, 816, 820, $822,825,826,827,828$.

Procedencia: Localidad 5 (nivel inferior).

Descripción: Compresiones de ejes de al menos tres órdenes. Las ramas de antepenúltimo orden son áfilas, de al menos $10 \mathrm{~cm}$ de largo y $2 \mathrm{~cm}$ de ancho (ejemplar 813). Los ejes de último y penúltimo orden poseen hojas simples o incisas, alargadas, de distribución que varía entre laxa y apretada, libres desde la base y con curvatura hacia el eje variable. Los ejes poseen un largo que oscila entre 0,95 y 4,3 cm, y un ancho de entre 0,2 y 1,25 cm. Las hojas miden entre 0,45 y 0,57 $\mathrm{mm}$ de largo, y $0,1 \mathrm{~mm}$ de ancho. Sobre algunas ramas de último orden se observan óvulos ovalados, con ápice inciso o redondeado, ortótropos, simples, dispuestos en posición axilar a las hojas, sin conformar cono (Lámina 10 Figuras A-C). Semillas asociadas de mayor tamaño que los óvulos (3-4 mm de largo y 1,5 mm de ancho), con pico nucelar.

Comparaciones: La presencia de óvulos ortótropos axilares a hojas, dispuestos en forma laxa en las ramas, y hojas heteromórficas, apoya la asignación de los ejemplares al género Genoites. El material aquí descripto comparte las características generales con Genoites patagonica, se diferencian en que las hojas de G. patagónica presentan mayor grado de incisión, mientras que en este material las hojas son mayormente simples, con algunas multífidas en sectores apicales.

Siguiendo a Taylor et al. (2009), se descarta la asignación al género Buriadia dado que la reinvestigación del género (Singh et al., 2003) determinó la ausencia de óvulos en disposición laxa sobre las ramas, y se desconocen las estructuras reproductivas que portaría este taxón. 
Semillas. Los óvulos o semillas, al estado disperso, se denominan utilizando morfotaxones. Para cada caso se indica la afinidad botánica.

Género Cornucarpus Arber 1914 emend. A. Archangelsky 2001

Especie tipo: Cornucarpus acutus (Lindley \& Hutton) Arber 1914.

Cornucarpus sp. A

Lámina IV.2.14 Figura 1

Material: L2Ninf: 217, 220-223, 241, 251, 269, 275, 276, 277, 293, 295, 299, 306, 307, $310,311,312,313,315,317,318,320,321,323,324,325,327,332$; L3: 655, 658, 663, 686, 693, 695, 697, 699-702, 706, 707, 711, 719; L4: 721, 722, 730, 733, 735, 738; L5Nmed: 858, 892 .

Procedencia: Localidad 2, nivel inferior; Localidad 3; Localidad 4; Localidad 5, nivel medio. Descripción: semillas ovalada a redondeada, con ápice y base enteros. Núculo de igual contorno que el general. Sarcotesta angosta, de ancho uniforme. Relación AS/AN < 0,22.

Medidas: 349 semillas, Largo 0,21 a 0,73; Ancho 0,14 a 0,67 cm.

Comentarios: en Arroyo Totoral se la encuentra siempre en asociación con hojas de Glossopteris wilsonii y Gangamopteris obovata. Es muy similar a Cornucarpus patagonicus, pero no presenta el mismo patrón estriado.

Género Eucerospermum (Feruglio) A. Archangelsky 2001

Especie tipo: Eucerospermum patagonicum (Feruglio) A. Archangelsky 2001.

Eucerospermum sp.

Lámina IV.2.14 Figuras C, F-I

Material: L2Nsup: 357, 358, 374, 384, 392, 395-407, 409-411, 414-417, 437, 444, 445; L3: 513, 519, 573-579, 587, 609; L4: 715, 731, 767, 793.

Procedencia: Localidad 2, nivel superior; Localidad 3, Localidad 4. 
Descripción: Semillas platispérmicas de simetría bilateral y contorno cordiforme. El ápice es bifurcado, con dos espinas que se abren suavemente. La base es redondeada o presenta una pequeña escotadura. La forma general es cordiforme, en algunos ejemplares se observa que el núculo es ovalado, y hay una capa más delicada, externa.

Medidas: 262 semillas, largo entre 0,24 y 1,06 cm, ancho entre 0,19 y $1 \mathrm{~cm}$.

Afinidad botánica: Familia Ferugliocladaceae (Archangelsky, 2001).

Comentarios: la ausencia de una carena longitudinal marcada y el grado variable en que el ápice se recurva hacia el núculo previenen la asignación a Eucerospermum nitens.

\section{Género Samaropsis Goeppert}

Especie tipo: Samaropsis ulmiformis Goeppert

Afinidad botánica: Glossopteridales (White, 1908; Holmes, 1974; Kovács-Endrödy, 1974; Rigby et al., 1980; Anderson y Anderson, 1985), Coniferales (Geinitz, 1880) y Cordaitales (Arber, 1914).

Samaropsis sp. A.

Lámina IV.2.14 Figuras B, D

Material: L2Ninf: 213, 214, 267; L5Nmed: 863.

Procedencia: Localidad 2, nivel inferior; Localidad 5, nivel medio.

Descripción: Semilla platispérmica, alada, circular a ovalada. Esclerotesta de contorno redondeado. Sarcotesta bien desarrollada, de ancho uniforme, base redondeada y ápice con escotadura angosta.

Medidas: 4 semillas, largo 0,42 a $0,6 \mathrm{~cm}$, ancho entre 0,3 y $0,35 \mathrm{~cm}$, sarcotesta 0,1 a $0,2 \mathrm{~cm}$.

Samaropsis sp. B

Lámina IV.2.14 Figura E

Material: L2Ninf: 215, 255, 256, 300 
Procedencia: Localidad 2, nivel inferior;

Descripción: Semilla platispérmica, alada, circular a ovalada. Esclerotesta de contorno subcircular, ápice acuminado y base pedunculada. Sarcotesta bien desarrollada, de ancho uniforme, base cordada y ápice con escotadura angosta.

Medidas: 2 semillas. Largo entre 0,42 y 0,54 cm; ancho entre 0,35 y 0,4 cm. Sarcotesta 0,18$0,2 \mathrm{~cm}$.

Comentarios: Los ejemplares son de menor tamaño que Samaropsis kurtzii Leguizamón 1971 y que aparecen en Bajo de Véliz, pero la forma general es similar. 


\section{Discusión general}

En este estudio se reconocieron un total de 21 taxones, entre los que se encuentran los taxones previamente mencionados, y nuevos hallazgos para la Formación. Como novedades, se confirma el registro del género Cruciaetheca fuera de la Cuenca Tepuel-Genoa. Se presenta una segunda especie de Asterotheca, comparable a formas presentes en Cuenca de La Golondrina. Dentro de las Gimnospermas, se describe una segunda especie de estructura reproductiva de glossopteridal y el primer hallazgo de una estructura reproductiva en conexión orgánica con una hoja de Glossopteris wilsonii para Paganzo. Asimismo, se confirma la presencia del género Genoites en la Formación.

\begin{tabular}{|c|c|c|c|c|}
\hline $\begin{array}{l}\text { Archangelsky y } \\
\text { Arrondo (1973) }\end{array}$ & $\begin{array}{l}\text { Álvarez y } \\
\text { Fernández Seveso } \\
\text { (1987) }\end{array}$ & $\begin{array}{l}\text { Barreda y Césari } \\
\text { (1995) }\end{array}$ & $\begin{array}{l}\text { Archangelsky et } \\
\text { al. (1996) }\end{array}$ & Esta Tesis \\
\hline $\begin{array}{l}\quad \text { Phyllotheca } \\
\text { leptophylla } \\
\text { Asterotheca } \\
\text { feruglioi } \\
\text { Sphenopteris sp. } \\
\text { Glossopteris } \\
\text { occidentalis } \\
\text { Gangamopteris } \\
\text { obovata } \\
\text { Cordaites hislopi } \\
\text { Paranocladus? } \\
\text { Fallax } \\
\text { Samaropsis sp. } \\
\text { Arberia cf. } \\
\text { minasica } \\
\text { Botrychiopsis } \\
\text { plantiana } \\
\text { Gingkophyllum } \\
\text { criciumensis }\end{array}$ & $\begin{array}{l}\text { Phyllotheca } \\
\text { leptophylla, } \\
\text { Paracalamites } \\
\text { australis, } \\
\text { Botrychiopsis } \\
\text { plantiana, } \\
\text { Gangamopteris } \\
\text { obovata, } \\
\text { Cordaites hislopi, } \\
\text { Genoites cf. } \\
\text { patagonica, } \\
\text { Paranocladus sp. } \\
\text { Cordaicarpus sp. } \\
\text { A. }\end{array}$ & $\begin{array}{l}\text { "Articuladas" } \\
\text { Gangamopteris } \\
\text { obovata } \\
\text { Glossopteris } \\
\text { wilsonii } \\
\text { Ottokaria sp. } \\
\text { Cordaicarpus sp. }\end{array}$ & $\begin{array}{l}\text { Asterotheca } \\
\text { feruglioi } \\
\text { Paracalamites } \\
\text { australis } \\
\text { Phyllotheca } \\
\text { leptophylla } \\
\text { Phyllotheca sp. } \\
\text { Botrychiopsis } \\
\text { plantiana } \\
\text { Sphenopteris sp. } \\
\text { Cordaites hislopi, } \\
\text { Ferugliocladus } \\
\text { riojanum } \\
\text { Paranocladus (?) } \\
\text { fallax, } \\
\text { Ginkgophyllum } \\
\text { sp., } \\
\text { Arberia cf. } \\
\text { minasica, } \\
\text { Gangamopteris } \\
\text { obovata } \\
\text { Glossopteris cf. } \\
\text { occidentalis } \\
\text { Glossopteris } \\
\text { wilsonii } \\
\text { Cordaicarpus sp. }\end{array}$ & $\begin{array}{l}\text { Asterotheca } \\
\text { feruglioi } \\
\text { Asterotheca sp. } \\
\text { Paracalamites } \\
\text { australis } \\
\text { Paracalamites cf. } \\
\text { P. frigidus } \\
\text { Phyllotheca } \\
\text { leptophylla } \\
\text { Cruciaetheca } \\
\text { patagonica } \\
\text { Botrychiopsis } \\
\text { plantiana } \\
\text { Eusphenopteris sp. } \\
\text { Arberia cf. } \\
\text { minasica, } \\
\text { Arberia cf. } \\
\text { madagascariensis } \\
\text { Gangamopteris } \\
\text { obovata } \\
\text { Glossopteris } \\
\text { occidentalis } \\
\text { Glossopteris } \\
\text { wilsonii } \\
\text { Cordaites hislopi, } \\
\text { Ferugliocladus }\end{array}$ \\
\hline
\end{tabular}




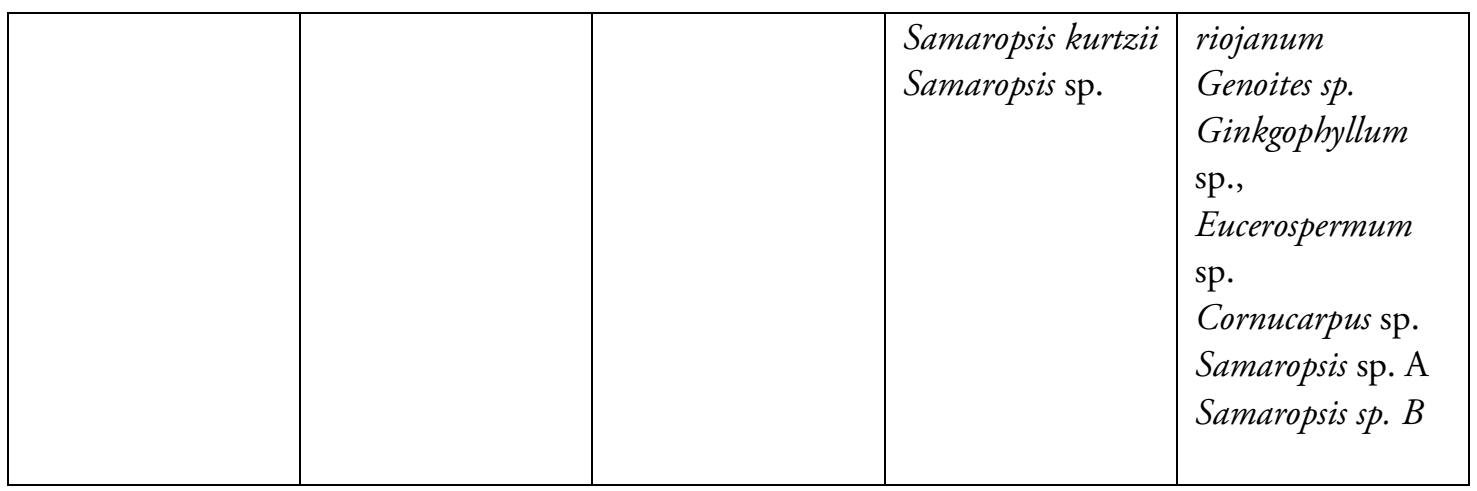

\section{Consideraciones acerca de los grupos descriptos}

\section{ESFENÓFITAS}

Las Equisetales son abundantes a lo largo de todo el perfil de Arroyo Totoral. En esta tesis se describen por primera vez para esta localidad equisetales con estructuras reproductivas asociadas o en conexión orgánica con los órganos vegetativos. Estas están acompañadas de abundantes ejes vegetativos dispersos, clasificados como Paracalamites. El género Cruciaetheca fue descripto inicialmente para la Cuenca de Tepuel Genoa. Su Especie tipo, C. patagonica, fue determinada inicialmente por Frenguelli (1951) como Phyllotheca patagonica. La asociación de “cruciatecas" de Tepuel-Genoa posee 3 especies que se diferencian en su parte vegetativa por la proporción entre la vaina y el largo de la parte libre de la hoja. En la asociación de Arroyo Totoral, se ha descripto también P. leptophylla (Archangelsky y Arrondo, 1973), la cual es de mayor tamaño general que Cruciaetheca. Para esta especie no se hallaron estructuras reproductivas asociadas, pero no debería descartarse que éstas sean de tipo cruciado y se deba añadir una especie local al género Cruciaetheca.

Las Equisetales son plantas hidro-higrófilas, y son indicadoras de ambientes húmedos. En general se las halla asociadas a cuerpos de agua, sean ríos, arroyos o lagos.

\section{FILICÓFITAS}

Los helechos descriptos para Arroyo Totoral pertenecen a la Familia Asterothecaceae, del Orden Marattiales. Dentro del género Asterotheca, se describe la presencia de un segundo 
morfotipo, del cual por la escasez del material no puede hacerse una asignación específica, pero es similar a los presentes en la Cuenca La Golondrina, del Pérmico Superior. Frondes de tipo Sphenopteris/Eusphenopteris están también asociadas a este grupo. Las Asterothecaceae son reconstruidas en base a la conexión de tallos (Psaronius) y frondes (Asterotheca, Dizeugotheca) como helechos arborescentes. Se las considera indicadoras paleoclimáticas, de climas templadocálidos, húmedos. En Arroyo Totoral tienen escasa representación.

\section{GIMNOSPERMAS.}

Botrychiopsis se reconstruye como un arbusto, asociado frecuentemente a ambientes de tundra y taiga (Archangelsky, 1971, 1978, 1984; Rocha-Campos y Archangelsky, 1985; Retallack, 1980, 1999). Jasper et al. (2003) lo refirieron también a climas templado cálidos. El género incluye 3 especies, B. weissiana (Carbonífero Superior), B. plantiana (Carbonífero cuspidal-Pérmico Inferior) y B. valida (Feistmantel) Archangelsky y Arrondo, 1971 (Pérmico Inferior a Medio). Se puede hacer un correlato general entre las especies y el clima: B. weissiana es característica de las asociaciones de clima frío, periglaciales, del Carbonífero Superior; $B$. plantiana aparece en las sucesiones de deglaciación, en la transición entre ambientes templado fríos a templado cálidos, y B. valida se asentaría en ambientes de clima templado-cálido (Jasper et al., 2003).

Las Glossopteridales constituyen uno de los taxones más abundantes de la Formación Arroyo Totoral, pero esta abundancia se genera por la proliferación del morfotaxón Glossopteris. En cuanto a estructuras reproductivas, se han hallado dos especies del género Arberia, lo que indicaría que hay al menos dos entes biológicos distintos en la Formación. Glossopteris se adaptó, durante el Pérmico, a una variedad de climas: desde el riguroso clima polar, hasta climas templado-cálidos, y se ha demostrado que también se adaptaron a una gran diversidad de ambientes (Cúneo et al., 1993). Actualmente se reconstruye a Glossopteris como un árbol, por la co-ocurrencia de las hojas con tallos (Taylor et al., 2009), pero también se lo ha interpretado como de hábito herbáceo (Singh, 2000) o inclusive, lianas (Pant, 1999). 
Las Cordaitales están representadas sólo por órganos foliares. Estas plantas habitaron gran diversidad de ambientes: su utilidad a nivel paleoambiental mejorará a medida que se conozca su diversidad (Césari y Hünicken, 2013).

Respecto de las coníferas, durante el Pérmico se observa gran diversidad a nivel global, representada por las "Voltziales" en la región paleoecuatorial y septentrional, y Ferugliocladaceae y Buriadiaceae en Gondwana (Taylor et al., 2009). Las Ferugliocladaceae presentarían un mayor rango de variación ecológica que las coníferas presentes en el cinturón paleoecuatorial para el mismo período. Se las reconoce como taxones higro-mesófilos por la asociación que forman en la Formación Arroyo Totoral con las esfenofitas, cordaitales y glossopteridales (Archangelsky y Cúneo, 1987).

\section{Distribución de los taxones}

La distribución de los taxones en los niveles es la siguiente:

\section{Localidad 1.}

Nivel inferior: Paracalamites australis, P. frigidus, Botrychiopsis plantiana, Gangamopteris obovata, Glossopteris occidentalis, G. wilsonii, Arberia cf. minasica; A. cf. madagascariensis, Cordaites hislopi, Ferugliocladus riojanum.

Nivel superior: Paracalamites australis, P. frigidus, Botrychiopsis plantiana, Glossopteris wilsonii, Cordaites hislopi.

\section{Localidad 2.}

Nivel inferior: Paracalamites australis, P. frigidus, Phyllotheca leptophylla, Botrychiopsis plantiana, Gangamopteris obovata, Glossopteris occidentalis, G. wilsonii, Arberia cf. minasica, A. cf. madagascariensis, Cordaites hislopi.

Nivel superior: Phyllotheca leptophylla, Gangamopteris obovata, Glossopteris occidentalis, G. wilsonii, Arberia cf. madagascariensis, Cordaites hislopi, Ferugliocladus riojanum. 
Eliana Paula Coturel - Bioestratigrafía del Pérmico de la Sierra de los llanos...

\section{Localidad 3.}

Nivel fosilífero: Paracalamites australis, P. frigidus, Asterotheca feruglioi, A. sp., Eusphenopteris sp., Glossopteris occidentalis, G. wilsonii, Arberia cf. minasica, Cordaites hislopi, Ferugliocladus riojanum.

\section{Localidad 4.}

Nivel fosilífero: Paracalamites australis, Phyllotheca leptophylla, Asterotheca feruglioi, Gangamopteris obovata, Glossopteris occidentalis, G. wilsonii, Arberia cf. minasica, Cordaites hislopi, Ferugliocladus riojanum.

\section{Localidad 5.}

Nivel inferior: Paracalamites australis, Ginkgophyllum sp., Genoites nov sp.

Nivel medio: Paracalamites australis, Phyllotheca leptophylla, Gangamopteris obovata, Glossopteris occidentalis, G. wilsonii, Cordaites hislopi.

Nivel superior: Phyllotheca leptophylla.

En cada nivel se trató de colectar la mayor cantidad de material determinable transportable. De acuerdo al material colectado, la abundancia relativa de los taxones por nivel es la siguiente:

\section{Localidad 1.}

- Nivel inferior: Bp: $60 \%$, Ch: 13\%, Pa: 6,5\%;

Glw: 6,5\%, Pf: 5\% Glo: 5\%, Gao: 2\%, Ami: $<1 \%$, Ama: $<1 \%$, Fr: $<1 \%$;

- Nivel superior: Bp: $85 \%$, Ch: 4\%, Glw: 4\%, PaPf: $7 \%$;
Código de iniciales:

$\mathrm{Pa}$ Paracalamites australis

Pf Paracalamites sp. cf. P. frigidus

PI Phyllotheca leptophylla

Af Asterotheca feruglioi

As Asterotheca sp.

Bp Botrychiopsis plantiana

Es Eusphenopteris sp.

Gao Gangamopteris obovata

Glo Glossopteris occidentalis

Glw Glossopteris wilsonii

Ami Arberia cf. minasica

Ama Arberia cf. madagascariensis

Gs Ginkgophyllum sp.

Ch Cordaites hislopi

Ges Genoites sp.

Fr Ferugliocladus riojanum 
Localidad 2.

- Nivel inferior: Glw: $31 \%$, Ch: $28 \%$, Pa: 14,5\%, Ami: $7 \%$, Pf: $6 \%$, Gao: $5 \%$, Glo: $4 \%$, Bp: 2,5\% Ama: 1\%, Pl: 1\%

- Nivel superior: Fr: 65\%, Glw: 15\%, Glo: 8\%, Ch: 6\%, Ama: 3\%, Gao: 1,5\%, As: $1,5 \%$

Localidad 3.

- Nivel fosilífero: Fr: 51\%, Ch: $16 \%$, Glw: 9\%, Pa: 5\%, Pf: 4\%, Glo: 4\%, Af: 4\%; Ami: $2,5 \%$, As: $2,5 \%$, Es: $2 \%$

Localidad 4.

- Nivel fosilífero: Fr: 45\%, Glw: 16\%, Pa: 13\%, Glo: 10\%, Ch: $7 \%$, Gao: 3\%; Ami: 3\%, Pl: 3\%,

Localidad 5.

- Nivel inferior: Ges: 83\%, Pa: 8,5\%, Gs: 8,5\%

- Nivel medio: Ch: 42\%, Glo: 27\%, Gw: 15\%, Gao: 8\%, Pl: 4\%, Pa: 4\%

- Nivel superior: Pl: $100 \%$

La distribución por grupos es la siguiente:

Equisetales Helechos Botrychiopsis Glossopterid. Cordaitales Ginkgoales

Coníferas

G. F.

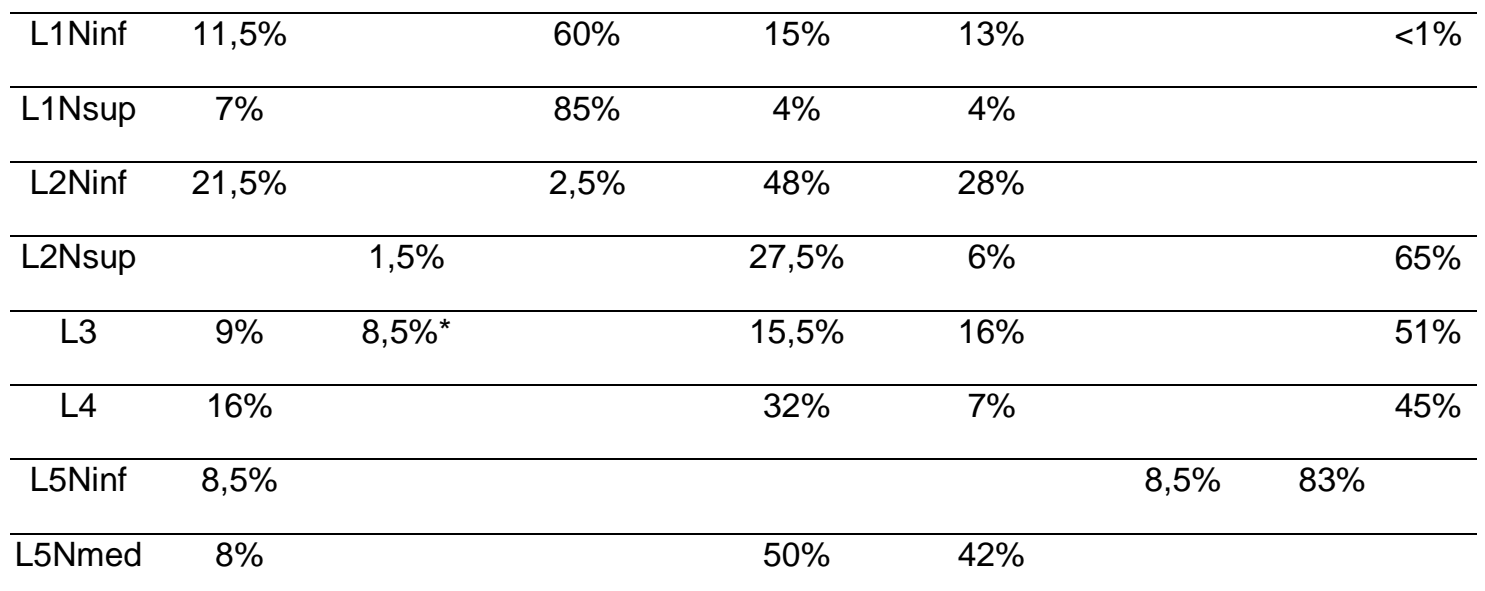

L5Nsup 100\%

Cuadro IV.2.b. Distribución porcentual de los grupos en los niveles. Referencias: G. = Genoites, F.= Ferugliocladus, *incluye Eusphenopteris 
- Puede observarse que la Localidad 5, en su nivel inferior, posee una flora característica y diferente a las demás localidades. Ésta está dominada por coniferofitas tipo Genoites y esfenófitas. El registro de glossopteridales es escaso (un ejemplar fragmentario).

- En la Localidad 5, nivel medio, comienza el registro propiamente dicho de Glossopteridales y Cordaites, las cuales junto con las esfenofitas se mantienen en los restantes niveles.

- Las localidades 3, 4 y 5 (nivel superior), correlacionables, presentan una tafoflora con coníferas, helechos, glossopteridales, cordaitales y esfenofitas.

- En la Localidad 1, ambos niveles, aparece Botrychiopsis plantiana, acompañada de glossopteridales, cordaitales y esfenofitas. En el nivel inferior se registran coníferas, ausentes en el nivel superior.

- Por último, en la Localidad 2 se mantiene la asociación glossopteridales + cordaitales + esfenofitas, acompañadas de estructuras reproductivas de glossopteridales, y en el nivel superior, de helechos.

De este modo, pueden definirse las siguientes Paleocomunidades. Se ordenan de acuerdo a la estratigrafía.

\begin{tabular}{llllll}
\hline \hline Tafocenosis & Tipo de & Elementos & Elementos & Localidad y \\
& vegetación & dominantes & secundarios & nivel \\
& & & & \\
\hline Paleocomunidad 1 & Arbórea & Estrato arbóreo & Equisetales cercanas a & L5Ninf \\
& & dominado & por & cuerpos de agua & \\
& & Coníferas & & \\
& & & & \\
\hline \hline
\end{tabular}


Eliana Paula Coturel - Bioestratigrafía del Pérmico de la Sierra de los llanos...

\begin{tabular}{|c|c|c|c|c|}
\hline Paleocomunidad 2 & Arbórea & $\begin{array}{l}\text { Estrato arbóreo } \\
\text { dominado por } \\
\text { árboles deciduos de } \\
\text { Glossopteridales y } \\
\text { Cordaitales }\end{array}$ & $\begin{array}{l}\text { Equisetales cercanas a } \\
\text { cuerpos de agua }\end{array}$ & L5Nmed \\
\hline Paleocomunidad 3 & Arbórea & $\begin{array}{lr}\text { Estrato arbóreo } \\
\text { dominado } \\
\text { Coníferas }\end{array}$ & $\begin{array}{l}\text { Glossopteridales, } \\
\text { Cordaitales, } \\
\text { sotobosque con } \\
\text { helechos. }\end{array}$ & L3, L4, \\
\hline Paleocomunidad 4 & Herbácea & Equisetales. & & L5Nsup \\
\hline Paleocomunidad 5 & $\begin{array}{l}\text { Arbórea- } \\
\text { Arbustiva }\end{array}$ & $\begin{array}{l}\text { Estrato arbóreo } \\
\text { poco desarrollado, } \\
\text { Glossopteridales y } \\
\text { Cordaitales, } \\
\text { Sotobosque } \\
\text { dominado por } \\
\text { arbustos tipo } \\
\text { Botrychiopsis }\end{array}$ & $\begin{array}{l}\text { Equisetales cercanas a } \\
\text { cuerpos de agua. }\end{array}$ & L1Ninf,sup \\
\hline Paleocomunidad 6 & Arbórea & $\begin{array}{l}\text { Estrato arbóreo con } \\
\text { Glossopteridales y } \\
\text { Cordaitales. } \\
\text { Cercano a cuerpos } \\
\text { de agua, Equisetales }\end{array}$ & $\begin{array}{l}\text { Sotobosque con } \\
\text { Botrychiopsis }\end{array}$ & L2Ninf \\
\hline Paleocomunidad 7 & Arbórea & $\begin{array}{lr}\text { Estrato } & \text { arbóreo } \\
\text { dominado } & \text { por }\end{array}$ & $\begin{array}{l}\text { Estrato arbóreo con } \\
\text { Cordaitales, }\end{array}$ & L2Nsup \\
\hline
\end{tabular}




\begin{tabular}{llll}
\hline \hline Coníferas & y & Sotobosque con \\
Glossopteridales & helechos & \\
& \\
\hline \hline
\end{tabular}

Cuadro IV.2.c. Paleocomunidades reconocidas.

Cúneo y Archangelsky (1996) reconocieron para Arroyo Totoral 2 tipos de comunidades, relacionadas con la posición del nivel freático. Por un lado, una comunidad hidro-higrofítica de Equisetales, que crecían formando poblaciones densas en el margen del lago. En segundo lugar, una comunidad arborescente, dominada por coníferas, glossopteridales y cordaitales, meso a mesoxerofítica.

Entre las paleocomunidades reconocidas en esta Tesis, se verifica la presencia de stands de Equisetales en la Localidad 5, Nivel superior (Paleocomunidad 4), compuesto exclusivamente por Phyllotheca.

El resto de las asociaciones tiene predominancia de taxones arbóreos, y el elemento dominante alterna entre árboles siempreverdes (coníferas, de tipo Genoites o Ferugliocladus) y árboles de hojas caducas (siempre dominando las Glossopteridales respecto de las Cordaitales). Debe destacarse que estos tres grupos son generalmente clasificados como Meso a Macrofanerófitos (Raunkier, 1934), reconstruidos como árboles de al menos $10 \mathrm{~m}$ de altura, pero que en las diferentes localidades no se han hallado troncos de gran tamaño preservados, y no debería descartarse que hubiera entre ellos formas microfanerófitas $(<2 \mathrm{~m}$ de altura). De hecho, la presencia de árboles caducifolios (Glossopteridales, Cordaitales) parece excluir la formación de un sotobosque (Paleocomunidades 2 y 6 )

En la Paleocomunidad 5 dominan elementos microfanerófitos de tipo Botrychiopsis, los arbóreos se encuentran restringidos. A su vez, la abundancia de elementos arbóreos en las otras paleocomunidades se acompaña con la restricción en la presencia de elementos de sotobosque (helechos, Botrychiopsis). Esta aparente incompatibilidad puede explicarse por la presencia de parches arbóreos en determinadas zonas, y por otro lado, que alguno de estos elementos "arbóreos" sea en realidad arbustivo, y forme el sotobosque. 
La flora de Arroyo Totoral correspondería a una flora de clima estacional, lluvioso, con una marcada variación lateral en la flora, determinada por la distancia al cuerpo de agua (río o lago) que dominaba el paleovalle, y a la variación altitudinal producida por la configuración de las sierras.

\section{La Flora del Arroyo Totoral en el contexto paleoclimático del Gondwana occidental}

Durante el Neopaleozoico ocurrieron tres grandes cambios en la configuración paleogeográfica a nivel global: rotación en sentido horario de Gondwana, traslación de este supercontinente a latitudes más benignas y conformación de Pangea (ver capítulo Introducción). Estos cambios paleogeográficos estuvieron acompañados de cambio climático. Limarino et al. (2013) definen cuatro etapas paleoclimáticas para el neopaleozoico de Sudamérica, que en las cuencas del margen occidental se caracterizan de la siguiente manera:

- Glacial (Viseano tardío - Bashkiriano temprano), dos intervalos glaciales, el inferior representado por diamictitas glaciomarinas proximales (Fm Loma de los Piojos), el superior por diamictitas terrestres que rellenan fiordos y paleovalles (los parte más baja del grupo Paganzo)

- Glacial terminal (Bashkiriano - Cisuraliano más temprano), transgresiones marinas postglaciales, seguidas de sedimentación fluvial. Mantos carbonosos depositados en planicies aluviales y ambientes de estuario (Grupo Paganzo inferior)

- Postglacial (Cisuraliano - Guadalupiano temprano), sedimentación fluvial reemplazada por sucesiones eólicas incluyendo depósitos de duna, interduna y extraduna. En algunas localidades predominan los sedimentos de playa asociados a lagos, y fluviales efímeros (Grupo Paganzo, superior)

- Semiárida a árida (Guadalupiano medio - Lopingiano), Sedimentos eólicos, capas rojas asociadas a sistemas fluviales efímeros y playa (Formaciones Talampaya y La Veteada). 
La etapa Postglacial se presenta en Paganzo en las Formaciones Arroyo Totoral, Bajo de Véliz, El Imperial, La Colina y Tasa Cuna, y en la Cuencas Paraná y Chaco-Paraná, Formaciones Río Bonito e Iratí en Brasil (Limarino et al. 2013). En Sierra de los Llanos, la transición de un ambiente fluvial a uno eólico se observa en la sucesión Arroyo Totoral-La Colina.

Se reconocen también tres cinturones climáticos, en sentido Norte-Sur: un clima húmedo en las Cuencas Paraná y Chaco-Paraná, un cinturón climático lluvioso para el dominio oriental de Paganzo, y un cinturón árido para el dominio occidental. Limarino et al. (2013) especulan que la formación de estos cinturones climáticos estaría influenciada por la presencia de barreras geográficas, el arco de las Sierras Pampeanas que separa Paganzo de Chaco-Paraná bloquearía el camino de vientos cargados de humedad provenientes del Este, provocando que éstos descarguen la mayor parte de su contenido en los sectores de Paraná y Chaco Paraná, donde se han descripto floras con mayor diversidad y se formaron mantos de carbón (Iannuzzi, 2010), y luego de sobrepasar las Sierras Pampeanas descarguen en forma de lluvias el resto del contenido sobre el borde oriental de Paganzo. A pesar de la distancia paleogeográfica respecto del borde de cuenca, el conjunto serrano de los Llanos habría actuado como concentrador de la humedad restante de los vientos provenientes del Este, y por esta razón se desarrolló una flora similar a la del borde de cuenca (Bajo de Véliz y Tasa Cuna), mientras en los sectores donde se desarrolla la Formación Patquía se produjo aridización. Esta situación es comparable a la que sucede en la actualidad en la Patagonia chilena y argentina, donde los vientos cargados de humedad del Océano Pacífico generan una flora más diversa sobre el margen occidental de Sudamérica, se elevan para atravesar la Cordillera de los Andes, y descargan el resto de la humedad sobre la ladera oriental, dispersándose en la meseta patagónica como vientos secos, clave en la diferenciación florística que se observa entre las provincias Subantártica (Dominio Subantártico, Distritos del Bosque Caducifolio y Valdiviano) y Patagónica (Dominio Andino-Patagónico) (Cabrera, 1971). 
Eliana Paula Coturel - Bioestratigrafía del Pérmico de la Sierra de los llanos...

Lámina IV.2.1. Paracalamites australis.
A. Ejemplar 65. Escala: $1 \mathrm{~cm}$
B. Ejemplar 809. Tallo en posición de vida. Escala: $1 \mathrm{~cm}$
C. Ejemplar 838. Escala: $1 \mathrm{~cm}$
D. Ejemplar 343. Escala: $1 \mathrm{~cm}$
E. Ejemplar 344. Escala: $1 \mathrm{~cm}$ 
Eliana Paula Coturel - Bioestratigrafía del Pérmico de la Sierra de los llanos...

\section{LÁMINA IV.2.1}
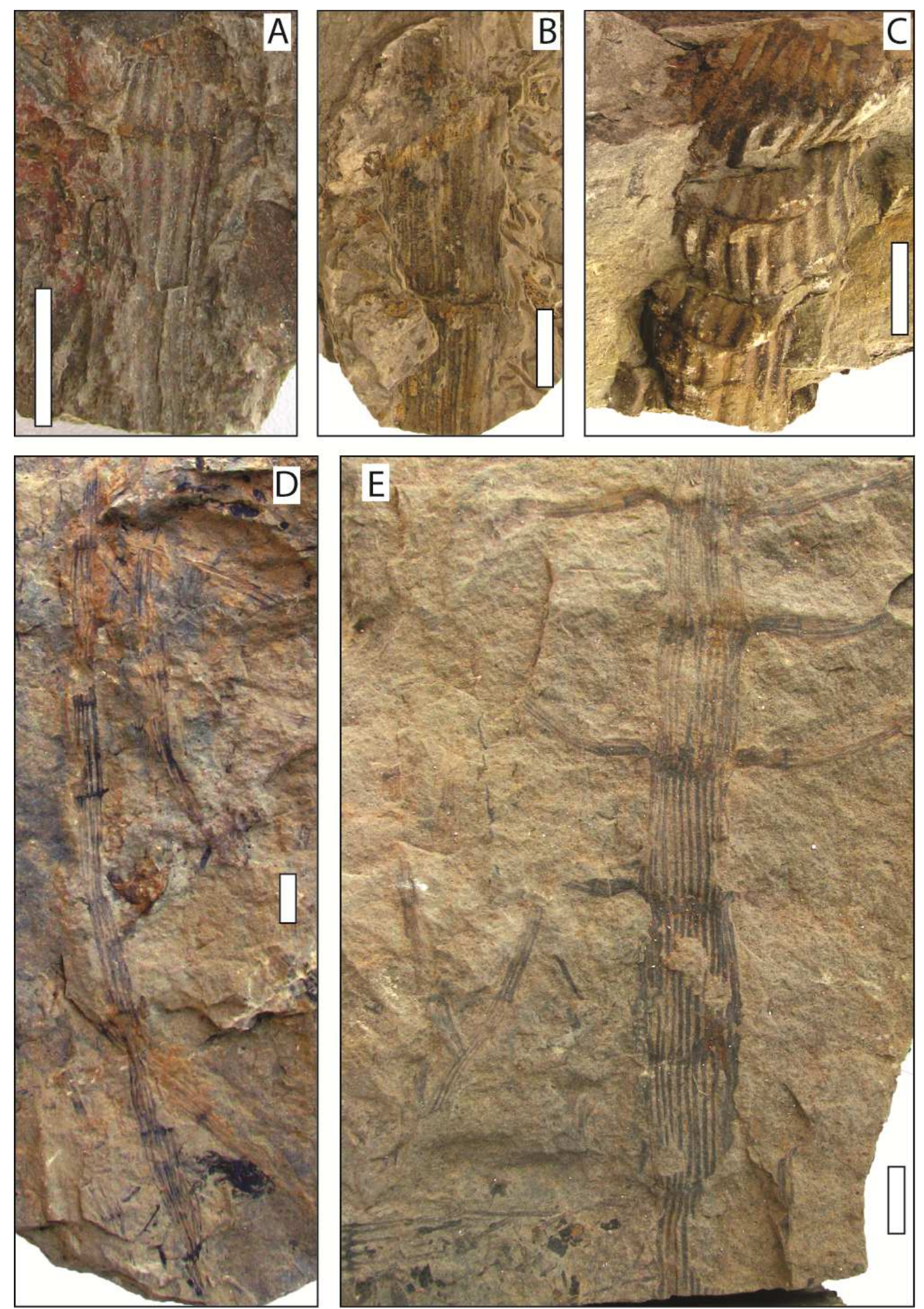

$\sim 88 \sim$ 
Eliana Paula Coturel - Bioestratigrafía del PÉrmico de la SierRa de los llanos...

Lámina IV.2.2. Paracalamites cf. Frigidus
A. Ejemplar 58. Escala: $1 \mathrm{~cm}$
B. Ejemplar 234. Escala: $1 \mathrm{~cm}$
C. Ejemplar 70. Escala: $1 \mathrm{~cm}$
D. Ejemplar 341. Escala: $1 \mathrm{~cm}$ 
Eliana Paula Coturel - Bioestratigrafía del Pérmico de la SierRa de los llanos...

\section{LÁMINA IV.2.2}
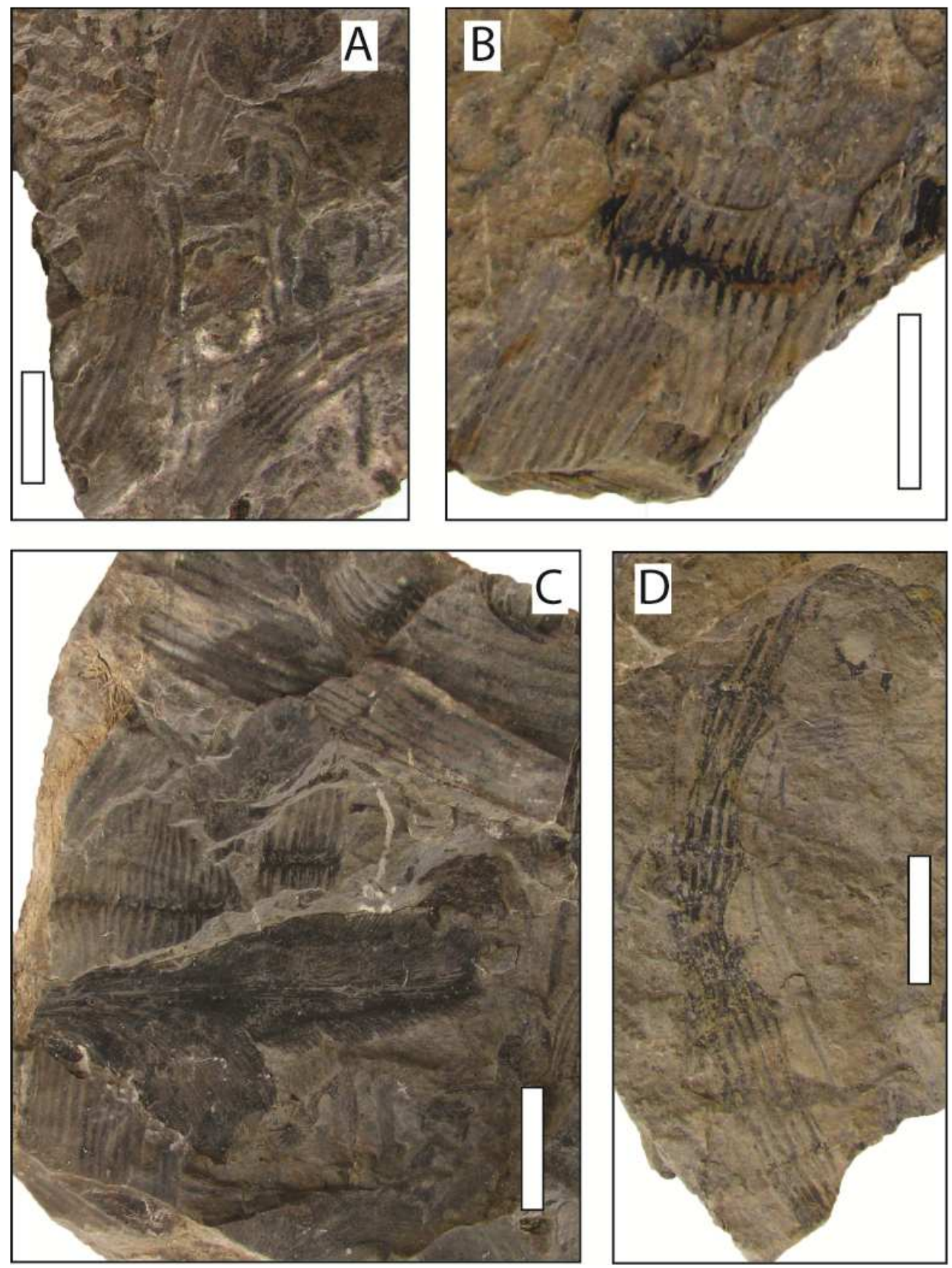
Eliana Paula Coturel - Bioestratigrafía del Pérmico de la Sierra de los llanos...

Lámina IV.2.3. Phyllotheca leptophylla
A. Ejemplar 895. Escala: $1 \mathrm{~cm}$
B. Ejemplar 901. Escala: $1 \mathrm{~cm}$
C. Ejemplar 907b. Escala: $1 \mathrm{~cm}$
D. Ejemplar 907a. Escala: $1 \mathrm{~cm}$
E. Ejemplar 913. Escala: $1 \mathrm{~cm}$ 


\section{LÁMINA IV.2.3}
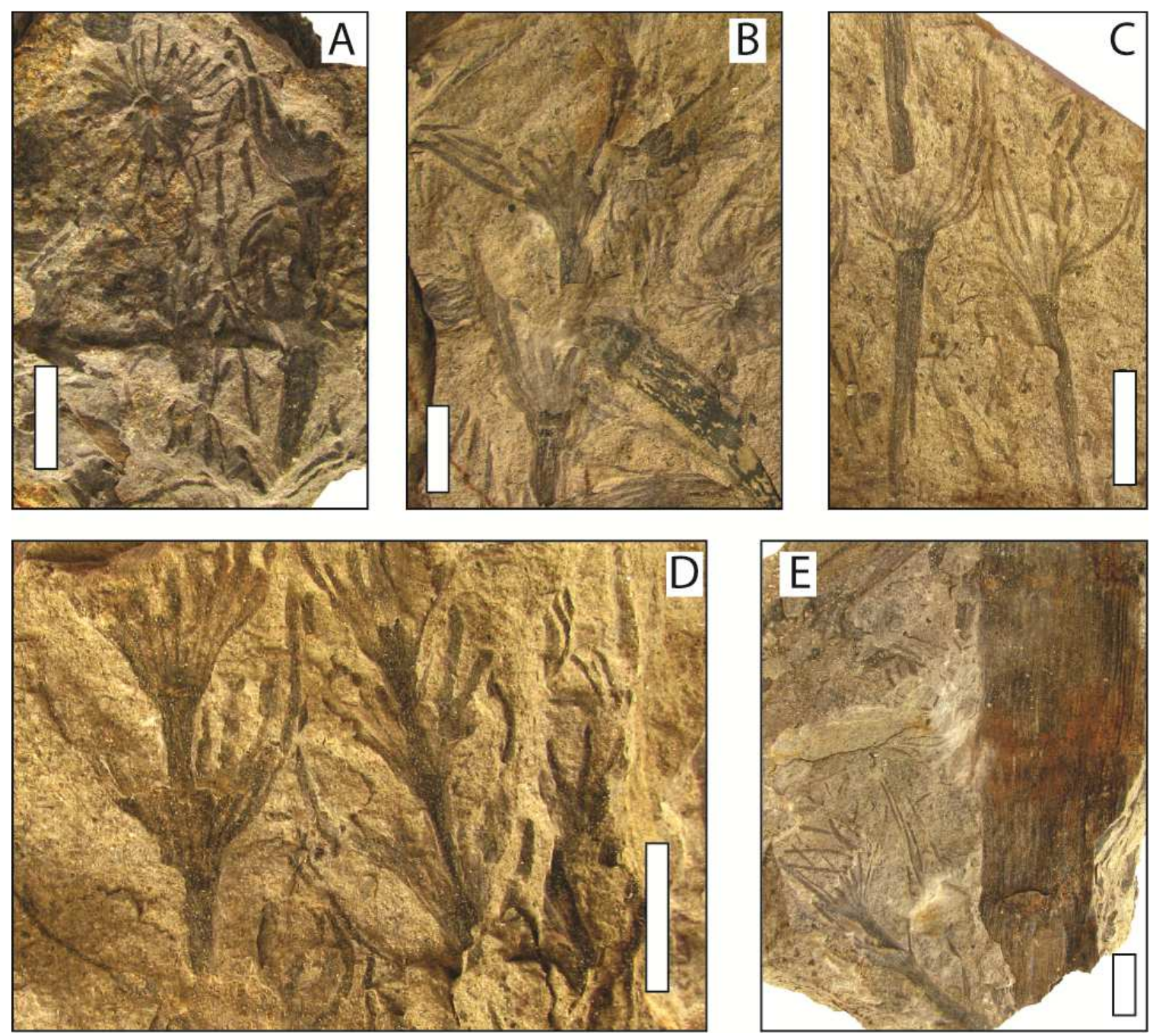
Lámina IV.2.4. Cruciaetheca patagónica
A. BAPb 1105. Escala: $1 \mathrm{~cm}$
B. Detalle de porción apical de A.
C. BAPb 1107 . Escala: $1 \mathrm{~cm}$
D. Detalle de ramificación secundaria de C
E. BAPb 1106. Tallo con ramas secundarias fértiles. Escala: $1 \mathrm{~cm}$
F. Detalle de E.
G. Detalle de E.
H. BAPb 538. Escala: $1 \mathrm{~cm}$
I. BAPb 591. Verticilo foliar en vista transversal y esporangióforos cruciados dispersos. . Escala: $1 \mathrm{~cm}$ 
Eliana Paula Coturel - Bioestratigrafía del Pérmico de la Sierra de los llanos...

\section{LÁMINA IV.2.4}
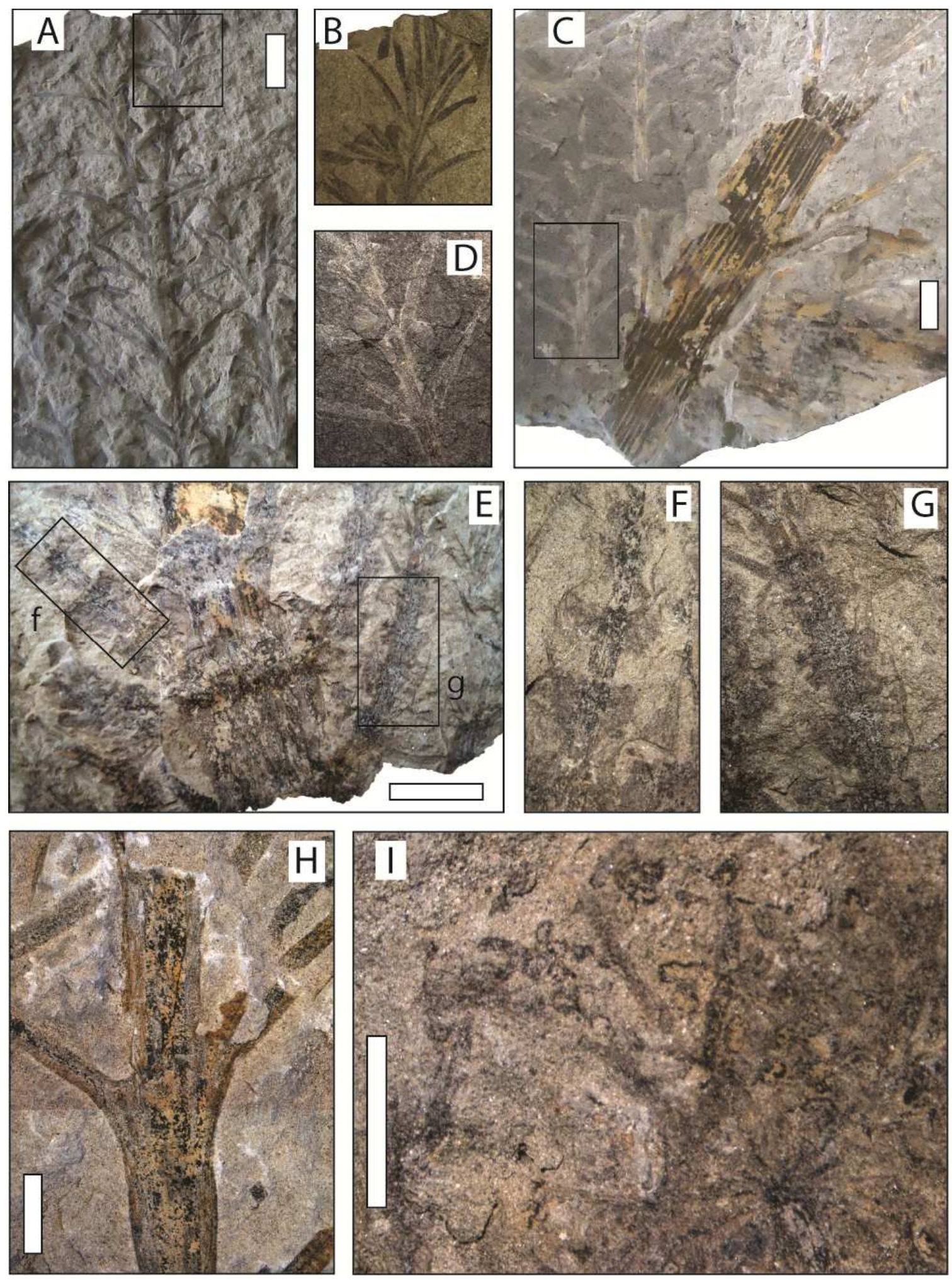
Eliana Paula Coturel - Bioestratigrafía del Pérmico de la Sierra de los llanos...

Lámina IV.2.5. Asterotheca spp.
A. Asterotheca feruglioi Ejemplar 564. Escala $5 \mathrm{~mm}$
B. Asterotheca feruglioi contraimpronta de Ejemplar 564 . Escala $5 \mathrm{~mm}$
C. Asterotheca feruglioi Ejemplar 564. Detalle de pinnula con esporangios fusionados en la base.
D.
E. Asterotheca feruglioi Ejemplar 565. Escala $5 \mathrm{~mm}$
F. Asterotheca sp. Ejemplar 566. Escala $5 \mathrm{~mm}$.
G. Asterotheca sp. Ejemplar 566. Detalle de raquis e inserción de pinnas. Escala 5 mm. 


\section{LÁMINA IV.2.5}
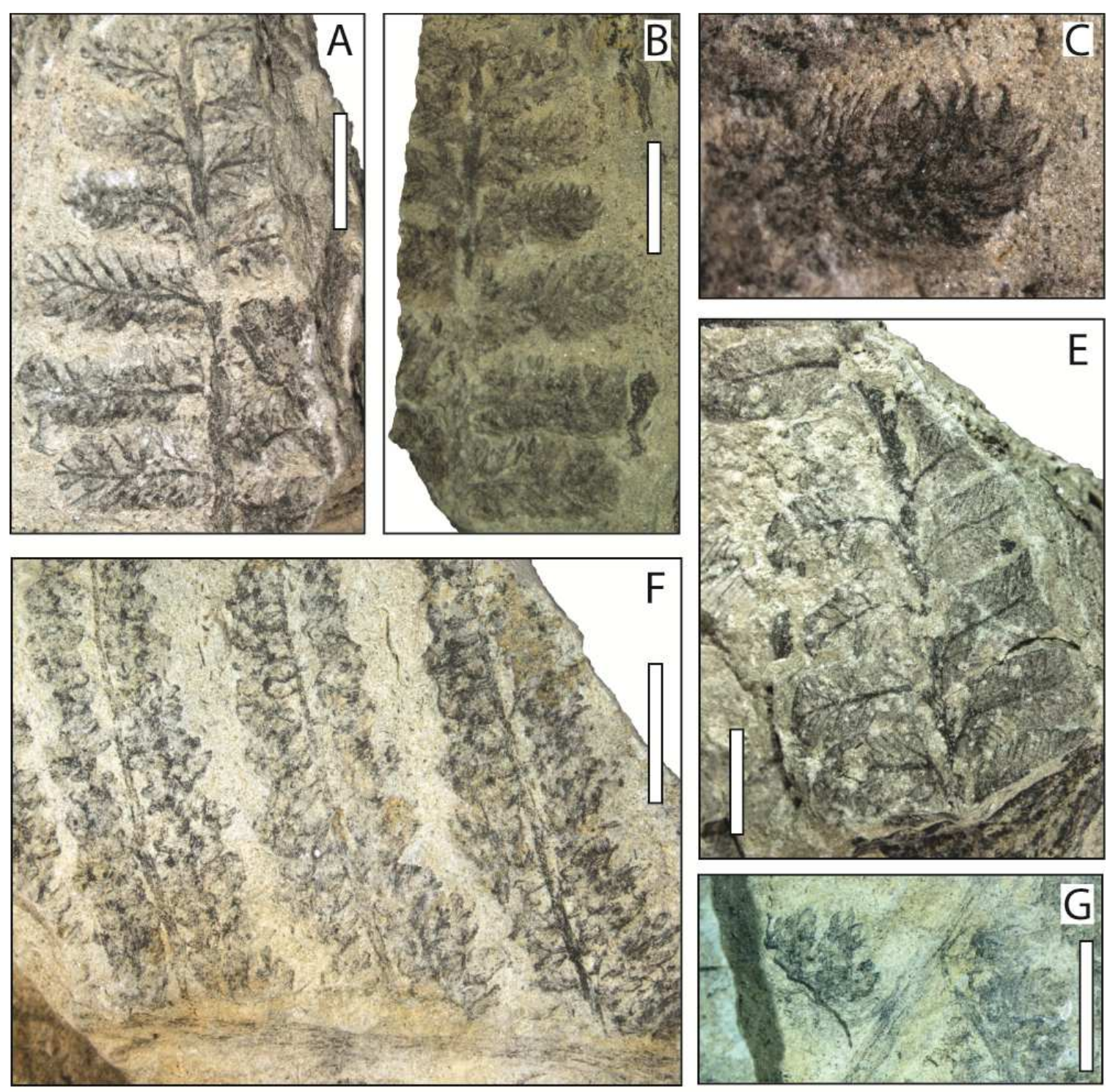
Lámina IV.2.6. Pteridospermas
A. Botrychiopsis plantiana. Ejemplar 13. Escala: $1 \mathrm{~cm}$
B. Botrychiopsis plantiana. Ejemplar 19. Escala: $1 \mathrm{~cm}$
C. Botrychiopsis plantiana. Ejemplar 21. Escala: $1 \mathrm{~cm}$
D. Botrychiopsis plantiana. Ejemplar 24. Escala: $1 \mathrm{~cm}$
E. Botrychiopsis plantiana. Ejemplar 36. Escala: $1 \mathrm{~cm}$
F. Botrychiopsis plantiana. Ejemplar 143. Escala: $1 \mathrm{~cm}$
G. Eusphenopteris sp. Ejemplar 630. Escala: $1 \mathrm{~cm}$
H. Eusphenopteris sp. Ejemplar 505. Se preservan los ráquises y la venación. Escala: $1 \mathrm{~cm}$
I. Eusphenopteris sp. Ejemplar 492. Raquis con dos pinnas, Escala: $1 \mathrm{~cm}$ 
Eliana Paula Coturel - Bioestratigrafía del Pérmico de la Sierra de los llanos...

\section{LÁMINA IV.2.6}
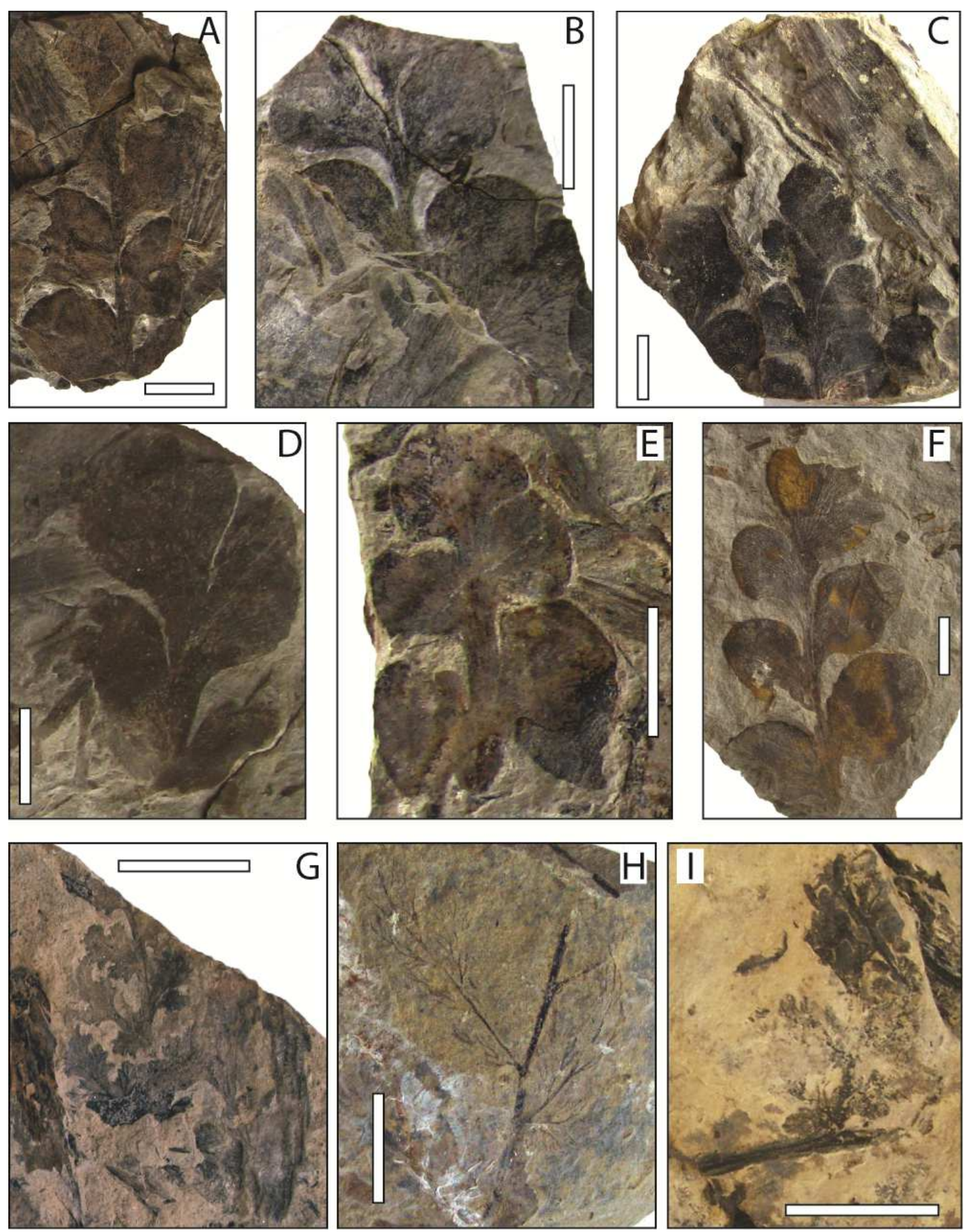
Eliana Paula Coturel - Bioestratigrafía del PÉrmico de la SierRa de los llanos...

Lámina IV.2.7. Glossopteridales I. Gangamopteris obovata
A. Ejemplar 131. Escala: $1 \mathrm{~cm}$
B. Ejemplar 279. Escala: $1 \mathrm{~cm}$
C. Ejemplar 314b. Escala: $1 \mathrm{~cm}$
D. Ejemplar 314a. Escala: $1 \mathrm{~cm}$
E. Ejemplar 141. Escala: $1 \mathrm{~cm}$
F. Ejemplar 332. Escala: $1 \mathrm{~cm}$
G. Ejemplar 454a. Escala: $1 \mathrm{~cm}$ 
Eliana Paula Coturel - Bioestratigrafía del Pérmico de la Sierra de los llanos...

\section{LÁMINA IV.2.7}
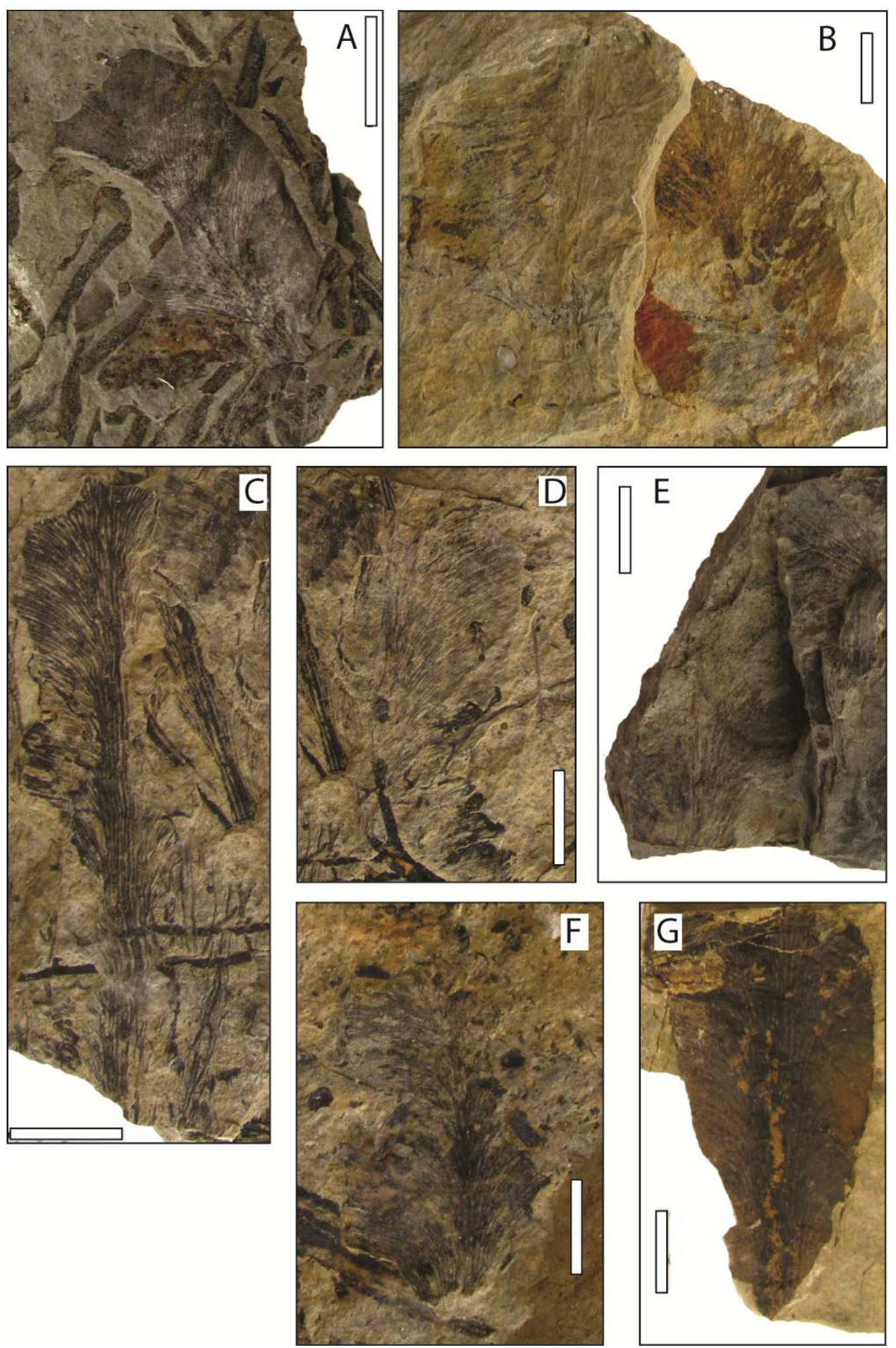

$\sim 100 \sim$ 
Eliana Paula Coturel - Bioestratigrafía del PÉrmico de la SierRa de los llanos...

Lámina IV.2.8. Glossopteridales II. Glossopteris occidentalis
A. Ejemplar 453. Escala: $1 \mathrm{~cm}$
B. Ejemplar 456. Escala: $1 \mathrm{~cm}$
C. Ejemplar 651. Escala: $1 \mathrm{~cm}$
D. Ejemplar 161. Escala: $1 \mathrm{~cm}$
E. Ejemplar 750. Escala: $1 \mathrm{~cm}$
F. Ejemplar 663. Escala: $1 \mathrm{~cm}$
G. Ejemplar 485. Escala: $1 \mathrm{~cm}$
H. Ejemplar 297. Escala: $1 \mathrm{~cm}$
I. Ejemplar 751. Escala: $1 \mathrm{~cm}$ 
Eliana Paula Coturel - Bioestratigrafía del Pérmico de la Sierra de los Llanos...

\section{LÁMINA IV.2.8}
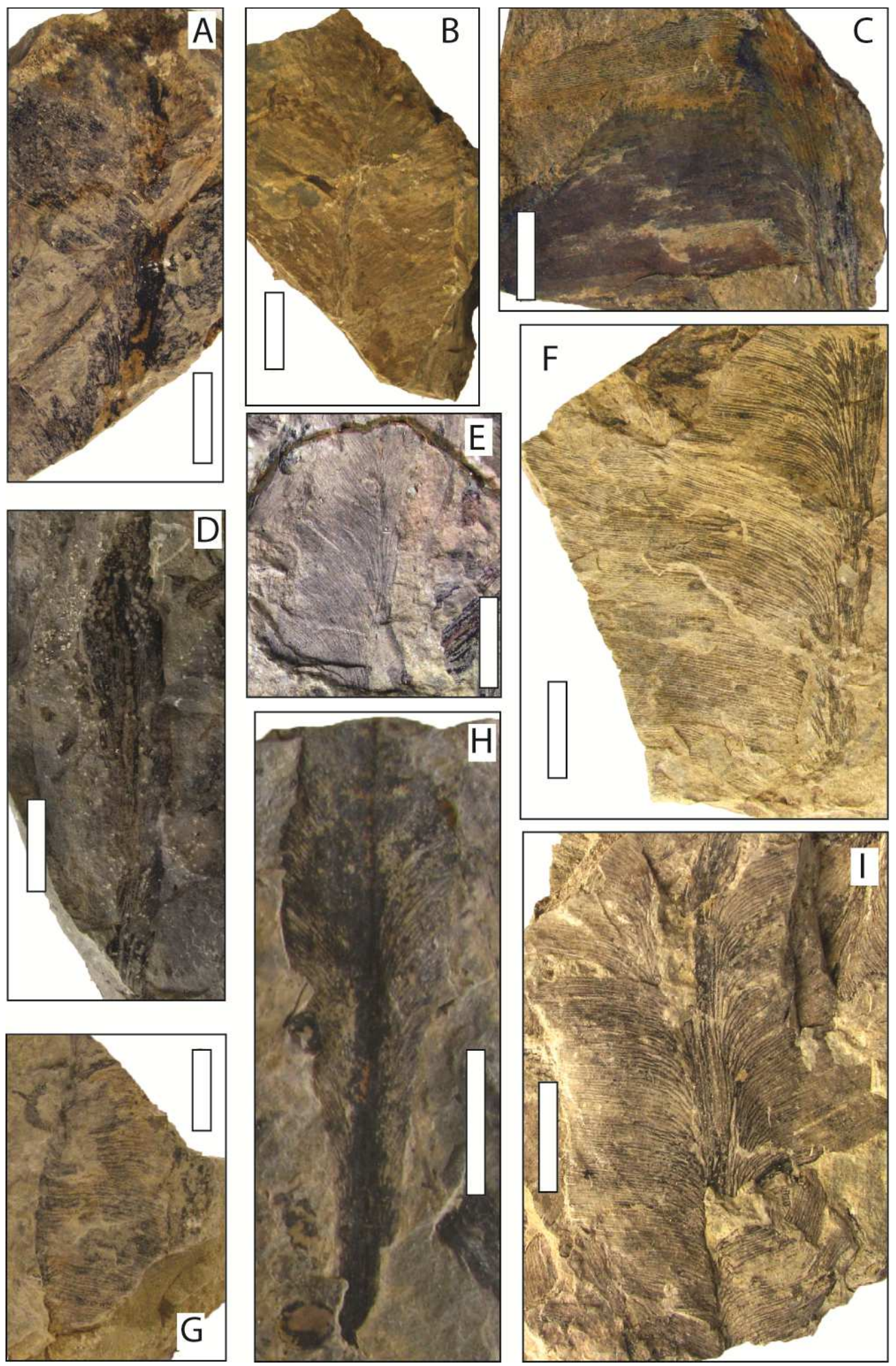

$\sim 102 \sim$ 
Eliana Paula Coturel - Bioestratigrafía del PÉrmico de la SierRa de los llanos...

Lámina IV.2.9. Glossopteridales III. Glossopteris wilsonii
A. Ejemplar 60. Escala: $1 \mathrm{~cm}$
B. Ejemplar 64. Escala: $1 \mathrm{~cm}$
C. Ejemplar 273. Escala: $1 \mathrm{~cm}$
D. Ejemplar 312. Escala: $1 \mathrm{~cm}$
E. Ejemplar 77. Escala: $1 \mathrm{~cm}$
F. Ejemplar 286. Escala: $1 \mathrm{~cm}$
G. Ejemplar 285. Escala: $1 \mathrm{~cm}$
H. Ejemplar 217. Escala: $1 \mathrm{~cm}$ 
Eliana Paula Coturel - Bioestratigrafía del Pérmico de la SierRa de los llanos...

\section{LÁMINA IV.2.9}
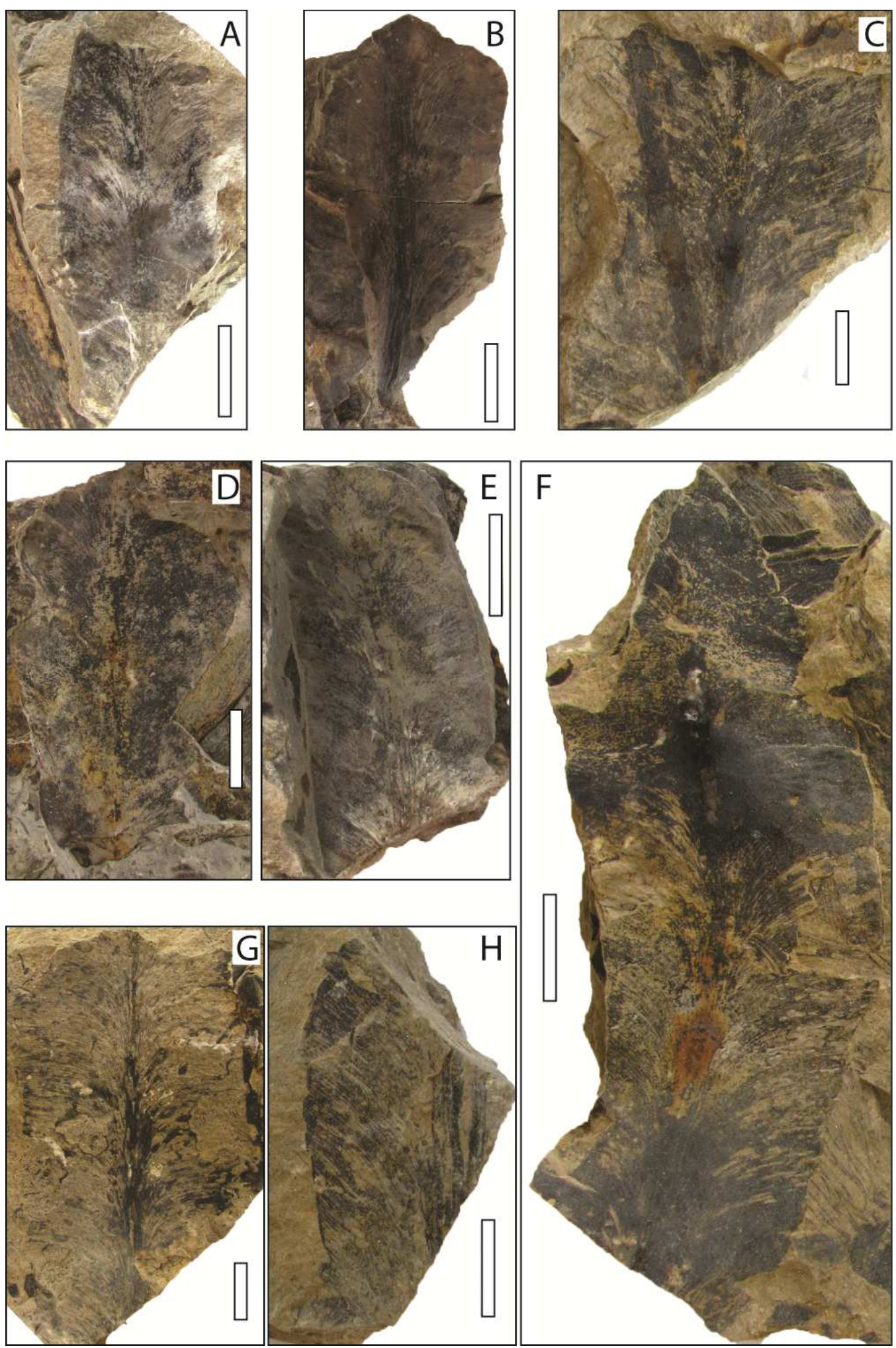

$\sim 104 \sim$ 
Lámina IV.2.10. Glossopteridales IV. Género Arberia
A. Arberia cf. minasica. Ejemplar 307. Escala $5 \mathrm{~mm}$.
B. Arberia cf. minasica. Ejemplar 304. Escala $5 \mathrm{~mm}$.
C. Arberia sp. Ejemplar 271. Escala $5 \mathrm{~mm}$.
D. Arberia sp. Ejemplar 500. Escala $5 \mathrm{~mm}$.
E. Arberia cf. minasica. Ejemplar 105. Escala $5 \mathrm{~mm}$.
F. Arberia cf. minasica. Ejemplar 334. Escala $5 \mathrm{~mm}$.
G. Arberia sp. Ejemplar 470. Escala $5 \mathrm{~mm}$.
H. Arberia cf. minasica. Ejemplar 692a. Escala $5 \mathrm{~mm}$.
I. Arberia cf. minasica. Ejemplar 692b. Contraimpronta de H. Escala 5 mm.
J. Arberia cf. minasica. Ejemplar 692b. Detalle de I.
K. Arberia sp. Ejemplar 268. Detalle del receptáculo que inserta en el pecíolo de Glossopteris y en su extreme sostiene una polisperma. Nótese la constricción del receptáculo. Escala $1 \mathrm{~cm}$.
L. Arberia cf. minasica. Ejemplar 566b. Escala $5 \mathrm{~mm}$.
M. Arberia cf. minasica. Ejemplar 566a. Escala $5 \mathrm{~mm}$. 
Eliana Paula Coturel - Bioestratigrafía del Pérmico de la Sierra de los llanos...

\section{LÁMINA IV.2.10}
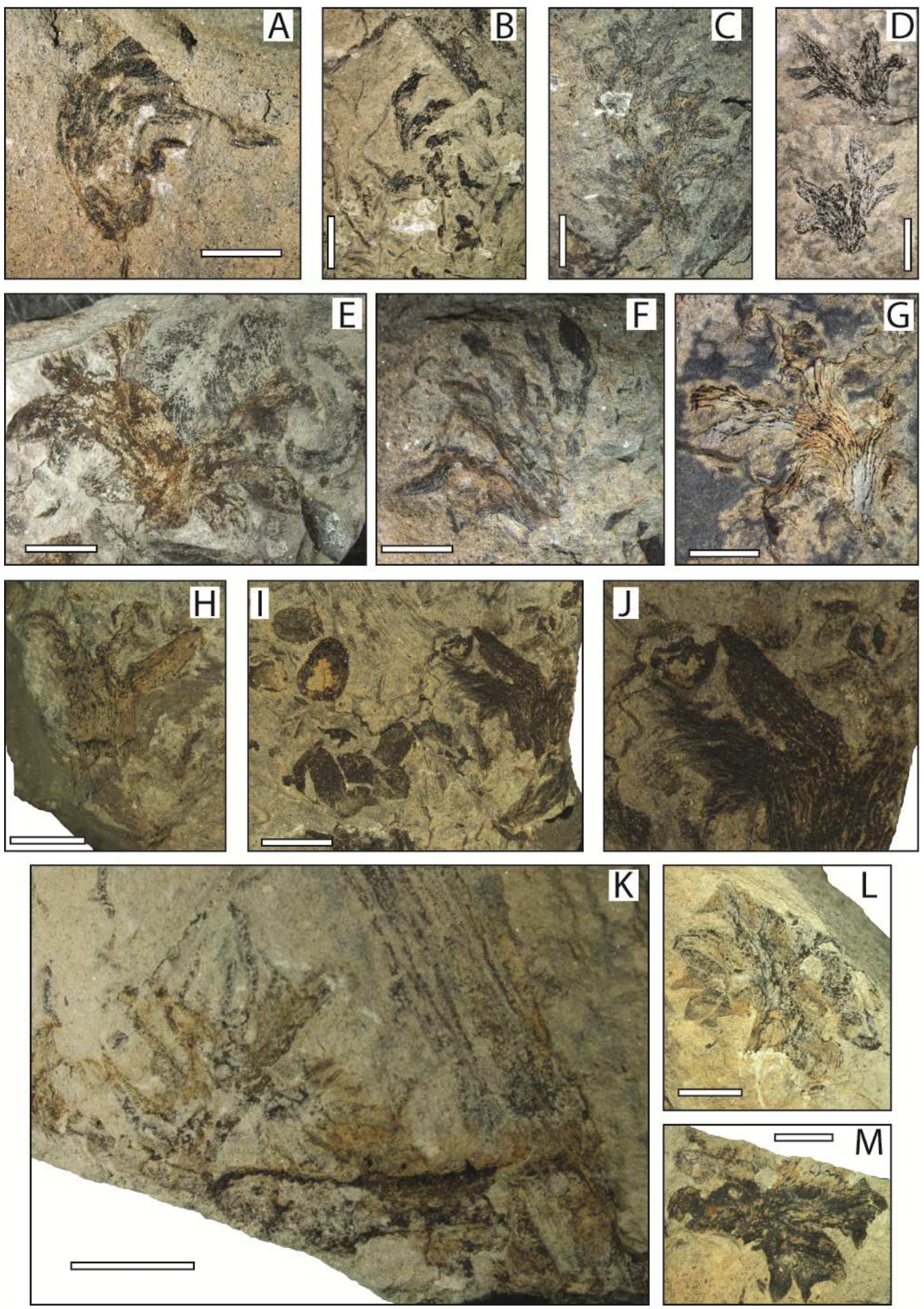
Eliana Paula Coturel - Bioestratigrafía del Pérmico de la Sierra de los llanos...

Lámina IV.2.11. Cordaites hislopi.
A. Ejemplar 61. Escala $1 \mathrm{~cm}$.
B. Ejemplar 96. Escala $1 \mathrm{~cm}$.
C. Ejemplar 100. Escala $1 \mathrm{~cm}$.
D. Ejemplar 468. Detalle venación y estrías entre venas. Escala $5 \mathrm{~mm}$.
E. Ejemplar 335. Escala $5 \mathrm{~mm}$. 
Eliana Paula Coturel - Bioestratigrafía del Pérmico de la Sierra de los llanos...

\section{LÁMINA IV.2.11}
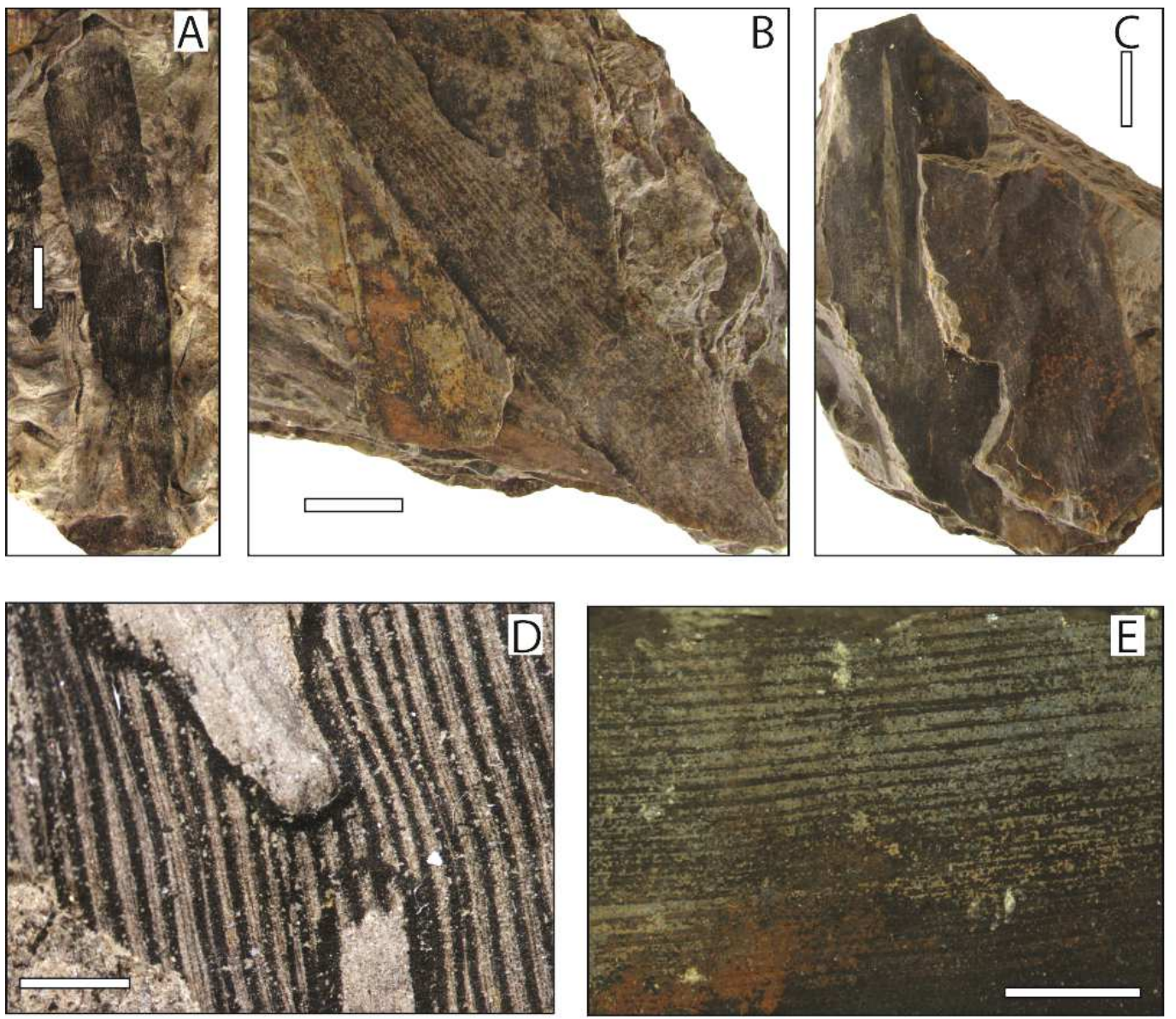
Eliana Paula Coturel - Bioestratigrafía del PÉrmico de la SierRa de los llanos...

Lámina IV.2.12. Ferugliocladus riojanum.
A. Ejemplar 529. Escala $1 \mathrm{~cm}$.
B. Ejemplar 522. Escala $1 \mathrm{~cm}$.
C. Ejemplar 445. Escala $5 \mathrm{~mm}$.
D. Ejemplar 527 . Escala $1 \mathrm{~cm}$.
E. Ejemplar 449. Escala $5 \mathrm{~mm}$.
F. Ejemplar 447. Escala $5 \mathrm{~mm}$.
G. Ejemplar 534. Escala $1 \mathrm{~cm}$.
H. Ejemplar 598. Escala $1 \mathrm{~cm}$. 
Eliana Paula Coturel - Bioestratigrafía del Pérmico de la SierRa de los llanos...

\section{LÁMINA IV.2.12}
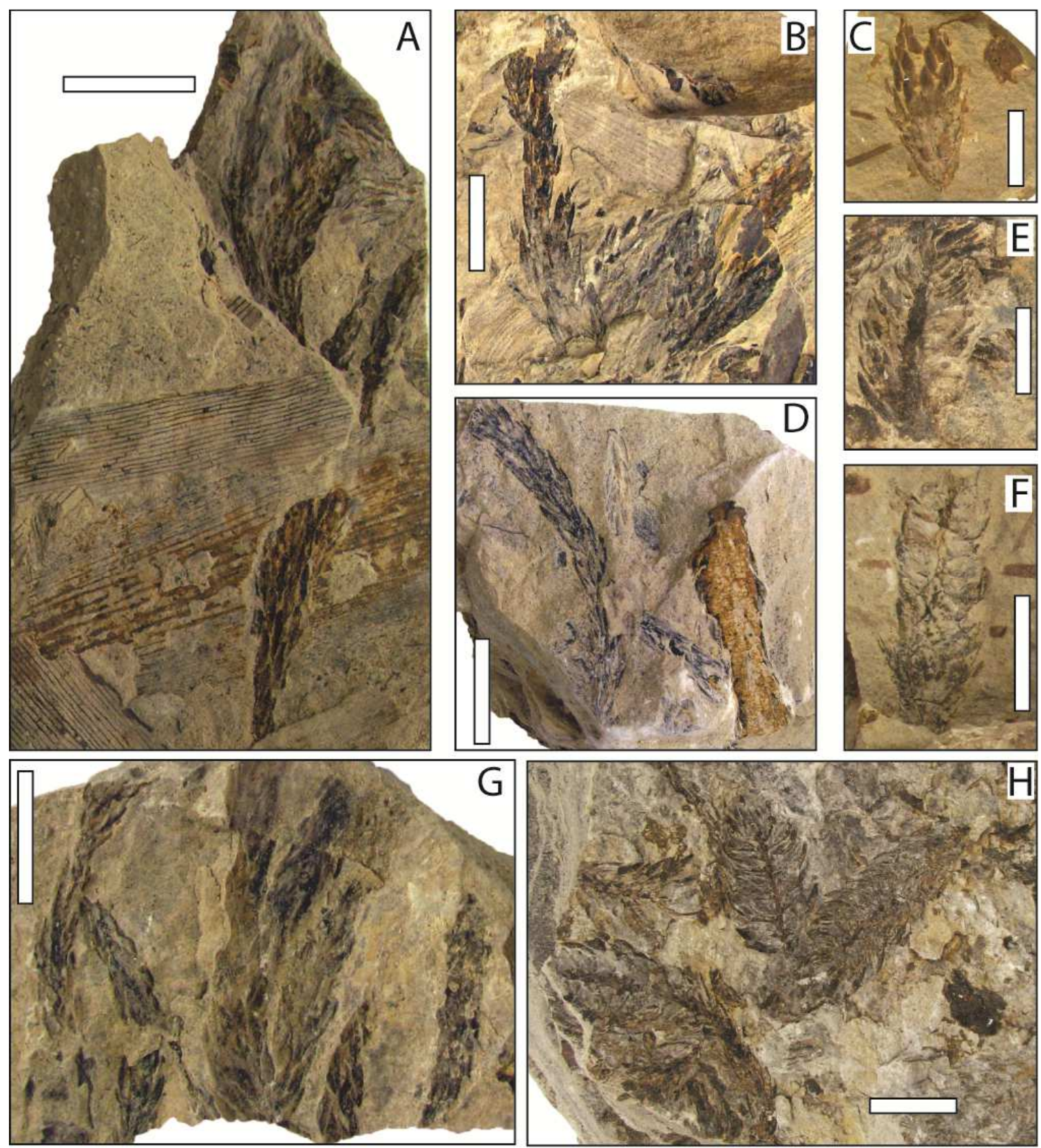
Eliana Paula Coturel - Bioestratigrafía del PÉrmico de la SierRa de los llanos...

Lámina IV.2.13. Genoites nov. sp.
A. Ejemplar 802a. Escala $1 \mathrm{~cm}$.
B. Detalle de Ejemplar 802a.
C. Detalle de Ejemplar 802a.
D. Ejemplar 813. Escala $1 \mathrm{~cm}$.
E. Ejemplar 801. Escala $1 \mathrm{~cm}$.
F. Ejemplar 804. Escala $1 \mathrm{~cm}$. 
Eliana Paula Coturel - Bioestratigrafía del Pérmico de la Sierra de los llanos...

\section{LÁMINA IV.2.13}
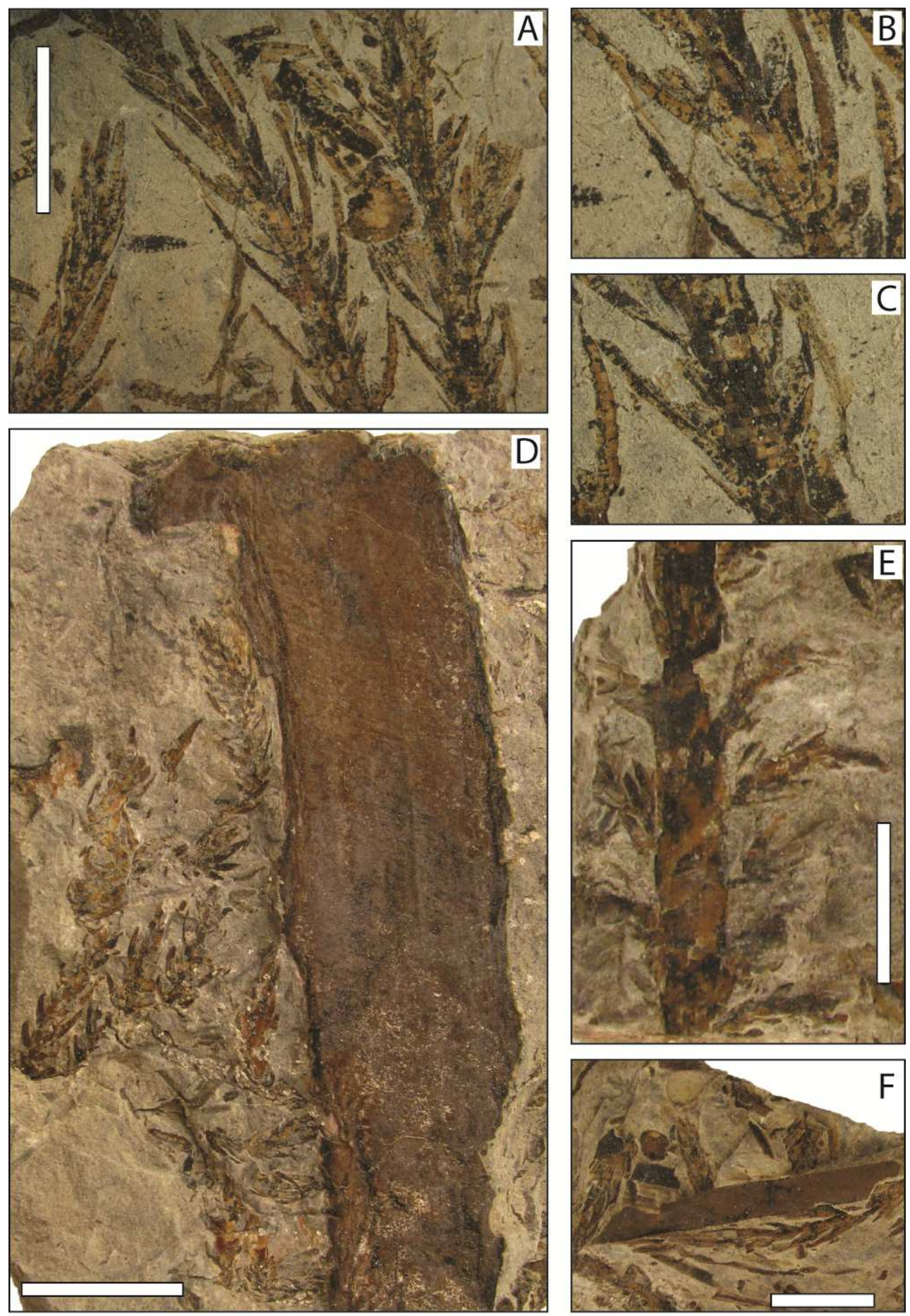
Lámina IV.2.14. Semillas dispersas
A. Ejemplar 521. Escala $1 \mathrm{~cm}$.
B. Ejemplar 213. Escala $5 \mathrm{~mm}$.
C. Ejemplar 577. Escala $1 \mathrm{~cm}$.
D. Ejemplar 214. Escala $5 \mathrm{~mm}$.
E. Ejemplar 215. Escala $5 \mathrm{~mm}$.
F. Ejemplar 573. Escala $1 \mathrm{~cm}$.
G. Ejemplar 519. Escala $5 \mathrm{~mm}$.
H. Ejemplar 587. Escala $5 \mathrm{~mm}$.
I. Ejemplar 715. Escala $5 \mathrm{~mm}$. 
Eliana Paula Coturel - Bioestratigrafía del Pérmico de la SierRa de los Llanos...

\section{LÁMINA IV.2.14}
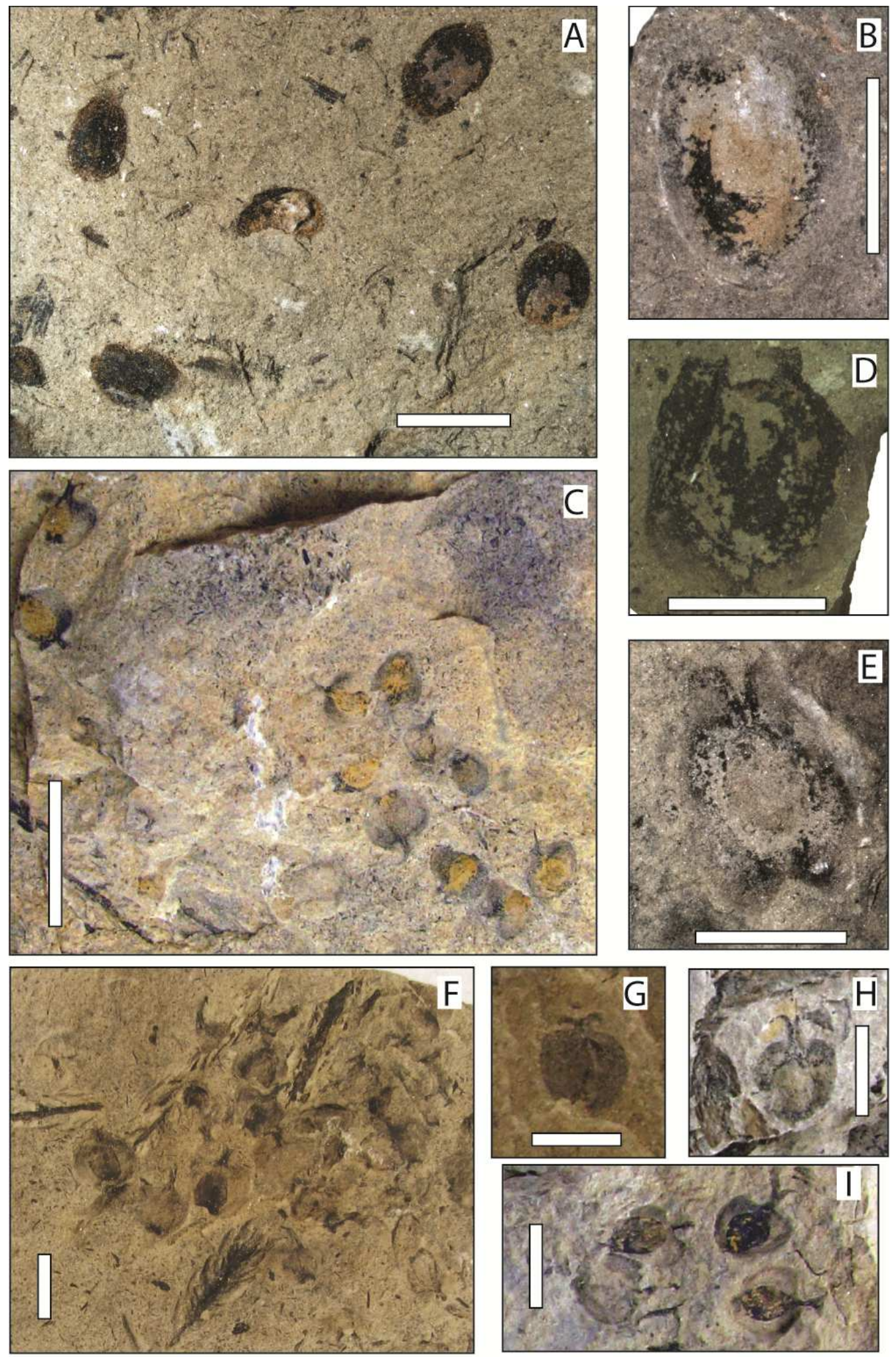

$\sim 114 \sim$ 


\section{IV.3 Análisis morfográfico de Glossopteris}

Cuando se desea explicar qué es un morfogénero, el ejemplo superador es el género Glossopteris. Descripto por primera vez dos siglos atrás, posee más de 100 especies, las cuales se diferencian por su venación (características de la vena media y las venas secundarias), su forma, tamaño y caracteres cuticulares. Esta cantidad de especies de hojas no acompaña la diversidad reproductiva del Orden Glossopteridales, que es la que nos revela la diversidad biológica dentro de un grupo.

Existen dos criterios para llevar a cabo la sistemática a nivel específico: separación en muchas especies, o reducción del número de taxones. En general, desde Maheshwari (1965) hasta Singh (2000) se ha puntualizado que el problema en la clasificación de las especies de Glossopteris se sustenta en la completa falta de criterios aceptados y seguidos por todos los autores para esto. Aún reconociendo esto, se siguieron creando especies.

Varias veces se ensayaron estudios de la diversidad del Género Glossopteris (KovacsEndrödy, 1976; Singh, 2000). En general, se señalan y analizan los caracteres morfográficos que son importantes para la circunscripción específica. Singh (2000) además los compara con su desarrollo en hojas actuales. Así, se puede recopilar este listado de caracteres:

- Forma (linear, linear-lanceolada, lanceolada, lanceolada-espatulada, espatulada, oblonga, obovada, cordada, obcordada), este carácter varía de forma intraespecífica en la actualidad, por lo tanto se lo señala como carácter secundario;

- Margen, que salvo en una especie es siempre contínuo;

- Ápice (agudo, acuminado, obtuso, retuso o emarginado), se lo señala como de poca importancia salvo cuando hay amplias diferencias entre los taxones.

- Base (sésil o peciolada), se señala que este carácter, aunque invariable de manera intraespecífica, es importante cuando se lo toma en conjunto con otros caracteres; 
- Naturaleza de la vena media,

- Patrón de venación, que incluye ángulo de origen, curso de las venas, densidad, anastomosis, frecuencia de las dicotomías y forma de las mallas.

El acuerdo general es que el patrón de venación es la característica más importante a la hora de clasificar. Éste está compuesto por tres elementos: el recorrido de la vena secundaria desde que surge de la vena media hasta que llega al margen, la densidad de venas secundarias, y las uniones entre las venas, que nos dan el patrón anastomosado que caracteriza a la hoja.

- Recorrido de la vena secundaria: se lo describe puntualizando en forma numérica los ángulos de salida desde la vena media y llegada al margen, en rangos bastante amplios (ej: $50-70^{\circ}$ ), el arqueamiento de la vena se describe en forma verbal, refiriéndose a la zona de mayor arqueamiento y cómo es el transcurso a posteriori de éste.

- Densidad: se prioriza la densidad en el sector medio de la hoja, y en las zonas media y distal respecto de la vena media.

- Anastomosis: se describe a través de la forma y densidad de las aréolas, en algunos casos se indica cuales son los tipos de anastomosis. Se puntualiza la zona donde ocurren dicotomías.

En este capítulo se intentará analizar el patrón de venación de las hojas de Glossopteris mediante un análisis de agrupación (“cluster analysis”). Este tipo de análisis son frecuentes para comparar poblaciones (Lanteri y Cigliano, 2006 y bibliografía allí referida), se aplican para encontrar grupos jerárquicos en sets de datos multivariados, y no tienen valor filogenético (no son análisis cladísticos, a pesar de presentar sus resultados en dendrogramas).

\section{Materiales y Métodos}

Se utilizó como set de datos el libro "Revision of the Indian species of Glossopteris" (Chandra y Surange, 1979), dado que cuenta con un amplio stock de dibujos a cámara clara de 
hojas de Glossopteris, y datos de forma, dimensiones, y localización geográfica y estratigráfica de las especies.

Para la obtención de datos (conteos) se utilizó el programa Adobe Photoshop CS3. Los datos secundarios se obtuvieron mediante el programa Excel de Microsoft Office. El análisis de agrupamiento se realizó con el programa PAST. Las comparaciones se realizaron con el programa Mesquite.

\section{Estandarización.}

Para realizar la comparación, se realizó primero una estandarización de las hojas. De este modo, se buscó descartar a priori el factor de tamaño y aquellos dependientes de él. La estandarización se realizó en un eje de coordenadas $(\mathrm{x}, \mathrm{y})(-1,+1)$, colocando la vena media sobre $(-1,0)$ y el margen de la lámina en $(1,0)$, procurando que una vena pase por el centro de coordenadas $(0,0)$. Así, se fue aumentando o disminuyendo el tamaño de una hemilámina, respetando las proporciones originales. Los distintos caracteres a estudiar se obtuvieron a partir de la hoja estandarizada.

Observándose que en las descripciones de las especies y ejemplares se hace referencia a la posición respecto de la vena media/margen, se delimitaron tres zonas, en sentido horizontal:

- Medial, $-1>x>-0,4$;

- Central, $-0,4>x>0,4$;

- Marginal, $0,4>\mathrm{x}>1$;

Algunos caracteres cuantitativos (densidad) dependen del dibujo completo a cámara clara de la hoja. Arbitrariamente, se multiplicó la hoja ya estandarizada y se rellenaron los espacios faltantes. Para optimizar el estudio, debería en un futuro realizarse el dibujo a cámara clara de la hoja completa (o estandarizarse directamente una fotografía). En el análisis, se realizó

- Vena secundaria. Para tomar este carácter, se dibujó el trazado de la vena en otra capa (Figura IV.3.a). Sobre la grilla, se obtuvieron los datos de coordenadas del trazo de la 
vena. Éstos fueron tratados en el programa Excel, donde se reprodujo la forma de la vena secundaria. A partir de la gráfica, se obtuvo una función que describe la curva de la vena: una función polinómica de grado 4 , con una incógnita $(\mathrm{x})$ y raíz en $(0,0)$.

Densidad de la venación. Los datos de densidad se tomaron considerando las venas que cruzan los ejes $\mathrm{y}$ en $\mathrm{x}=-0,4 ; 0$ y 0,4 .

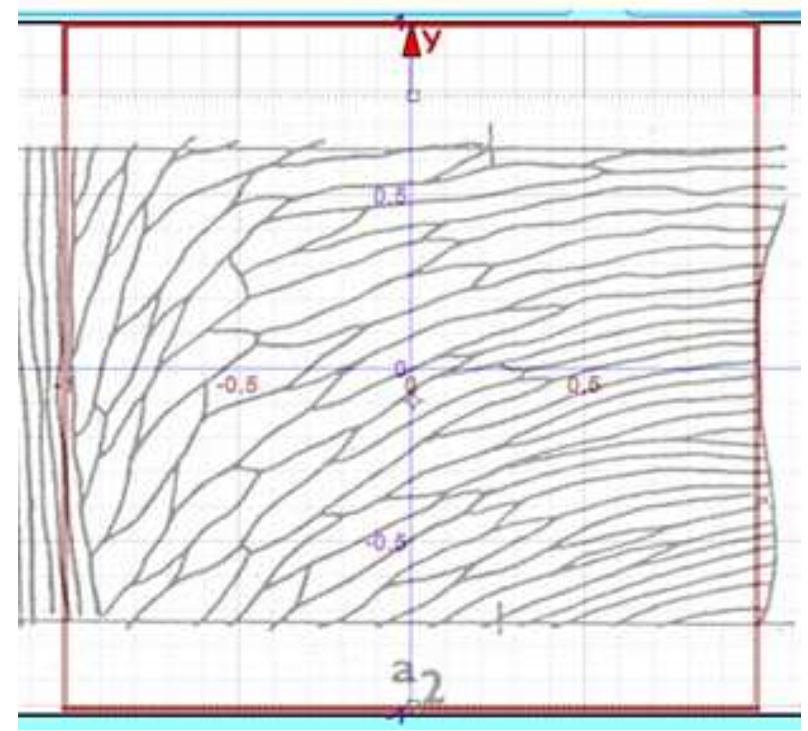

Figura IV.3.a. La hoja de Glossopteris en el eje de coordenadas. tipos de anastomosis en las hojas de Glossopteridales: tipo (oblicuas), tipo $\mathrm{T}$ (transversas) y tipo X (cruciadas). Se cuantificaron por tipo en cada zona. También se consideraron las dicotomías $(\mathrm{Y})$.

\section{Método:}

1) Se definieron como OTUs las imágenes en cámara clara presentes en el libro de Chandra y Surange (1979). La denominación de cada OTU proviene de la unión entre el número de lámina y la letra que caracteriza al dibujo.

2) Estandarización de la hoja. Se tomó el dibujo a cámara clara de la hoja, y se amplió/redujo para que encaje en el eje de coordenadas. Para esto, es esencial que se mantenga la proporción entre alto y ancho.

3) Datos que se tomaron de las hojas:

a. Venación secundaria: coordenadas $(x, y)$ de una vena que cruza el eje de coordenadas en $(0,0)$. 
b. Densidad: se computó la cantidad de venas que atravesaban el eje vertical en $\mathrm{x}=-0,4 ; 0 ; 0,4$.

c. Anastomosis: se computó cada tipo de anastomosis por zona (medial, central, marginal). En Excel, se calcularon las anastomosis totales y porcentaje por zona.

4) En Excel: Construcción de una tabla de datos $x, y$. Obtención de gráfico de dispersión entre esos datos. Se solicita la presentación de una Línea de Tendencia, que indique la fórmula y su $\mathrm{R}^{2}$ en el gráfico. La línea de tendencia solicitada es la Polinómica de Grado 4, salvo casos donde la simplicidad de la línea permite utilizar una de menor grado.

5) La fórmula general de la ecuación es: $a x^{4}+b x^{3}+c x^{2}+d x+e$, se separaron los coeficientes a, b, c, d y e, y se realizó la matriz de datos por carácter. Luego, en columnas adyacentes, se calcularon usando estos coeficientes los valores de $\mathrm{y}$ para $\mathrm{x}=$ $-1 ;-0,8 ;-0,6 ;-0,4 ;-0,2 ; 0 ; 0,2 ; 0,4 ; 0,6 ; 0,8 ; 1$. De este modo, para venas que en el eje estandarizado no alcanzaban el margen y/o la vena media por su forma general y decurrencia, se pudo obtener ese dato.

6) Se copiaron y pegaron estos datos en el programa PAST. Para la obtención de matrices se utilizó el algoritmo UPGMA (los grupos se unen de acuerdo a la distancia media entre todos los miembros de los dos grupos). Los índices de distancia debían ser aptos para caracteres numéricos continuos, se utilizaron:

a. Índice de distancia Euclideana (entre hileras)

b. Índice de Manhattan

c. Índice de Correlación (de las variables a lo largo de las hileras)

7) Se compararon los grupos obtenidos con cada índice, buscándose coincidencias.

8) Los grupos se describieron usando: las fórmulas de las venas secundarias, la densidad y los porcentajes de anastomosis. 
Eliana Paula Coturel - Bioestratigrafía del Pérmico de la Sierra de los llanos...

\section{Resultados}

La matriz básica de datos se adjunta en el Anexo al final de este trabajo. Presenta 277 OTU's y 11 caracteres. A partir de ella se obtuvieron tres dendrogramas, uno por cada algoritmo utilizado.

\begin{tabular}{|l|l|l|}
\hline Algoritmo & Coeficiente de ajuste & Grupos reconocidos \\
\hline Correlación (similitud) & 0,9333 & $10(+6$ subgrupos $)$ \\
\hline Manhattan (distancia) & 0,9225 & $12(+9$ subgrupos $)$ \\
\hline Distancia Euclidiana & 0,9516 & $11(+14$ subgrupos $)$ \\
\hline
\end{tabular}

Los tres árboles presentan varios grupos de no más de diez OTU’s cada uno, con similitud entre 0,2 y 0,8 o distancia entre 1,8 y 0,3, y luego un gran cúmulo de OTU's agrupados dentro del máximo grado de similitud/menor grado de distancia, cuyas relaciones jerárquicas son más evidentes en los árboles generados por coeficientes de distancia (Manhattan, Euclidiana).

A continuación se presentan los grupos reconocidos y sus relaciones según cada coeficiente, y las OTU's que los componen.

\begin{tabular}{|l|l|}
\hline COEFICIENTE DE CORRELACIÓN & \\
\hline G1(G2(G3(G4(G5(G6(G7(((G8a, G8b), G8c), G10), (G9a, G9b), G9c) $))))))$ \\
\hline Grupos & OTU's \\
\hline Grupo 1 & $52 \mathrm{E}, 33 \mathrm{~b}, 53 \mathrm{H}$ \\
\hline Grupo 2 & $48 \mathrm{~K}, 16 \mathrm{c} 2,3 \mathrm{a} 2,46 \mathrm{R}, 9 \mathrm{~b}$ \\
\hline Grupo 4 & $49 \mathrm{~K}$ \\
\hline Grupo 5 & $33 \mathrm{~d} 1,35 \mathrm{~b}, 37 \mathrm{e} 2,8 \mathrm{a} 1,48 \mathrm{~B}, 10 \mathrm{~d} 2,30 \mathrm{e}, 9 \mathrm{c} 1$, \\
\hline Grupo 6 & $45 \mathrm{~L}, 33 \mathrm{c} 2$ \\
\hline
\end{tabular}


Eliana Paula Coturel - Bioestratigrafía del Pérmico de la Sierra de los llanos...

\begin{tabular}{|c|c|c|}
\hline & & $54 \mathrm{~L}, 25 \mathrm{e}, 32 \mathrm{e} 2$ \\
\hline \multicolumn{2}{|l|}{ Grupo 7} & $49 \mathrm{C}$ \\
\hline \multirow[t]{3}{*}{ Grupo 8} & Subgrupo 8a & $\begin{array}{l}\text { 16d3, 18c, 53F, 28c, 44I, 54E, 31g, 41d2, } \\
\text { 19a1, 24i, 4a3, 3d, 8e, 44M, 46N, 9a1, 26a, } \\
\text { 54M, 19b2, 26b, 2a2, 49R, 10b, 49P, 54C, } \\
\text { 1b1, 45D, 31e, 1d, 26k2, 11b, 28g, 48H, } \\
\text { 25k, 31a, 31d1, 32b, 48G, 16d2, 22g, 18d, } \\
\text { 54I, 14c2, 44H, 19a2, 46V, 48J, 44L, 47C, } \\
\text { 46A, 10a, 26h, 48A, 3a1, 21b, 30a1, 11a2, } \\
\text { 53K, 5d, 13c, 20f1, 45H, 42d2, 46H, 45B, } \\
\text { 47K, 27h, 29f2, 42b, 47A, 44F, 48M, 47L, } \\
29 \mathrm{e}, 47 \mathrm{M}, 48 \mathrm{~N}, 54 \mathrm{D}, 4 \mathrm{a} 2,7 \mathrm{~d}, 23 \mathrm{c}, 29 \mathrm{~g} 2 \\
\text { 50N, 50A, 45F, 50C, 54N, 43d, 3b2, 50E, } \\
\text { 12h, 30a2, 24d, 18a, 47O, 34d, 50M, } \\
\text { 50I19e1, 52A, 52D, 23h, 50B, 48L, 31d, } \\
\text { 31f, 54Q, 10c, 37f, 53E, 20b2, 48I, 2012, } \\
\text { 36a2, 51G, 4b3, 37a, 40b, 44D, 46L }\end{array}$ \\
\hline & Subgrupo 8b & $\begin{array}{l}\text { 6a, 53D, 46I, 48F, 32c, 30d, 51D, 21c2, } \\
\text { 22a2, 27i, 36b1, 36b2, 41c, 50J, 51F }\end{array}$ \\
\hline & Subgrupo 8c & $\begin{array}{l}\text { 5b, 7a2, 53J, 44B, 6e, 45G, 53B, 48C, 49F, } \\
\text { 52B, 12f2, 42c, 46C, 50F, 54G, 12a2, 44A, } \\
\text { 47J, 29a2, 30c, 49D }\end{array}$ \\
\hline Grupo 9 & Subgrupo 9a & $\begin{array}{l}\text { 19c, 31h, 34a, 46B, 29c, 50D, 49E, 33a, 51J, } \\
\text { 49M, 1a2, 6f, 11c, 41a2, 21a2, 1c, 50H, } \\
\text { 32e1, 14b2, 45C, 6b, 24i, 54O, 53I, 54H, } \\
\text { 48E, 44J, 46W, 5a, 13g, 44E, 11d, 44G, } \\
\text { 42b2, 45J, 50Q, 25b, 35c, 45M, 53C, 27g, } \\
\text { 51B, 47D, 53A, }\end{array}$ \\
\hline
\end{tabular}


Eliana Paula Coturel - Bioestratigrafía del PÉrmico de la SierRa de los llanos...

\begin{tabular}{|c|c|c|}
\hline & Subgrupo 9b & $\begin{array}{l}\text { 5c, 7b, 44C, 9a2, 22b, 45E, 54P, 52H, 54J, } \\
\text { 26k1, 49N, 52G, 34b2, 16b, 8b2, 27a1, 28e, } \\
\text { 42b1, 46D, 51I, 49B, }\end{array}$ \\
\hline & Subgrupo 9c & $8 \mathrm{a} 2,45 \mathrm{I}, 23 \mathrm{~g}, 45 \mathrm{~N}, 46 \mathrm{U}$ \\
\hline Grupo 10 & & $\begin{array}{l}\text { 17a, 37e1, 17b, 18b2, 15a, 54A, 3b1, 45A, } \\
49 \mathrm{I}, 51 \mathrm{H}, 52 \mathrm{~F}, 36 \mathrm{c}, 54 \mathrm{~K}, 15 \mathrm{~b}, 51 \mathrm{~A}, 26 \mathrm{~d} \\
34 \mathrm{c}, 48 \mathrm{D}\end{array}$ \\
\hline
\end{tabular}

\begin{tabular}{|c|c|c|}
\hline \multicolumn{3}{|c|}{$\begin{array}{l}\text { Coeficiente de Distancia de Manhat } \\
(\mathrm{G} 1(\mathrm{G} 2(\mathrm{G} 9(\mathrm{G} 3(\mathrm{G} 10(\mathrm{G} 11(((\mathrm{G} 5 \mathrm{a}, \\
(\mathrm{G} 12 \mathrm{~d}(\mathrm{G} 12 \mathrm{c}(\mathrm{G} 12 \mathrm{a}, \mathrm{G} 12 \mathrm{~b}))))))))))))))\end{array}$} \\
\hline \multicolumn{2}{|c|}{ Grupos } & OTU's \\
\hline \multicolumn{2}{|l|}{ Grupo 1} & $9 \mathrm{~b}$ \\
\hline \multicolumn{2}{|l|}{ Grupo 2} & $29 \mathrm{c}, 46 \mathrm{D}, 30 \mathrm{e}$ \\
\hline \multicolumn{2}{|l|}{ Grupo 3} & 13b2, 30b2, 32f, 3a2, 46R, 16c2, \\
\hline \multicolumn{2}{|l|}{ Grupo 4} & $\begin{array}{l}\text { 12a2, 29a2, 54G, 50K, 50J, 24a2, 25e, 28d, } \\
47 \mathrm{~B}, 17 \mathrm{a}, 3 \mathrm{~b} 1,47 \mathrm{O}\end{array}$ \\
\hline \multirow[t]{2}{*}{ Grupo 5} & Subgrupo 5a & $\begin{array}{l}\text { 18c, 44I, 8e, 29g2, 45F, 4a3, 26h, 46V, 29e, } \\
\text { 47M, 2a2, 46W, 5a, 8a2, 9a2, 45E, 11c, } \\
\text { 21a2, 14b2, 50H, 54O, 23g, 45N }\end{array}$ \\
\hline & Subgrupo $5 b$ & $1 \mathrm{a} 2,26 \mathrm{a}, 31 \mathrm{~h}, 25 \mathrm{k}, 46 \mathrm{I}, 46 \mathrm{~L}, 48 \mathrm{~N}, 54 \mathrm{Q}$ \\
\hline \multicolumn{2}{|l|}{ Grupo 6} & $33 \mathrm{c} 2$ \\
\hline \multicolumn{2}{|l|}{ Grupo 7} & $\begin{array}{l}\text { 20i2, 34d, 42d2, 36a2, 40b, 41c, 30d, 51D, } \\
42 \mathrm{~b} 2,34 \mathrm{a}, 52 \mathrm{D}, 36 \mathrm{c}, 51 \mathrm{H}, 51 \mathrm{G}, 37 \mathrm{f}, 52 \mathrm{~A}, \\
\text { 51F, 37e1, 52F, 54A, 27g, 34b2, 50D, 52H, } \\
\text { 36b1, 51J, 52G, 51I, 34b1, 51A, 35b, 37e2, } \\
\text { 40a, 51E, 27a1, 53A, 35c, 47D, 33a, 49M, }\end{array}$ \\
\hline
\end{tabular}


Eliana Paula Coturel - Bioestratigrafía del Pérmico de la Sierra de los llanos...

\begin{tabular}{|c|c|c|}
\hline & & $53 \mathrm{C}, 42 \mathrm{~b} 1,49 \mathrm{~N}, 33 \mathrm{~b}, 53 \mathrm{H}, 49 \mathrm{~K}, 33 \mathrm{~d} 1,52 \mathrm{E}$ \\
\hline \multicolumn{2}{|l|}{ Grupo 8} & $\begin{array}{l}\text { 18a, 6e, 44B, 4b3, 48I, 37a, 7d, 54M, 24i, } \\
41 \mathrm{~d} 2,50 \mathrm{~A}, 18 \mathrm{~d}, 19 \mathrm{a} 2,48 \mathrm{G}, 6 \mathrm{a}, 47 \mathrm{~A}, 16 \mathrm{~d} 2, \\
\text { 47L, 43d, 50E, 53E, 19e1, 11a2, 53K, 20f1, } \\
\text { 45H, 3a1, 47K, 10a, 54D, 23c, 54I, 50F, } \\
\text { 44D, 20b2, 21b, 30a1, 27h, 52B, 45G, 48C, } \\
\text { 48A, 53B, 47G, 49D, 6f, 51B, 41a2, 48H, } \\
\text { 54E, 49P, 6c2, 12h, 31a, 30a2, 21c2, 15b, } \\
48 \mathrm{D}, 49 \mathrm{E}, 32 \mathrm{e} 2,54 \mathrm{~K}\end{array}$ \\
\hline \multicolumn{2}{|l|}{ Grupo 9} & $\begin{array}{l}26 \mathrm{~d}, 7 \mathrm{~b}, 54 \mathrm{P}, 16 \mathrm{~b}, 44 \mathrm{~J}, 46 \mathrm{~B}, 22 \mathrm{~b}, 44 \mathrm{C}, 54 \mathrm{~J}, \\
49 \mathrm{~B}, 25 \mathrm{~b}, 50 \mathrm{Q}\end{array}$ \\
\hline \multicolumn{2}{|l|}{ Grupo 10} & $8 \mathrm{a} 1,9 \mathrm{c} 1,45 \mathrm{~L}, 28 \mathrm{e}, 26 \mathrm{k} 1$ \\
\hline \multicolumn{2}{|l|}{ Grupo 11} & $48 \mathrm{~K}$ \\
\hline \multirow[t]{7}{*}{ Grupo 12} & Subgrupo $12 \mathrm{a}$ & $\begin{array}{l}19 \mathrm{c}, 19 \mathrm{~b} 2,54 \mathrm{C}, 10 \mathrm{~b}, 46 \mathrm{~N}, 24 \mathrm{j}, 5 \mathrm{~d}, 13 \mathrm{c}, \\
12 \mathrm{f} 2,44 \mathrm{~L}, 46 \mathrm{~A}, 7 \mathrm{a} 2,42 \mathrm{c}, 31 \mathrm{~d}, 50 \mathrm{~B}, 45 \mathrm{~B} \\
31 \mathrm{f}, 50 \mathrm{M}, 24 \mathrm{~d}, 36 \mathrm{~b} 2,49 \mathrm{~F}\end{array}$ \\
\hline & Subgrupo $12 \mathrm{~b}$ & $\begin{array}{l}16 \mathrm{~d} 3,50 \mathrm{C}, 13 \mathrm{~g}, 45 \mathrm{~J}, 45 \mathrm{D}, 19 \mathrm{a} 1,44 \mathrm{~F}, 22 \mathrm{~g}, \\
54 \mathrm{~N}, 48 \mathrm{M}, 26 \mathrm{k} 2,28 \mathrm{~g}, 44 \mathrm{M}, 4 \mathrm{a} 2,31 \mathrm{e}, 32 \mathrm{~b}, \\
3 \mathrm{~b} 2,53 \mathrm{D}, 3 \mathrm{~d}, 29 \mathrm{f} 2,14 \mathrm{c} 2,44 \mathrm{H}, 46 \mathrm{H}, 42 \mathrm{~b}, \\
48 \mathrm{~J}, 48 \mathrm{~F}, 5 \mathrm{~b}, 53 \mathrm{~J}, 23 \mathrm{~h}, 48 \mathrm{~L}, 46 \mathrm{C}, 47 \mathrm{C}, 9 \mathrm{a} 1, \\
49 \mathrm{R}, 50 \mathrm{~N}, 31 \mathrm{~d} 1,26 \mathrm{~b}, 28 \mathrm{c}, 53 \mathrm{I},\end{array}$ \\
\hline & Subgrupo $12 \mathrm{c}$ & $\begin{array}{l}1 \mathrm{~b} 1,10 \mathrm{c}, 11 \mathrm{~b}, 31 \mathrm{~g}, 48 \mathrm{E}, 32 \mathrm{e} 1,45 \mathrm{C}, 53 \mathrm{~F}, \\
54 \mathrm{H}, 44 \mathrm{E}, 1 \mathrm{c}, 6 \mathrm{~b}, 11 \mathrm{~d}, 44 \mathrm{G}, 45 \mathrm{I}, 22 \mathrm{a} 2,32 \mathrm{c}, \\
27 \mathrm{i}, 46 \mathrm{U},\end{array}$ \\
\hline & Subgrupo $12 \mathrm{~d}$ & $17 \mathrm{~b}, 30 \mathrm{c}, 44 \mathrm{~A}, 54 \mathrm{~L}, 47 \mathrm{~J}$ \\
\hline & Subgrupo $12 \mathrm{e}$ & $5 \mathrm{c}, 45 \mathrm{M}$ \\
\hline & Subgrupo $12 \mathrm{f}$ & $18 \mathrm{~b} 2,15 \mathrm{a}, 45 \mathrm{~A}, 49 \mathrm{I}, 34 \mathrm{c}, 50 \mathrm{I}$ \\
\hline & Subgrupo $12 \mathrm{~g}$ & $8 \mathrm{~b} 2,49 \mathrm{C}, 10 \mathrm{~d} 2,48 \mathrm{~B}$ \\
\hline
\end{tabular}




\begin{tabular}{|c|c|c|}
\hline \multicolumn{3}{|c|}{$\begin{array}{l}\text { COEFICIENTE DE DistanCia EuClidianA } \\
(\mathrm{G} 1(\mathrm{G} 2(\mathrm{G} 3(\mathrm{G} 4(\mathrm{G} 5(\mathrm{G} 6(\mathrm{G} 7 \text { ( (G8a, G8b), (G9 , ((G10e(G10d(G10c }(\mathrm{G} 10 \mathrm{a}, \mathrm{G} 10 \mathrm{~b})))) \\
((((((\mathrm{G} 11 \mathrm{a}, \mathrm{G} 11 \mathrm{~b})(\mathrm{G} 11 \mathrm{c}, \mathrm{G} 11 \mathrm{~d}))(\mathrm{G} 11 \mathrm{e}, \mathrm{G} 11 \mathrm{f})) \mathrm{G} 11 \mathrm{~g}) \mathrm{G} 11 \mathrm{~h}) \mathrm{G} 11 \mathrm{i})))))))))\end{array}$} \\
\hline \multicolumn{2}{|l|}{ Grupos } & OTU's \\
\hline \multicolumn{2}{|l|}{ Grupo 1} & $9 \mathrm{~b}$ \\
\hline \multicolumn{2}{|l|}{ Grupo 2} & $29 \mathrm{c}, 46 \mathrm{D}, 30 \mathrm{e}$ \\
\hline \multicolumn{2}{|l|}{ Grupo 3} & $16 \mathrm{c} 2,3 \mathrm{a} 2,46 \mathrm{R}$ \\
\hline \multicolumn{2}{|l|}{ Grupo 4} & $\begin{array}{l}\text { 7b, 54P, 16b, 44J, 46B, 22b, 44C, 49B, 54J, } \\
25 \mathrm{~b}, 50 \mathrm{Q}, 26 \mathrm{~d}\end{array}$ \\
\hline \multicolumn{2}{|l|}{ Grupo 5} & $13 \mathrm{~b} 2,30 \mathrm{~b} 2,32 \mathrm{f}$ \\
\hline \multicolumn{2}{|l|}{ Grupo 6} & $8 \mathrm{a} 1,9 \mathrm{c} 1,45 \mathrm{~L}, 28 \mathrm{e}$ \\
\hline \multicolumn{2}{|l|}{ Grupo 7} & $48 \mathrm{~K}$ \\
\hline \multirow[t]{2}{*}{ Grupo 8} & Subgrupo 8a & 17a, 24a2, 28d, 47B, 25e, 50K, 3b1, 54Q, \\
\hline & Subgrupo $8 \mathrm{~b}$ & $\begin{array}{l}1 \mathrm{a} 2,11 \mathrm{c}, 14 \mathrm{~b} 2,21 \mathrm{a} 2,46 \mathrm{~W} 54 \mathrm{O}, 50 \mathrm{H}, 23 \mathrm{~g} \\
9 \mathrm{a} 2,45 \mathrm{E}, 26 \mathrm{k} 1,25 \mathrm{k}, 46 \mathrm{I}, 46 \mathrm{~L}, 48 \mathrm{~N}, 26 \mathrm{a} \\
31 \mathrm{~h}\end{array}$ \\
\hline \multicolumn{2}{|l|}{ Grupo 9} & $10 \mathrm{~d} 2,48 \mathrm{~B}, 33 \mathrm{c} 2$ \\
\hline \multirow[t]{2}{*}{ Grupo 10} & Subgrupo $10 \mathrm{a}$ & $\begin{array}{l}18 \mathrm{a}, 4 \mathrm{~b} 3,37 \mathrm{a}, 36 \mathrm{a} 2,48 \mathrm{I}, 41 \mathrm{~d} 2,50 \mathrm{~A}, 6 \mathrm{e} \\
44 \mathrm{~B}, 18 \mathrm{~d}, 19 \mathrm{a} 2,48 \mathrm{G}, 53 \mathrm{E}, 6 \mathrm{a}, 47 \mathrm{~A}, 7 \mathrm{~d}, \\
54 \mathrm{M}, 24 \mathrm{i}, 50 \mathrm{E}, 16 \mathrm{~d} 2,47 \mathrm{~L}, 43 \mathrm{~d}, 54 \mathrm{~A}, 54 \mathrm{~K}, \\
27 \mathrm{a} 1,53 \mathrm{~A}, 33 \mathrm{a}, 49 \mathrm{M}, 53 \mathrm{C}, 47 \mathrm{D}, 42 \mathrm{~b} 1,49 \mathrm{~N}\end{array}$ \\
\hline & Subgrupo $10 \mathrm{~b}$ & $\begin{array}{l}20 \mathrm{i} 2,42 \mathrm{~d} 2,34 \mathrm{~d}, 40 \mathrm{~b}, 30 \mathrm{~d}, 51 \mathrm{D}, 41 \mathrm{c}, 37 \mathrm{f} \\
52 \mathrm{~A}, 52 \mathrm{D}, 36 \mathrm{c}, 51 \mathrm{H}, 37 \mathrm{e} 1,52 \mathrm{~F}, 27 \mathrm{~g} \\
\text { 50D52H, 34a, 42b2, 51I, 36b1, 51J, 52G, }\end{array}$ \\
\hline
\end{tabular}


Eliana Paula Coturel - Bioestratigrafía del Pérmico de la Sierra de los llanos...

\begin{tabular}{|c|c|c|}
\hline & & $\begin{array}{l}51 \mathrm{~F}, 34 \mathrm{~b} 1,51 \mathrm{~A}, 35 \mathrm{~b}, 37 \mathrm{e} 2,40 \mathrm{a}, 51 \mathrm{E}, 33 \mathrm{~b}, \\
53 \mathrm{H}, 49 \mathrm{~K}, 33 \mathrm{~d} 1\end{array}$ \\
\hline & Subgrupo 10c & $32 \mathrm{e} 2$ \\
\hline & Subgrupo $10 \mathrm{~d}$ & $52 \mathrm{E}$ \\
\hline & Subgrupo $10 \mathrm{e}$ & $49 \mathrm{C}$ \\
\hline Grupo 11 & Subgrupo 11a & $\begin{array}{l}16 \mathrm{~d} 3,26 \mathrm{k} 2,28 \mathrm{~g}, 31 \mathrm{e}, 32 \mathrm{~b}, 13 \mathrm{~g}, 45 \mathrm{~J}, 45 \mathrm{D}, \\
19 \mathrm{a} 1,44 \mathrm{~F}, 22 \mathrm{~g}, 54 \mathrm{~N}, 48 \mathrm{M}, 50 \mathrm{C}, 53 \mathrm{D}, 1 \mathrm{c}, \\
\text { 19c, 4a2, 9a1, 49R, 44M, 50N, 31d1, 26b, } \\
\text { 28c, 53I, }\end{array}$ \\
\hline & Subgrupo $11 \mathrm{~b}$ & $\begin{array}{l}19 \mathrm{~b} 2,54 \mathrm{C}, 10 \mathrm{~b}, 1 \mathrm{~d}, 24 \mathrm{j}, 46 \mathrm{~N}, 6 \mathrm{~b}, 11 \mathrm{~d}, 44 \mathrm{G}, \\
32 \mathrm{e} 1,45 \mathrm{C}, 53 \mathrm{~F}, 54 \mathrm{H}, 44 \mathrm{E}, 32 \mathrm{c}, 48 \mathrm{~F}, 22 \mathrm{a} 2, \\
27 \mathrm{i}, 45 \mathrm{I}, 46 \mathrm{U}\end{array}$ \\
\hline & Subgrupo $11 \mathrm{c}$ & $\begin{array}{l}3 \mathrm{~d}, 14 \mathrm{c} 2,44 \mathrm{H}, 46 \mathrm{H}, 29 \mathrm{f} 2,42 \mathrm{~b}, 48 \mathrm{~J}, 23 \mathrm{~h}, \\
48 \mathrm{~L}, 47 \mathrm{C}, 46 \mathrm{C}, 3 \mathrm{~b} 2,5 \mathrm{~b}, 53 \mathrm{~J}\end{array}$ \\
\hline & Subgrupo $11 \mathrm{~d}$ & $\begin{array}{l}\text { 5d, 13c, 45B, 31f, 44L, 46A, 31d, 50B, 50M, } \\
\text { 24d, 7a2, 12f2, 42c, 49F, 36b2, }\end{array}$ \\
\hline & Subgrupo $11 \mathrm{e}$ & 17b, 54L, 30c, 44A, 47G, 49D, 47J, \\
\hline & Subgrupo $11 \mathrm{f}$ & $\begin{array}{l}\text { 19e1, 11a2, 53K, 20f1, 45H, 47K, 3a1, } \\
\text { 20b2, 50F, 10a, 54I, 23c, 31a, 54D, 21b, } \\
\text { 30a1, 27h, 48A, 53B, 45G, 48C, 52B, 1b1, } \\
\text { 11b, 31g, 48E, 6f, 41a2, 51B, 6c2, 12h, } \\
\text { 30a2, 48H, 54E, 49P, 21c2, 10c, 15b, 44D, } \\
\text { 49E, 48D }\end{array}$ \\
\hline & Subgrupo $11 \mathrm{~g}$ & $18 \mathrm{~b} 2,15 \mathrm{a}, 45 \mathrm{~A}, 49 \mathrm{I}, 50 \mathrm{I}, 34 \mathrm{c}$ \\
\hline & Subgrupo $11 \mathrm{~h}$ & $\begin{array}{l}18 \mathrm{c}, 44 \mathrm{I}, 8 \mathrm{e}, 45 \mathrm{~F}, 2 \mathrm{a} 2,4 \mathrm{a} 3,29 \mathrm{~g} 2,26 \mathrm{~h}, 46 \mathrm{~V}, \\
29 \mathrm{e}, 47 \mathrm{M}, 12 \mathrm{a} 2,29 \mathrm{a} 2,54 \mathrm{G}, 47 \mathrm{O}, 50 \mathrm{~J},\end{array}$ \\
\hline & Subgrupo $11 \mathrm{i}$ & $5 \mathrm{a}, 5 \mathrm{c}, 8 \mathrm{a} 2,45 \mathrm{M}, 45 \mathrm{~N}, 8 \mathrm{~b} 2$ \\
\hline
\end{tabular}


Gráficamente, estas son las relaciones jerárquicas entre grupos:
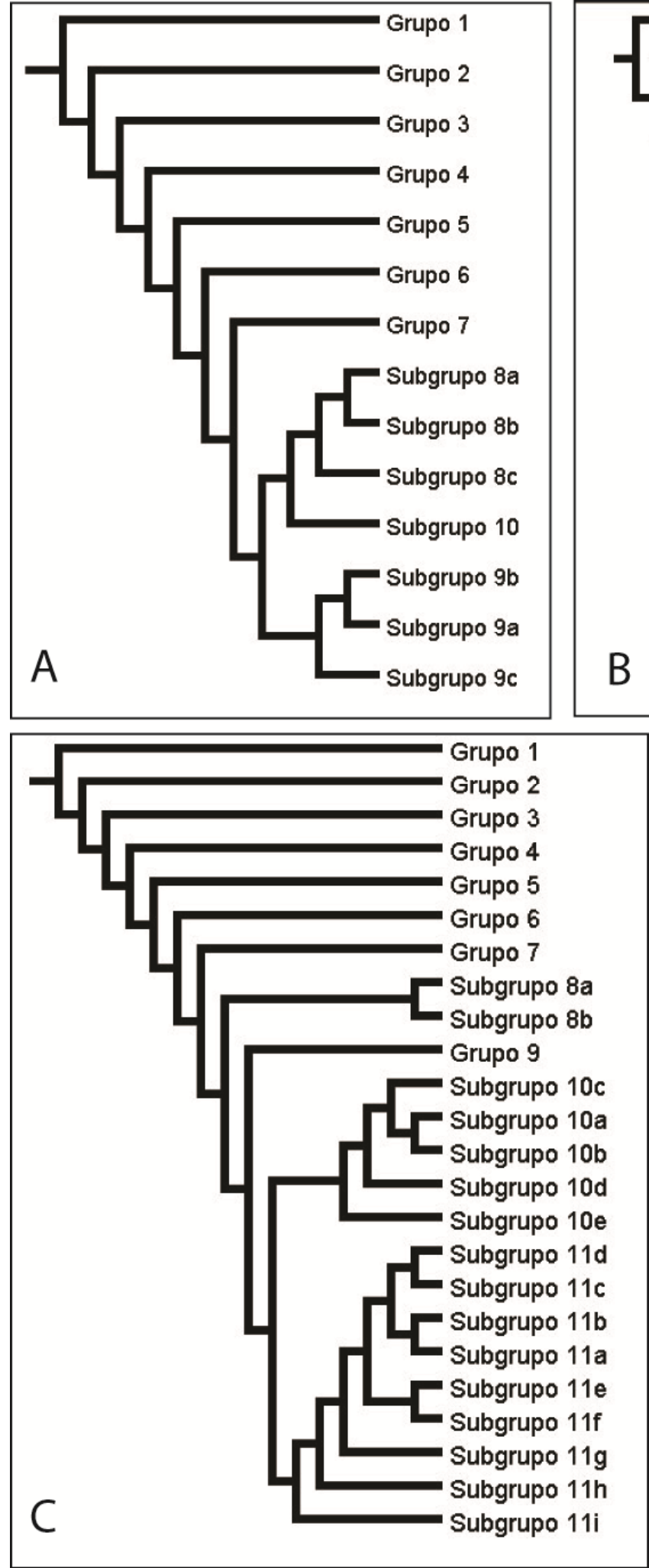
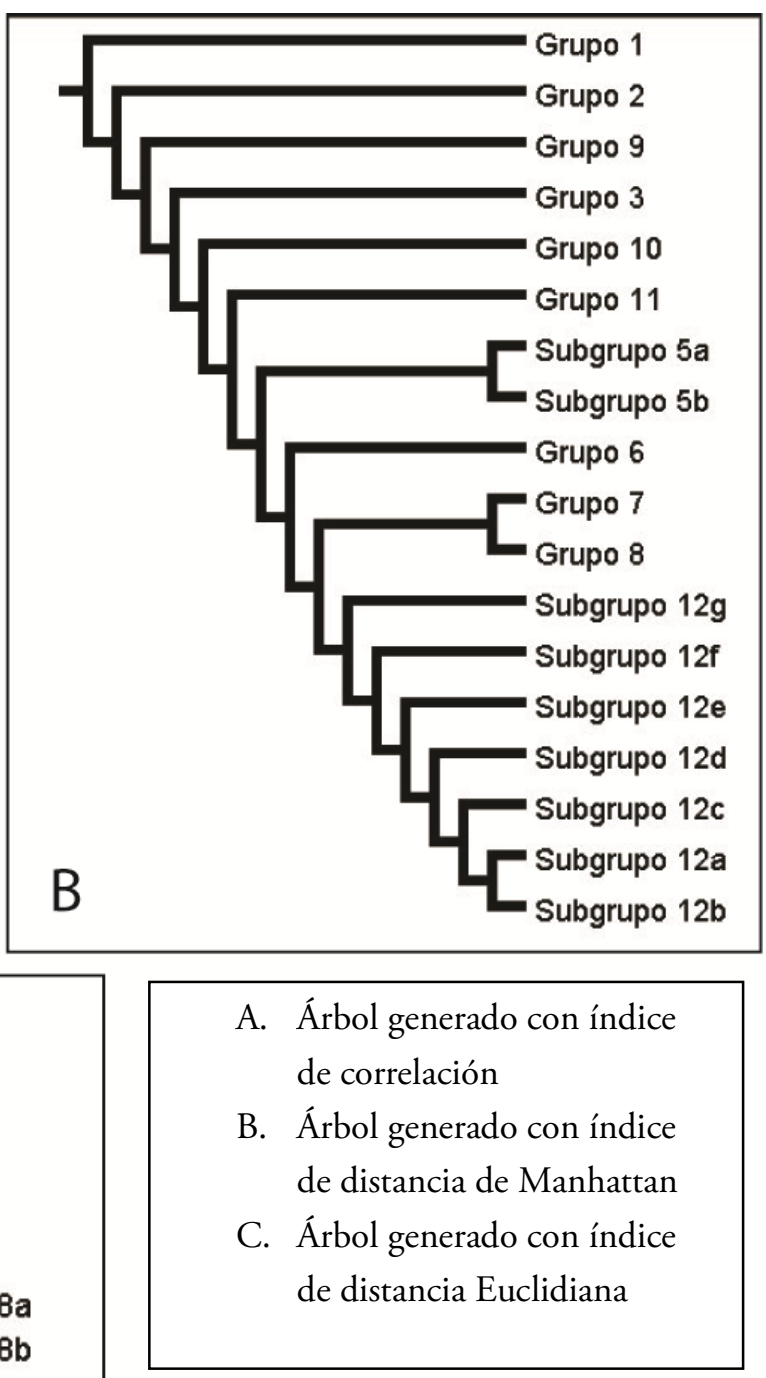
Comparando los grupos de OTUs, se observa que los grupos generados con el Índice de Correlación son distintos a los generados por los índices de Distancia (Manhattan, Euclidiana), y que estos dos últimos poseen la siguiente equivalencia:

\begin{tabular}{|l|l|l|}
\hline Manhattan & Euclidiana & Nombre Grupo \\
\hline G1 & G1 & Grupo A \\
G3 & G2 & Grupo B \\
G4 + G5a + G5b & G8a. G8b. G11h & Grupo D \\
G7 & G10b (G10a, 10d) & Grupo E \\
G8 & G10a + G11f & Grupo F \\
G9 & G4 & Grupo G \\
G10 & G6 & Grupo H \\
G11 & G7 & Grupo I \\
G12a & G11d (G11b) & Grupo J \\
G12b & G11a + G11c & Grupo K \\
G12c & G11b & Grupo L \\
G12d & G11e & Grupo M \\
G12e+G12g & G9 + G11i + G10e & Grupo N \\
G12f & G11g & Grupo O \\
\hline
\end{tabular}

Esto es esperable dado que los dos son índices de distancia, y se diferencian en la mayor complejidad de la fórmula del índice de distancia Euclidiana.

La caracterización de los grupos se realiza considerando los coeficientes de las funciones que describen el recorrido de la vena, la densidad (estandarizada) de venas, los máximos y mínimos conteos de anastomosis, y el porcentaje de anastomosis por zona. 


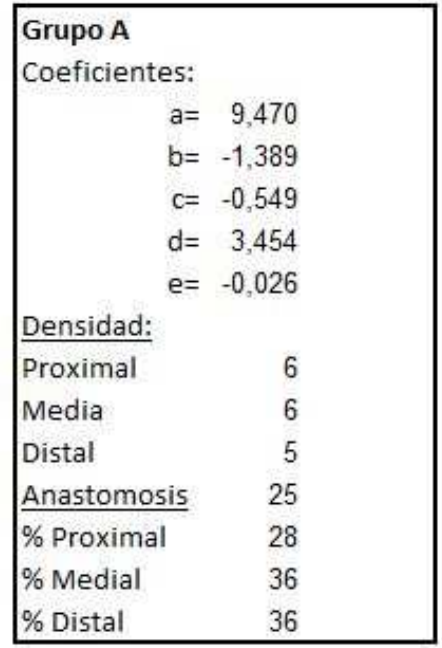

\begin{tabular}{|c|c|c|}
\hline \multicolumn{3}{|l|}{ Grupo D } \\
\hline \multicolumn{3}{|l|}{ Coeficientes: } \\
\hline$a=$ & $=-0,203$ & \\
\hline & $=0,166$ & \\
\hline & $=-0,194$ & \\
\hline & $=1,29$ & \\
\hline$e=$ & $=-0,006$ & \\
\hline \multicolumn{3}{|c|}{ Densidad: } \\
\hline Proximal & $4 a$ & 24 \\
\hline Media & $5 \mathrm{a}$ & 30 \\
\hline Distal & $6 a$ & 34 \\
\hline Anastomosis & 10 & 127 \\
\hline$\%$ Proximal & 31 & \\
\hline$\%$ Medial & 38 & \\
\hline$\%$ Distal & 31 & \\
\hline
\end{tabular}

\begin{tabular}{|c|c|c|}
\hline \multirow{2}{*}{\multicolumn{3}{|c|}{$\begin{array}{l}\text { Grupo G } \\
\text { Coeficientes: }\end{array}$}} \\
\hline & \multicolumn{2}{|c|}{ Coeficientes: } \\
\hline$a=$ & $-1,418$ & \\
\hline$b=$ & 1,605 & \\
\hline$c=$ & $-0,695$ & \\
\hline$d=$ & 1,519 & \\
\hline$e=$ & 0,006 & \\
\hline \multicolumn{3}{|l|}{ Densidad: } \\
\hline Proximal & $3 a$ & 16 \\
\hline Media & 4 a & 16 \\
\hline Distal & $5 \mathrm{a}$ & 20 \\
\hline Anastomosis & $11 \mathrm{a}$ & 154 \\
\hline$\overline{\% \text { Proximal }}$ & 35 & \\
\hline$\%$ Medial & 41 & \\
\hline$\%$ Distal & 25 & \\
\hline
\end{tabular}

\begin{tabular}{|c|c|c|}
\hline \multirow{2}{*}{\multicolumn{3}{|c|}{ Grupo B }} \\
\hline & & \\
\hline \multicolumn{3}{|l|}{ Coeficientes: } \\
\hline$a=$ & $-5,685$ & \\
\hline$b=$ & 2,374 & \\
\hline$c=$ & 0,656 & \\
\hline$d=$ & 1,577 & \\
\hline$e=$ & 0,003 & \\
\hline \multicolumn{3}{|l|}{ Densidad: } \\
\hline Proximal & $3 a$ & 9 \\
\hline Media & $3 a$ & 9 \\
\hline Distal & $3 a$ & 11 \\
\hline Anastomosis & $7 a$ & 25 \\
\hline$\%$ Proximal & 23 & \\
\hline$\%$ Medial & 39 & \\
\hline$\%$ Distal & 38 & \\
\hline
\end{tabular}

\begin{tabular}{|c|c|}
\hline Grupo C & \\
\hline Coeficientes: & \\
\hline$a=$ & 4,179 \\
\hline$b=$ & $-0,828$ \\
\hline$c=$ & $-1,255$ \\
\hline$d=$ & 1,564 \\
\hline $\mathrm{e}=$ & $-0,012$ \\
\hline Densidad: & \\
\hline Proximal & 5 a 16 \\
\hline Media & 6 a 28 \\
\hline Distal & 7 a 29 \\
\hline Anastomosis & 20 a 110 \\
\hline$\%$ Proximal & 23 \\
\hline \% Medial & 39 \\
\hline$\%$ Distal & 38 \\
\hline
\end{tabular}

\section{Grupo E}

Coeficientes:

$$
\begin{array}{rr}
a= & -0,083 \\
b= & 0,087 \\
c= & -0,007 \\
d= & 0,102 \\
e= & -0,002
\end{array}
$$

\begin{tabular}{|c|c|c|}
\hline Proximal & $8 a$ & 60 \\
\hline Media & $10 \mathrm{a}$ & 80 \\
\hline Distal & 9 a & 80 \\
\hline Anastomosis & $14 \mathrm{a}$ & 352 \\
\hline$\%$ Proximal & 29 & \\
\hline$\%$ Medial & 37 & \\
\hline$\%$ Distal & 34 & \\
\hline
\end{tabular}

Densidad:

\section{Grupo H}

Coeficientes:

$$
\begin{array}{lr}
a= & -2,463 \\
b= & 0,05 \\
c= & 0,424 \\
d= & 1,097 \\
e= & -0,017
\end{array}
$$

Densidad:

\begin{tabular}{lllll}
\hline Proximal & & 5 a & 22 \\
Media & & 6 a & 24 \\
Distal & & 7 a & 25 \\
Anastomosis & & 18 a & 100 \\
\% Proximal & & 31 & \\
\% Medial & & 40 & \\
\% Distal & & 29 & \\
\hline
\end{tabular}

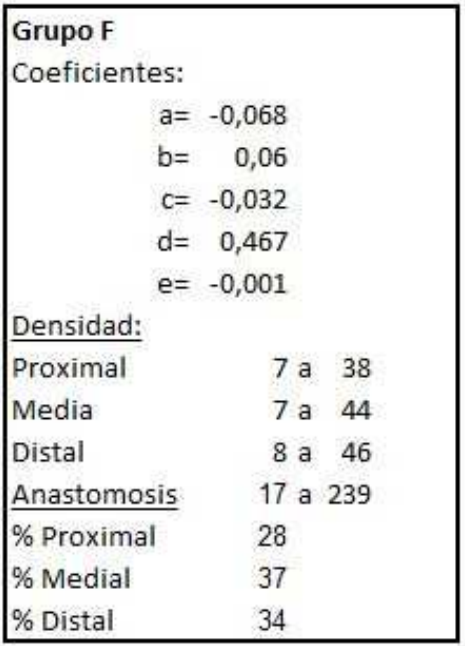

\section{Grupo I}

Coeficientes:

$$
\begin{aligned}
& a=0,958 \\
& b=-1,85 \\
& c=0,017 \\
& d=1,845 \\
& e=0,008
\end{aligned}
$$

Densidad:

\begin{tabular}{lr} 
Proximal & 8 \\
Media & 11 \\
Distal & 13 \\
Anastomosis & 32 \\
\hline \% Proximal & 44 \\
\% Medial & 44 \\
\% Distal & 12
\end{tabular}




\begin{tabular}{|c|c|c|c|}
\hline \multirow{2}{*}{\multicolumn{4}{|c|}{$\begin{array}{l}\text { Grupo J } \\
\text { Coeficientes: }\end{array}$}} \\
\hline & & & \\
\hline & $a=$ & \multicolumn{2}{|c|}{$=-0,096$} \\
\hline & $b=$ & \multicolumn{2}{|l|}{0,066} \\
\hline & $c=$ & \multicolumn{2}{|l|}{$-0,071$} \\
\hline & $d=$ & \multicolumn{2}{|l|}{0,783} \\
\hline & $e=$ & \multicolumn{2}{|l|}{0,007} \\
\hline \multicolumn{4}{|c|}{ Densidad: } \\
\hline Proximal & & $7 \mathrm{a}$ & 31 \\
\hline Media & & $8 \mathrm{a}$ & 32 \\
\hline Distal & & 9 a & 40 \\
\hline Anastomosis & & $18 \mathrm{a}$ & 104 \\
\hline$\%$ Proximal & & 31 & \\
\hline$\%$ Medial & & 39 & \\
\hline$\%$ Distal & & 31 & \\
\hline
\end{tabular}

\begin{tabular}{|c|c|c|}
\hline \multirow{2}{*}{\multicolumn{3}{|c|}{$\begin{array}{l}\text { Grupo M } \\
\text { Coeficientes: }\end{array}$}} \\
\hline & & \\
\hline \multicolumn{3}{|c|}{$a=0,454$} \\
\hline$b=$ & \multicolumn{2}{|l|}{$-0,281$} \\
\hline$c=$ & \multicolumn{2}{|l|}{$-0,261$} \\
\hline$d=$ & \multicolumn{2}{|l|}{0,983} \\
\hline$e=$ & \multicolumn{2}{|l|}{$-0,002$} \\
\hline \multicolumn{3}{|c|}{ Densidad: } \\
\hline Proximal & $8 a$ & 24 \\
\hline Media & $9 \mathrm{a}$ & 25 \\
\hline Distal & $12 \mathrm{a}$ & 28 \\
\hline Anastomosis & 22 a & 73 \\
\hline$\%$ Proximal & 26 & \\
\hline \% Medial & 44 & \\
\hline$\%$ Distal & 29 & \\
\hline
\end{tabular}

\begin{tabular}{|c|c|c|}
\hline \multirow{2}{*}{\multicolumn{3}{|c|}{$\begin{array}{l}\text { Grupo K } \\
\text { Coeficientes: }\end{array}$}} \\
\hline & & \\
\hline \multicolumn{3}{|c|}{$a=-0,069$} \\
\hline \multicolumn{3}{|c|}{$b=0,101$} \\
\hline \multicolumn{3}{|c|}{$c=-0,232$} \\
\hline \multicolumn{3}{|c|}{$d=0,931$} \\
\hline \multicolumn{3}{|c|}{$e=-0,006$} \\
\hline \multicolumn{3}{|c|}{ Densidad: } \\
\hline$\overline{\text { Proximal }}$ & $6 a$ & 24 \\
\hline Media & $6 \mathrm{a}$ & 28 \\
\hline Distal & $8 a$ & 33 \\
\hline Anastomosis & $10 a$ & 165 \\
\hline$\%$ Proximal & 31 & \\
\hline$\%$ Medial & 41 & \\
\hline$\%$ Distal & 28 & \\
\hline
\end{tabular}

\begin{tabular}{|c|c|}
\hline Grupo L & \\
\hline Coeficientes: & \\
\hline$a=$ & $-0,182$ \\
\hline$b=$ & 0,086 \\
\hline$c=$ & $-0,214$ \\
\hline$d=$ & 0,681 \\
\hline $\mathrm{e}=$ & $-0,002$ \\
\hline Densidad: & \\
\hline Proximal & 9 a 44 \\
\hline Media & 10 a 48 \\
\hline Distal & 10 a 54 \\
\hline Anastomosis & 13 a 202 \\
\hline$\%$ Proximal & 28 \\
\hline$\%$ Medial & 41 \\
\hline$\%$ Distal & 30 \\
\hline
\end{tabular}

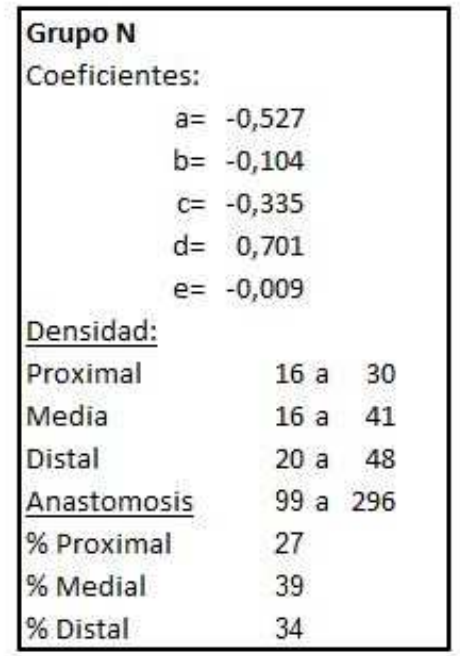

\begin{tabular}{|c|c|}
\hline Grupo 0 & \\
\hline Coeficientes: & \\
\hline$a=$ & 0,276 \\
\hline$b=$ & 0,625 \\
\hline$c=$ & $-0,061$ \\
\hline$d=$ & 0,606 \\
\hline $\mathrm{e}=$ & 0,002 \\
\hline Densidad: & \\
\hline Proximal & 9 a 28 \\
\hline Media & 9 a 33 \\
\hline Distal & 8 a 36 \\
\hline Anastomosis & 27 a 162 \\
\hline$\%$ Proximal & 19 \\
\hline$\%$ Medial & 42 \\
\hline$\%$ Distal & 38 \\
\hline
\end{tabular}

\section{Discusión y conclusiones}

Analizando solamente la forma de la vena secundaria se lograron establecer grupos, los cuales fueron caracterizados en forma general agregando información de densidad de venación y anastomosis. A partir del Grupo J, los datos fueron obtenidos de subgrupos, y eso puede estar determinando que haya rangos amplios de las variables independientes contrastadas (densidad y anastomosis). Deberán definirse grupos internos, el proceso a seguir debería ser separar cada grupo y realizar nuevos análisis de agrupamiento, sólo con las OTU’s de ese grupo, 
para así establecer grupos menores y verificar si existe una correlación entre otros caracteres y la forma de la vena secundaria. Otra opción es correr a través de los programas utilizados bases de datos más amplias, incluyendo todas las variables, pero dadas las características de éstas (números altos, discretos, en cuanto a densidades, y números que incluyen negativos provenientes de las ecuaciones de las venas) deberán establecerse rangos y esto podría causar un sesgo en el análisis.

Sea cual fuere el camino a seguirse, y considerando la posibilidad de que no haya coincidencias totales entre los morfogrupos y los taxones descriptos hasta la actualidad, se debe seguir analizando los caracteres y buscar el establecimiento de morfogrupos robustos, inclusive dando un giro a cómo se visualizan los caracteres, que es lo que se pretendía en este capítulo. Análisis teóricos previos (Srivastava, 1991) sugieren que hay una relación estratigráfica (y evolutiva) en la variación del conjunto de la venación. Con el conjunto de herramientas (software como TNT, PAST, Mesquite) de las que se disponen actualmente, debería buscarse corroborar o desmentir estas hipótesis. 
Eliana Paula Coturel - Bioestratigrafía del Pérmico de la Sierra de los llanos...

\section{CAPÍTULO V. BIOESTRATIGRAFÍA}




\section{V.1 Antecedentes relativos a la ubicación temporal de la flora del Arroyo Totoral}

Bodenbender (1911) fue quien realizó los primeros estudios comparativos de la Flora, analizó las determinaciones de Kurtz, y ubicó a los "estratos del Arroyo Totoral" en el Piso I de los Estratos de Paganzo. Comparó la edad del piso con el "grupo de los Talschir y Karharbari" de la India, Dwyka y Vaal-conglomerado de África, a los "estratos de Tubarao" de la "formación Santa Catarina" (sensu White), dando una edad Permo-carbonífera a todo el conjunto. El piso II, de estratos rojos -comparables con la Formación La Colina en nuestra área-, correspondería según el autor al Grupo Damuda (Barakar-Raniganj) de la India, también del Pérmico. Von Freyberg (1927) dio a la flora del Arroyo Totoral edad pérmica superior. Bracaccini (1944), basándose en Frenguelli (1942) dio al "Nivel del Arroyo Totoral” edad carbonífera superior o pérmica más baja. Frenguelli (1949) dio a esta flora edad Pérmica inferior.

Andreis et al. (1984) describieron la secuencia pérmica temprana de sierra de los Llanos diferenciando las Formaciones Arroyo Totoral y La Colina. Esta propuesta fue revisada por Limarino y Page (1999), quienes incluyen a ambas formaciones dentro de la Formación Patquía. En estudios de vertiente geológica, Net (1998) dio a las formaciones Solca y Arroyo Totoral edad pérmica temprana. Net y Limarino (1999) en su interpretación paleogeográfica indican que la depositación de las formaciones Solca y Arroyo Totoral se produjo durante el lapso Estefaniano-Pérmico.

Archangelsky y Cúneo (1984) realizaron una propuesta integral de zonación estratigráfica para el Pérmico de Argentina, que fue reevaluada por Archangelsky et al. (1996). Se definió allí una Zona de Gangamopteris para el Pérmico Temprano de las cuencas de San Rafael y Paganzo y se refierió la Formación Arroyo Totoral a la Zona de Gangamopteris, del Pérmico Temprano. Todas las referencias paleobotánicas posteriores a la flora del Arroyo Totoral han sido dentro de esta Zona, de la que se ha sugerido una división en dos 
subunidades, inferior y superior (Archangelsky y Cúneo, 1990). La inferior comprendería las floras de las formaciones Arroyo Totoral, Bajo de Véliz, De la Cuesta y parte de La Colina. La superior, a las formaciones La Colina y Tasa Cuna. La Zona de Gangamopteris fue equiparada con la Superzona de Ferugliocladus de la Cuenca Tepuel-Genoa, siendo ambas referidas al Piso Lubeckense (Pérmico inferior, Asseliano a Artinskiano, Archangelsky y Cúneo, 1984).

Crisafulli y Herbst (2008) dieron a la Formación Solca edad pérmica temprana. Net y Limarino (1998) le otorgaron edad Carbonífero superior-Pérmico temprano. Barreda y Césari (1995) refirieron los dos niveles fosilíferos hallados en la localidad de La Huerta, en el flanco oriental de la sierra de los Llanos, a la Formación Arroyo Totoral, mientras que el nivel fosilífero inferior fue referido por Coturel et al. (2009) a la Formación Solca, y temporalmente a la Zona de Intervalo, del Carbonífero cuspidal.

\section{V.2 Biozonación paleoflorística del Pérmico de Argentina}

El esquema bioestratigráfico para el Neopaleozoico aceptado actualmente en Argentina es el desarrollado en Archangelsky y Cúneo (1984) y en "El Sistema Pérmico de la República Argentina y la República Oriental del Uruguay" (Archangelsky, 1996). En este último se definen y reconocen las siguientes biozonas:

- Zona Intervalo [ZI], corresponde al cambio florístico ocurrido a fines del Carbonífero. Taxones exclusivos son Cornucarpus patagonicus y Krauselcladus argentinus. En la zona se extinguen Bergiopteris insignis, Botrychiopsis weissiana, Ginkgophyllum diazii, Malanzania nana y Cordaites riojanus y se da la primera aparición de Botrychiopsis plantiana, Paranocladus? fallax, Pecopteris sp. y semillas de Samaropsis spp. Fue citada en Paganzo, en las Formaciones Trampeadero, Libertad, Chancaní y Solca; en Calingasta-Uspallata en la Formación Cerro Agua Negra, y en San Rafael, en la Formación El Imperial. Para Tepuel Genoa, el miembro superior de la Formación 
Mojón de Hierro es referido a esta Zona. Como criterio, se sostiene que la zona es prepérmica por la ausencia de glossopteridales.

- Zona Gangamopteris [G], en esta zona aparecen las glossopteridales, con una predominancia de Gangamopteris sobre Glossopteris, y especies de este género con pocas anastomosis. Se divide en dos subzonas, denominadas informalmente "inferior" y “superior". La subzona inferior se caracteriza por la presencia exclusiva de Ferugliocladus riojanum, Euryphyllum whittianum y Glossopteris occidentalis, y se reconoce en las Formaciones Arroyo Totoral, La Colina (en Loma Larga y La Desabrida), Bajo de Véliz, Solca y De la Cuesta, mientras que la subzona superior se reconoce en las Formaciones Tasa Cuna y La Colina (en Los Colorados).

- Superzona Ferugliocladus [F], definida para la Cuenca de Tepuel-Genoa, referida para la Formación Andapaico en Paganzo (Correa et al., 2012). Se caracteriza porque dominan las coníferas (Ferugliocladus patagonicus, Ugartecladus genoensis, Paranocladus? fallax, Eucerospermum) y se divide en dos Zonas:

- Zona Nothorhacopteris chubutiana $[\mathrm{Nc}]$, se caracteriza por la presencia del taxón que le da nombre, y son especies características Sphenophyllum chubutianum, S. patagonicum y Corynepteris australis.

- Zona Ginkgoites eximia [Ge], zona de extensión con G. eximia y Genoites patagonica como especies índice. Taxones característicos son Botrychiopsis valida, Cordaites casildensis, Barakaria dichotoma, Polyspermophyllym sergii, Eucerospermum patagonicum, Gangamopteris mosesi. Se divide en dos subzonas:

- Subzona A: aparecen Ginkgoites eximia, Asterotheca feruglioi, Genoites patagonica, Ferugliocladus sp. y Eucerospermum patagonicum. Presencia exclusiva de Stellotheca sp., Sphenophyllum sp., Sphenopteris spp. y Alloiopteris spp. 
- Subzona B: primera aparición de Asterotheca golondrinensis, A. andersonii. Son exclusivos Bumbudendron millani, Polyspermophyllym sergii, y algunas especies de Phyllotheca y Sphenopteris.

- Zona Glossopteris [Gl], definida por el dominio de las glossopteridales, a veces presente en concentraciones casi puras. Se ha restringido en el país a las Sierras Australes e Islas Malvinas (Archangelsky et al. 1996), estaría presente en Carapacha (La Pampa, Melchor y Césari, 1996)

- Superzona Dizeugotheca [D], definida para la Cuenca de La Golondrina, referida para la Cuenca de Carapacha (Melchor y Césari, 1996). La edad es referida desde el Kunguriano al Wuchiapingiano (Archangelsky et al. 1996). La Superzona está caracterizada por la presencia de Dizeugotheca neuburgiae, Glossopteris argentina, G. ampla y Asterotheca golondrinensis y se divide en las Zonas Dizengotheca waltonii [Dw] y Asterotheca singeri [As]. Cariglino (2012, no publicado) reestructura la zonación paleoflorística para La Golondrina y extiende la edad de las biozonas al Changhsingiano.

\section{Edad de las biozonas.}

El Piso Lubeckiano - Archangelsky y Cúneo (1984) definen este piso, que abarca el Pérmico inferior y se desarrolla en Paganzo y Tepuel Genoa de la siguiente manera:

Cuenca Paganzo - Archangeslky et al. (1996) asignan a este piso todo el Cisuraliano (Asseliano a Kunguriano), caracterizado en la Zona de Gangamopteris. El primer registro de Glossopteris tendría edad pérmica, aunque el registro de insectos en Bajo de Véliz (Zona Gangamopteris inferior) sugiere una antigüedad Pennsylvaniana tardía. Menciones anteriores sobre la Zona de Gangamopteris la refieren al "Pérmico Inferior más bajo" (Archangelsky et al., 1980; Melchor y Césari, 1996). Posteriormente, Césari et al. (2011) presentan un esquema bio-cronoestratigráfico, donde esta Zona se restringe a la parte inferior del Asseliano, pudiendo comenzar en el Carbonífero Superior más alto. Limarino et al. (2013), basándose en las 
dataciones de Gulbranson et al. (2010) y Césari et al. (2011) sugieren que la depositación en el sector oriental de Paganzo abarca hasta el Asseliano.

Cuenca Tepuel-Genoa - Archangeslky et al. (1996) asignan a este piso parte del Cisuraliano (Asseliano a Artinskiano), intervalo al que se refiere la Superzona de Ferugliocladus y las Zonas que la componen.

Por otro lado, la Zona Glossopteris es referida al Pérmico Inferior alto por Archangelsky y Cúneo (1980). Archangelsky et al. (1996), por el contenido florístico, sugieren una edad sakmariana-artinskiana, aunque la comparan con floras de Glossopteris del Pérmico medio a superior del resto de Gondwana. Melchor y Césari (1996) comparan el contenido de la flora de Carapachá con la Zona Glossopteris y la Superzona Dizengotheca, de La Golondrina, indicando para ambas edad pérmica temprana-tardía a pérmica tardía. En el esquema estratigráfico presentado en Limarino et al. (2013), las Formaciones Bonete y Tunas abarcan el intervalo Sakmariano-Roadiano.

\section{V.3 La Flora del Arroyo Totoral en Cuenca Paganzo}

El contexto paleoecológico que enmarca el desarrollo de la flora de Arroyo Totoral fue discutido en el capítulo de Paleobotánica. El mejoramiento climático que comienza en el Carbonífero tardío es acompañado por un primer evento de aridización en esta Cuenca, durante el cual se desarrollan floras en Sierra de los Llanos (Solca y Arroyo Totoral), Bajo de Véliz, Tasa Cuna y La Colina, dentro del ámbito oriental, y Andapaico en el ámbito occidental.

En el cuadro 1 se comparan los componentes de las asociaciones presentes en las seis formaciones referidas al Pérmico. 
Aunque la tafoflora de la Sierra de los Llanos muestra una mayor diversidad taxonómica, todas las floras se caracterizan por presentar:

EQUISETALES, se registran morfotaxones de tallos vegetativos. En algunos casos se preserva la zona reproductiva, que no es coincidente entre localidades (Cruciaetheca en $\mathrm{A}^{\circ}$ Totoral, Stephanophyllites en Bajo de Véliz).

GLOSSOPTERIDALES, especies de hojas similares y poca diversidad a nivel reproductivo. Para Sierra de los Llanos se describieron tres especies de hojas e igual cantidad de estructuras reproductivas. Para las otras localidades aún no hay registro de estructuras reproductivas.

CORDAITALES, hasta Hünicken y Césari (2013) no se habían hallado inconescencias, y sólo había registro de hojas, para las cuales se describieron varias especies.

CONÍFERAS, representadas por ramas foliosas, se preservan formas con cono (Ferugliocladus) y con óvulos dispuestos laxamente en las ramas (Genoites).

Elementos secundarios pero con relevancia son las Marattiales (helechos de tipo Asterotheca), pteridospermas de tipo Botrychiopsis y esfenopterídeas. Elementos accesorios son las licófitas.

La flora descripta por Coturel et al. (2009) para la Formación Solca puede ser comparada con los niveles inferiores de Arroyo Totoral en Anzulón. Botrychiopsis plantiana se ha descrito en Argentina para las Formaciones El Trampeadero y Libertad, Solca, Bajo de Véliz y La Colina. En Solca, se halla dentro de dos asociaciones (El Loro y Loma Larga; Cúneo, 1987) con licófitas y sin Glossopteridales. Por otro lado, en la Formación La Colina (Loc. Tacopayana) se ha hallado en una asociación que incluye glossopteridales. Para la Formación Solca, además, se han determinado leños fósiles de filiación pérmica (Crisafulli y Herbst, 2008). La Formación Solca interdigitaría con la Formación Arroyo Totoral hacia el paleovalle de Anzulón (Net y Limarino, 1999). Si tomamos en cuenta esta relación estratigráfica, puede considerarse la ausencia de glossopteridales como una cuestión ecológica, y correlacionarse la 
parte superior de Solca, con la inferior de La Colina en Tacopayana y con Arroyo Totoral en Anzulón.

La flora de Bajo de Véliz es la que comparte más taxones con la flora de Sierra de los Llanos, remarcándose especialmente la presencia de Botrychiopsis plantiana, Asterothecaceae y licófitas. Estos taxones sugieren el desarrollo florístico bajo condiciones ambientales similares.

La flora de Tasa Cuna posee diferencias a nivel específico dentro de las Glossopteridales. Es atribuida a la Zona de Gangamopteris superior. Pese a que se registran helechos (Pecopteris andersonii), la ausencia de Botrychiopsis plantiana puede deberse a una aridización relativa respecto de Bajo de Véliz y Arroyo Totoral.

La Formación La Colina posee dos floras: la más antigua, asignada a la zona Gangamopteris inferior, es una flora que se habría desarrollado en un clima más árido respecto de la de Sierra de los Llanos. La más joven es comparable a la de la FormaciónTasa Cuna, y se la asigna junto a ella a la Zona Gangamopteris superior.

Para la Formación Andapaico se ha descripto una flora en la sección inferior, que carece de Glossopteridales pero posee elementos característicos del Pérmico inferior de la Cuenca de Tepuel Genoa, como son Ferugliocladus patagonicus y Eucerospermum spp. Por esta razón Correa et al (2012) la refieren con reservas a la Superzona de Ferugliocladus, del Cisuraliano de Tepuel Genoa. La parte superior de la Formación presenta una microflora asignable al Cisuraliano-Guadalupiano.

\section{Correlación local}

A nivel local se observa un patrón resultado de los cambios climáticas detallados por Limarino et al. (2013): en aquellas zonas protegidas (Bajo de Véliz, Sierra de los Llanos) las floras son más diversas que en los sitios coetáneos paleogeográficamente más expuestos y que sufren la aridización temprana (Andapaico inferior, La Colina inferior). Posteriormente 
continúa la aridización, que se refleja en las floras más empobrecidas de La Colina superior y Tasa Cuna.

Las dataciones en la Formación La Colina asignan a estas floras una edad asseliana: la base con una antigüedad de 298 a 301 Ma correspondiente a un basalto cercano a la base de Patquía (Césari et al., 2011) y los niveles cuspidales, 296,08 + 0,09 Ma obtenidos de tufas sobre arenitas eólicas (Gulbranson et al, 2010). Debe considerarse que las floras podrían haberse desarrollado a partir del Carbonífero superior, y que esto deberá ser precisado con dataciones que incluyan el sector de Sierra de los Llanos, Bajo de Véliz y Andapaico.

\section{V.4 Correlación con otras cuencas de Argentina}

Para las Cuencas de Río Blanco y Calingasta Uspallata se han descripto escasas tafofloras, siendo mayor el registro fosilífero de ambiente marino y de palinomorfos. En la Formación Cerro Agua Negra (Provincia de San Juan) se ha descripto una flora compuesta por elementos de la Zona NBG como Nothorhacopteris argentinica y Botrychiopsis weissiana, asociados a Paranocladus (?) fallax y Velizia sp. cf. Velizia inconstans. Esta asociación fue hallada en niveles localizados por encima de una fauna referida al Pérmico inferior. Se ha asignado tentativamente a la Biozona de Intervalo (Coturel et al., 2006).

La Formación El Imperial, de la Cuenca de San Rafael, es referida al lapso Carbonífero superior-Pérmico. Posee dos miembros, el inferior con elementos característicos de la Zona NBG, y el superior que contiene una flora con Gangamopteris obovata, Glossopteris cf. occidentalis, semillas de Cordaicarpus acuminatus, Cordaicarpus sp. y Paracalamites levis. Esta flora es comparable a la presente en Paganzo.

La Cuenca de Carapacha, en La Pampa, presenta dos asociaciones (Melchor y Césari, 1991, 1992, 1997). La más antigua, denominada ESR (Estancia San Roberto) presenta una 
asociación pobre, compuesta por Glossopteris wilsonii, $G$. cf. occidentalis, $G$. cf. angustifolia y $G$. argentina, junto a esfenófitas mal preservadas. Es correlacionada por su contenido con la Biozona de Gangamopteris, con el añadido de que, pese a presentar las especies de Glossopteridales de la Superzona de Ferugliocladus, no se han hallado otros taxones que sean característicos de ésta. La asociación más reciente, denominada CR (Río Curacó), es comparada con la Superzona de Dizengotheca de la Cuenca La Golondrina y con la Biozona de Glossopteris de Islas Malvinas.

La comparación más interesante surge con la Cuenca Tepuel Genoa. Esta cuenca presenta una mayor diversidad florística que las cuencas del centro-oeste. La Formación Mojón de Hierro, en su nivel superior presenta Asterotheca piatnizky, A. sp., Pecopteris sp., Sphenopteris sp., Glossopteris wilsonii, Gangamopteris sp., Eucerospermum cf. nitens y Paranocladus? sp. (Archangelsky y Cúneo, 1984; Cúneo, 1991). Fue referida a la Zona A por Andreis et. al. (1996). Para la Formación Río Genoa se ha descripto una asociación con mayor abundancia de helechos (Asterotheca spp.) y esfenófitas (en particular, variedad de Sphenophyllales, aunque también se registra Phyllotheca), presencia de licófitas (Bumbudendron millani, Brasilodendron pedroanum), Botrychiopsis valida, Nothorhacopteris chubutiana, Ferugliocladus patagonicum, y Glossopteridales, entre otras. La Formación Río Genoa es referida en su porción basal a la Zona de Nothorhacopteris chubutiana, y las localidades donde se desarrolla la parte superior poseen elementos de la Zona de Ginkgoites eximia, para la cual Cúneo (1987) sugirió una subdivisión en dos Subzonas (A y B). La A, caracterizada por la presencia de Asterotheca feruglioi, Genoites patagonica, Ferugliocladus sp., Stellotheca sp., Sphenopteris spp. y Alloiopteris sp. En la B, más moderna, aparecen Asterotheca golondrinensis, A. andersonii, y son exclusivos Annularia sp., Bumbudendron millani, Phyllotheca spp., y Sphenopteris spp. La composición taxonómica de la Formación Río Genoa es comparable a la de la Formación Arroyo Totoral por la presencia de taxones como Asterotheca feruglioi, Ferugliocladaceae, Gangamopteris obovata y Glossopteris wilsonii. Alloiopteris sp., taxón exclusivo de la Subzona A, es similar a Eusphenopteris sp. de Arroyo Totoral, y fue mencionado por Cúneo (1987) para la Fm. Solca. La descripción de Cruciaetheca patagónica y Genoites sp. en Arroyo Totoral sugiere la 
correlación entre la Zona de Gangamopteris (inferior) en Paganzo y la Zona de Ginkgoites eximia en Tepuel Genoa.

El Grupo Pillahuincó, de La Cuenca Sauce Grande-Colorado, presenta contenido paleoflorístico en las formaciones Bonete y Tunas, ambas con floras de edad pérmica. Para la Formación Bonete se ha descripto Gangamopteris obovata, G. angustifolia, Glossopteris indica, G. browniana, G. angustifolia, G. decipiens, G. communis, Ottokaria cf. bengalensis, Noeggerathiopsis hislopi, cf. Buriadia heterophylla, Cordaicarpus sp., y Phyllotheca sp. (Menéndez, 1996; el registro de 'Lanceolatus' bonariensis es discutido por McLoughlin, 2012). La Formación Tunas, que suprayace a la anterior, presenta Bumbudendron millani, Phyllotheca sp., Paracalamites levis, Glossopteris indica y Gangamopteris obovata (Menéndez, 1966).

La flora de la Formación Bonete se ha referido a la Zona de Glossopteris, por la dominancia de Glossopteris sobre Gangamopteris y la presencia de Ottokaria. La edad de la flora es discutida, pero estratigráficamente es más joven que la Zona de Gangamopteris.

La flora de la Cuenca de La Golondrina presenta una diversidad taxonómica mucho mayor respecto de las otras floras neopaleozoicas de Argentina. Recientemente, en su trabajo de Tesis, Cariglino (2011) ha sugerido la modificación del esquema bioestratigráfico para esta cuenca, especialmente por el hallazgo de megaflora en el Miembro Inferior de la Formación La Golondrina, donde dominaría Gangamopteris sobre Glossopteris y se registran formas de Asterotheca con pínnulas de pequeño tamaño. Las especies de glossopterídeas descriptas son diferentes a las halladas en Arroyo Totoral, y en La Golondrina aparecen licófitas y sphenophyllales ausentes en la flora de Arroyo Totoral. Se da una edad tentativa ArtinskianaRoadiana para la flora del Miembro Inferior. El resto de la secuencia alcanza el Pérmico superior, y posee mayor diversidad taxonómica (Archangelsky, 1959; Cariglino, 2011). 


\section{Correlación y edad de las Biozonas}

La Zona Gangamopteris se desarrolla en Paganzo, San Rafael y Carapacha (ESR). Las floras de las tres cuencas son correlacionables, y la variación taxonómica puede referirse a diferencias paleoambientales entre ellas.

La Zona Gangamopteris inferior presenta elementos que permiten correlacionarla con la Zona Ginkgoites eximia de la Cuenca Tepuel Genoa: la asociación de coníferas, Cruciaetheca patagonica, Genoites sp., sphenopterídeas de tipo Alloiopteris, la abundancia de Arberia como estructura reproductiva de Glossopteridal y la asociación de Glossopteris wilsonii y Gangamopteris obovata, que aunque generalizadas, son características del Cisuraliano. La edad acotada por dataciones de la Zona Gangamopteris en Paganzo, reflejable en un Piso Lubeckiano que abarcaría solo el Asseliano, y la correlación entre esta Zona y la Zona de Ginkgoites eximia, es sugerente respecto de que la extensión que alcanzaría en Tepuel-Genoa el Piso Lubeckiano sería también restringible al Asseliano, o a lo sumo Asseliano-Sakmariano inferior.

\section{IV.5 Comparación con otras floras pérmicas de Gondwana}

\section{- Uruguay}

El Pérmico en Uruguay está representado en las Formaciones Tres Islas, Melo y Yaguarí. En éstas es abundante el registro de xilofloras (Crisafulli 1995, 1998a, 1998b, 2001, 2002, 2003, Crisafulli y Lutz, 1995, 1997; Zamuner, 1996) pero también se han descripto tafofloras de impresiones-compresiones (Gutiérrez y Herbst, 1994; Herbst et al., 1992; Herbst 
y Gutiérrez, 1995). La Formación Melo es asignada a la Zona Gangamopteris, mientras que la Formación Yaguarí es referida a la Zona Glossopteris y al Pérmico Superior.

La Formación Melo presenta licófitas liguladas (Gutiérrez y Herbst, 1994), las cuales poseen una asignación abierta, pero con la combinación de Bumbudendron versiforme en un género que incluya especímenes con foseta ligular, este material sin dudas podrá ser referido a este taxón. Esto refuerza, asimismo, la referencia a la Zona de Gangamopteris.

\section{- Brasil}

La Cuenca de Paraná, de Brasil, representa la continuación geográfica de la Cuenca Chaco-Paranaense. Es intensamente estudiada desde hace 140 años por la presencia de carbones (“coal measures”). Dentro de esta Cuenca, la secuencia neopaleozoica está conformada por el Supergrupo Tubarao y el Supergrupo Passa Dois, el primero abarca el Carbonífero hasta el Cisuraliano, y el segundo, del Cisuraliano al Lopingiano. Del Supergrupo Tubarao, entran en consideración para la comparación los Grupos Itararé y Guatá.

Se han propuesto varios esquemas de biozonación en la Cuenca Paraná. GuerraSommer y Cazzulo-Kleipzig (1993) realizaron un esquema de biozonación para el Pérmico inferior del Estado de Río Grande do Sul, que comprende la Zona de Botrychiopsis plantiana con dos subzonas, Gangamopteris obovata la inferior y Phyllotheca australis la superior. Esta Zona se desarrolla en el Grupo Itararé. Por encima de ésta, en la Formación Río Bonito, describen la zona de Glossopteris/Rhodeopteridium.

La Zona de Botrychiopsis plantiana se caracteriza por la abundancia local de Botrychiopsis plantiana, y porque ocurre la primera aparición de las glossopteridales, grupo en el que dominan las hojas de tipo Gangamopteris por sobre las de Glossopteris. Además de estos grupos, destaca la presencia de esfenópsidas y cordaitales. Las coníferas y ginkgoales son raras (Iannuzzi 
et al., 2010a). El límite inferior de la zona está determinado por la primera aparición de glossopteridales.

La Zona de Botrychiopsis plantiana se halla dividida en dos subzonas. La subzona inferior, denominada "Subzona de Gangamopteris obovata" posee como especies diagnósticas a Cornucarpus patagonicus y Cordaicarpus truncata (Iannuzzi et al. 2010a). La subzona superior, de Phyllotheca australis, está definida por la aparición de P. australis y Stephanophyllites sp. cf. S. sanpaulensis, Cheirophyllum speculare, Kawizophyllum sp., Glossopteris occidentalis, Samaropsis kurtzii, Samaropsis gigas.

La Subzona de Gangamopteris obovata fue inicialmente definida para la parte superior del Grupo Itararé, mientras que la Subzona de Phyllotheca australis lo fue para la parte basal de la Formación Río Bonito. Iannuzzi et al (2003a, b; 2006; 2010) en cambio ubican a ambas subzonas en la parte superior del Grupo Itararé.

La Zona de Glossopteris/Rhodeopteridium se caracteriza por presentar una mayor proporción de formas de Glossopteris sobre Gangamopteris, y aparecen como elementos acompañantes licófitas (Brasilodendron pedroanum, Cyclodendron sp.), helechos (Asterotheca sp., Pecopteris sp., Sphenopteris sp. Neomariopteris sp.), otras formas de pteridospermas (Botrychiopsis valida, aunque se mantiene el registro de B. plantiana), ginkgoales (Ginkgophytopsis sp.), coníferas (Coricladus quiterensis) y se amplía el registro de estructuras reproductivas de glossopteridales, con la aparición de especies de Arberia y Ottokaria. Estas asociaciones denotan una gran diversidad, suelen estar asociadas a los mantos de carbón, y forman parte de la "Flora de Glossopteris".

Iannuzzi y Souza (2005) propusieron para la Cuenca de Paraná el desarrollo de tres floras. De ellas, la Flora de Phyllotheca-Gangamopteris comprende asociaciones donde dominan las hojas de tipo Gangamopteris por sobre las de Glossopteris y aparecen varios grupos de esfenofitas, donde las más recurrentes son aquellas de tipo Phyllotheca. Esta flora es comparable con la zona de B. plantiana y caracteriza al Grupo Itararé. La flora de BrasilodendronGlossopteris caracteriza a la Formación Río Bonito. Las licófitas aparecen desde la base de esta 
Formación, mientras que Glossopteris incrementa su proporción en relación a Gangamopteris a lo largo de ésta. Aparecen también helechos pecopterídeos y esfenopterídeos. Todos estos indican un mejoramiento climático respecto de la flora anterior.

Iannuzzi (2010) presenta un esquema donde se observa la sucesión florística presente en la Formación Río Bonito, en las localidades de São João do Triunfo, Figueira, Quitéria, Morro do Papaléo e Irapuá (Tabla 1, Iannuzzi 2010). Hace un recuento de las especies presentes y establece un esquema de asociaciones tafonómicas (Tabla 2, pp. 12) para la sucesión florística. De éstas, la flora que presenta mayor similitud taxonómica con Paganzo es la de Quitéria, especialmente por la presencia de estructuras reproductivas de Glossopteridales similares (Arberia spp., Ottokaria spp.).

La edad del Grupo Itararé es debatida. Las dataciones radimétricas le dan una edad Pennsylvaniana, la cual es discutida por el contenido fosilífero (Holtz et al., 2010; Iannuzzi, 2010). En el esquema definido por Holtz et al (2010), el Grupo Itararé llega al Sakmariano más bajo, mientras que la Formación Río Bonito tiene una edad Sakmariano medioArtinskiano medio. Simas et al. (2012) presentan una calibración de la bioestratigrafía y determinan que los principales niveles de carbón tiene una edad media de $291 \pm 1,3 \mathrm{Ma}$. Estos están dentro de la Zona de Asociación de Glossopteris/Rhodopteridium, del Sakmariano inferiormedio a Artinskiano inferior, y la Zona de Botrychiopsis plantiana se desarrolla del Asseliano medio hasta la parte baja del Sakmariano.

De lo anterior se puede resumir que la flora de Paganzo es similar, aunque empobrecida, respecto de la flora de Paraná. La comparación con la flora de Brasil debe hacerse considerando las diferencias paleogeográficas. La Cuenca Paraná es una cuenca de intraplaca, de vertiente oriental, mientras que la Cuenca Paganzo es una cuenca de antepaís localizada en el margen occidental. Esto promueve diferencias en la tasa de subsidencia, el magmatismo y los movimientos tectónicos: las cuencas de intraplaca son más estables y presentan un registro continuo, como es el caso de la Cuenca Paraná, que puede ser dividida en seis supersecuencias que abarcan desde el Ordovícico hasta el Cretácico. La Supersecuencia Gondwánica (en la 
secuencia denominada Gondwana I, Milani et.al.1988) inicia su subsidencia en el Pennsylvaniano y llega al Pérmico, e incluye dos Supergrupos: Tubarão y Passa Dois. Durante el Pennsylvaniano se depositaron diamictitas glaciales y lutitas marinas (Subgrupo Itararé), mientras que en el Pérmico temprano estas secuencias fueron reemplazadas por sedimentos fluviales y de estuario, que incluyen además mantos de carbón (Formaciones Río Bonito y Palermo, Grupo Guatá) (Limarino et. al. 2013). La edad del cambio en la depositación (el pasaje entre Itararé y Rio Bonito) es discutida: algunos autores sugieren que es coincidente con el límite Carbonífero-Pérmico (Guerra Sommer et al, 2008a, b), mientras otros autores lo hacen llegar al Sakmariano (Jasper et. al., 2003; Ianuzzi, 2010). Este cambio en la depositación está ligado a un cambio climático en la cuenca.

Si se hace una comparación entre las biozonas propuestas para Paraná y la composición florística de Arroyo Totoral, ésta es comparable con:

1) La Subzona de Botrychiopsis plantiana, dentro de la Zona de Botrychiopsis propuesta por Jasper (2007), que comprende el Grupo Itararé y el sector inferior de la Formación Río Bonito.

2) La Zona de Phyllotheca-Gangamopteris propuesta por Ianuzzi y Guerra-Sommer (2005), que caracteriza al Grupo Itararé.

3) La flora de Quitéira (Formación Río Bonito), ubicada en la Zona BrasilodendronGlossopteris (Ianuzzi y Guerra-Sommer, 2005), principalmente por la presencia de estructuras reproductivas de glossopteridales asociadas a Botrychiopsis plantiana y helechos.

Si no se considera como techo la datación en La Colina (Gulbranson et al. 2010), por comparación con la flora de Brasil la Zona Gangamopteris puede abarcar hasta el Sakmariano inferior a medio, 


\section{- Sudáfrica, India, Australia y Antártida.}

Las floras descriptas para el Pérmico inferior en los otros continentes que conformaban Gondwana poseen una diversidad taxonómica mucho mayor respecto de la presente en la Formación Arroyo Totoral. Asimismo, la composición específica de los géneros compartidos es diferente. Se realiza entonces una comparación general con dichas floras.

\section{- Sudáfricica}

El Pérmico inferior sudafricano (Grupo Ecca, Formación Vryheid) contiene una megaflora donde se presentan licófitas arborescentes (Cyclodendron), helechos de la Familia Asterothecaceae, y entre las esfenofitas destacan las Sphenophyllales. Las hojas de Glossopteris son más diversas que las de Gangamopteris, con especies distintas a las presentes en Arroyo Totoral. En cuanto a las estructuras reproductivas, se han hallado especies de Arberia y Ottokaria (ver Addendorf, 2005, pág. 330). Se asigna a esta Formación edad ArtinskianaKunguriana (Catuneanu et.al. 2005). Arberia sp. descripta para Arroyo Totoral es una forma similar a Arberia madagascariensis, hallada en la localidad de Hammanskral.

\section{- India}

El Pérmico inferior en India se desarrolla en el denominado "Lower Gondwana", en las secuencias de Talchir (inferior y superior), Karharbari y Barakar (inferior y superior). En ellas se observa el dominio y declinación de Gangamopteris en contraste de la aparición y diversificación de Glossopteris, que domina en las asociaciones del Pérmico medio a superior. Srivastava (2010) señala que Gangamopteris se registra desde la secuencia superior de Talchir hasta la secuencia inferior de Barakar inclusive, y que su asociación con Noeggerathiopsis indica la presencia de la Flora de Karharbari. Respecto de Barakar, comprendería una secuencia transicional entre las floras de Gangamopteris y Glossopteris, donde la secuencia de Barakar (inferior) contiene Noeggerathiopsis, Gangamopteris, Euryphyllum y Buriadia, que son comunes en la flora de Karharbari, mientras que la secuencia de Barakar superior presenta directamente hojas de Glossopteris asociadas a helechos. Considerando la cuestión taxonómica 
Noeggerathiopsis/Cordaites, y la menor diversidad de taxones, en sus rasgos generales, la Formación Arroyo Totoral es comparable con la Flora de Karharbari, presente en la secuencia homónima y en la secuencia inferior de Barakar.

\section{- Australia}

Las floras del Pérmico inferior son conocidas de las cuencas de Collie, Perth, Tasmania, Sydney y Bowen, y de afloramientos en Victoria. En ellos se puede observar cómo las Glossopteridales, acompañadas de esfenófitas, colonizaron los ambientes que quedaron habitables después del último máximo glacial del Neopaleozoico (durante el límite Carbonífero-Pérmico). El registro de palinofloras comienza en el Sakmariano, junto con algunas asociaciones florísticas, que se extienden hasta el Artinskiano (Briggs, 1998; Warne et al. 2003; McCoy, 1875; Rigby \& Chandra, 1990, Rigby 1966, 1993, Rigby et al. 1988). Las floras del Pérmico medio a superior son más diversas, debido al mejoramiento climático.

\section{- Antártidla}

La flora del Pérmico de Antártida estuvo condicionada en su desarrollo a la posición geográfica del continente, a través del cual se desplazó el polo magnético, y que durante este período sufrió el emplazamiento de cuatro eventos de glaciación, cada vez más breves. El primero ocurrió durante el Asseliano hasta el Sakmariano inferior; el segundo, desde el Sakmariano más alto hasta el Artinskiano más bajo; el tercero entre el Kunguriano y el Roadiano, y la cuarta glaciación, entre el Wordiano y el Capitaniano (Cantrill y Poole, 2012, Figura 3.3). Para el Pérmico inferior existen registros de Lycopodiopsis pedroanus, Paracalamites australis, Buriadia heterophylla y cf. Walkomiella transvaalensis, pero la mayor diversidad observada se halla dentro de las Glossopteridales, con Gangamopteris cf. G. angustifolia, G. cf. G. douglasii, G. cf. G. obovata, Glossopteris angustifolia, G. cf. G. communis, G. cf. G. conspicua, dentro de los tipos foliares; se hallaron estructuras reproductivas: Eretmonia?, Plumsteadia ovata, y semillas del tipo Samaropsis. Además, raíces correspondientes al género Vertebraria. La 
mayor diversificación, sin embargo, ocurre en el Pérmico superior, con el mejoramiento de las condiciones ambientales (Cantrill y Poole, 2012).

\section{6 Conclusiones}

La Formación Arroyo Totoral posee una flora que permite incluirla en la Zona Gangamopteris, definida para el Cisuraliano de las cuencas del Centro-Oeste de Argentina.

La flora descripta permite correlacionar a la Zona Gangamopteris con la Zona Ginkgoites eximia (Superzona Ferugliocladus) de la Cuenca Tepuel Genoa.

La presencia de licófitas liguladas permite correlacionar a la Formación Arroyo Totoral con la Formación Melo de Uruguay, referida también a la Zona Gangamopteris.

La flora de Arroyo Totoral es comparable con la Flora de Quitéira, en Brasil, especialmente por las estructuras reproductivas de glossopteridales presentes. El resto de los taxones la asemeja también a floras de edad más antigua.

Las dataciones en Paganzo dan una edad asseliana para la Zona Gangamopteris. La comparación con la flora en Brasil sugiere una extensión hasta el Sakmariano medio. Por estas dos referencias, el Piso Lubeckiano, para Paganzo, comprendería Asseliano o Asseliano a Sakmariano medio. La correlación con Tepuel Genoa restringiría al Piso Lubeckiano en esta Cuenca para la misma edad que en Paganzo. 
Eliana Paula Coturel - Bioestratigrafía del Pérmico de la SierRa de los llanos...

\begin{tabular}{|c|c|c|c|c|c|c|}
\hline & Arroyo Totoral & Solca & Bajo de Véliz & Tasa Cuna & La Colina & Andapaico \\
\hline Licófitas & & $\begin{array}{l}\text { Bumbudendron } \\
\text { versiforme } \\
\text { Brasilodendron sp. }\end{array}$ & Sanluisia casasii & & & \\
\hline Equisetales & $\begin{array}{l}\text { Paracalamites } \\
\text { australis } \\
\text { Paracalamites } \\
\text { frigidus } \\
\text { Phyllotheca } \\
\text { leptophylla } \\
\text { Cruciaetheca } \\
\text { patagonica }\end{array}$ & $\begin{array}{l}\text { Paracalamites } \\
\text { australis }\end{array}$ & $\begin{array}{l}\text { Stephanophyllites } \\
\text { sanpaulensis }\end{array}$ & $\begin{array}{l}\text { Paracalamites } \\
\text { australis }\end{array}$ & $\begin{array}{l}\text { Paracalamites } \\
\text { australis }\end{array}$ & \\
\hline Helechos & $\begin{array}{l}\text { Asterotheca } \\
\text { feruglioi } \\
\text { Asterotheca sp. }\end{array}$ & & & $\begin{array}{l}\text { Pecopteris } \\
\text { andersonii } \\
\text { Pecopteris } s p .\end{array}$ & & \\
\hline $\begin{array}{l}\text { Pteridospermas } \\
\text { incertae sedis }\end{array}$ & $\begin{array}{l}\text { Botrychiopsis } \\
\text { plantiana } \\
\text { Eusphenopteris } \\
\text { sp. }\end{array}$ & Eusphenopteris $s p$. & $\begin{array}{l}\text { Botrychiopsis } \\
\text { plantiana }\end{array}$ & Sphenopteris sp. & & \\
\hline Glossopteridales & $\begin{array}{l}\text { Gangamopteris } \\
\text { obovata } \\
\text { Glossopteris } \\
\text { wilsonii } \\
\text { Glossopteris } \\
\text { occidentalis } \\
\text { Arberia cf. } \\
\text { minasica } \\
\text { Arberia cf } \\
\text { madagascariensis } \\
\text { Ottokaria sp. }\end{array}$ & & $\begin{array}{l}\text { Euryphyllum } \\
\text { whittianum } \\
\text { Gangamopteris } \\
\text { obovata } \\
\text { Glossopteris } \\
\text { wilsonii }\end{array}$ & $\begin{array}{l}\text { Gangamopteris } \\
\text { angustifolia } \\
\text { Gangamopteris } \\
\text { buriadica } \\
\text { Glossopteris } \\
\text { spathulo-cordata }\end{array}$ & $\begin{array}{l}\text { Euryphyllum } \\
\text { whittianum } \\
\text { Gangamopteris } \\
\text { buriadica } \\
\text { Gangamopteris } \\
\text { obovata } \\
\text { Glossopteris cf. } \\
\text { occidentalis } \\
\text { Glossopteris } \\
\text { wilsonii }\end{array}$ & \\
\hline Cordaitales & $\begin{array}{l}\text { Cordaites hislopi } \\
\text { Cordaitanthus? } \\
\text { sp. }\end{array}$ & $\begin{array}{l}\text { Cordaites sp. } \\
\text { Cordaites hislopi }\end{array}$ & $\begin{array}{l}\text { Cordaites bifolius } \\
\text { Cordaites hislopi } \\
\text { Cordaitanthus sp. } \\
1 \\
\text { Cordaitanthus? sp. } \\
2\end{array}$ & Cordaites hislopi & $\begin{array}{l}\text { Cordaites } \\
\text { spathulata }\end{array}$ & \\
\hline
\end{tabular}


Eliana Paula Coturel - Bioestratigrafía del Pérmico de la SierRa de los llanos...

\begin{tabular}{|c|c|c|c|c|c|c|}
\hline Ginkgoales? & Ginkgophyllum sp. & $\begin{array}{l}\text { Ginkgophyllum } \\
\text { diazii }\end{array}$ & Velizia inconstans & & & \\
\hline $\begin{array}{l}\text { Coniferopsida } \\
\text { Ferugliocladaceae }\end{array}$ & $\begin{array}{l}\text { Paranocladus? } \\
\text { fallax } \\
\text { Ferugliocladus } \\
\text { riojanum }\end{array}$ & $\begin{array}{l}\text { Krauselcladus } \\
\text { argentinus } \\
\text { Paranocladus? } \\
\text { fallax }\end{array}$ & $\begin{array}{l}\text { Paranocladus? } \\
\text { fallax }\end{array}$ & $\begin{array}{l}\text { Paranocladus? } \\
\text { fallax }\end{array}$ & & $\begin{array}{l}\text { Ferugliocladus } \\
\text { patagonicus }\end{array}$ \\
\hline Buriadiaceae & & & & & & \\
\hline Semillas & $\begin{array}{l}\text { Samaropsis sp. } \\
\text { Cordaicarpus sp. } \\
\text { Eucerospermum } \\
\text { nitens }\end{array}$ & $\begin{array}{l}\text { Cordaicarpus } \\
\text { acuminatus } \\
\text { Cordaicarpus } \\
\text { cesariae } \\
\text { Cordaicarpus sp. } \\
\text { Samaropsis } \\
\text { nunezii } \\
\text { Eucerospermum } \\
\text { nitens }\end{array}$ & $\begin{array}{l}\text { Samaropsis kurtzii } \\
\text { Samaropsis sp. }\end{array}$ & $\begin{array}{l}\text { Samaropsis kurtzii } \\
\text { Samaropsis sp. }\end{array}$ & Samaropsis sp. & $\begin{array}{l}\text { Samaropsis } \\
\text { nunezi } \\
\text { Samaropsis } \\
\text { cuerdai } \\
\text { Cordaicarpus } \\
\text { cesariae } \\
\text { Cordaites riojanus } \\
\text { Eucerospermum } \\
\text { nitens }\end{array}$ \\
\hline Leños & & $\begin{array}{l}\text { Agathoxylon } \\
\text { kumarpurensis } \\
\text { Agathoxylon } \\
\text { ningahense } \\
\text { Podocarpoxylon } \\
\text { indicum } \\
\text { Chapmanoxylon } \\
\text { jamuriense } \\
\text { Chapmanoxylon } \\
\text { oltaense }\end{array}$ & & & & \\
\hline
\end{tabular}

Cuadro V.a. Formaciones de la Cuenca Paganzo y sus plantas fósiles. 
Eliana Paula Coturel - Bioestratigrafía del Pérmico de la Sierra de los llanos...

\section{CAPÍTULO VI. CONCLUSIONES}




\section{Conclusiones generales}

1. Se realizaron dos viajes de campo, donde se localizaron las localidades previas y se idenfiticaron nuevas localidades. El trabajo realizado en el campo permitió hallar nueve niveles fosilíferos repartidos en cinco localidades, tres de los cuales permitieron la correlación de los perfiles entre ellas y de éstas con el perfil tipo. Este tipo de integración de los perfiles, sumado a las paleocomunidades descriptas permitieron discernir la evolución de la flora dentro de la Formación Arroyo Totoral, en comparación con trabajos previamente publicados.

2. El estudio sistemático de la flora permitió identificar 21 taxones. A nivel genérico, se presenta el primer registro para la Formación Arroyo Totoral y la Cuenca Paganzo de Cruciaetheca Cúneo y Escapa. A nivel específico, es la primera mención de Paracalamites cf. frigidus, Cruciaetheca patagónica y Arberia cf. madagascariensis para la zona de Anzulón. Se halló material que resultará en nuevos taxones, dentro de Asterothecaceae, Glossopteridales y Ferugliocladaceae. De los estudios realizados surge la necesidad de la revisión de las licófitas asignadas al género Bumbudendron.

3. El estudio paleoecológico local permitió discriminar 9 paleocomunidades, las cuales se desarrollaron a lo largo de la evolución del sistema fluvio-lacustre que caracteriza a la Formación Arroyo Totoral, y permiten ubicar a esta Formación dentro del contexto paleoclimático de la Cuenca Paganzo.

4. Se desarrolla un análisis de agrupación basado en la morfografía del género Glossopteris. Se presenta una variante para la descripción de las venas secundarias, cuantificando su recorrido a través de una función polinómica. Sobre ésta, se realiza un cluster analysis y se lograron caracterizar varios grupos morfológicos. Se abre la discusión sobre la posibilidad de empezar a usar esta metodología para clasificar morfotipos dentro de Glossopteris.

5. En el análisis bioestratigráfico, se verifica que la megaflora de la Formación Arroyo Totoral responde al mismo esquema que el resto de la Cuenca Paganzo, ubicándose dentro de la Zona Gangamopteris, reconociéndose que los cambios a lo largo de esta Zona se 
Eliana Paula Coturel - Bioestratigrafía del Pérmico de la Sierra de los llanos...

producen por la evolución climática que ocurrió en la Cuenca Paganzo. El hallazgo de nuevos taxones permitió una correlación directa con la Cuenca Tepuel Genoa, que podría ajustar la edad para esta segunda cuenca. Las dataciones locales y la correlación con la Cuenca Paraná en Brasil permiten restringir a la Zona Gangamopteris a una edad Asseliana o AsselianaSakmariana. 


\section{Bibliografía}

Adendorff, R., 2005. A revision of the ovuliferous fructifications of glossopterids from the Permian of South Africa. Ph.D. Thesis, University of the Witwatersrand, Johannesburg, 421 pp.

Álvarez, L. y Fernández Seveso, F. 1987. Estratigrafía del cerro Horcobola: su importancia como elemento de correlación, nueva localidad fosilífera del Pérmico inferior en la Argentina. X Congreso Geológico Argentino, tomo 3: 121-124

Anderson, J.M., Anderson, H.M., 1985. Palaeoflora of southern Africa. Prodromus of South African megafloras: Devonian to Lower Cretaceous. Rotterdam: A.A. Balkema, 423 pp.

Andreis, R., Leguizamón, R. y Archangelsky, S. 1986. El paleovalle de Malanzán: nuevos criterios para la estratigrafía del Neopaleozoico de la Sierra de Los Llanos, La Rioja, República Argentina. Boletín de la Academia Nacional de Ciencias, 57(1-2): 3-119. Córdoba.

Andreis, R., Cúneo, R., Rolón, A. D. 1984. Definición formal de los estratos de Arroyo Totoral, Pérmico inferior, Sierra de Los Llanos, provincia de La Rioja. Actas del Noveno Congreso Geológico Argentino, tomo 5: 209-229. San Carlos de Bariloche.

Andreis, R.R., Archangelsky, S., 1996. The Neo-Paleozoic Basins of southern South America. En: Moullade, M., Nairn, A.E.M., (Eds.), The Phanerozoic Geology of the World, The Paleozoic, B. Chapter 5, pp. 341-650. Elsevier, Amsterdam.

Archangelsky, A., 1999. Semillas del Paleozoico Superior de Argentina; su utilización bioestratigráfica. Ameghiniana 36, 465-476.

Archangelsky, A., 2000. Estudio sobre semillas neopaleozoicas de Argentina. Boletín Academia Nacional Ciencias 64, 79-115. 
Archangelsky, S. 1958. Estudio geológico y paleontológico del Bajo de la Leona (Santa Cruz). Acta Geológica Lilloana 2: 5-133.

Archangelsky S., 1971. Las tafofloras del Sistema Paganzo en la República Argentina. Anais da Academia Brasileira de Ciençias 43 (Suplemento): 67-88. Río de Janeiro.

Archangelsky, S. 1979. Paleoecología del Paleozoico Superior argentino sobre la base de sus plantas fósiles. Ameghiniana 15(1-2) [1978]: 73-84. Buenos Aires.

Archangelsky, S. (ed.). 1987. El Sistema Carbonífero en la República Argentina. Academia Nacional de Ciencias (Córdoba), 383 pp.

Archangelsky, S., (ed.). 1996. El Sistema Pérmico en la República Argentina y en la República Oriental del Uruguay, Academia Nacional de Ciencias (Córdoba), 431 pp.

Archangelsky, S. y O.G. Arrondo. 1971a. Palaeophytología Kurtziana. III. 1. Notas sobre los vegetales carbónicos y pérmicos de la Colección Kurtz. Ameghiniana 8(3-4): 181-188. Buenos Aires.

Archangelsky, S. y O.G. Arrondo. 1971b. Palaeophytología Kurtziana. III. 2. Estudio sobre el género Botrychiopsis Kurtz (=Gondwanidium Gothan) del Carbónico y Pérmico gondwánico. Ameghiniana 8(3-4): 189-227. Buenos Aires.

Archangelsky, S. y O.G. Arrondo. 1973. Palaeophytologia Kurtziana III. 10. La Tafoflora Pérmica de Sierra de Los Llanos, Provincia de La Rioja. Ameghiniana 10(3):201-228

Archangelsky, S. y Cúneo R. 1984. Conos femeninos y masculinos de coníferas hallados en conexión orgánica con ramas en el Pérmico Inferior de Chubut. In: Actas del III Congreso Argentino de Paleontología y Bioestratigrafía. Corrientes, 6-10/10/1982.

Archangelsky S. y Cúneo N.R., 1984. Zonación del Pérmico continental de Argentina sobre la base de sus plantas fósiles. $3^{\circ}$ Congreso Latinoamericano de Paleontología (México), Memorias: 143-154. 
Archangelsky, S. y Cúneo, N.R. 1987. Ferugliocladaceae, a new conifer family from the Permian of Gondwana. Review of Palaeobotany and Palynology. Vol. 51, nº1-3, pp. 3-30

Archangelsky, S. y Cúneo, N.R. 1991. The neopaleozoic succession from northwestern Argentina. A new perspective. In: H. Ulbrich \& A.C. Rocha Campos (eds), Gondwana Seven Proceedings, apers presented at the Seventh International Gondwana Symposium, Instituto de Geoçiências, Universidade de Sâo Paulo, pp. 469-481.

Archangelsky, S., Archangelsky, A. y Cúneo,R. 1981. Algunos elementos paleoflorísticos de las Fs. Piedra Shotel y Nueva Lubecka, Pérmico inferior, Estancia La Casilda, Provincia de Chubut. Ameghiniana 18 (3-4): 207-220.

Archangelsky S., Césari S.N. y Cúneo N.R., 1999. Revisión de Asterotheca golondrinensis Herbst, helecho pérmico de Patagonia, Argentina. Asociación Paleontológica Argentina, Publicación Especial 6: 23-26. Buenos Aires.

Archangelsky, S., Azcuy C.L., Césari, S.N., González, C.R., Hünicken, M.A., Mazzoni A. y

Sabattini, N., 1996a. Correlación y edad de las biozonas. En: Archangelsky (S.), ed., El Sistema Pérmico en la República Argentina y en la República Oriental del Uruguay, Academia Nacional de Ciencias, pp. 203-226. Córdoba.

Archangelsky, S., González, C.R., Cúneo (N.R Sabattini, N., Césari, S.N, Aceñolaza F.G., García G.B., Buatois L.A., Ottone E.G., Mazzoni A., Hünicken M.A. y Gutiérrez P.R., 1996b. Paleontología, bioestratigrafía y paleoecología de las Cuencas Paganzo, Calingasta-Uspallata, Río Blanco y San Rafael. En: Archangelsky (S.), ed., El Sistema Pérmico en la República Argentina y en la República Oriental del Uruguay, Academia Nacional de Ciencias, pp. 177-201. Córdoba.

Austin, L., Escapa, I. \& Cúneo R. Revisión de elementos paleoflorísticos de la Formación Arroyo Totoral (Pérmico Inferior), Provincia de La Rioja, Argentina. In: V Simposio Argentino del Paleozoico Superior. Resúmenes. Buenos Aires, 2008. P. 1. 
Azcuy C.L. 1975. Consideraciones sobre el Carbónico y Pérmico en las Sierras de los Llanos y Malanzán. Rev. Asoc. Geológica Argentina, 30(3): 291-293

Azcuy C.L. y Morelli J.R., 1970. 7. The Paganzo Basin. Tectonic and sedimentary characateristics of the Gondwana sequences in Northwestern Argentina. Proceedings $2^{\circ}$ Gondwana Symposium (Pretoria), Proceeding and Papers, pp. 241-247.

Barreda, V.D. 1986. Palinología de la Formación El Trampeadero, Paleozoico Superior, Provincia de La Rioja. In: IV Congreso Argentino de Paleontología y Bioestratigrafía.. Actas 1. Mendoza, 1986.

Barreda, V.D. Nuevas localidades plantíferas del Paleozoico superior en la Sierra de Los Llanos, inmediaciones de Olta, provincia de La Rioja. 5o Simposio Argentino de Paleobotánica y Palinología 6-7.

Barreda, V.D. y Césari S.N. 1995. Glossopteridales y estructuras reproductivas asociadas en el Flanco Oriental de la Sierra de Los Llanos (Pérmico), prov. de La Rioja, Argentina. In: VI Congreso Argentino de Paleontología y Bioestratigrafía. Actas, Trelew 1994, p. 39-46.

Barreda, V.D., Bellosi, E.S. y Jalfin, G. 1984. La sedimentación aluvial neopaleozoica en el flanco oriental de la sierra de los Llanos, La Rioja. Argentina. In: Late Paleozoic of South America annual meeting of the working group, Abstracts, Bariloche, p. 44-45.

Barreda, V.D.; Bellosi, E.S. y Jalfin, G. 1985. Facies y sedimentación lacustres en el Carbónico Superior de la sierra de Ambato, Catamarca. Late paleozoic of south america, encuentro anual del grupo argentino de trabajo, Comunicaciones, Buenos Aires, p. 22-23.

Bernardes de Oliveira, M.E.C., 1977. Frutificaçôes de pteridospermófitas eogondvânicas da camada Irapuá, Formação Rio Bonito, nos arredores de Criciúma, SC. En: Anais do Congresso Brasileiro de Geologia, 2, 986-1001.

Bodenbender, G. 1896. Sobre la edad de algunas formaciones carboníferas de la República Argentina. Revista del Museo de La Plata 7: 131-148. Córdoba. 
Bodenbender, G. 1897. Devono y Gondwana en la República Argentina. Las formaciones sedimentarias de la parte noroeste. Boletín de la Academia Nacional de Ciencias 15: 201-252. Córdoba.

Bodenbender, G. 1911. Constitución geológica de la parte meridional de La Rioja y Regiones limítrofes. Boletín de la Academia Nacional de Ciencias, ,19: 1-221 Córdoba

Boureau, E. 1964. Traité de Paléobotanique, 3. Sphenophyta, Noeggerathiophyta. Masson et Cie, París, 544 pp.

Bracaccini, O. 1946. Los estratos de Paganzo y sus niveles plantíferos en la Sierra de Los Llanos (provincia de La Rioja). Asoc. Geol. Arg. Rev.1:19-61.

Bracaccini, O. 1948. Sobre la presencia del Carbonífero Inferior de la Sierra de los Llanos. Bol.Inf.Petrol.Y.P.F. 281:63-69.

Cabrera, A.L. 1971. Fitogeografía de la República Argentina. Boletín de la Sociedad Argentina de Botánica XIV 1-2

Caminos 1979. Descripción geológica de las Hojas 21f, Sierra de las Minas y 21g, Ulapes. Provincias de La Rioja, Córdoba, San Juan y San Luis. Servicio Geológico Nacional, Boletín 172, 56 p. Buenos Aires.

Cantrill, D. y Poole, I. 2012, The Vegetation of Antarctica Through Geological Time. Cambridge University Press

Cariglino, B., 2012. El Pérmico de la Cuenca La Golondrina: paleobotánica, bioestratigrafía y consideraciones paleoecológicas. Tesis doctoral (no publicada).

Césari, S.N. 1987. Estudio sistemático de las plantas fósiles de la Formación La Colina (Paleozoico Superior), provincia de La Rioja. Anales Academia Nacional de Ciencias Exactas, Físicas y Naturales 39:179-194. Buenos Aires 
Césari, S.N. y Hünicken, M. 1991. Stephanophyllites sanpaulensis Millan y Dolianiti, un nuevo integrtante de las floras neopaleozoicas de la Argentina. Academia Nacional de Ciencias, Miscellaneas 83, 9 pp. Córdoba.

Césari, S.N. y Hünicken, M. 2013. Heterophylly in Cordaites-like foliage from western Gondwana. Review of Palaeobotany and Palinology, vol. 196 p. $9-18$

Césari, S.N., Gutiérrez, P.R., y Hünicken, M. 1995. Un nuevo género de licofita de la Formación Bajo de Véliz (Paleozoico Superior), provincia de San Luis, Argentina. Ameghiniana 32(4): 359-364. Buenos Aires.

Césari, S.N., Limarino, C.O. y Gulbranson, E.. 2013. An Upper Paleozoic biochronostratigraphic scheme for the western margin of Gondwana. Earth-Science Reviews 106: $149-160 \mathrm{C}$

Chandra, S., Surange, K.R., 1979. Revision of the Indian species of Glossopteris. Birbal Sahni Institute of Palaeobotany Monograph 2, pp. 291. Lucknow, India.

Correa, G. A, Carrevedo, M.L, y Gutiérrez, P.R. 2012. Paleoambiente y paleontología de la Formación Andapaico (Paleozoico superior, Precordillera Central, Argentina). Andean geology, $39(1), 22-52$

Coturel, E.P., Gutiérrez, P.R. y Barreda, V.D. 2009. Megaflora del Pennsylvaniano de la sierra de Los Llanos, La Rioja, Argentina. Revista Brasileira de Paleontologia, vol. 12, 2009, p.17-26

Crisafulli, A. 1995. Idioxylon lutzii nov. Gen et sp (Coniferopsida del Pérmico Inferior (Formación Melo) de Uruguay. Actas del VI Congreso Argentino de Paleontología y Bioestratigrafía: 91- 97 .

Crisafulli, A. 1998a. Leños gimnospérmicos de la Formación Melo (Pérmico Inferior) Uruguay. Parte II: Stiloxylon,Polysolenoxylon y Bageopitys. Ameghiniana: 35: 133-140. 
Crisafulli, A. 1998b. Leños gimnospérmicos de la Formación Melo (Pérmico Inferior) Uruguay. Parte III: Paulistoxylon, Austroscleromedulloxylon, Piracicaboxylon. Ameghiniana, 35: 217-225.

Crisafulli, A. 2001. Leños pérmicos de la Formación Yaguarí (Pérmico Superior) Uruguay. Ameghiniana 38: 61-72.

Crisafulli, A. 2002. Contribución a la paleoxiloflora de la Formación Yaguarí, Pérmico Superior de Uruguay. Revista del Museo Argentino de Ciencias Naturales, ns 4: 45-54.

Crisafulli, A. 2003. Nuevos registros para la xilotafoflora de la Formación Yaguarí, Pérmico Superior de Uruguay, Revista del Museo Argentino de Ciencias Naturales, ns. 5: 169-180.

Crisafulli, A. y Herbst, R. 2008. Maderas gimnospérmicas de la Formación Solca (Pérmico Inferior), provincia de La Rioja, Argentina: Ameghiniana, v. 45, p. 737-752

Crisafulli, A. y Lutz, A. 1995. Taxopitys uruguaya nov. sp. (Coniferopsida, Taxales) del Pérmico de Uruguay, Argentina. Ameghinana 32: 391-399.

Crisafulli, A. y Lutz, A. 1997. Leños gimnospérmicos de la Formación Melo (Pérmico Inferior) Uruguay. Parte I: Barakaroxylon Surange y Maithy ,1961 y Araucarioxylon Kraus 1870. Ameghiniana, 34: 437-445

Cuerda, A. 1996. Introducción: El Pérmico en la República Argentina. Desarrollo de su conocimiento histórico. In: S. Archangelsky (ed.), El Sistema Pérmico en la República Argentina y en la República Oriental del Uruguay. Academia Nacional de Ciencias, p. 3-18.

Cúneo 1984. Primeros resultados fitopaleoecológicos de la Formación Arroyo Totoral, Pérmico inferior, La Rioja. 9º Congreso Geológico Argentino (San Carlos de Bariloche), Actas 4: 318336.

Cúneo, N.R., 1987. Fitopaleoecología de la Formación Río Genoa en la localidad Lomas Chatas, Pérmico de Chubut, Argentina. Ameghiniana 24(1-2): 3-15. Buenos Aires. 
Cúneo, N.R. 1991. La tafoflora de la Formación Mojón de Hierro (Grupo Tepuel) en la localidad Arroyo Garrido, Paleozoico superior, provincia de Chubut. Ameghiniana 27(3-4): 225-238. Buenos Aires.

Cúneo, N.R., y Archangelsky, A. 1996. Nuevos resultados fitopaleoecológicos de la Formación Arroyo Totoral, Pérmico inferior, provincia de La Rioja. Ameghiniana 32(2): 145-154. Buenos Aires.

Cúneo, N.R. y Escapa, I. 2006. The Equisetalen genus Cruciaetheca nov. From the Lower Permian of Patagonia, Argentina. International Journal of Plant Sciences, 167:167-177.

Di Paola, E.C., 1972. Litología de la sección media del Grupo Paganzo en las comarcas Paganzo-Amaná y Olta-Malanzán, prov. de La Rioja, Rep. Argentina. Revista de la Asociación Geológica Argentina 27(2): 206-214. Buenos Aires.

Durán, M, Hünicken, M.A. y Antón A.M. 1997. Novedosos hallazgos de Sphenopsida en la Formación Bajo de Véliz, provincia de San Luis, Argentina. Ameghiniana 34(3): 259-264. Buenos Aires.

Frenguelli, J., 1944. Apuntes acerca del Paleozoico Superior del noroeste argentino. Revista del Museo de La Plata, nueva serie, Geología 2(15): 213-265. La Plata.

Frenguelli, J. 1946. Consideraciones acerca de la Serie de Paganzo en las provincias de San Juan y La Rioja. Revista del Museo de La Plata, nueva serie, Geología 2: 313-376. La Plata.

Frenguelli, J. 1949 a. Acerca de un nuevo descubrimiento de plantas en los Estratos del Arroyo Totoral, en la sierra de Los Llanos, La Rioja. Revista de la Asociación Geológica Argentina 4(3): 153-164. Buenos Aires.

Frenguelli, J. 1953. Las pecopterídeas del Pérmico de Chubut. Revista del Museo de La Plata, nueva serie, Paleontología 16(99): 287-296. La Plata. 
Freyberg, B. von, 1927. Resultados de un viaje de estudios geológicos a las Sierras de Los Llanos (provincia de La Rioja). Comunicación preliminar. Academia Nacional de Ciencias, Boletín 30: 123-127. Córdoba

Furque. 1968. Bosquejo geológico de la Sierra de Malanzán, La Rioja. 3o Jornadas Geológicas Argentinas (Comodoro Rivadavia 1966), Actas I: 110-120.

Guerra-Sommer, M., Cazzulo-Kleipzig, M. y Marques-Toigo, M. 1995.

Gondwanostachyaceae (Equisetopsida) no Gondwana Sul-Brasileiro (formacao Rio Bonito) com Mega e Microflora associados. Pesquisas, 22:64-73

Guerra-Sommer, M., Cazzulo-Klepzig, M., Formoso, M.L.L., Menegat, R., Mendonça, J.G., 2008a. U-Pb dating of tonstein layers from a coal succession of the southern Paraná Basin (Brazil): a new geochronological approach. Gondwana Research 14 (3), 474-482.

Guerra-Sommer, M., Cazzulo-Klepzig, M., Menegat, Rualdo, Formoso, M.L.L., Basei, M.A.S., Barboza, E.G., Simas, M.W., 2008b. Geochronological data from Faxinal coal succession in Southern Paraná Basin: a preliminary approach combining radiometric $\mathrm{U} / \mathrm{Pb}$ age and palynostratigraphy. Journal of South American Earth Sciences 25, 246-256.

Guerra-Sommer, M.; Cazzulo-Klepzig, M. 1993. Biostratigraphy of the Southern Brazilian Neopaleozoic Gondwana Sequence: A Preliminary Paleobotanical Approach. In: AGA, Int. Congrès Strat. Géol. Carbonifère et Permien, 12, 1991, Comptes Rendus, v.2, p. 61-72

Gulbranson, E.L., Montañez, I.P., Schmitz, M.D., Limarino, C.O., Isbell, J.L., Marenssi, S.A. y Crowley, J.L.. 2010. High-precision U-Pb calibration of Carboniferous glaciation and climate history, Paganzo Group, NW Argentina. Geological Society of America Bulletin, vol. $122,1480-1498$

Gutiérrez P.R. y Herbst, R. 1995. Una licofita ligulada en la Formación Melo (Pérmico Inferior) de Uruguay. In: $6^{\circ}$ Congreso Argentino de Paleontología y Bioestratigrafía, 1994. Actas, Trelew-Chubut, p. 149-154. 
Gutiérrez, P.R., Ottone, E.G. y Japas, S.M. (Eds.) 2006. Léxico Estratigráfico de la Argentina. Volumen VII. Pérmico. Asociación Geológica Argentina, Serie B (Didáctica y Complementaria) 28: $368 \mathrm{pp}$

Gutiérrez, P.R.; Césari, S.N. \& Limarino, C.O. 1986. Bumbudendron versiforme a new lycophyte species from the late Paleozoic of Argentina. Review of Palaeobotany and Palynology $36(3-4): 377-386$.

Hammer, Ø., Harper, D.A.T., y P. D. Ryan, 2001. PAST: Paleontological Statistics Software Package for Education and Data Analysis. Palaeontologia Electronica, 4(1): 9 pp

Herbst, R, Lutz, A, Montaña, J y Ferrando, L. 1992. La tafoflora de Glossopteris del Arroyo del Blanquillo (Dpto. Rivera) del Pérmico superior (Formación Yaguari) del Uruguay.

FACENA 9: 39-75.

Herbst, R., y Gutiérrez, P. 1995. Cyclodendron andreisii nov. Sp. (Lycopodiaceae, Lycophyta) del Pérmico Superior de Uruguay. Ameghiniana, 32: 141 - 150

Holz, M., França A.B., Souza, P.A., Iannuzzi, R y Rohn, R. 2010. A stratigraphic chart of the Late Carboniferous/Permian succession of the eastern border of the Paraná Basin, Brazil, South America. Journal of South American Earth Sciences, 29: 381-399

Iannuzzi, R., Souza, P.A., 2005. Floral succession in the Lower Permian deposits of the Brazilian Paraná Basin: an up-to-date overview. In: Lucas, S.G., Zigler, K.E. (Eds.), The Nonmarine Permian: New Mexico. New Mexico Museum of Natural History and Science Bulletin, 30, 144-149.

Ianuzzi, R., 2010. The flora of Early Permian coal measures from the Paraná Basin in Brazil: A review. International Journal of Coal Geology 83, 229-247.

Isbell, J.L., Henry, L.C., Gulbranson, E.L., Limarino, C.O., Fraiser, M.L., Koch, Z.J., Ciccioli, P.L., Dineen, A.A., 2012. Evaluations of glacial paradoxes during the late Paleozoic 
Ice Age using the concept of the equilibrium line altitude (ELA) as a control on glaciations. Gondwana Research, 22, 1-19.

Jasper, A., Guerra-Sommer, M., Cazzulo-Klepzig, M., Menegat, R. 2003. The Botrychiopsis genus and its biostratigraphic implications in Southern Paraná Basin. Anais da Academia Brasileira de Ciências, 75(4): 513-535

Kenrick, P. y Crane, P. R. 1997. The origin and early diversification of land plants: a cladistic study. Smithsonian series in comparative evolutionary biology. Smithsonian Institution Press, Washington, DC, 441 pp.

Kovâcs- Endrödy, É., 1979. A re-evaluation of the venation structure of Glossopteris. Annals of the Geological Survey of South Africa 12, 107-141.

Kurtz, F. 1921. Atlas de plantas fósiles de la República Argentina. Academia Nacional de Ciencias. Córdoba. 7:129-153.

Leguizamón, R.R. 1971. Paleophytología Kurtziana III. 6. Revisión de las semillas platispérmicas de Bajo de los Velez (San Luis), ilustradas en el “Atlas de plantas fósiles de la República Argentina”, (F. Kurtz, 1921). Ameghiniana Tomo VIII N³ y 4. 259-264.

Leguizamón, R.R. 1972. Estudio paleobotánico de la Formación Tasa Cuna, Pérmico Inferior de la provincia de Córdoba. Ameghiniana Tomo IX N 4:305-342.

Limarino, C.O. 1984. Areniscas eólicas en la Formación La Colina (Paleozoico superior), provincia de La Rioja. Revista de la Asociación Geológica Argentina 39(1-2): 58-67. Buenos Aires.

Limarino, C.O y Césari, S.N. 1985. Primer registro paleofloristico de la Formación La Colina(Paleozoico Superior), Cuenca Paganzo, República Argentina. Boletim Instituto de Geociencias, Universidade de Sâo paulo 15[1984]: 32-37. Sâo Paulo. 
Eliana Paula Coturel - Bioestratigrafía del Pérmico de la Sierra de los llanos...

Limarino, C.O. y Page S. 1999. Hoja Geológica 3166-I, Chamical, La Rioja y San Juan, escala 1:250000. Servicio Geológico Nacional, 102 p. (Boletín 257).

Limarino, C.O., Andreis R. R., Gutiérrez P. R. \& Ottone E. G. 1996. Cuenca Paganzo. In: S. Archangelsky (ed.), El Sistema Pérmico en la República Argentina y en la República Oriental del Uruguay. Academia Nacional de Ciencias, p. 115-140.

Limarino, C.O., Césari, S.N., Spalletti, L.A., Taboada, A., Isbell, J.L., Geuna, S., y E.L. Gulbranson, 2013. A paleoclimatic review of southern South America during the late Paleozoic: A record from icehouse to extreme greenhouse conditions. Gondwana Research. Available online 23 January 2013, ISSN 1342-937X, http://dx.doi.org/10.1016/j.gr.2012.12.022.

López-Gamundi, O.R., y Buatois, L. 2010. Introduction: Late Paleozoic glacial events and Postglacial transgressions in Gondwana. The Geological Society of America Special Paper 468 p. v-viii

Maddison, W. P. y D.R. Maddison. 2011. Mesquite: a modular system for evolutionary analysis. Version 2.75 http://mesquiteproject.org

Maheshwari, H.K., 1965. Studies in the Glossopteris Flora of India-22. On some species of the genus Glossopteris from the Raniganj Stage of the Raniganj Coalfield, Bengal. Palaeobotanist $13,129-143$.

Mcloughlin, S. 2011. Glossopteris - insights into the architecture and relationships of an iconicpermian Gondwanan plant. J. Botan. Soc. Bengal. 65 (2) : 1-14

Melchor R.N. y Césari S.N., 1991. Algunos elementos paleoflorísticos de la Formación Carapacha (Permico Inferior), provincia de La Pampa, República Argentina. Ameghiniana 28(3-4): 347-352. Buenos Aires.

Melchor R.N. y Césari S.N., 1997. Permian floras from Carapacha basin, La Pampa province, central Argentina. Description and importance. Geobios 30(3-4): 607-633. Lyon. 
Menéndez, C.A., 1966. "Plantas fósiles", Borrello, A.V. (Eds.), Paleontografía Bonaerense, vol. 2. $35 \mathrm{pp}$.

Net, L.I. 1998. Reubicación estratigráfica del miembro Conglomerado Amarillo Verdoso a Violado (Formación Loma Larga) en la Formación Solca (Paleozoico superior), provincia de La Rioja, Argentina. Actas $10^{\circ}$ Congreso Latinoamericano de Geología y $6^{\circ}$ Congreso Nacional de Geología Económica, 1:191-196, Buenos Aires.

Net, L.I. y Limarino, C.O. 1999. Paleogeografía y correlación estratigráfica del Paleozoico Tardío de la Sierra de Los Llanos, Provincia de La Rioja, Argentina. Revista de la Asociación Geológica Argentina, 54(3): 229-239

Raunkier, C. 1934. The life forms of plants and statistical plant geography. Clarendon, Oxford, 632 pp.

Rigby, J.F. 1966. The Lower Gondwana Floras of the Perth and Collie Basins, Western Australia. Palaeontographica Abt. B 118 (4-6): 123-126.

Rigby, J.F., 1972. On Arberia White, and some related Lower Gondwana female fructifications. Palaeontology 15, 108-120.

Simas, M., Guerra-Sommer, M., Cazzulo-Klepzig, M., Menegat, R., Schneider Santos, J., Fonseca Ferreira, J., Degani-Schmidt, I. 2012. Geochronological correlation of the main coal interval in Brazilian Lower Permian: Radiometric dating of tonstein and calibration of biostratigraphic framework, Journal of South American Earth Sciences, Vol. 39, 1-15

Singh, S.M., 2000. Taxonomy and diversity of the genus Glossopteris. Palaeobotanist 49, 333352.

Srivastava, A.K. 1991. Evolutionary tendency in the venation pattern of Glossopteridales. Geobios, 4:383-386. 
Srivastava, A.K. y Agnihotri, D., 2010. Dilemma of late palaeozoic mixed floras in Gondwana. Palaeogeography,Palaeoclimatology, Palaeoecology 298, 54-6

Stewart, W.N. y Rothwell, G.W. 1993. Paleobotany and the evolution of plants. Cambridge, Cambridge University Press, 521 p.

Taylor, T.N., Taylor, E.L.y Krings, M., Paleobotany. The biology and evolution of fossil plants, 2009. $1230 \mathrm{pp}$.

Tybusch, G.P., y Iannuzzi, R. 2010. Glossopteris occidentalis white emended: geographic and biostratigraphic implications. Rev. Bras. Paleontol. 13(1):33-40

Unger, F. 1850. Genera et species plantarum fossilium. Viena.

Zampirolli, A.P; Bernardes de Oliveira, M.E. 2000. O género Paracalamites Zalessky 1927, na tafoflora de Itapeva, Carbonífero Superior do Subgrupo Itararé, Grupo Tubaráo, sudoeste do Estado Sao Paulo, Brasil. Revista do Instituto Geológico de Sao Paulo 21 (1-2): 7-15.

Zamuner, A. 1996. Araucarioxylon petriellae, n.sp. Una posible glossopteridal de la Formación Melo (Pérmico Inferior) Uruguay. Ameghiniana, 33: 77-82. 
Eliana Paula Coturel - Bioestratigrafía del Pérmico de la Sierra de los llanos...

Anexo

$\sim 169 \sim$ 
En esta sección se presentan las tablas con los datos utilizados en el cluster analysis presentado en el capítulo IV.3.

Las mediciones, curvas y ecuaciones calculadas a partir de las venas secundarias aparecen en la Tabla 1. La tabla contiene también todos los datos obtenidos de las mediciones:

- Hoja: nombre del archivo de extensión .psd (Photoshop) donde se guardó el escaneo de las imágenes del libro de Chandra y Surange (1979).

- Imagen y letra: identificación de cada dibujo a cámara clara. Se corresponden con el presente en el libro de Glossopteris.

- Fórmula: fórmulas obtenidas con el software Microsoft Office Excel 2007 tras el ploteo de la venación, y el R2 calculado para verificar la similitud de la curva con el trazo de la venación.

- Fórmula venación: coeficientes de la fórmula desglosados (permite mayor comodidad para el cálculo de los puntos en el trazo de la vena).

- Densidad venación: $\mathrm{n}^{\circ}$ de venas que atraviesan el correspondiente valor de $\mathrm{x}$.

- Densidad anastomosis: cantidad de contactos entre venas observadas en una zona determinada de la hoja (proximal, media, distal respecto de la vena media). Se desglosan según el tipo en:

- T: la venilla que une las venas es transversa

- 1: unión entre dos venas, que continúan como una sola

- X: las venas se unen en diagonal y luego se dividen, formando una X

- Y: dicotomía de venas

La Tabla 2, "Grupos y características", presenta los datos de la tabla 1, reunidos según los grupos obtenidos tras el cluster analysis, acompañado de los porcentajes de anastomosis y los estadísticos básicos (mediana, promedio) aplicados. 


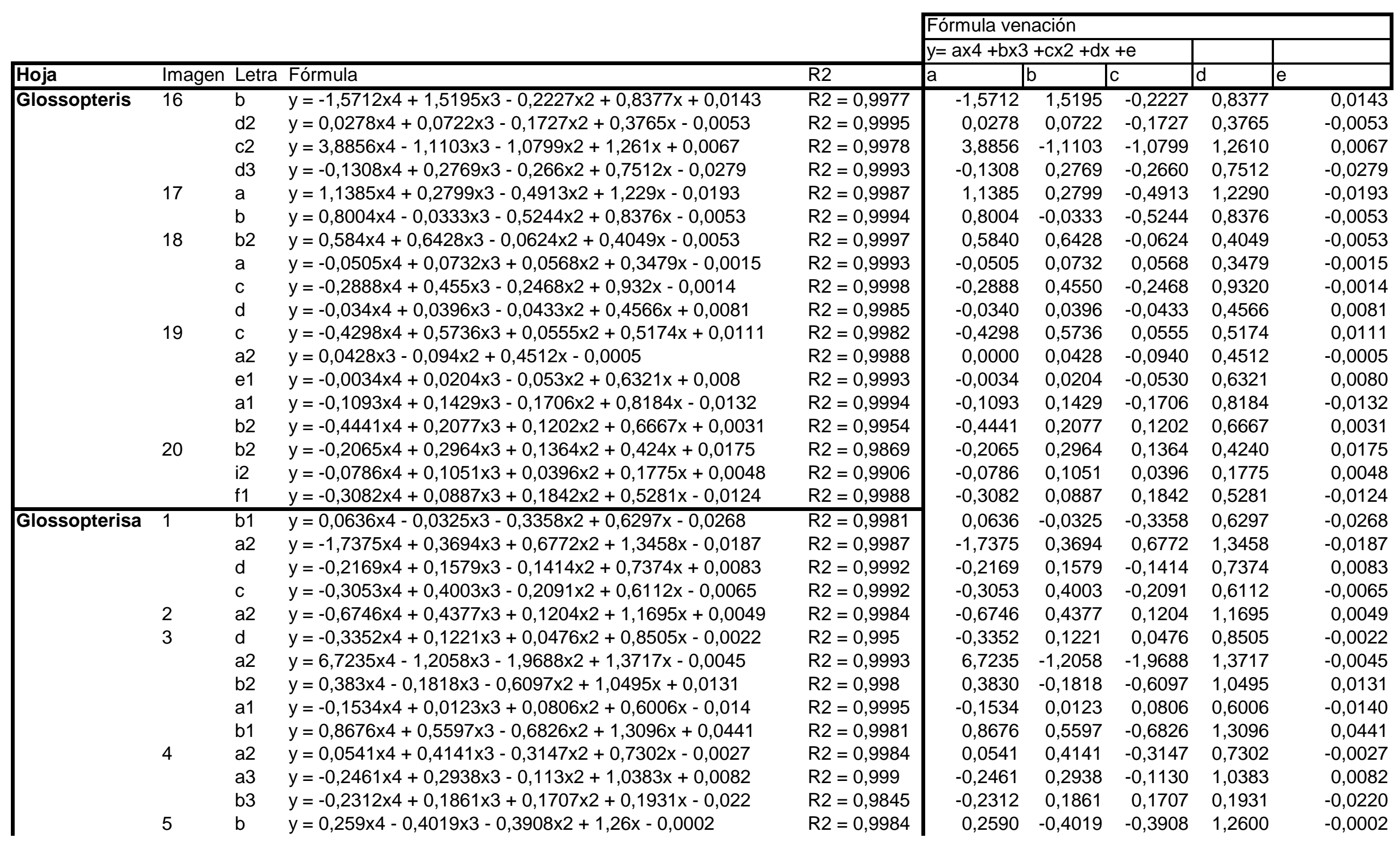




\begin{tabular}{|c|c|c|c|c|c|c|c|c|c|}
\hline & & a & $y=0,017 x 4+0,1557 \times 3-0,7017 x 2+1,0823 x+0,0011$ & $\mathrm{R} 2=0,999$ & 0,0170 & 0,1557 & $-0,7017$ & 1,0823 & 0,0011 \\
\hline & & c & $y=-0,9485 x 4+0,2496 \times 3-0,0092 \times 2+0,7461 x-0,0069$ & $\mathrm{R} 2=0,9971$ & $-0,9485$ & 0,2496 & $-0,0092$ & 0,7461 & $-0,0069$ \\
\hline & & d & $y=-0,2358 \times 4-0,1018 \times 3+0,1153 \times 2+0,914 x-0,0145$ & $\mathrm{R} 2=0,9974$ & $-0,2358$ & $-0,1018$ & 0,1153 & 0,9140 & $-0,0145$ \\
\hline & 6 & e & $y=-0,0795 \times 4-0,09 \times 3+0,0199 \times 2+0,3968 x-0,0077$ & $\mathrm{R} 2=0,9985$ & $-0,0795$ & $-0,0900$ & 0,0199 & 0,3968 & $-0,0077$ \\
\hline & & a & $y=-0,0613 x 4-0,0704 \times 3-0,0773 x 2+0,4246 x+0,0021$ & $R 2=0,9988$ & $-0,0613$ & $-0,0704$ & $-0,0773$ & 0,4246 & 0,0021 \\
\hline & & f & $y=-0,226 x 4+0,1365 \times 3-0,0775 \times 2+0,3328 x+0,0043$ & $\mathrm{R} 2=0,9993$ & $-0,2260$ & 0,1365 & $-0,0775$ & 0,3328 & 0,0043 \\
\hline & & b & $y=-0,2864 x 4+0,3231 \times 3-0,1556 x 2+0,5908 x+0,026$ & $\mathrm{R} 2=0,9975$ & $-0,2864$ & 0,3231 & $-0,1556$ & 0,5908 & 0,0260 \\
\hline & & c2 & $y=0,0189 x 4-0,0111 \times 3-0,161 x 2+0,5552 x-0,0038$ & $\mathrm{R} 2=0,9989$ & 0,0189 & $-0,0111$ & $-0,1610$ & 0,5552 & $-0,0038$ \\
\hline & 7 & d & $y=0,0117 x 4+0,0876 \times 3-0,1146 \times 2+0,308 x+0,0078$ & $\mathrm{R} 2=0,9983$ & 0,0117 & 0,0876 & $-0,1146$ & 0,3080 & 0,0078 \\
\hline & & a2 & $y=0,075 x 4-0,2766 \times 3-0,1167 \times 2+0,9727 x+0,0029$ & $\mathrm{R} 2=0,9995$ & 0,0750 & $-0,2766$ & $-0,1167$ & 0,9727 & 0,0029 \\
\hline & & b & $y=-2,1633 \times 4+0,8604 \times 3-0,1182 \times 2+1,5523 x-0,0139$ & $\mathrm{R} 2=0,9994$ & $-2,1633$ & 0,8604 & $-0,1182$ & 1,5523 & $-0,0139$ \\
\hline & 8 & e & $y=-0,294 x 4+0,4378 \times 3-0,1762 \times 2+1,0451 x-0,0171$ & $\mathrm{R} 2=0,9977$ & $-0,2940$ & 0,4378 & $-0,1762$ & 1,0451 & $-0,0171$ \\
\hline & & b2 & $y=0,1585 x 4+0,1714 x 3-0,9546 \times 2+0,568 x-0,0191$ & $\mathrm{R} 2=0,9911$ & 0,1585 & 0,1714 & $-0,9546$ & 0,5680 & $-0,0191$ \\
\hline & & a2 & $y=-0,6993 x 4-0,0078 \times 3-0,1935 \times 2+1,0705 x-0,0037$ & $R 2=0,9998$ & $-0,6993$ & $-0,0078$ & $-0,1935$ & 1,0705 & $-0,0037$ \\
\hline & & a1 & $y=-3,5969 x 4-1,5595 x 3+1,2483 x 2+1,973 x-0,0231$ & $R 2=0,9996$ & $-3,5969$ & $-1,5595$ & 1,2483 & 1,9730 & $-0,0231$ \\
\hline Glossoperisb & 9 & a2 & $y=-1,5443 \times 4+0,3438 \times 3+0,4409 \times 2+0,9051 x+0,0069$ & $\mathrm{R} 2=0,9982$ & $-1,5443$ & 0,3438 & 0,4409 & 0,9051 & 0,0069 \\
\hline & & c1 & $y=-3,0254 x 4+0,3939 x 3+0,6384 x 2+0,8664 x-0,0187$ & $\mathrm{R} 2=0,9984$ & $-3,0254$ & 0,3939 & 0,6384 & 0,8664 & $-0,0187$ \\
\hline & & b & $y=9,4697 \times 4-1,3889 \times 3-0,5492 \times 2+3,4544 x-0,026$ & $\mathrm{R} 2=0,9995$ & 9,4697 & $-1,3889$ & $-0,5492$ & 3,4544 & $-0,0260$ \\
\hline & & a1 & $y=-0,4132 x 4+0,3176 \times 3+0,0593 x 2+0,8755 x-0,0012$ & $\mathrm{R} 2=0,9994$ & $-0,4132$ & 0,3176 & 0,0593 & 0,8755 & $-0,0012$ \\
\hline & 10 & d2 & $y=-0,9909 x 4-0,7519 x 3+0,0054 x 2+1,0288 x+0,0012$ & $\mathrm{R} 2=1$ & $-0,9909$ & $-0,7519$ & 0,0054 & 1,0288 & 0,0012 \\
\hline & & $\mathrm{b}$ & $y=-0,3579 x 4+0,1373 \times 3-0,0054 \times 2+0,739 x+0,0249$ & $\mathrm{R} 2=0,9984$ & $-0,3579$ & 0,1373 & $-0,0054$ & 0,7390 & 0,0249 \\
\hline & & a & $y=-0,1118 x 4+0,0204 \times 3-0,045 \times 2+0,6539 x+0,0039$ & $\mathrm{R} 2=0,9983$ & $-0,1118$ & 0,0204 & $-0,0450$ & 0,6539 & 0,0039 \\
\hline & & c & $y=0,3945 x 4+0,2746 \times 3-0,4932 x 2+0,5275 x+0,0007$ & $\mathrm{R} 2=0,9998$ & 0,3945 & 0,2746 & $-0,4932$ & 0,5275 & 0,0007 \\
\hline & 11 & b & $y=-0,1886 x 4+0,0897 \times 3-0,0978 \times 2+0,6491 x+0,0025$ & $\mathrm{R} 2=0,9997$ & $-0,1886$ & 0,0897 & $-0,0978$ & 0,6491 & 0,0025 \\
\hline & & c & $y=-0,637 x 4+0,4012 x 3-0,1937 \times 2+1,0041 x+0,0031$ & $\mathrm{R} 2=0,9988$ & $-0,6370$ & 0,4012 & $-0,1937$ & 1,0041 & 0,0031 \\
\hline & & a2 & $y=-0,2792 x 4+0,0019 x 3+0,18 x 2+0,6388 x-0,0039$ & $\mathrm{R} 2=0,999$ & $-0,2792$ & 0,0019 & 0,1800 & 0,6388 & $-0,0039$ \\
\hline & & d & $y=-0,2436 \times 4+0,1596 \times 3-0,2151 x 2+0,6807 x-0,0005$ & $\mathrm{R} 2=0,9996$ & $-0,2436$ & 0,1596 & $-0,2151$ & 0,6807 & $-0,0005$ \\
\hline & 12 & a2 & $y=1,1637 x 4-0,335 x 3-1,122 x 2+1,4312 x-0,0133$ & $\mathrm{R} 2=0,998$ & 1,1637 & $-0,3350$ & $-1,1220$ & 1,4312 & $-0,0133$ \\
\hline & & $\mathrm{h}$ & $y=0,0964 \times 4-0,0258 \times 3-0,2728 \times 2+0,595 x+0,0375$ & $\mathrm{R} 2=0,995$ & 0,0964 & $-0,0258$ & $-0,2728$ & 0,5950 & 0,0375 \\
\hline & & $\mathrm{f} 2$ & $y=0,207 \times 4-0,0897 \times 3-0,2672 \times 2+0,879 x-0,0017$ & $\mathrm{R} 2=0,9994$ & 0,2070 & $-0,0897$ & $-0,2672$ & 0,8790 & $-0,0017$ \\
\hline & 13 & $\mathrm{~g}$ & $y=-0,0051 x 4+0,1319 \times 3-0,4472 \times 2+0,8254 x+0,0145$ & $\mathrm{R} 2=0,9992$ & $-0,0051$ & 0,1319 & $-0,4472$ & 0,8254 & 0,0145 \\
\hline & & $\mathrm{c}$ & $y=-0,1227 x 4-0,0519 x 3+0,0111 x 2+0,9115 x-0,0106$ & $\mathrm{R} 2=0,9982$ & $-0,1227$ & $-0,0519$ & 0,0111 & 0,9115 & $-0,0106$ \\
\hline & & b2 & $y=2,5592 x 4-0,3052 \times 3-0,8459 x 2+1,7716 x-0,0152$ & $\mathrm{R} 2=0,9997$ & 2,5592 & $-0,3052$ & $-0,8459$ & 1,7716 & $-0,0152$ \\
\hline & 14 & b2 & $y=-0,3872 x 4+0,6196 \times 3-0,5441 x 2+0,9475 x+0,0087$ & $\mathrm{R} 2=0,9984$ & $-0,3872$ & 0,6196 & $-0,5441$ & 0,9475 & 0,0087 \\
\hline & & c2 & $y=-0,0258 x 4+0,0153 x 3-0,1293 x 2+0,9458 x-0,0055$ & $\mathrm{R} 2=0,999$ & $-0,0258$ & 0,0153 & $-0,1293$ & 0,9458 & $-0,0055$ \\
\hline & 15 & a & $y=0,7698 \times 4+0,6829 \times 3-0,3307 \times 2+0,578 x+0,0138$ & $\mathrm{R} 2=0,9987$ & 0,7698 & 0,6829 & $-0,3307$ & 0,5780 & 0,0138 \\
\hline
\end{tabular}




\begin{tabular}{|c|c|c|c|c|}
\hline \multirow{3}{*}{\multicolumn{2}{|c|}{\begin{tabular}{|l} 
Glossopteris2 2 \\
\end{tabular}}} & $\mathrm{~b}$ & $y=0,0853 x 4+0,6172 \times 3-0,1633 x 2+0,1769 x-0,0153$ & $\mathrm{R} 2=0,9893$ \\
\hline & & $\mathrm{b}$ & $y=-0,206 \times 4+0,0138 \times 3+0,1332 \times 2+0,5524 x+0,0035$ & $\mathrm{R} 2=0,9989$ \\
\hline & & a2 & $y=-1,0101 x 4+0,5177 x 3+0,0051 x 2+0,9943 x+4 E-12$ & $\mathrm{R} 2=1$ \\
\hline & $\overline{21}$ & c2 & $y=-0,0782 x 4-0,2607 \times 3-0,1921 \times 2+0,6932 x+0,0277$ & $\mathrm{R} 2=0,9973$ \\
\hline & \multirow[t]{3}{*}{22} & $g$ & $y=0,0527 \times 4+0,1959 \times 3-0,3854 \times 2+0,825 x+0,0153$ & $\mathrm{R} 2=0,999$ \\
\hline & & b & $y=-2,2722 x 4+1,5618 \times 3-0,4616 \times 2+1,6316 x-0,0138$ & $\mathrm{R} 2=0,9997$ \\
\hline & & a2 & $y=-0,2151 \times 4-0,267 \times 3-0,2236 \times 2+0,9581 x-0,0004$ & $\mathrm{R} 2=0,9995$ \\
\hline & \multirow[t]{3}{*}{23} & c & $y=-0,0742 x 4+0,129 \times 3-0,0969 x 2+0,6128 x+0,0029$ & $\mathrm{R} 2=0,9977$ \\
\hline & & $\mathrm{g}$ & $y=-1,459 \times 4-0,4702 x 3+0,3893 \times 2+1,6986 x-0,0008$ & $\mathrm{R} 2=0,9986$ \\
\hline & & $\mathrm{h}$ & $y=0,215 x 4+0,2279 \times 3-0,3148 \times 2+0,8696 x-0,0074$ & $\mathrm{R} 2=0,9998$ \\
\hline & \multirow[t]{4}{*}{24} & j & $y=-0,2015 x 4+0,1397 x 3-0,046 x 2+0,7398 x-0,0121$ & $\mathrm{R} 2=0,9997$ \\
\hline & & d & $y=0,5406 x 4+0,0936 \times 3-0,7312 x 2+0,7349 x+0,1014$ & $\mathrm{R} 2=0,9761$ \\
\hline & & a2 & $y=1,4622 x 4-0,9601 \times 3-1,0128 x 2+1,9408 x+0,0129$ & $\mathrm{R} 2=0,9998$ \\
\hline & & $\mathrm{i}$ & $y=-0,0861 x 4+0,1409 \times 3-0,1142 \times 2+0,2692 x+0,0354$ & $\mathrm{R} 2=0,9932$ \\
\hline & \multirow[t]{3}{*}{25} & $\mathrm{k}$ & $y=-0,3887 x 4+0,0198 \times 3-0,2333 \times 2+1,6378 x-0,0138$ & $\mathrm{R} 2=0,9998$ \\
\hline & & e & $y=1,9386 x 4-0,5183 x 3-1,3228 x 2+1,7545 x+0,0061$ & $\mathrm{R} 2=0,999$ \\
\hline & & b & $y=-0,8582 x 4+2,0103 x 3-1,7457 x 2+1,6572 x+0,0129$ & $\mathrm{R} 2=0,9999$ \\
\hline \multirow[t]{10}{*}{ Glossopteris3 } & \multirow[t]{6}{*}{26} & k2 & $y=-0,2191 x 4+0,1411 x 3-0,1983 x 2+0,8753 x+0,0062$ & $\mathrm{R} 2=0,9991$ \\
\hline & & $\mathrm{k} 1$ & $y=-1,335 x 4+1,2205 \times 3-0,0362 \times 2+0,4676 x-0,0154$ & $\mathrm{R} 2=0,9821$ \\
\hline & & a & $y=-0,4668 \times 4+0,7028 \times 3-0,0854 \times 2+1,2389 x-0,0097$ & $\mathrm{R} 2=0,9998$ \\
\hline & & $\mathrm{h}$ & $y=-0,3117 x 4+0,0055 \times 3+0,01 x 2+1,2538 x+0,0017$ & $\mathrm{R} 2=0,9993$ \\
\hline & & d & $y=3,1522 \times 3-0,2029 x 2+1,3404 x+0,0377$ & $R^{2}=0,9838$ \\
\hline & & b & $y=-0,6513 x 4+0,3448 \times 3+0,1904 \times 2+0,9473 x-0,0074$ & $\mathrm{R} 2=0,9957$ \\
\hline & \multirow[t]{4}{*}{27} & $\mathrm{i}$ & $y=-0,3055 x 4-0,1093 \times 3-0,1911 x 2+0,859 x-0,034$ & $\mathrm{R} 2=0,9983$ \\
\hline & & $\mathrm{g}$ & $y=-0,024 x 4+0,0321 \times 3-0,094 \times 2+0,142 x-1 E-13$ & $\mathrm{R} 2=1$ \\
\hline & & $\mathrm{h}$ & $y=-0,224 x 4+0,0902 x 3+0,1495 x 2+0,4974 x+0,0098$ & $\mathrm{R} 2=0,9997$ \\
\hline & & a1 & $y=-0,0046 \times 4+0,0864 \times 3-0,2639 \times 2+0,2039 x-0,009$ & $\mathrm{R} 2=0,9976$ \\
\hline \multirow[t]{9}{*}{ Glossopteris4 } & \multirow[t]{4}{*}{28} & $\mathrm{c}$ & $y=-0,0352 x 4+0,2842 \times 3-0,4269 \times 2+0,9317 x-0,0163$ & $\mathrm{R} 2=0,9972$ \\
\hline & & e & $y=-2,045 x 4+0,3061 \times 3+0,1039 x 2+1,1815 x-0,0284$ & $\mathrm{R} 2=0,9974$ \\
\hline & & d & $y=1,3968 \times 4-0,6349 \times 3-0,9892 x 2+1,8387 x+3 E-12$ & $\mathrm{R} 2=1$ \\
\hline & & $\mathrm{g}$ & $y=-0,1618 x 4+0,1547 \times 3-0,247 x 2+0,9049 x-0,0007$ & $\mathrm{R} 2=0,9997$ \\
\hline & \multirow[t]{5}{*}{29} & $\mathrm{e}$ & $y=-0,566 \times 4-0,0949 \times 3+0,2484 x 2+1,3717 x-0,0133$ & $\mathrm{R} 2=0,9998$ \\
\hline & & g2 & $y=0,0433 \times 4+0,228 \times 3-0,3567 x 2+1,1111 x-0,0176$ & $\mathrm{R} 2=0,9993$ \\
\hline & & $\mathrm{f} 2$ & $y=-0,2268 x 4+0,2392 \times 3+0,064 \times 2+0,8168 x-0,0297$ & $\mathrm{R} 2=0,9966$ \\
\hline & & c & $y=-2,1092 x 4+5,1168 \times 3-0,963 \times 2+1,1877 x+0,0082$ & $\mathrm{R} 2=0,9999$ \\
\hline & & a2 & $y=0,9304 x 4-0,0896 \times 3-0,7309 x 2+1,3876 x-0,0278$ & $\mathrm{R} 2=0,9981$ \\
\hline
\end{tabular}

$\begin{array}{rrrrr}0,0853 & 0,6172 & -0,1633 & 0,1769 & -0,0153 \\ -0,2060 & 0,0138 & 0,1332 & 0,5524 & 0,0035 \\ -1,0101 & 0,5177 & 0,0051 & 0,9943 & 0,0000 \\ -0,0782 & -0,2607 & -0,1921 & 0,6932 & 0,0277 \\ 0,0527 & 0,1959 & -0,3854 & 0,8250 & 0,0153 \\ -2,2722 & 1,5618 & -0,4616 & 1,6316 & -0,0138 \\ -0,2151 & -0,2670 & -0,2236 & 0,9581 & -0,0004 \\ -0,0742 & 0,1290 & -0,0969 & 0,6128 & 0,0029 \\ -1,4590 & -0,4702 & 0,3893 & 1,6986 & -0,0008 \\ 0,2150 & 0,2279 & -0,3148 & 0,8696 & -0,0074 \\ -0,2015 & 0,1397 & -0,0460 & 0,7398 & -0,0121 \\ 0,5406 & 0,0936 & -0,7312 & 0,7349 & 0,1014 \\ 1,4622 & -0,9601 & -1,0128 & 1,9408 & 0,0129 \\ -0,0861 & 0,1409 & -0,1142 & 0,2692 & 0,0354 \\ -0,3887 & 0,0198 & -0,2333 & 1,6378 & -0,0138 \\ 1,9386 & -0,5183 & -1,3228 & 1,7545 & 0,0061 \\ -0,8582 & 2,0103 & -1,7457 & 1,6572 & 0,0129 \\ -0,2191 & 0,1411 & -0,1983 & 0,8753 & 0,0062 \\ -1,3350 & 1,2205 & -0,0362 & 0,4676 & -0,0154 \\ -0,4668 & 0,7028 & -0,0854 & 1,2389 & -0,0097 \\ -0,3117 & 0,0055 & 0,0100 & 1,2538 & 0,0017 \\ 0,0000 & 3,1522 & -0,2029 & 1,3404 & 0,0377 \\ -0,6513 & 0,3448 & 0,1904 & 0,9473 & -0,0074 \\ -0,3055 & -0,1093 & -0,1911 & 0,8590 & -0,0340 \\ -0,0240 & 0,0321 & -0,0940 & 0,1420 & 0,0000 \\ -0,2240 & 0,0902 & 0,1495 & 0,4974 & 0,0098 \\ -0,0046 & 0,0864 & -0,2639 & 0,2039 & -0,0090 \\ -0,0352 & 0,2842 & -0,4269 & 0,9317 & -0,0163 \\ -2,0450 & 0,3061 & 0,1039 & 1,1815 & -0,0284 \\ 1,3968 & -0,6349 & -0,9892 & 1,8387 & 0,0000 \\ -0,1618 & 0,1547 & -0,2470 & 0,9049 & -0,0007 \\ -0,5660 & -0,0949 & 0,2484 & 1,3717 & -0,0133 \\ 0,0433 & 0,2280 & -0,3567 & 1,1111 & -0,0176 \\ -0,2268 & 0,2392 & 0,0640 & 0,8168 & -0,0297 \\ -2,1092 & 5,1168 & -0,9630 & 1,1877 & 0,0082 \\ 0,9304 & -0,0896 & -0,7309 & 1,3876 & -0,0278\end{array}$




\begin{tabular}{|c|c|c|c|c|c|c|c|c|c|}
\hline Glossopteris5 & 30 & $\mathrm{a} 1$ & $y=-0,1667 x 4-0,0254 \times 3+0,1094 \times 2+0,5778 x+0,0046$ & $\mathrm{R} 2=0,999$ & $-0,1667$ & $-0,0254$ & 0,1094 & 0,5778 & 0,0046 \\
\hline & & b2 & $y=2,8312 x 4-0,9996 \times 3-0,9421 \times 2+1,8775 x-0,0168$ & $\mathrm{R} 2=0,9992$ & 2,8312 & $-0,9996$ & $-0,9421$ & 1,8775 & $-0,0168$ \\
\hline & & a2 & $y=0,1169 \times 4-0,0668 \times 3-0,2616 \times 2+0,5965 x-0,0251$ & $\mathrm{R} 2=0,998$ & 0,1169 & $-0,0668$ & $-0,2616$ & 0,5965 & $-0,0251$ \\
\hline & & c & $y=0,2474 \times 4-0,0626 \times 3-0,1565 \times 2+0,7798 x+0,0085$ & $\mathrm{R} 2=0,9995$ & 0,2474 & $-0,0626$ & $-0,1565$ & 0,7798 & 0,0085 \\
\hline & & e & $y=-8,2725 x 4-1,4814 x 3+2,1645 x 2+2,2297 x+0,0091$ & $\mathrm{R} 2=0,9975$ & $-8,2725$ & $-1,4814$ & 2,1645 & 2,2297 & 0,0091 \\
\hline & & d & $y=-0,087 \times 4-0,0169 \times 3+0,007 \times 2+0,1969 x-6 E-14$ & $\mathrm{R} 2=1$ & $-0,0870$ & $-0,0169$ & 0,0070 & 0,1969 & 0,0000 \\
\hline & 31 & a & $y=-0,1402 x 4+0,027 \times 3-0,0818 x 2+0,5883 x-0,0072$ & $\mathrm{R} 2=0,9992$ & $-0,1402$ & 0,0270 & $-0,0818$ & 0,5883 & $-0,0072$ \\
\hline & & e & $y=0,0987 x 4+0,0311 \times 3-0,4907 \times 2+0,9706 x-0,0025$ & $\mathrm{R} 2=0,9979$ & 0,0987 & 0,0311 & $-0,4907$ & 0,9706 & $-0,0025$ \\
\hline & & d & $y=0,0299 x 4+0,181 x 3-0,1452 x 2+0,68 x+0,009$ & $\mathrm{R} 2=0,9996$ & 0,0299 & 0,1810 & $-0,1452$ & 0,6800 & 0,0090 \\
\hline & & $f$ & $y=0,0618 \times 4+0,2355 \times 3-0,1789 x 2+0,7036 x+0,0028$ & $\mathrm{R} 2=0,9998$ & 0,0618 & 0,2355 & $-0,1789$ & 0,7036 & 0,0028 \\
\hline & & d1 & $y=-0,3607 \times 4+0,05 \times 3-0,0637 \times 2+1,0983 x+0,0149$ & $\mathrm{R} 2=0,9987$ & $-0,3607$ & 0,0500 & $-0,0637$ & 1,0983 & 0,0149 \\
\hline & & $\mathrm{h}$ & $y=-1,0981 x 4+1,243 \times 3+0,2787 \times 2+0,8804 x-0,0007$ & $\mathrm{R} 2=0,9993$ & $-1,0981$ & 1,2430 & 0,2787 & 0,8804 & $-0,0007$ \\
\hline & & $\mathrm{g}$ & $y=-0,0388 x 4+0,1871 \times 3-0,2068 \times 2+0,4962 x-0,0207$ & $\mathrm{R} 2=0,999$ & $-0,0388$ & 0,1871 & $-0,2068$ & 0,4962 & $-0,0207$ \\
\hline Glossopteris6 & $\overline{32}$ & $f$ & $y=3,5985 x 4+1,5064 x 3-1,4331 \times 2+0,8228 x-0,0122$ & $\mathrm{R} 2=0,9976$ & 3,5985 & 1,5064 & $-1,4331$ & 0,8228 & $-0,0122$ \\
\hline & & $b$ & $y=-0,0042 x 4+0,1107 x 3-0,3687 x 2+0,959 x-0,0331$ & $\mathrm{R} 2=0,9984$ & $-0,0042$ & 0,1107 & $-0,3687$ & 0,9590 & $-0,0331$ \\
\hline & & c & $y=-0,0191 x 4-0,3075 \times 3-0,2592 \times 2+0,9995 x-0,0233$ & $\mathrm{R} 2=0,9967$ & $-0,0191$ & $-0,3075$ & $-0,2592$ & 0,9995 & $-0,0233$ \\
\hline & & e2 & $y=0,3373 x 4-0,4391 \times 3-0,0468 x 2+0,6444 x+0,01$ & $R 2=0,9989$ & 0,3373 & $-0,4391$ & $-0,0468$ & 0,6444 & 0,0100 \\
\hline & & e1 & $y=-0,2374 x 4+0,3191 \times 3-0,1994 \times 2+0,4824 x+0,0004$ & $R 2=0,9992$ & $-0,2374$ & 0,3191 & $-0,1994$ & 0,4824 & 0,0004 \\
\hline & 33 & a & $y=-0,2567 x 4+0,1878 \times 3+0,0886 \times 2+0,113 x-0,0287$ & $\mathrm{R} 2=0,9743$ & $-0,2567$ & 0,1878 & 0,0886 & 0,1130 & $-0,0287$ \\
\hline & & b & $y=-0,0787 x 4-0,0581 \times 3+0,1078 \times 2-0,0136 x-0,0018$ & $\mathrm{R} 2=0,76$ & $-0,0787$ & $-0,0581$ & 0,1078 & $-0,0136$ & $-0,0018$ \\
\hline & & c2 & $y=-3,0587 x 4-1,284 x 3+1,9471 x 2+0,9845 x-0,0795$ & $\mathrm{R} 2=0,7962$ & $-3,0587$ & $-1,2840$ & 1,9471 & 0,9845 & $-0,0795$ \\
\hline & & d1 & $y=0,0491 x 4+0,2489 \times 3-0,3383 \times 2-0,1768 x+0,0188$ & $\mathrm{R} 2=0,9732$ & 0,0491 & 0,2489 & $-0,3383$ & $-0,1768$ & 0,0188 \\
\hline & 34 & b2 & $y=-0,0865 x 4+0,0941 \times 3-0,0406 \times 2+0,0564 x-0,0019$ & $\mathrm{R} 2=0,9992$ & $-0,0865$ & 0,0941 & $-0,0406$ & 0,0564 & $-0,0019$ \\
\hline & & b1 & $y=0,0456 \times 4+0,0777 \times 3-0,0545 \times 2-0,0216 x-0,0049$ & $R 2=0,9302$ & 0,0456 & 0,0777 & $-0,0545$ & $-0,0216$ & $-0,0049$ \\
\hline & & c & $y=0,243 x 4+0,9956 \times 3-0,2865 \times 2+0,492 x-0,0048$ & $R 2=0,9901$ & 0,2430 & 0,9956 & $-0,2865$ & 0,4920 & $-0,0048$ \\
\hline & & a & $y=-0,1731 x 4+0,1324 \times 3+0,0747 \times 2+0,1014 x-0,014$ & $R 2=0,9961$ & $-0,1731$ & 0,1324 & 0,0747 & 0,1014 & $-0,0140$ \\
\hline & & d & $y=-0,046 x 4+0,0343 \times 3+0,0412 x 2+0,209 x-0,003$ & $R 2=0,9964$ & $-0,0460$ & 0,0343 & 0,0412 & 0,2090 & $-0,0030$ \\
\hline & 35 & c & $y=-0,1053 x 4+0,178 \times 3-0,1812 \times 2+0,2229 x+0,0059$ & $\mathrm{R} 2=0,9918$ & $-0,1053$ & 0,1780 & $-0,1812$ & 0,2229 & 0,0059 \\
\hline & & b & $y=-0,3792 x 4+0,2603 \times 3+0,1587 \times 2-0,0968 x-0,0104$ & $\mathrm{R} 2=0,9836$ & $-0,3792$ & 0,2603 & 0,1587 & $-0,0968$ & $-0,0104$ \\
\hline & 36 & c & $y=-0,0612 x 4+0,0388 \times 3+0,0853 \times 2+0,1253 x-7 E-14$ & $\mathrm{R} 2=1$ & $-0,0612$ & 0,0388 & 0,0853 & 0,1253 & 0,0000 \\
\hline & & a2 & $y=-0,1197 x 4+0,1092 \times 3+0,0661 x 2+0,2066 x-0,007$ & $\mathrm{R} 2=0,9994$ & $-0,1197$ & 0,1092 & 0,0661 & 0,2066 & $-0,0070$ \\
\hline & & b2 & $y=-0,4856 \times 4-0,2627 \times 3+0,3176 \times 2+0,9282 x+0,0008$ & $\mathrm{R} 2=0,9997$ & $-0,4856$ & $-0,2627$ & 0,3176 & 0,9282 & 0,0008 \\
\hline & & b1 & $y=-0,0133 \times 4-0,0267 \times 3-0,0567 \times 2+0,1167 x+2 E-14$ & $\mathrm{R} 2=1$ & $-0,0133$ & $-0,0267$ & $-0,0567$ & 0,1167 & 0,0000 \\
\hline Glossopteris7 & 37 & $\mathrm{e} 2$ & $y=-0,4326 x 4+0,2582 \times 3+0,3154 \times 2-0,0848 x-0,0159$ & $\mathrm{R} 2=0,966$ & $-0,4326$ & 0,2582 & 0,3154 & $-0,0848$ & $-0,0159$ \\
\hline & & e1 & $y=0,1709 x 4+0,0361 x 3-0,1061 x 2+0,1456 x+0,0195$ & $\mathrm{R} 2=0,9748$ & 0,1709 & 0,0361 & $-0,1061$ & 0,1456 & 0,0195 \\
\hline & & f & $y=0,1025 x 4+0,0537 \times 3-0,1122 x 2+0,1472 x+0,0101$ & $\mathrm{R} 2=0,9941$ & 0,1025 & 0,0537 & $-0,1122$ & 0,1472 & 0,0101 \\
\hline
\end{tabular}




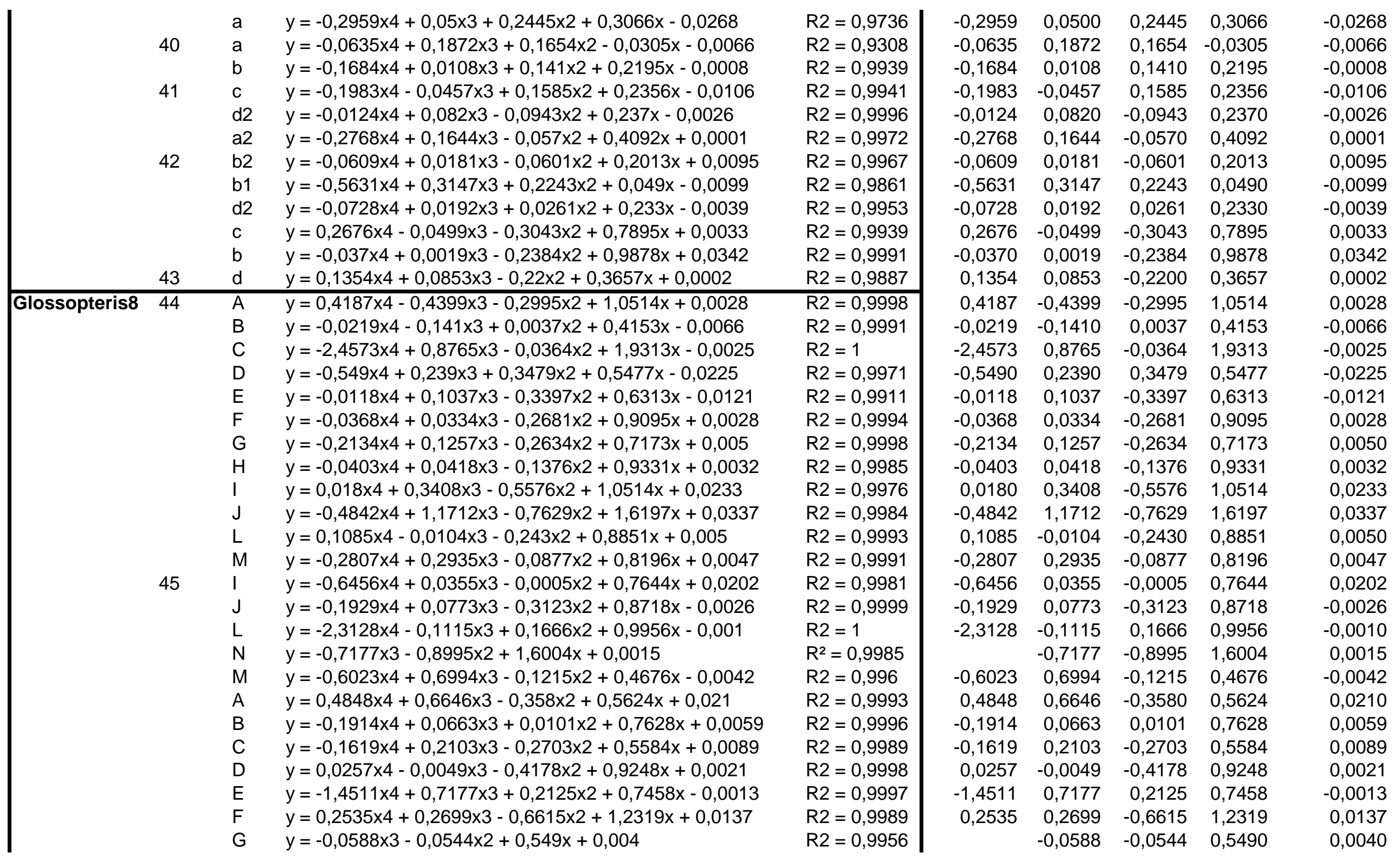




\begin{tabular}{|c|c|c|c|c|c|c|c|c|}
\hline & $\mathrm{H}$ & $y=-0,2836 \times 4+0,1159 x 3+0,1468 \times 2+0,5115 x-0,0026$ & $R 2=0,9939$ & $-0,2836$ & 0,1159 & 0,1468 & 0,5115 & $-0,0026$ \\
\hline \multirow[t]{13}{*}{ Glossopteris9 } & $\bar{A}$ & $y=0,1044 x 4+0,0168 \times 3-0,2864 \times 2+0,8577 x+0,0076$ & $\mathrm{R} 2=0,9999$ & 0,1044 & 0,0168 & $-0,2864$ & 0,8577 & 0,0076 \\
\hline & B & $y=-0,5748 x 4+2,1141 \times 3-0,9476 \times 2+1,2088 x-0,0015$ & $\mathrm{R} 2=0,9922$ & $-0,5748$ & 2,1141 & $-0,9476$ & 1,2088 & $-0,0015$ \\
\hline & C & $y=0,337 x 4-0,004 \times 3-0,3417 x 2+1,0449 x-0,0043$ & $\mathrm{R} 2=0,9995$ & 0,3370 & $-0,0040$ & $-0,3417$ & 1,0449 & $-0,0043$ \\
\hline & D & $y=-6,6725 x 4+3,4868 \times 3+0,7672 x 2+1,3149 x-0,0072$ & $\mathrm{R} 2=0,9994$ & $-6,6725$ & 3,4868 & 0,7672 & 1,3149 & $-0,0072$ \\
\hline & $\mathrm{H}$ & $y=-0,275 x 4+0,0924 x 3+0,0798 \times 2+0,8757 x-0,0089$ & $\mathrm{R} 2=0,9984$ & $-0,2750$ & 0,0924 & 0,0798 & 0,8757 & $-0,0089$ \\
\hline & 1 & $y=-0,6034 \times 4-0,4142 \times 3-0,135 \times 2+1,9345 x-0,0079$ & $\mathrm{R} 2=0,9987$ & $-0,6034$ & $-0,4142$ & $-0,1350$ & 1,9345 & $-0,0079$ \\
\hline & $\mathrm{L}$ & $y=-1,3645 x 4+0,3941 \times 3+0,8059 x 2+1,3726 x-0,0185$ & $\mathrm{R} 2=0,9995$ & $-1,3645$ & 0,3941 & 0,8059 & 1,3726 & $-0,0185$ \\
\hline & $\mathrm{N}$ & $y=-0,1818 x 4+0,2863 \times 3-0,099 x 2+0,6825 x+0,0034$ & $\mathrm{R} 2=0,9991$ & $-0,1818$ & 0,2863 & $-0,0990$ & 0,6825 & 0,0034 \\
\hline & Q & $y=-158,33 x 4+121,67 \times 3-30,917 x 2+5,5333 x+5 E-13$ & $R^{2}=1$ & & $-23,2860$ & 12,4140 & 0,9377 & 0,0366 \\
\hline & $\mathrm{R}$ & $y=5,4785 x 4-2,8543 \times 3-1,2591 x 2+2,2785 x-0,0292$ & $\mathrm{R} 2=0,9991$ & 5,4785 & $-2,8543$ & $-1,2591$ & 2,2785 & $-0,0292$ \\
\hline & $\mathrm{U}$ & $y=-0,4749 x 4-0,5707 \times 3-0,1442 x 2+1,161 x+0,0187$ & $\mathrm{R} 2=0,9993$ & $-0,4749$ & $-0,5707$ & $-0,1442$ & 1,1610 & 0,0187 \\
\hline & V & $y=-0,0383 x 4+0,0914 \times 3-0,2214 \times 2+1,1746 x+0,0024$ & $R 2=0,9996$ & $-0,0383$ & 0,0914 & $-0,2214$ & 1,1746 & 0,0024 \\
\hline & W & $y=-1,161 \times 4+0,6448 \times 3+0,3283 \times 2+1,0533 x-0,0088$ & $\mathrm{R} 2=0,9996$ & $-1,1610$ & 0,6448 & 0,3283 & 1,0533 & $-0,0088$ \\
\hline \multirow[t]{22}{*}{ Glossopteris10 47} & $\bar{A}$ & $y=-0,033 x 4-0,0238 \times 3-0,0886 x 2+0,4228 x+0,0162$ & $\mathrm{R} 2=0,9988$ & $-0,0330$ & $-0,0238$ & $-0,0886$ & 0,4228 & 0,0162 \\
\hline & B & $y=0,7976 x 4-0,7617 x 3-0,3774 x 2+1,8756 x-0,0199$ & $\mathrm{R} 2=0,9994$ & 0,7976 & $-0,7617$ & $-0,3774$ & 1,8756 & $-0,0199$ \\
\hline & C & $y=0,0782 x 4-0,0267 x 3-0,2626 x 2+1,1083 x-0,0111$ & $\mathrm{R} 2=0,9987$ & 0,0782 & $-0,0267$ & $-0,2626$ & 1,1083 & $-0,0111$ \\
\hline & D & $y=0,0377 x 4+0,0916 \times 3-0,3107 x 2+0,2586 x+0,0105$ & $R 2=0,9662$ & 0,0377 & 0,0916 & $-0,3107$ & 0,2586 & 0,0105 \\
\hline & G & $y=0,5401 x 4-0,2686 \times 3-0,3691 x 2+0,8242 x-0,022$ & $\mathrm{R} 2=0,9982$ & 0,5401 & $-0,2686$ & $-0,3691$ & 0,8242 & $-0,0220$ \\
\hline & J & $y=0,2886 x 4-0,4789 x 3-0,17 x 2+1,2525 x-0,0038$ & $\mathrm{R} 2=0,9981$ & 0,2886 & $-0,4789$ & $-0,1700$ & 1,2525 & $-0,0038$ \\
\hline & $\mathrm{K}$ & $y=-0,2261 x 4+0,0845 \times 3+0,1141 x 2+0,5631 x+0,003$ & $R 2=0,9995$ & $-0,2261$ & 0,0845 & 0,1141 & 0,5631 & 0,0030 \\
\hline & $\mathrm{L}$ & $y=-0,0297 x 4+0,0455 \times 3-0,0854 \times 2+0,4004 x-0,0091$ & $\mathrm{R} 2=0,9991$ & $-0,0297$ & 0,0455 & $-0,0854$ & 0,4004 & $-0,0091$ \\
\hline & M & $y=-0,631 x 4-0,012 x 3+0,3057 x 2+1,3329 x-0,0555$ & $\mathrm{R} 2=0,9972$ & $-0,6310$ & $-0,0120$ & 0,3057 & 1,3329 & $-0,0555$ \\
\hline & $\mathrm{O}$ & $y=0,0291 x 4+0,2642 \times 3+0,0283 x 2+1,2483 x-0,0294$ & $\mathrm{R} 2=0,9988$ & 0,0291 & 0,2642 & 0,0283 & 1,2483 & $-0,0294$ \\
\hline & $\mathrm{N}$ & $y=-0,6993 x 4-0,1671 x 3+0,169 \times 2+1,8197 x+0,0219$ & $\mathrm{R} 2=0,9988$ & $-0,6993$ & $-0,1671$ & 0,1690 & 1,8197 & 0,0219 \\
\hline & A & $y=-0,0773 \times 4-0,0328 \times 3-0,0313 \times 2+0,5732 x+0,0008$ & $\mathrm{R} 2=0,9996$ & $-0,0773$ & $-0,0328$ & $-0,0313$ & 0,5732 & 0,0008 \\
\hline & B & $y=-1,2529 \times 4-0,6663 \times 3-0,0096 \times 2+0,8107 x-0,0065$ & $R 2=0,9993$ & $-1,2529$ & $-0,6663$ & $-0,0096$ & 0,8107 & $-0,0065$ \\
\hline & C & $y=-0,0512 x 4-0,073 \times 3+0,0204 x 2+0,5563 x+0,0011$ & $\mathrm{R} 2=0,9988$ & $-0,0512$ & $-0,0730$ & 0,0204 & 0,5563 & 0,0011 \\
\hline & D & $y=0,522 x 4+0,6513 \times 3-0,3762 \times 2+0,0672 x+0,0107$ & $\mathrm{R} 2=0,9529$ & 0,5220 & 0,6513 & $-0,3762$ & 0,0672 & 0,0107 \\
\hline & $\mathrm{E}$ & $y=-0,2508 \times 4+0,2263 \times 3-0,0384 \times 2+0,4693 x-0,007$ & $\mathrm{R} 2=0,9994$ & $-0,2508$ & 0,2263 & $-0,0384$ & 0,4693 & $-0,0070$ \\
\hline & $\mathrm{F}$ & $y=-0,3905 \times 4-0,2805 \times 3+0,0859 \times 2+1,0755 x-0,0167$ & $\mathrm{R} 2=0,9983$ & $-0,3905$ & $-0,2805$ & 0,0859 & 1,0755 & $-0,0167$ \\
\hline & G & $y=-0,0458 x 4+0,0561 \times 3-0,133 \times 2+0,4269 x+0,0172$ & $\mathrm{R} 2=0,9989$ & $-0,0458$ & 0,0561 & $-0,1330$ & 0,4269 & 0,0172 \\
\hline & $\mathrm{H}$ & $y=-0,0362 x 4+0,0889 \times 3-0,1768 \times 2+0,4513 x-0,0061$ & $\mathrm{R} 2=0,9996$ & $-0,0362$ & 0,0889 & $-0,1768$ & 0,4513 & $-0,0061$ \\
\hline & I & $y=-0,13 x 4+0,1304 x 3+0,091 x 2+0,2239 x+0,0057$ & $\mathrm{R} 2=0,9974$ & $-0,1300$ & 0,1304 & 0,0910 & 0,2239 & 0,0057 \\
\hline & $\mathrm{J}$ & $y=-0,0739 x 4+0,0649 \times 3-0,1405 \times 2+0,9831 x-0,0133$ & $\mathrm{R} 2=0,9995$ & $-0,0739$ & 0,0649 & $-0,1405$ & 0,9831 & $-0,0133$ \\
\hline & $\mathrm{K}$ & $y=0,9581 x 4-1,8504 x 3+0,0167 x 2+1,8447 x+0,008$ & $\mathrm{R} 2=0,9992$ & 0,9581 & $-1,8504$ & 0,0167 & 1,8447 & 0,0080 \\
\hline
\end{tabular}




\begin{tabular}{|c|c|c|c|c|c|c|c|c|}
\hline & $\begin{array}{l}L \\
M\end{array}$ & $\begin{array}{l}y=0,2295 \times 4+0,3387 \times 3-0,3589 \times 2+0,8714 x-0,0147 \\
y=-0,0924 \times 4+0,0785 \times 3-0,2149 \times 2+0,9351 x-0,0031\end{array}$ & $\begin{array}{l}R 2=0,9996 \\
R 2=0,9998\end{array}$ & $\begin{array}{r}0,2295 \\
-0,0924\end{array}$ & $\begin{array}{l}0,3387 \\
0,0785\end{array}$ & $\begin{array}{l}-0,3589 \\
-0,2149\end{array}$ & $\begin{array}{l}0,8714 \\
0,9351\end{array}$ & $\begin{array}{l}-0,0147 \\
-0,0031\end{array}$ \\
\hline \multirow[t]{24}{*}{ Glossopteris11 49} & $\bar{B}$ & $y=-2,2658 \times 4+1,6994 \times 3-0,694 \times 2+0,9529 x-0,0086$ & $\mathrm{R} 2=0,9897$ & $-2,2658$ & 1,6994 & $-0,6940$ & 0,9529 & $-0,0086$ \\
\hline & C & $y=0,4713 x 4-0,3289 \times 3-0,9187 x 2+0,5869 x-0,0214$ & $R 2=0,9911$ & 0,4713 & $-0,3289$ & $-0,9187$ & 0,5869 & $-0,0214$ \\
\hline & D & $y=0,1815 x 4-0,0788 \times 3-0,0203 x 2+0,6175 x-0,0038$ & $\mathrm{R} 2=0,9981$ & 0,1815 & $-0,0788$ & $-0,0203$ & 0,6175 & $-0,0038$ \\
\hline & $\mathrm{E}$ & $y=-0,7284 x 4+0,6436 \times 3+0,4033 x 2+0,1997 x-0,0133$ & $\mathrm{R} 2=0,9943$ & $-0,7284$ & 0,6436 & 0,4033 & 0,1997 & $-0,0133$ \\
\hline & $\mathrm{F}$ & $y=-0,2967 x 4-0,1737 x 3+0,2504 x 2+1,0046 x-0,0055$ & $\mathrm{R} 2=0,9979$ & $-0,2967$ & $-0,1737$ & 0,2504 & 1,0046 & $-0,0055$ \\
\hline & I & $y=0,1336 x 4+0,6742 x 3+0,0633 x 2+0,5997 x+0,0165$ & $\mathrm{R} 2=0,997$ & 0,1336 & 0,6742 & 0,0633 & 0,5997 & 0,0165 \\
\hline & $\mathrm{K}$ & $y=0,3275 x 4-0,0341 x 3-0,4051 x 2+0,0422 x+5 E-05$ & $\mathrm{R} 2=0,8224$ & 0,3275 & $-0,0341$ & $-0,4051$ & 0,0422 & 0,0001 \\
\hline & M & $y=-0,2649 x 4+0,235 \times 3+0,0707 \times 2+0,0827 x-0,0166$ & $R 2=0,9795$ & $-0,2649$ & 0,2350 & 0,0707 & 0,0827 & $-0,0166$ \\
\hline & $\mathrm{N}$ & $y=-0,3658 x 4+0,3127 x 3+0,0372 x 2+0,1028 x+0,0002$ & $\mathrm{R} 2=0,9881$ & $-0,3658$ & 0,3127 & 0,0372 & 0,1028 & 0,0002 \\
\hline & $\mathrm{P}$ & $y=-0,2307 x 4+0,1131 x 3+0,0236 x 2+0,4514 x-0,0071$ & $\mathrm{R} 2=0,998$ & $-0,2307$ & 0,1131 & 0,0236 & 0,4514 & $-0,0071$ \\
\hline & $\mathrm{R}$ & $y=-0,4442 x 4+0,2857 x 3+0,0284 x 2+0,8952 x-0,0058$ & $\mathrm{R} 2=0,9995$ & $-0,4442$ & 0,2857 & 0,0284 & 0,8952 & $-0,0058$ \\
\hline & A & $y=0,0519 x 4+0,0887 \times 3-0,1308 \times 2+0,2608 x+0,0097$ & $\mathrm{R} 2=0,9879$ & 0,0519 & 0,0887 & $-0,1308$ & 0,2608 & 0,0097 \\
\hline & B & $y=0,1269 \times 4+0,1869 \times 3-0,1928 \times 2+0,6679 x+0,0248$ & $\mathrm{R} 2=0,9981$ & 0,1269 & 0,1869 & $-0,1928$ & 0,6679 & 0,0248 \\
\hline & C & $y=0,2155 x 4+0,162 x 3-0,4718 x 2+0,8098 x-0,0277$ & $\mathrm{R} 2=0,996$ & 0,2155 & 0,1620 & $-0,4718$ & 0,8098 & $-0,0277$ \\
\hline & D & $y=-0,1401 x 4+0,1814 x 3+0,0334 x 2+0,0248 x-0,0078$ & $\mathrm{R} 2=0,9937$ & $-0,1401$ & 0,1814 & 0,0334 & 0,0248 & $-0,0078$ \\
\hline & $\mathrm{E}$ & $y=0,1733 x 4-0,0267 x 3-0,2681 \times 2+0,4314 x-0,0028$ & $\mathrm{R} 2=0,9988$ & 0,1733 & $-0,0267$ & $-0,2681$ & 0,4314 & $-0,0028$ \\
\hline & $\mathrm{F}$ & $y=0,189 x 4+0,0425 x 3-0,1916 x 2+0,6417 x-0,0025$ & $\mathrm{R} 2=0,9987$ & 0,1890 & 0,0425 & $-0,1916$ & 0,6417 & $-0,0025$ \\
\hline & $\mathrm{H}$ & $y=-0,5245 x 4+0,6294 x 3-0,3811 x 2+1,1196 x-0,0188$ & $\mathrm{R} 2=0,9972$ & $-0,5245$ & 0,6294 & $-0,3811$ & 1,1196 & $-0,0188$ \\
\hline & I & $y=-0,5588 x 4+0,0891 x 3+0,6089 x 2+0,9987 x-0,0282$ & $\mathrm{R} 2=0,9943$ & $-0,5588$ & 0,0891 & 0,6089 & 0,9987 & $-0,0282$ \\
\hline & $\mathrm{J}$ & $y=-0,2708 x 4-0,641 x 3+0,0566 x 2+1,58 x-0,0077$ & $\mathrm{R} 2=0,9994$ & $-0,2708$ & $-0,6410$ & 0,0566 & 1,5800 & $-0,0077$ \\
\hline & $\mathrm{K}$ & $y=1,0455 x 4-0,4208 \times 3-0,6123 x 2+1,4171 x-0,0313$ & $\mathrm{R} 2=0,9987$ & 1,0455 & $-0,4208$ & $-0,6123$ & 1,4171 & $-0,0313$ \\
\hline & M & $y=-0,2497 x 4+0,1302 x 3+0,2103 x 2+0,7116 x-0,0232$ & $\mathrm{R} 2=0,9982$ & $-0,2497$ & 0,1302 & 0,2103 & 0,7116 & $-0,0232$ \\
\hline & $\mathrm{N}$ & $y=-0,0225 x 4+0,2457 \times 3-0,2629 \times 2+0,9413 x-0,0065$ & $R 2=0,9993$ & $-0,0225$ & 0,2457 & $-0,2629$ & 0,9413 & $-0,0065$ \\
\hline & Q & $y=0,8159 x 4+1,5346 \times 3-2,8415 x 2+2,347 x-0,0086$ & $\mathrm{R} 2=0,9994$ & 0,8159 & 1,5346 & $-2,8415$ & 2,3470 & $-0,0086$ \\
\hline \multirow[t]{10}{*}{ Glossopteris12 51} & A & $y=0,0001 x 4+0,0724 x 3-0,0061 x 2+0,0212 x+0,001$ & $R^{2}=0,9599$ & 0,0001 & 0,0724 & $-0,0061$ & 0,0212 & 0,0010 \\
\hline & B & $y=-0,014 x 4+0,1023 \times 3-0,3317 x 2+0,4062 x-0,0012$ & $R^{2}=0,9986$ & $-0,0140$ & 0,1023 & $-0,3317$ & 0,4062 & $-0,0012$ \\
\hline & D & $y=-0,1137 x 4-0,0003 \times 3+0,0307 x 2+0,1848 x+0,0071$ & $R^{2}=0,998$ & $-0,1137$ & $-0,0003$ & 0,0307 & 0,1848 & 0,0071 \\
\hline & $\mathrm{E}$ & $y=0,0346 \times 4+0,2544 \times 3+0,0985 \times 2-0,0159 x-0,0014$ & $R^{2}=0,989$ & 0,0346 & 0,2544 & 0,0985 & $-0,0159$ & $-0,0014$ \\
\hline & $\mathrm{F}$ & $y=-0,0957 x 4-0,079 \times 3+0,0461 \times 2+0,1853 x+0,0018$ & $R^{2}=0,9931$ & $-0,0957$ & $-0,0790$ & 0,0461 & 0,1853 & 0,0018 \\
\hline & G & $y=-0,1189 x 4+0,0513 \times 3+0,0985 x 2+0,1289 x+0,0005$ & $R^{2}=0,9943$ & $-0,1189$ & 0,0513 & 0,0985 & 0,1289 & 0,0005 \\
\hline & $\mathrm{H}$ & $y=0,0199 \times 4+0,0618 \times 3+0,0027 \times 2+0,101 x+0,0034$ & $R^{2}=0,9896$ & 0,0199 & 0,0618 & 0,0027 & 0,1010 & 0,0034 \\
\hline & I & $y=-0,1133 x 4+0,0723 \times 3-0,012 \times 2+0,0296 x-0,0062$ & $R^{2}=0,9832$ & $-0,1133$ & 0,0723 & $-0,0120$ & 0,0296 & $-0,0062$ \\
\hline & $\mathrm{J}$ & $y=-0,1308 \times 4+0,073 \times 3+0,0597 \times 2+0,0435 x-0,0059$ & $R^{2}=0,9923$ & $-0,1308$ & 0,0730 & 0,0597 & 0,0435 & $-0,0059$ \\
\hline & A & $y=-0,015 x 4+0,0204 \times 3-0,0056 \times 2+0,179 x+0,0097$ & $R^{2}=0,9916$ & $-0,0150$ & 0,0204 & $-0,0056$ & 0,1790 & 0,0097 \\
\hline
\end{tabular}




\begin{tabular}{|c|c|c|c|c|c|c|c|c|}
\hline & B & $y=-0,1948 x 4-0,0895 x 3+0,1588 \times 2+0,5737 x+0,0102$ & $R^{2}=0,9962$ & $-0,1948$ & $-0,0895$ & 0,1588 & 0,5737 & 0,0102 \\
\hline & D & $y=0,0083 \times 4+0,0221 \times 3-0,0295 \times 2+0,1804 x-0,0178$ & $R^{2}=0,9872$ & 0,0083 & 0,0221 & $-0,0295$ & 0,1804 & $-0,0178$ \\
\hline & $\mathrm{F}$ & $y=-0,0454 \times 4+0,1335 \times 3+0,0985 x 2+0,1049 x+0,0054$ & $R^{2}=0,9914$ & $-0,0454$ & 0,1335 & 0,0985 & 0,1049 & 0,0054 \\
\hline & $\mathrm{E}$ & $y=-0,2506 \times 4-0,4024 \times 3-0,0554 \times 2+0,1674 x+0,0066$ & $R^{2}=0,9864$ & $-0,2506$ & $-0,4024$ & $-0,0554$ & 0,1674 & 0,0066 \\
\hline & G & $y=-0,1501 x 4+0,101 x 3+0,0443 x 2+0,0346 x-0,0025$ & $R^{2}=0,9654$ & $-0,1501$ & 0,1010 & 0,0443 & 0,0346 & $-0,0025$ \\
\hline & $\mathrm{H}$ & $y=-0,2352 x 4+0,1104 x 3+0,0622 x 2+0,0812 x-0,0057$ & $R^{2}=0,99$ & $-0,2352$ & 0,1104 & 0,0622 & 0,0812 & $-0,0057$ \\
\hline 53 & A & $y=0,0805 x 4+0,1164 \times 3-0,2849 x 2+0,1525 x-0,0035$ & $R^{2}=0,9961$ & 0,0805 & 0,1164 & $-0,2849$ & 0,1525 & $-0,0035$ \\
\hline & B & $y=0,0387 x 4-0,0729 \times 3-0,0748 \times 2+0,6129 x-0,008$ & $R^{2}=0,999$ & 0,0387 & $-0,0729$ & $-0,0748$ & 0,6129 & $-0,0080$ \\
\hline & C & $y=-0,0661 x 4+0,1584 x 3-0,1103 x 2+0,1245 x+0,0037$ & $R^{2}=0,9983$ & $-0,0661$ & 0,1584 & $-0,1103$ & 0,1245 & 0,0037 \\
\hline & D & $y=-0,0208 x 4-0,269 \times 3-0,3805 x 2+1,1238 x-0,0112$ & $R^{2}=0,9991$ & $-0,0208$ & $-0,2690$ & $-0,3805$ & 1,1238 & $-0,0112$ \\
\hline & E & $y=0,1101 x 4+0,2663 \times 3-0,1857 x 2+0,3098 x-0,0047$ & $R^{2}=0,9981$ & 0,1101 & 0,2663 & $-0,1857$ & 0,3098 & $-0,0047$ \\
\hline & $\mathrm{F}$ & $y=-0,0523 x 4+0,2518 \times 3-0,3143 \times 2+0,5803 x+0,0039$ & $R^{2}=0,9989$ & $-0,0523$ & 0,2518 & $-0,3143$ & 0,5803 & 0,0039 \\
\hline & $\mathrm{H}$ & $y=0,1188 x 4+0,133 \times 3-0,1163 x 2-0,157 x-0,0144$ & $R^{2}=0,9449$ & 0,1188 & 0,1330 & $-0,1163$ & $-0,1570$ & $-0,0144$ \\
\hline & I & $y=-0,4047 x 4+0,2793 \times 3-0,1561 x 2+0,9108 x-0,0014$ & $R^{2}=0,9999$ & $-0,4047$ & 0,2793 & $-0,1561$ & 0,9108 & $-0,0014$ \\
\hline & $\mathrm{J}$ & $y=0,1962 x 4-0,2847 x 3-0,2762 x 2+1,128 x-0,0081$ & $R^{2}=0,9986$ & 0,1962 & $-0,2847$ & $-0,2762$ & 1,1280 & $-0,0081$ \\
\hline & $\mathrm{K}$ & $y=-0,2704 x 4+0,0157 x 3+0,1631 x 2+0,6532 x-0,007$ & $R^{2}=0,9972$ & $-0,2704$ & 0,0157 & 0,1631 & 0,6532 & $-0,0070$ \\
\hline Glossopteris13 54 & $\bar{A}$ & $Y=0,1775 \times 4+0,1646 \times 3-0,0875 \times 2+0,1746 x-0,0007$ & $\mathrm{R}^{2}=0,9978$ & 0,1775 & 0,1646 & $-0,0875$ & 0,1746 & $-0,0007$ \\
\hline & C & $y=-0,348 \times 4+0,1427 x 3+0,0363 \times 2+0,689 x+0,0099$ & $R^{2}=0,9985$ & $-0,3480$ & 0,1427 & 0,0363 & 0,6890 & 0,0099 \\
\hline & D & $y=-0,2122 x 4-0,0745 x 3+0,0163 x 2+0,6926 x+0,0094$ & $R^{2}=0,9996$ & $-0,2122$ & $-0,0745$ & 0,0163 & 0,6926 & 0,0094 \\
\hline & $\mathrm{E}$ & $y=0,0421 x 4+0,1612 \times 3-0,2501 x 2+0,4209 x-0,0127$ & $R^{2}=0,9991$ & 0,0421 & 0,1612 & $-0,2501$ & 0,4209 & $-0,0127$ \\
\hline & G & $y=0,3891 x 4-0,2278 x 3-0,3648 x 2+1,3937 x-0,0073$ & $R^{2}=0,9995$ & 0,3891 & $-0,2278$ & $-0,3648$ & 1,3937 & $-0,0073$ \\
\hline & $\mathrm{H}$ & $y=-0,2721 x 4+0,2219 \times 3-0,1115 x 2+0,5696 x+0,0005$ & $R^{2}=0,999$ & $-0,2721$ & 0,2219 & $-0,1115$ & 0,5696 & 0,0005 \\
\hline & 1 & $y=-0,0713 x 4+0,0501 x 3-0,0321 x 2+0,6584 x-0,0196$ & $R^{2}=0,9985$ & $-0,0713$ & 0,0501 & $-0,0321$ & 0,6584 & $-0,0196$ \\
\hline & J & $y=-3,4887 x 4+1,7128 \times 3+0,0244 x 2+1,6351 x+0,0178$ & $R^{2}=0,9997$ & $-3,4887$ & 1,7128 & 0,0244 & 1,6351 & 0,0178 \\
\hline & $\mathrm{K}$ & $y=-0,2029 x 4+0,0676 \times 3+0,3412 x 2+0,3195 x-0,0258$ & $R^{2}=0,9886$ & $-0,2029$ & 0,0676 & 0,3412 & 0,3195 & $-0,0258$ \\
\hline & L & $y=0,5132 x 4-0,3891 x 3-0,1541 x 2+0,9916 x-0,0115$ & $R^{2}=0,9994$ & 0,5132 & $-0,3891$ & $-0,1541$ & 0,9916 & $-0,0115$ \\
\hline & M & $y=-0,1336 x 4+0,1335 x 3+0,0147 x 2+0,2762 x-0,0111$ & $R^{2}=0,9969$ & $-0,1336$ & 0,1335 & 0,0147 & 0,2762 & $-0,0111$ \\
\hline & $\mathrm{N}$ & $y=0,1793 \times 4+0,113 \times 3-0,4584 x 2+0,9009 x-0,0017$ & $R^{2}=0,9998$ & 0,1793 & 0,1130 & $-0,4584$ & 0,9009 & $-0,0017$ \\
\hline & 0 & $y=-0,4009 x 4+0,5091 \times 3-0,3598 \times 2+1,084 x+0,0027$ & $R^{2}=0,9998$ & $-0,4009$ & 0,5091 & $-0,3598$ & 1,0840 & 0,0027 \\
\hline & $\mathrm{P}$ & $y=-1,6969 x 4+1,0412 \times 3-0,3294 x 2+1,5133 x+0,001$ & $R^{2}=0,9998$ & $-1,6969$ & 1,0412 & $-0,3294$ & 1,5133 & 0,0010 \\
\hline & Q & $y=-0,1877 x 4+0,5564 \times 3-0,0049 x 2+1,53 x-0,0226$ & $R^{2}=0,9996$ & $-0,1877$ & 0,5564 & $-0,0049$ & 1,5300 & $-0,0226$ \\
\hline
\end{tabular}




\begin{tabular}{|c|c|c|c|c|c|c|c|c|c|c|c|c|c|c|}
\hline \multirow{2}{*}{\multicolumn{3}{|c|}{$\begin{array}{l}\text { Densidad venación } \\
N^{\circ} \text { de venas en } x=\end{array}$}} & \multicolumn{12}{|c|}{ Densidad anastomosis } \\
\hline & & & \multicolumn{3}{|c|}{ Zona proximal x[-1, $-0,4]$} & & \multicolumn{4}{|c|}{ Zona media x[-0,4,0,4] } & \multicolumn{4}{|c|}{ Zona distal x[0,4;1] } \\
\hline$-0,4$ & 0 & 0,4 & $\mathrm{~T}$ & \begin{tabular}{|l|l}
$\lambda$ & \\
\end{tabular} & \begin{tabular}{|l|l}
$X$ & \\
\end{tabular} & $\mathrm{Y}$ & \begin{tabular}{l|l}
$T$ \\
\end{tabular} & \begin{tabular}{|l|}
$\lambda$ \\
\end{tabular} & $\mathrm{X}$ & Dicot & $\mathrm{T}$ & \begin{tabular}{|l|l}
$\lambda$ & \\
\end{tabular} & $\mathrm{X}$ & Dicot \\
\hline 16 & 14 & 17 & 4 & 6 & 0 & 12 & 11 & 5 & 0 & \begin{tabular}{r|}
5 \\
\end{tabular} & 2 & 10 & 0 & 3 \\
\hline 25 & 32 & 35 & 9 & 5 & 0 & 15 & 9 & 8 & 0 & 8 & 8 & 1 & 0 & 3 \\
\hline 15 & 25 & 29 & 7 & 2 & 2 & 11 & 16 & 3 & 3 & 15 & 20 & 1 & 4 & 4 \\
\hline 14 & 15 & 16 & 4 & 0 & 0 & 10 & 11 & 0 & 0 & 1 & 5 & 0 & 0 & 5 \\
\hline 7 & 12 & 10 & 5 & 0 & 1 & 7 & 6 & 4 & 0 & 11 & 2 & 8 & 0 & 3 \\
\hline 16 & 21 & 25 & 4 & 0 & 3 & 3 & 9 & 4 & 2 & 14 & 12 & 0 & 0 & 5 \\
\hline 28 & 33 & 36 & 18 & 2 & 3 & 12 & 17 & 8 & 3 & 8 & 19 & 17 & 5 & 12 \\
\hline 23 & 23 & 28 & 6 & 8 & 0 & 11 & 6 & 13 & 0 & 5 & 24 & 2 & 0 & 5 \\
\hline 21 & 20 & 27 & 7 & 0 & 0 & 12 & 0 & 10 & 0 & 16 & 4 & 10 & 0 & 14 \\
\hline 24 & 23 & 30 & 5 & 11 & 0 & 17 & 18 & 11 & 0 & 7 & 17 & 3 & 0 & 5 \\
\hline 15 & 22 & 22 & 10 & 5 & 0 & 9 & 9 & 8 & 0 & 12 & 9 & 7 & 0 & 10 \\
\hline 23 & 25 & 31 & 4 & 2 & 0 & 8 & 9 & 4 & 0 & 7 & 7 & 3 & 0 & 7 \\
\hline 26 & 29 & 29 & 9 & 14 & 2 & 17 & 9 & 20 & 0 & 12 & 18 & 9 & 0 & 15 \\
\hline 6 & 9 & 13 & 2 & 1 & 0 & 3 & 3 & 1 & 0 & 6 & 3 & 2 & 0 & 1 \\
\hline 9 & 9 & 15 & 5 & 3 & 0 & 4 & 5 & 2 & 0 & 5 & 8 & 5 & 0 & 6 \\
\hline 8 & 9 & 9 & 2 & 1 & 1 & 4 & 4 & 2 & 0 & 4 & 3 & 4 & 0 & 8 \\
\hline 30 & 31 & 33 & 9 & 4 & 1 & 17 & 24 & 7 & 1 & 11 & 12 & 6 & 0 & 13 \\
\hline 17 & 21 & 21 & 11 & 7 & 0 & 15 & 15 & 4 & 0 & 12 & 19 & 4 & 0 & 6 \\
\hline 26 & 30 & 40 & 2 & 15 & 0 & 16 & 8 & 9 & 0 & 26 & 16 & 22 & 0 & 9 \\
\hline 14 & 16 & 20 & 11 & 0 & 0 & 6 & 2 & 7 & 0 & 15 & 10 & 7 & 0 & 11 \\
\hline 30 & 33 & 38 & 10 & 2 & 0 & 17 & 11 & 6 & 0 & 11 & 8 & 2 & 0 & 7 \\
\hline 30 & 39 & 44 & 6 & 0 & 0 & 15 & 10 & 7 & 0 & 19 & 10 & 2 & 2 & 5 \\
\hline 8 & 7 & 9 & 0 & 0 & 1 & 4 & 3 & 5 & 0 & 7 & 3 & 1 & 1 & 3 \\
\hline 9 & 8 & 11 & 1 & 0 & 0 & 5 & 4 & 2 & 0 & 4 & 3 & 2 & 0 & 2 \\
\hline 16 & 28 & 29 & 20 & 0 & 4 & 4 & 20 & 4 & 0 & 15 & 28 & 0 & 0 & 15 \\
\hline 15 & 20 & 24 & 9 & 8 & 0 & 7 & 12 & 5 & 0 & 4 & 13 & 0 & 0 & 0 \\
\hline 26 & 28 & 29 & 16 & 0 & 0 & 10 & 15 & 2 & 3 & 12 & 30 & 6 & 0 & 20 \\
\hline 7 & 7 & 7 & 3 & 0 & 0 & 2 & 5 & 0 & 0 & 2 & 2 & 2 & 0 & 3 \\
\hline 24 & 26 & 32 & 14 & 2 & 0 & 18 & 30 & 8 & 3 & 3 & 8 & 0 & 0 & 8 \\
\hline 12 & 12 & 15 & 9 & 3 & 0 & 0 & 8 & 2 & 0 & 7 & 5 & 1 & 0 & 3 \\
\hline 24 & 27 & 31 & 2 & 10 & 0 & 16 & 10 & 17 & 0 & 15 & 14 & 5 & 0 & 10 \\
\hline 14 & 16 & 20 & 8 & 1 & 0 & 8 & 3 & 5 & 0 & 19 & 0 & 3 & 4 & 20 \\
\hline
\end{tabular}




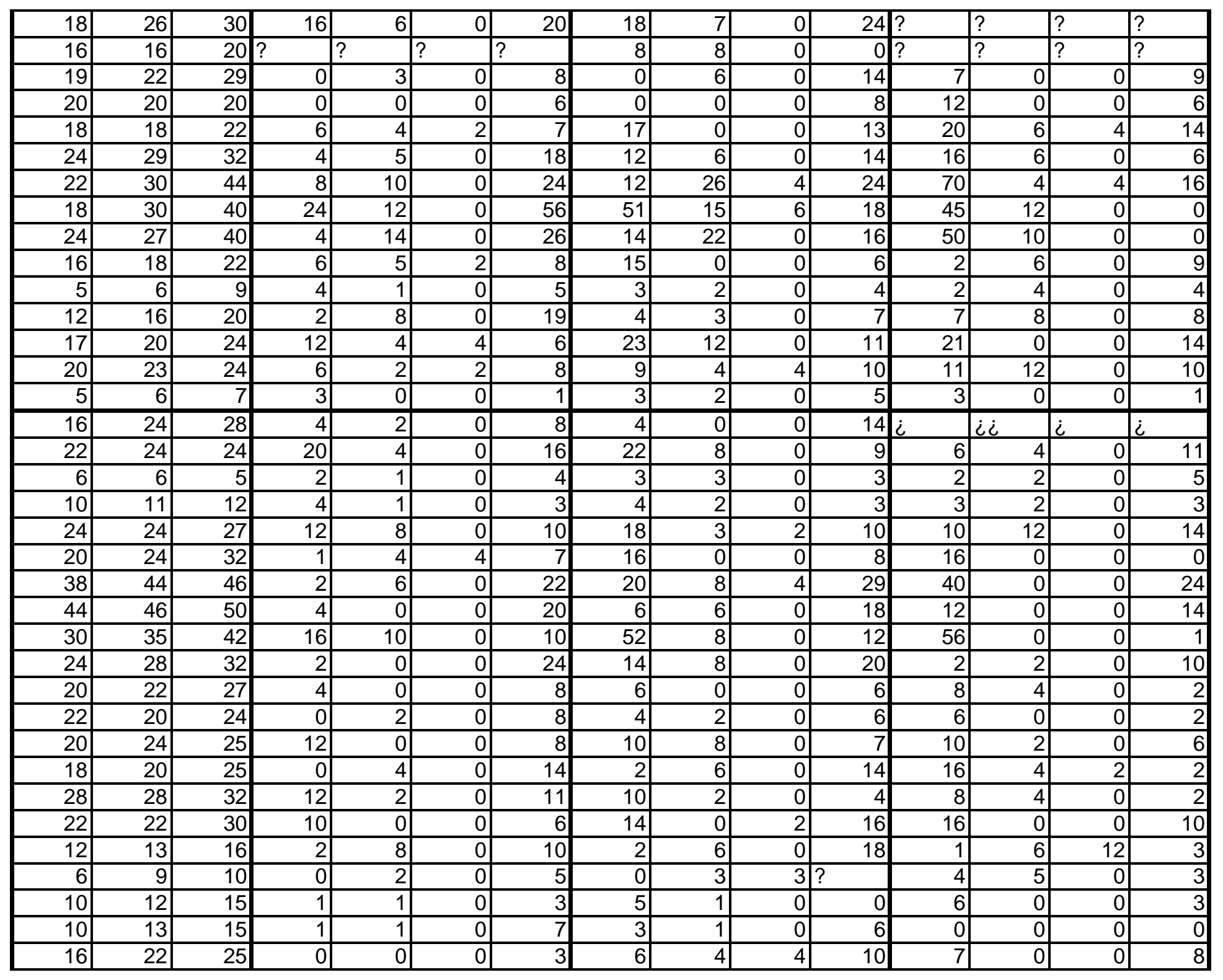




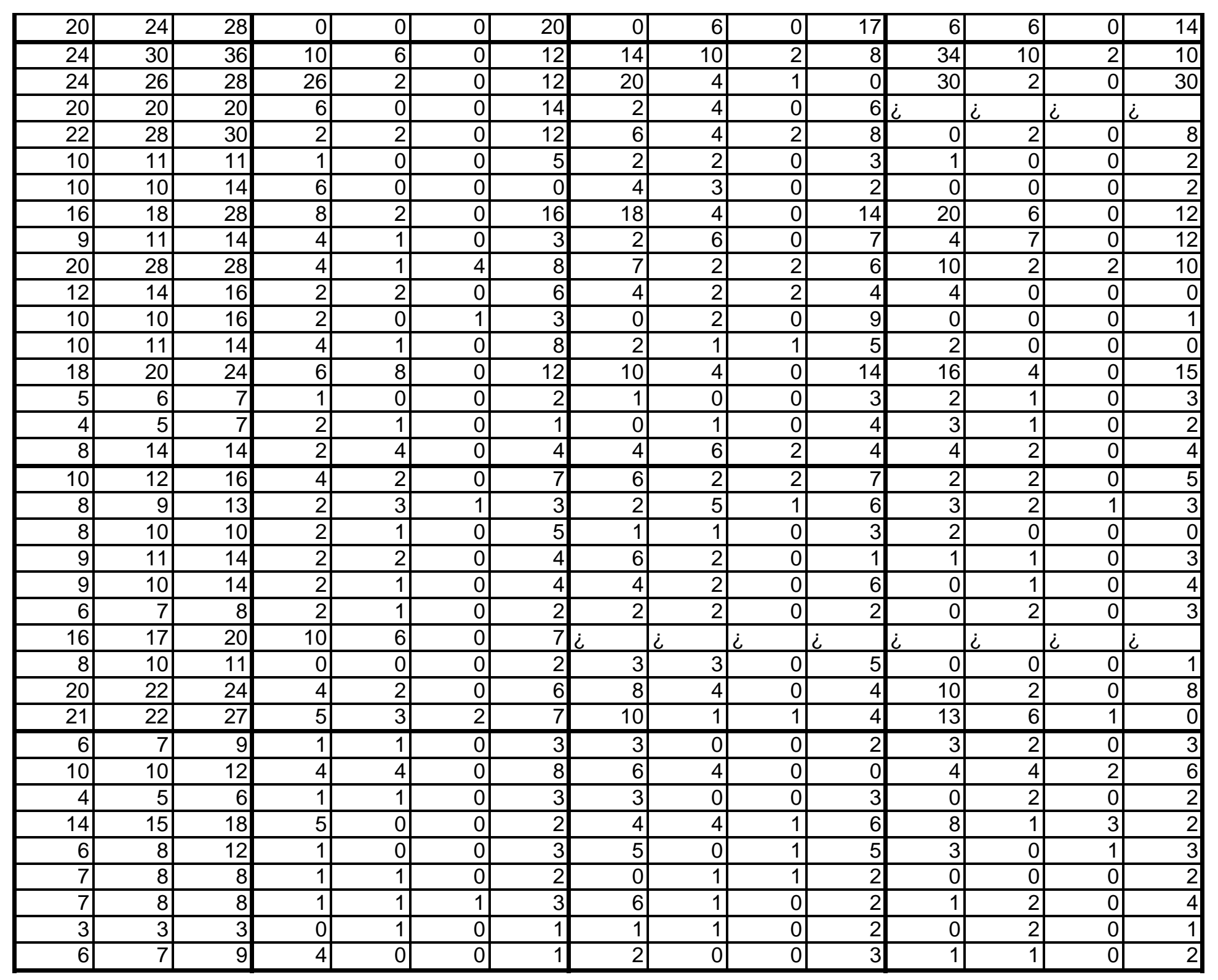




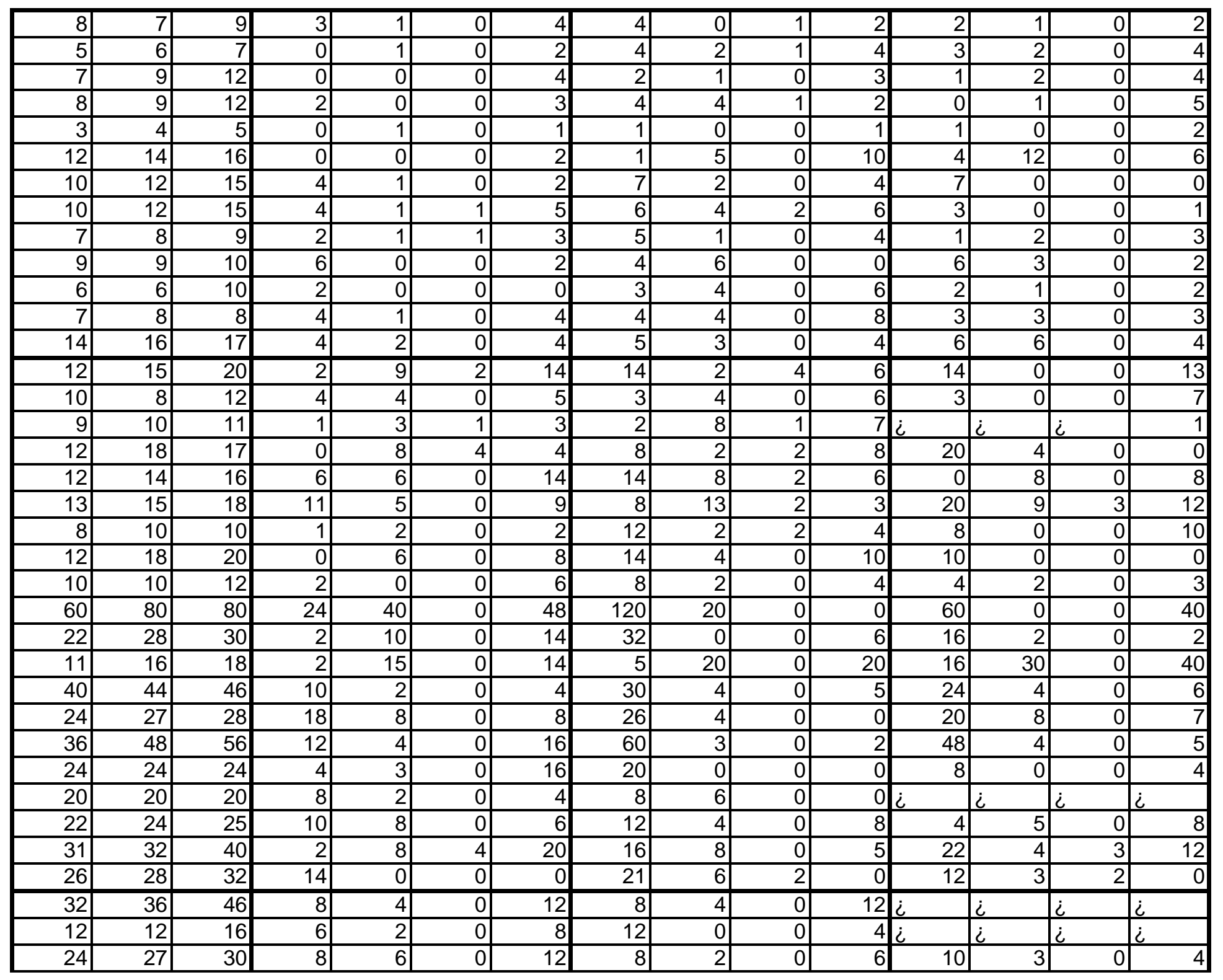




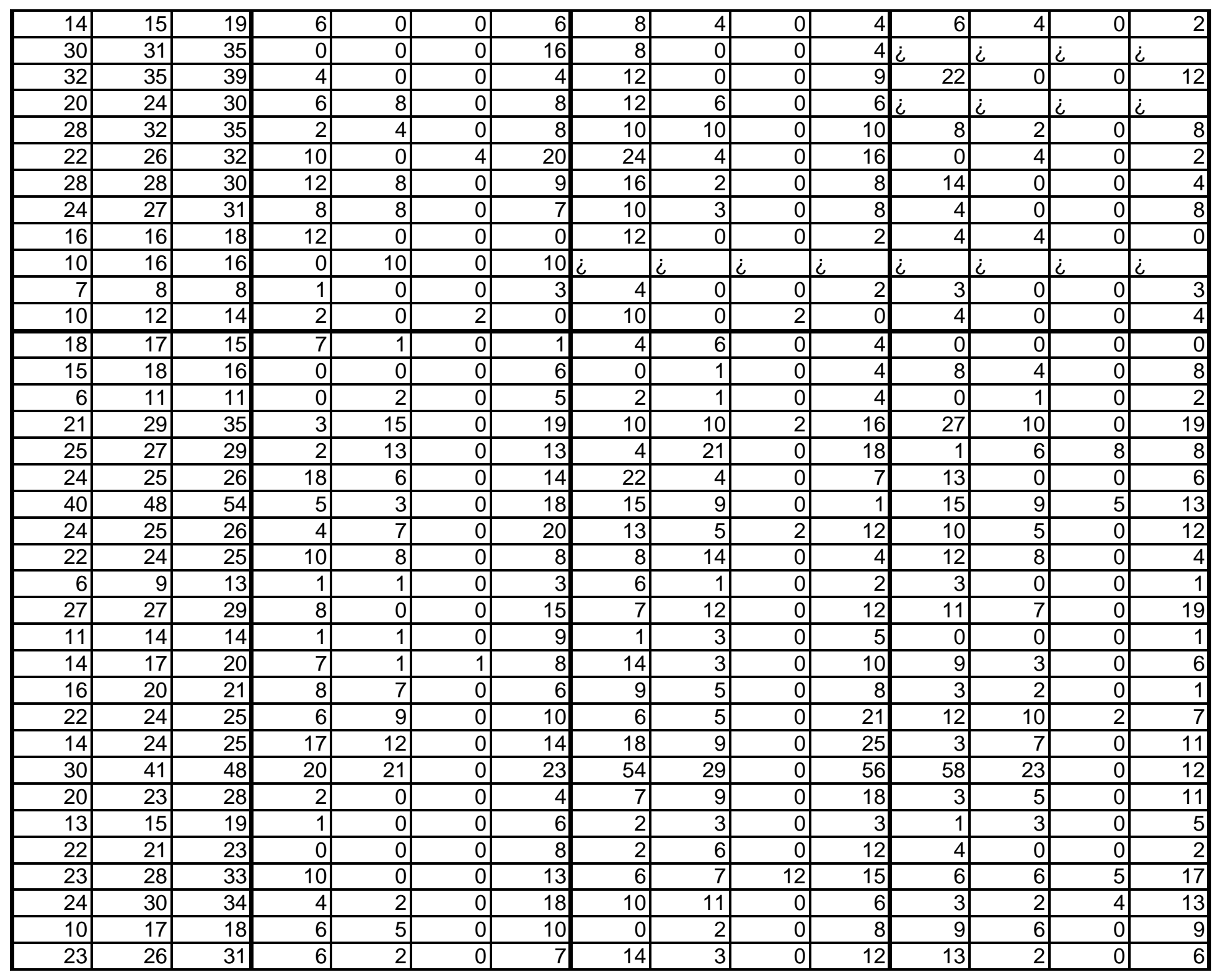




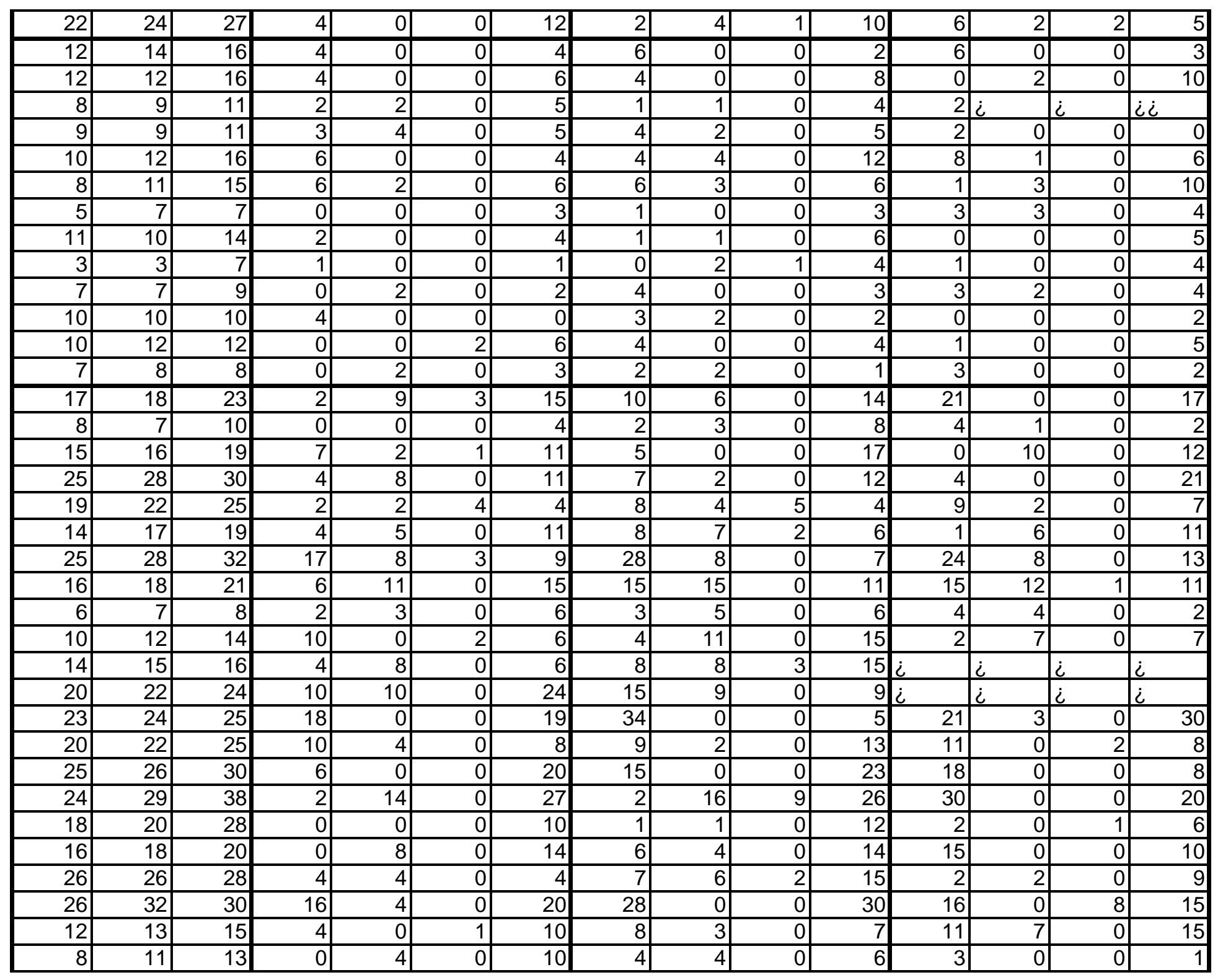




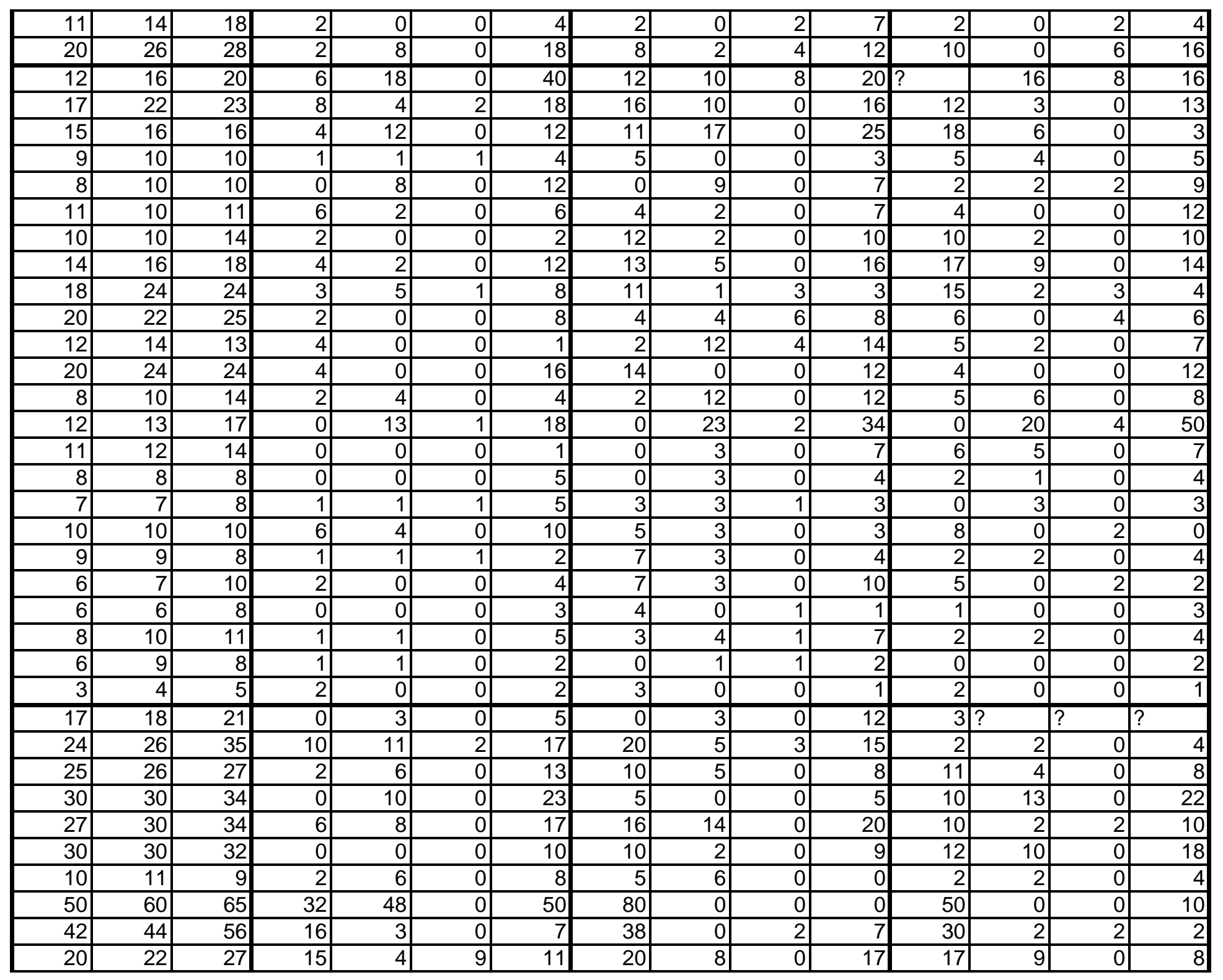




\begin{tabular}{|c|c|c|c|c|c|c|c|c|c|c|c|c|c|c|}
\hline 15 & 18 & 20 & 4 & 4 & 0 & 6 & 3 & 13 & 0 & 13 & 6 & 4 & 0 & 4 \\
\hline 18 & 26 & 34 & 4 & 7 & 0 & 16 & 3 & 16 & 0 & 12 & 12 & 17 & 0 & 18 \\
\hline 26 & 26 & 30 & 2 & 10 & 0 & 19 & 8 & 4 & 0 & 10 & 3 & 12 & 0 & 18 \\
\hline 21 & 24 & 25 & 9 & 6 & 0 & 9 & 18 & 6 & 3 & 4 & 4 & 0 & 0 & 16 \\
\hline 30 & 31 & 33 & 3 & 15 & 0 & 30 & 13 & 7 & 4 & 12 & 2 & 3 & 0 & 12 \\
\hline 20 & 24 & 25 & 12 & 6 & 0 & 8 & 13 & 7 & 0 & 8 & 4 & 8 & 0 & 12 \\
\hline 40 & 47 & 55 & 8 & 3 & 0 & 24 & 40 & 22 & 0 & 26 & 50 & 0 & 0 & 17 \\
\hline 26 & 27 & 28 & 10 & 2 & 0 & 14 & 18 & 0 & 0 & 9 & 35 & 5 & 0 & 17 \\
\hline 25 & 35 & 35 & 2 & 5 & 0 & 16 & 8 & 6 & 0 & 17 & 9 & 3 & 0 & 18 \\
\hline 18 & 22 & 25 & 5 & 14 & 0 & 18 & 11 & 14 & 0 & 22 & 12 & \begin{tabular}{l|}
12 \\
\end{tabular} & 0 & 0 \\
\hline 34 & 37 & 43 & 0 & 4 & 0 & 21 & 0 & 8 & 0 & 22 & 0 & 11 & 0 & 3 \\
\hline 28 & 36 & 38 & 2 & 2 & 0 & 22 & 11 & 8 & 2 & 13 & 2 & 4 & 9 & 4 \\
\hline 21 & 22 & 21 & 4 & 7 & 0 & 19 & 21 & 7 & 0 & 0 & 8 & 0 & 0 & 9 \\
\hline 11 & 15 & 18 & 2 & 2 & 2 & 10 & 2 & 5 & 0 & 9 & 0 & 9 & 0 & 7 \\
\hline 14 & 16 & 25 & 4 & 2 & 0 & 9 & 5 & 6 & 0 & 17 & 2 & 2 & 0 & 8 \\
\hline 18 & 21 & 24 & 10 & 6 & 0 & 10 & 12 & 8 & 1 & 17 & 11 & 6 & 5 & 10 \\
\hline 24 & 26 & 32 & 12 & 2 & 0 & 11 & 20 & 0 & 3 & 4 & 20 & 4 & 0 & 4 \\
\hline 9 & 11 & 15 & 4 & 2 & 0 & 2 & 6 & 1 & 0 & 3 & 5 & 2 & 1 & 1 \\
\hline 9 & 12 & 14 & 4 & 1 & 0 & 2 & 4 & 3 & 0 & 4 & 6 & 0 & 0 & 1 \\
\hline 18 & 23 & 30 & 4 & 2 & 0 & 8 & 8 & 8 & 0 & 6 & 8 & 8 & 0 & 7 \\
\hline 6 & 7 & 9 & 3 & 0 & 0 & 3 & 5 & 2 & 0 & 2 & 2 & 1 & 1 & 3 \\
\hline 14 & 16 & 25 & 6 & 1 & 0 & 7 & 7 & 1 & 0 & 10 & 17 & 6 & 2 & 3 \\
\hline 18 & 20 & 28 & 3 & 2 & 0 & 5 & 10 & 2 & 0 & 6 & 15 & 2 & 1 & 3 \\
\hline 8 & 10 & 11 & 4 & 3 & 1 & 3 & 4 & 1 & 0 & 5 & 2 & 0 & 0 & 1 \\
\hline 11 & 12 & 16 & 4 & 8 & 0 & 8 & 0 & 8 & 0 & 8 & 8 & 8 & 0 & 11 \\
\hline 24 & 25 & 28 & 6 & 0 & 0 & 8 & 8 & 4 & 0 & 4 & 12 & 18 & 0 & 13 \\
\hline 26 & 28 & 34 & 6 & 4 & 0 & 10 & \begin{tabular}{l|l}
12 \\
\end{tabular} & 2 & 0 & 4 & 4 & 5 & 0 & 6 \\
\hline 8 & 11 & 15 & 4 & 2 & 0 & 3 & 4 & 2 & 1 & 3 & 4 & 0 & 0 & 4 \\
\hline 11 & 12 & 14 & 2 & 1 & 0 & 2 & 4 & 1 & 0 & 1 & 4 & 0 & 0 & 3 \\
\hline 6 & 8 & 8 & 3 & 1 & 0 & 2 & 5 & 2 & 0 & 4 & 2 & 1 & 0 & 3 \\
\hline 9 & 9 & 10 & 2 & 2 & 0 & 4 & 3 & 0 & 0 & 1 & 2 & \begin{tabular}{l|l}
0 \\
\end{tabular} & 0 & 1 \\
\hline
\end{tabular}


Tabla Grupos y características

\begin{tabular}{|c|c|c|c|c|c|c|c|c|c|c|c|c|c|c|c|}
\hline \multirow[b]{3}{*}{ Eucli Manhattan } & \multicolumn{5}{|c|}{ Fórmula venación } & \multirow{2}{*}{\multicolumn{3}{|c|}{$\begin{array}{l}\text { Densidad venación } \\
\mathrm{N}^{\circ} \text { de venas en } \mathrm{x}=\end{array}$}} & \multirow{2}{*}{\multicolumn{4}{|c|}{\begin{tabular}{|l} 
Total Densidad Anastomosis \\
Cantidad
\end{tabular}}} & \multirow{3}{*}{\multicolumn{3}{|c|}{ Porcentajes }} \\
\hline & $y=a \times 4+b \times 3+$ & $-c \times 2+d x$ & $+e$ & & & & & & & & & & & & \\
\hline & $a$ & $b$ & c & d & e & 0 & 0 & 0 & Proximal & Media & Distal & Total & & & \\
\hline $\mathrm{G} 19 \mathrm{~b}$ & 9,470 & $-1,389$ & $-0,549$ & 3,454 & $-0,026$ & 6 & 6 & 5 & 7 & 9 & 9 & 25 & 28 & 36 & 36 \\
\hline
\end{tabular}

\begin{tabular}{|c|c|c|c|c|c|c|c|c|c|c|c|c|c|c|c|c|}
\hline \multirow[t]{3}{*}{$\mathrm{G} 2$} & $29 c$ & $-2,109$ & 5,117 & $-0,963$ & 1,188 & 0,008 & 3 & 3 & 3 & 2 & 4 & 3 & 9 & 22 & 44 & 33 \\
\hline & $30 e$ & $-8,273$ & $-1,481$ & 2,165 & 2,230 & 0,009 & 3 & 4 & 5 & 2 & 2 & 3 & 7 & 29 & 29 & 43 \\
\hline & 46D & $-6,673$ & 3,487 & 0,767 & 1,315 & $-0,007$ & 9 & 9 & 11 & 12 & 11 & 2 & 25 & 48 & 44 & 8 \\
\hline & Mínimo & $-8,273$ & $-1,481$ & $-0,963$ & 1,188 & $-0,007$ & 3 & 3 & 3 & 2 & 2 & 2 & 7 & 22 & 29 & 8 \\
\hline & Mediana & $-6,673$ & 3,487 & 0,767 & 1,315 & 0,008 & 3 & 4 & 5 & 2 & 4 & 3 & 9 & 29 & 44 & 33 \\
\hline & Promedio & $-5,685$ & 2,374 & 0,656 & 1,577 & 0,003 & 5 & 5 & 6 & 5 & 6 & 3 & 14 & 33 & 39 & 28 \\
\hline
\end{tabular}

\begin{tabular}{|c|c|c|c|c|c|c|c|c|c|c|c|c|c|c|c|c|}
\hline \multirow[t]{10}{*}{$\mathrm{G} 3+(\mathrm{G} 3$} & $13 b 2$ & 2,559 & $-0,305$ & $-0,846$ & \begin{tabular}{l|l}
1,772 \\
\end{tabular} & $-0,015$ & 6 & 9 & 10 & 7 & & $?$ & & & & \\
\hline & $16 c 2$ & 3,886 & $-1,110$ & $-1,080$ & 1,261 & 0,007 & 15 & 25 & 29 & 22 & 37 & 29 & 88 & 25 & 42 & 33 \\
\hline & $30 b 2$ & 2,831 & $-1,000$ & \begin{tabular}{|c|}
$-0,942$ \\
\end{tabular} & 1,878 & $-0,017$ & 5 & 6 & 7 & 3 & 11 & 9 & 23 & 13 & 48 & 39 \\
\hline & $32 f$ & 3,599 & 1,506 & $-1,433$ & 0,823 & $-0,012$ & 12 & 15 & 20 & 27 & 26 & 27 & 80 & 34 & 33 & 34 \\
\hline & $3 a 2$ & 6,724 & $-1,206$ & $-1,969$ & 1,372 & $-0,005$ & 16 & 28 & 29 & 28 & 39 & 43 & 110 & 25 & 35 & 39 \\
\hline & $46 \mathrm{R}$ & 5,479 & $-2,854$ & $-1,259$ & 2,279 & $-0,029$ & 7 & 7 & 9 & 4 & 7 & 9 & 20 & 20 & 35 & 45 \\
\hline & Máximo & 6,724 & 1,506 & $-0,846$ & 2,279 & 0,007 & 16 & 28 & 29 & 28 & 39 & 43 & 110 & 34 & 48 & 45 \\
\hline & Mínimo & 2,559 & $-2,854$ & $-1,969$ & 0,823 & $-0,029$ & 5 & & 7 & 3 & 6 & 9 & 20 & 13 & 33 & 33 \\
\hline & Mediana & 3,742 & $-1,055$ & $-1,170$ & 1,572 & $-0,014$ & 10 & 12 & 15 & 15 & 19 & 27 & 80 & 25 & 35 & 39 \\
\hline & Promedio & 4,179 & $-0,828$ & $-1,255$ & 1,564 & $-0,012$ & 10 & 15 & 17 & 15 & 21 & 23 & 64 & 23 & 39 & 38 \\
\hline
\end{tabular}

\begin{tabular}{|c|c|c|c|c|c|c|c|c|c|c|c|c|c|c|c|}
\hline G8a* G4+G 11c & $-0,637$ & 0,401 & $-0,194$ & 1,004 & 0,003 & 24 & 28 & 32 & 26 & 42 & 14 & 82 & 32 & 51 & 17 \\
\hline $12 \mathrm{a} 2$ & 1,164 & $-0,335$ & $-1,122$ & 1,431 & $-0,013$ & 20 & 24 & 25 & 20 & 25 & 18 & 63 & 32 & 40 & 29 \\
\hline $14 \mathrm{~b} 2$ & $-0,387$ & 0,620 & $-0,544$ & 0,948 & 0,009 & 10 & 12 & 15 & 5 & 6 & 9 & 20 & 25 & 30 & 45 \\
\hline $17 a$ & 1,139 & 0,280 & $-0,491$ & 1,229 & $-0,019$ & 7 & 12 & 10 & 13 & 21 & 13 & 47 & 28 & 45 & 28 \\
\hline $18 \mathrm{c}$ & $-0,289$ & 0,455 & $-0,247$ & 0,932 & $-0,001$ & 21 & 20 & 27 & 19 & 26 & 28 & 73 & 26 & 36 & 38 \\
\hline $1 \mathrm{a} 2$ & $-1,738$ & 0,369 & 0,677 & 1,346 & $-0,019$ & 14 & 16 & 20 & 17 & 24 & 28 & 69 & 25 & 35 & 41 \\
\hline $21 \mathrm{a} 2$ & $-1,010$ & 0,518 & 0,005 & 0,994 & 0,000 & 24 & 26 & 28 & 40 & 25 & 62 & 127 & 31 & 20 & 49 \\
\hline $23 g$ & $-1,459$ & $-0,470$ & 0,389 & 1,699 & $-0,001$ & 9 & 11 & 14 & 8 & 15 & 23 & 46 & 17 & 33 & 50 \\
\hline
\end{tabular}




\begin{tabular}{|c|c|c|c|c|c|c|c|c|c|c|c|c|c|c|c|}
\hline $24 a 2$ & 1,462 & $-0,960$ & $-1,013$ & 1,941 & 0,013 & 10 & 11 & 14 & 13 & 9 & 2 & 24 & 54 & 38 & 8 \\
\hline $25 \mathrm{e}$ & 1,939 & $-0,518$ & $-1,323$ & 1,755 & 0,006 & 4 & 5 & 7 & 4 & 5 & 6 & 15 & 27 & 33 & 40 \\
\hline $25 \mathrm{k}$ & $-0,389$ & 0,020 & $-0,233$ & 1,638 & $-0,014$ & 5 & 6 & 7 & 3 & 4 & 6 & 13 & 23 & 31 & 46 \\
\hline $26 a$ & $-0,467$ & 0,703 & $-0,085$ & 1,239 & $-0,010$ & 8 & 10 & 10 & 8 & 5 & 2 & 15 & 53 & 33 & 13 \\
\hline $26 \mathrm{~h}$ & $-0,312$ & 0,006 & 0,010 & 1,254 & 0,002 & 9 & 11 & 14 & 8 & 9 & 5 & 22 & 36 & 41 & 23 \\
\hline 26k1 & $-1,335$ & 1,221 & $-0,036$ & 0,468 & $-0,015$ & 8 & 9 & 13 & 9 & 14 & 9 & 32 & 28 & 44 & 28 \\
\hline $28 d$ & 1,397 & $-0,635$ & $-0,989$ & 1,839 & 0,000 & 4 & 5 & 6 & 5 & 6 & 4 & 15 & 33 & 40 & 27 \\
\hline $29 a 2$ & 0,930 & $-0,090$ & $-0,731$ & 1,388 & $-0,028$ & 6 & 7 & 9 & 5 & 5 & 4 & 14 & 36 & 36 & 29 \\
\hline $29 e$ & $-0,566$ & $-0,095$ & 0,248 & 1,372 & $-0,013$ & 6 & 8 & 12 & 4 & 11 & 7 & 22 & 18 & 50 & 32 \\
\hline $29 g 2$ & 0,043 & 0,228 & $-0,357$ & 1,111 & $-0,018$ & 7 & 8 & 8 & 4 & 4 & 2 & 10 & 40 & 40 & 20 \\
\hline $2 \mathrm{a} 2$ & $-0,675$ & 0,438 & 0,120 & 1,170 & 0,005 & 8 & 7 & 9 & 5 & 15 & 8 & 28 & 18 & 54 & 29 \\
\hline $31 \mathrm{~h}$ & $-1,098$ & 1,243 & 0,279 & 0,880 & $-0,001$ & 7 & 8 & 8 & 9 & 16 & 9 & 34 & 26 & 47 & 26 \\
\hline $3 b 1$ & 0,868 & 0,560 & $-0,683$ & 1,310 & 0,044 & 7 & 7 & 7 & 5 & 7 & 7 & 19 & 26 & 37 & 37 \\
\hline 441 & 0,018 & 0,341 & $-0,558$ & 1,051 & 0,023 & 22 & 24 & 25 & 26 & 26 & 24 & 76 & 34 & 34 & 32 \\
\hline $45 \mathrm{E}$ & $-1,451$ & 0,718 & 0,213 & 0,746 & $-0,001$ & 24 & 30 & 34 & 24 & 27 & 22 & 73 & 33 & 37 & 30 \\
\hline $45 \mathrm{~F}$ & 0,254 & 0,270 & $-0,662$ & 1,232 & 0,014 & 10 & 17 & 18 & 21 & 10 & 24 & 55 & 38 & 18 & 44 \\
\hline 461 & $-0,603$ & $-0,414$ & $-0,135$ & 1,935 & $-0,008$ & 8 & 11 & 15 & 14 & 15 & 14 & 43 & 33 & 35 & 33 \\
\hline $46 \mathrm{~L}$ & $-1,365$ & 0,394 & 0,806 & 1,373 & $-0,019$ & 5 & 7 & 7 & 3 & 4 & 10 & 17 & 18 & 24 & 59 \\
\hline $46 \mathrm{~V}$ & $-0,038$ & 0,091 & $-0,221$ & 1,175 & 0,002 & 10 & 12 & 12 & 8 & 8 & 6 & 22 & 36 & 36 & 27 \\
\hline $46 W$ & $-1,161$ & 0,645 & 0,328 & 1,053 & $-0,009$ & 7 & 8 & 8 & 5 & 5 & 5 & 15 & 33 & 33 & 33 \\
\hline 47B & 0,798 & $-0,762$ & $-0,377$ & 1,876 & $-0,020$ & 8 & 7 & 10 & 4 & 13 & 7 & 24 & 17 & 54 & 29 \\
\hline $47 \mathrm{M}$ & $-0,631$ & $-0,012$ & 0,306 & 1,333 & $-0,056$ & 6 & 7 & 8 & 11 & 14 & 10 & 35 & 31 & 40 & 29 \\
\hline 470 & 0,029 & 0,264 & 0,028 & 1,248 & $-0,029$ & 10 & 12 & 14 & 18 & 30 & 16 & 64 & 28 & 47 & 25 \\
\hline $48 N$ & $-0,699$ & $-0,167$ & 0,169 & 1,820 & 0,022 & 14 & 15 & 16 & 18 & 34 & $?$ & & & & \\
\hline $4 a 3$ & $-0,246$ & 0,294 & $-0,113$ & 1,038 & 0,008 & 12 & 12 & 15 & 12 & 17 & 9 & 38 & 32 & 45 & 24 \\
\hline $50 \mathrm{H}$ & $-0,525$ & 0,629 & $-0,381$ & 1,120 & $-0,019$ & 10 & 10 & 10 & 20 & 11 & 10 & 41 & 49 & 27 & 24 \\
\hline 50J & $-0,271$ & $-0,641$ & 0,057 & 1,580 & $-0,008$ & 6 & 7 & 10 & 6 & 20 & 9 & 35 & 17 & 57 & 26 \\
\hline $50 \mathrm{~K}$ & 1,046 & $-0,421$ & $-0,612$ & 1,417 & $-0,031$ & 6 & 6 & 8 & 3 & 6 & 4 & 13 & 23 & 46 & 31 \\
\hline $54 G$ & 0,389 & $-0,228$ & $-0,365$ & 1,394 & $-0,007$ & 6 & 7 & 9 & 6 & 9 & 7 & 22 & 27 & 41 & 32 \\
\hline 540 & $-0,401$ & 0,509 & $-0,360$ & 1,084 & 0,003 & 11 & 12 & 14 & 5 & 6 & 7 & 18 & 28 & 33 & 39 \\
\hline $54 Q$ & $-0,188$ & 0,556 & $-0,005$ & 1,530 & $-0,023$ & 9 & 9 & 10 & 8 & 4 & 3 & 15 & 53 & 27 & 20 \\
\hline $8 e$ & $-0,294$ & 0,438 & $-0,176$ & 1,045 & $-0,017$ & 12 & 16 & 20 & 29 & 14 & 23 & 66 & 44 & 21 & 35 \\
\hline $9 a 2$ & $-1,544$ & 0,344 & 0,441 & 0,905 & 0,007 & 16 & 24 & 28 & 14 & 18 & $?$ & 32 & & & \\
\hline Máximo & 1,939 & 1,243 & 0,806 & 1,941 & 0,044 & 24 & 30 & 34 & 40 & 42 & 62 & 127 & 54 & 57 & 59 \\
\hline
\end{tabular}


G10k G7 20i2

$27 a 1$

$27 \mathrm{~g}$

$30 d$

$33 a$

$33 b$

$33 \mathrm{~d} 1$

$34 a$

$34 \mathrm{~b} 1$

$34 \mathrm{~b} 2$

$34 d$

$35 b$

$35 c$

$36 a 2$

$36 \mathrm{~b} 1$

$36 c$

37e 1

37 e 2

$37 f$

$40 a$

$40 \mathrm{~b}$

$41 \mathrm{c}$

$42 \mathrm{~b} 1$

$42 \mathrm{~b} 2$

$42 \mathrm{~d} 2$

47D

$49 \mathrm{~K}$

$49 \mathrm{M}$

$49 N$

\begin{tabular}{|r|r|r|r|r|r|}
\hline$-0,079$ & 0,105 & 0,040 & 0,178 & 0,005 & 30 \\
\hline$-0,005$ & 0,086 & $-0,264$ & 0,204 & $-0,009$ & 21 \\
\hline$-0,024$ & 0,032 & $-0,094$ & 0,142 & 0,000 & \\
\hline$-0,087$ & $-0,017$ & 0,007 & 0,197 & 0,000 & 12 \\
\hline$-0,257$ & 0,188 & 0,089 & 0,113 & $-0,029$ & 13 \\
\hline$-0,079$ & $-0,058$ & 0,108 & $-0,014$ & $-0,002$ & \\
\hline 0,049 & 0,249 & $-0,338$ & $-0,177$ & 0,019 & \\
\hline
\end{tabular}

\begin{tabular}{|l|l|l|l|l|l|r|r|r|r|}
\hline 30 & 31 & 33 & 31 & 43 & 31 & 105 & 30 & 41 & 30 \\
\hline 21 & 22 & 27 & 17 & 16 & 20 & 53 & 32 & 30 & 38 \\
\hline
\end{tabular}

\begin{tabular}{l|l|l|l|l|}
$-0,079$ & $-0,058$ & 0,108 & $-0,014$ & $-0,002$ \\
\hline 0,049 & 0,249 & $-0,338$ & $-0,177$ & 0,019 \\
\hline
\end{tabular} \begin{tabular}{l|r|r|r|r|}
0,049 & 0,249 & $-0,338$ & $-0,177$ & 0,019 \\
\hline
\end{tabular}

\begin{tabular}{|r|r|r|r|r|r|}
\hline$-0,173$ & 0,132 & 0,075 & 0,101 & $-0,014$ & \\
\hline 0,046 & 0,078 & $-0,055$ & $-0,022$ & $-0,005$ &
\end{tabular}

\begin{tabular}{|r|r|r|r|r|l|l}
\hline 0,046 & 0,078 & $-0,055$ & $-0,022$ & $-0,005$ & \\
\hline$-0,087$ & 0,094 & $-0,041$ & 0,056 & $-0,002$ & \\
\hline$-0,046$ & 0,034 & 0,041 & 0,209 & $-0,003$ & \\
\hline
\end{tabular}

\begin{tabular}{l|l|l|l|l|}
$-0,046$ & 0,034 & 0,041 & 0,209 & $-0,003$ \\
\hline
\end{tabular}

\begin{tabular}{r|r|r|r|r|}
\hline$-0,379$ & 0,260 & 0,159 & $-0,097$ & $-0,010$ \\
\hline$-0,105$ & 0,178 & $-0,181$ & 0,223 & 0,006 \\
\hline
\end{tabular} \begin{tabular}{l|r|r|r|r|}
$-0,105$ & 0,178 & $-0,181$ & 0,223 & 0,006 \\
\hline
\end{tabular}

\begin{tabular}{|r|r|r|r|r|}
\hline$-0,120$ & 0,109 & 0,066 & 0,207 & $-0,007$ \\
\hline$-0,013$ & $-0,027$ & $-0,057$ & 0,117 & 0,000 \\
\hline$-0,061$ & 0,039 & 0,085 & 0,125 & 0,000 \\
\hline
\end{tabular}

\begin{tabular}{l|l|l|}
8 & 10 & 11
\end{tabular}

\begin{tabular}{r|r|r|}
\hline 12 & 10 & 11 \\
\hline 14 & 16 \\
\hline
\end{tabular}

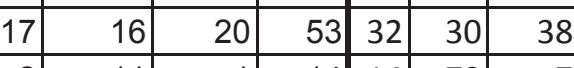

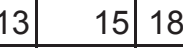
\begin{tabular}{l|l|l|}
8 & 10 & 10 \\
\hline
\end{tabular}

2

11

\begin{tabular}{l|l|l|}
10 & 10 & 12 \\
\hline
\end{tabular}

\begin{tabular}{l|l|l|}
40 & 44 & 46 \\
\hline 22 & 28 & 30
\end{tabular}

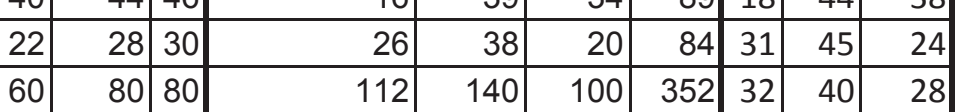

\section{\begin{tabular}{|l|l|l|l|l|}
0,171 & 0,036 & $-0,106$ & 0,146 & 0,020 \\
\hline
\end{tabular}} \begin{tabular}{r|r|r|r|r|}
\hline$-0,433$ & 0,258 & 0,315 & $-0,085$ & $-0,016$ \\
\hline
\end{tabular}

\begin{tabular}{l|l|l|}
24 & 27 & 28 \\
\hline
\end{tabular}
\begin{tabular}{|r|r|r|r|r|r|r|}
2 & 16 & 22 & 40 & 5 & 40 & 55 \\
\hline 25 & 26 & 44 & 95 & 26 & 27 & 46 \\
\hline
\end{tabular} \begin{tabular}{|r|r|r|r|r|r|}
0,103 & 0,054 & $-0,112$ & 0,147 & 0,010 \\
\hline
\end{tabular} \begin{tabular}{l|l|l|l|l|}
$-0,064$ & 0,187 & 0,165 & $-0,031$ & $-0,007$ \\
\hline
\end{tabular}

\begin{tabular}{l|l|l|}
24 & 24 & 24 \\
\hline
\end{tabular}

\begin{tabular}{l|l|l|}
24 & 24 & 24 \\
36 & 48 & 56 \\
\hline
\end{tabular}

\begin{tabular}{l|l|l|}
22 & 24 & 25 \\
\hline
\end{tabular}

\begin{tabular}{l|l|l|}
26 & 28 & 32 \\
\hline
\end{tabular}

\begin{tabular}{l|l|l|}
26 & 28 & 32 \\
20 & 20 & 20 \\
\hline
\end{tabular}

\begin{tabular}{l|l|l|}
12 & 12 & 16 \\
\hline 32 & 36 & 46 \\
\hline
\end{tabular}

\begin{tabular}{l|l|l|}
24 & 27 & 30 \\
\hline
\end{tabular}

\begin{tabular}{l|l|l|}
30 & 31 & 35 \\
\hline
\end{tabular}

$$
\begin{array}{l|r|r|r|r|r|}
-0,168 & 0,011 & 0,141 & 0,220 & -0,001 & \\
-0,198 & -0,046 & 0,159 & 0,236 & -0,011 &
\end{array}
$$
\begin{tabular}{l|l|l|l|l|}
$-0,563$ & 0,315 & 0,224 & 0,049 & $-0,010$ \\
\hline
\end{tabular} \begin{tabular}{l|l|l|}
30 & 31 & 35 \\
\hline 32 & 35 & 39 \\
\hline
\end{tabular} \begin{tabular}{l|l|l|l|l|}
$-0,061$ & 0,018 & $-0,060$ & 0,201 & 0,010 \\
\hline
\end{tabular} \begin{tabular}{l|l|l|l|l|}
$-0,073$ & 0,019 & 0,026 & 0,233 & $-0,004$ \\
\hline
\end{tabular}

\begin{tabular}{l|l|l|}
20 & 24 & 30 \\
\hline 24 & 27 & 31
\end{tabular}
\begin{tabular}{l|l|l|l|l|}
0,038 & 0,092 & $-0,311$ & 0,259 & 0,011 \\
\hline
\end{tabular} \begin{tabular}{l|l|l|l|l|}
0,328 & $-0,034$ & $-0,405$ & 0,042 & 0,000 \\
\hline
\end{tabular} \begin{tabular}{l|l|l|l|l|}
$-0,265$ & 0,235 & 0,071 & 0,083 & $-0,017$ \\
\hline
\end{tabular}

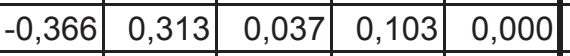
\begin{tabular}{r|r|r|r|r|}
$-0,140$ & 0,181 & 0,033 & 0,025 & $-0,008$ \\
\hline
\end{tabular} \begin{tabular}{l|l|l|}
24 & 27 & 31 \\
\hline 28 & 28 & 30 \\
\hline
\end{tabular} \begin{tabular}{l|l|l|}
16 & 16 & 18 \\
\hline
\end{tabular} \begin{tabular}{l|l|l|}
25 & 28 & 30 \\
\hline
\end{tabular} \begin{tabular}{l|l|l|}
10 & 10 & 14 \\
\hline 14 & 16 & 18
\end{tabular} \begin{tabular}{l|l|l|}
14 & 16 & 18 \\
\hline
\end{tabular} \begin{tabular}{l|l|l|}
18 & 24 & 24 \\
\hline
\end{tabular}

\begin{tabular}{l|l|l|}
11 & 12 & 14 \\
\hline
\end{tabular}

\begin{tabular}{|r|r|r|r|r|r|r|}
\hline 112 & 140 & 100 & 352 & 32 & 40 & 28 \\
\hline 34 & 30 & 35 & 99 & 34 & 30 & 35 \\
\hline 23 & 20 & 12 & 55 & 42 & 36 & 22 \\
\hline 24 & 65 & 57 & 154 & 21 & 42 & 37 \\
\hline 14 & 29 & 17 & 65 & 37 & 37 & 26 \\
\hline 14 & 14 & $?$ & 60 & 23 & 48 & 28 \\
\hline 16 & 16 & $?$ & & & & \\
\hline 24 & 24 & & & & & \\
\hline 26 & 16 & 17 & 59 & 44 & 27 & 29 \\
\hline 8 & 12 & & & & & \\
\hline 22 & 21 & 34 & 63 & 13 & 33 & 54 \\
\hline 23 & 21 & 12 & 56 & 41 & 38 & 21 \\
\hline 29 & 26 & 18 & 73 & 40 & 36 & 25 \\
\hline 12 & 14 & 8 & 34 & 35 & 41 & 24 \\
\hline 23 & 21 & 25 & 69 & 33 & 30 & 36 \\
\hline 4 & 24 & 22 & 50 & 8 & 48 & 44 \\
\hline 18 & 34 & 40 & 92 & 20 & 37 & 43 \\
\hline 17 & 18 & 24 & 59 & 29 & 31 & 41 \\
\hline 1 & 10 & 18 & 29 & 3 & 34 & 62 \\
\hline
\end{tabular}




\begin{tabular}{|c|c|c|c|c|c|c|c|c|c|c|c|c|c|c|c|c|}
\hline & $51 \mathrm{~A}$ & 0,000 & 0,072 & $-0,006$ & 0,021 & 0,001 & 17 & 18 & 21 & 8 & 15 & $?$ & & & & \\
\hline & 51D & $-0,114$ & 0,000 & 0,031 & 0,185 & 0,007 & 25 & 26 & 27 & 21 & 23 & 23 & 67 & 31 & 34 & 34 \\
\hline & $51 \mathrm{E}$ & 0,035 & 0,254 & 0,099 & $-0,016$ & $-0,001$ & 30 & 30 & 34 & 33 & 10 & 45 & 88 & 38 & 11 & 51 \\
\hline & $51 \mathrm{~F}$ & $-0,096$ & $-0,079$ & 0,046 & 0,185 & 0,002 & 27 & 30 & 34 & 31 & 50 & 24 & 105 & 30 & 48 & 23 \\
\hline & $51 G$ & $-0,119$ & 0,051 & 0,099 & 0,129 & 0,001 & 30 & 30 & 32 & 10 & 21 & 40 & 71 & 14 & 30 & 56 \\
\hline & $51 \mathrm{H}$ & 0,020 & 0,062 & 0,003 & 0,101 & 0,003 & 10 & 11 & 9 & 16 & 11 & 8 & 35 & 46 & 31 & 23 \\
\hline & 511 & $-0,113$ & 0,072 & $-0,012$ & 0,030 & $-0,006$ & 50 & 60 & 65 & 130 & 80 & 60 & 270 & 48 & 30 & 22 \\
\hline & 51J & $-0,131$ & 0,073 & 0,060 & 0,044 & $-0,006$ & 42 & 44 & 56 & 26 & 47 & 36 & 109 & 24 & 43 & 33 \\
\hline & $52 \mathrm{~A}$ & $-0,015$ & 0,020 & $-0,006$ & 0,179 & 0,010 & 20 & 22 & 27 & 39 & 45 & 34 & 118 & 33 & 38 & 29 \\
\hline & 52D & 0,008 & 0,022 & $-0,030$ & 0,180 & $-0,018$ & 18 & 26 & 34 & 27 & 31 & 47 & 105 & 26 & 30 & 45 \\
\hline & $52 \mathrm{E}$ & $-0,045$ & 0,134 & 0,099 & 0,105 & 0,005 & 26 & 26 & 30 & 31 & 22 & 33 & 86 & 36 & 26 & 38 \\
\hline & $52 \mathrm{~F}$ & $-0,251$ & $-0,402$ & $-0,055$ & 0,167 & 0,007 & 21 & 24 & 25 & 24 & 31 & 20 & 75 & 32 & 41 & 27 \\
\hline & $52 \mathrm{G}$ & $-0,150$ & 0,101 & 0,044 & 0,035 & $-0,003$ & 30 & 31 & 33 & 48 & 36 & 17 & 101 & 48 & 36 & 17 \\
\hline & $52 \mathrm{H}$ & $-0,235$ & 0,110 & 0,062 & 0,081 & $-0,006$ & 20 & 24 & 25 & 26 & 28 & 24 & 78 & 33 & 36 & 31 \\
\hline & $53 \mathrm{~A}$ & 0,081 & 0,116 & $-0,285$ & 0,153 & $-0,004$ & 40 & 47 & 55 & 35 & 88 & 67 & 190 & 18 & 46 & 35 \\
\hline & $53 \mathrm{C}$ & $-0,066$ & 0,158 & $-0,110$ & 0,125 & 0,004 & 25 & 35 & 35 & 23 & 31 & 30 & 84 & 27 & 37 & 36 \\
\hline & $53 \mathrm{H}$ & 0,119 & 0,133 & $-0,116$ & $-0,157$ & $-0,014$ & 21 & 22 & 21 & 30 & 28 & 17 & 75 & 40 & 37 & 23 \\
\hline & $54 \mathrm{~A}$ & 0,178 & 0,165 & $-0,088$ & 0,175 & $-0,001$ & 24 & 26 & 32 & 25 & 27 & 28 & 80 & 31 & 34 & 35 \\
\hline & Máximo & 0,328 & 0,315 & 0,315 & 0,259 & 0,020 & 60 & 80 & 80 & 130 & 140 & 100 & 352 & 48 & 79 & 62 \\
\hline & Mínimo & $-0,563$ & $-0,402$ & $-0,405$ & $-0,177$ & $-0,029$ & 8 & 10 & 9 & 1 & 10 & 1 & 14 & 3 & 11 & 7 \\
\hline & Mediana & $-0,076$ & 0,082 & 0,028 & 0,121 & $-0,001$ & 24 & 26 & 30 & 23 & 24 & 24 & 75 & 31 & 37 & 34 \\
\hline & Promedio & $-0,083$ & 0,087 & $-0,007$ & 0,102 & $-0,002$ & 24 & 27 & 30 & 25 & 30 & 29 & 87 & 29 & 37 & 34 \\
\hline G10 ¿ G8 & $10 a$ & $-0,112$ & 0,020 & $-0,045$ & 0,654 & 0,004 & 38 & 44 & 46 & 30 & 61 & 64 & 155 & 19 & 39 & 41 \\
\hline & $11 \mathrm{a} 2$ & $-0,279$ & 0,002 & 0,180 & 0,639 & $-0,004$ & 20 & 22 & 27 & 12 & 12 & 14 & 38 & 32 & 32 & 37 \\
\hline & $12 \mathrm{~h}$ & 0,096 & $-0,026$ & $-0,273$ & 0,595 & 0,038 & 18 & 20 & 25 & 18 & 22 & 24 & 64 & 28 & 34 & 38 \\
\hline & $15 b$ & 0,085 & 0,617 & $-0,163$ & 0,177 & $-0,015$ & 20 & 24 & 28 & 20 & 23 & 26 & 69 & 29 & 33 & 38 \\
\hline & $16 \mathrm{~d} 2$ & 0,028 & 0,072 & $-0,173$ & 0,377 & $-0,005$ & 25 & 32 & 35 & 29 & 25 & 12 & 66 & 44 & 38 & 18 \\
\hline & $18 a$ & $-0,051$ & 0,073 & 0,057 & 0,348 & $-0,002$ & 23 & 23 & 28 & 25 & 24 & 31 & 80 & 31 & 30 & 39 \\
\hline & $18 d$ & $-0,034$ & 0,040 & $-0,043$ & 0,457 & 0,008 & 24 & 23 & 30 & 33 & 36 & 25 & 94 & 35 & 38 & 27 \\
\hline & 19a2 & 0,000 & 0,043 & $-0,094$ & 0,451 & $-0,001$ & 23 & 25 & 31 & 14 & 20 & 17 & 51 & 27 & 39 & 33 \\
\hline & 19e 1 & $-0,003$ & 0,020 & $-0,053$ & 0,632 & 0,008 & 26 & 29 & 29 & 42 & 41 & 42 & 125 & 34 & 33 & 34 \\
\hline & $20 b 2$ & $-0,207$ & 0,296 & 0,136 & 0,424 & 0,018 & 8 & 9 & 9 & 8 & 10 & 15 & 33 & 24 & 30 & 45 \\
\hline & $20 f 1$ & $-0,308$ & 0,089 & 0,184 & 0,528 & $-0,012$ & 17 & 21 & 21 & 33 & 31 & 29 & 93 & 35 & 33 & 31 \\
\hline
\end{tabular}




\begin{tabular}{|c|c|c|c|c|c|c|c|c|c|c|c|c|c|c|c|}
\hline $21 b$ & $-0,206$ & 0,014 & 0,133 & 0,552 & 0,004 & 24 & 30 & 36 & 28 & 34 & 56 & 118 & 24 & 29 & 47 \\
\hline $21 c 2$ & $-0,078$ & $-0,261$ & $-0,192$ & 0,693 & 0,028 & 20 & 20 & 20 & 20 & 12 & $?$ & & & & \\
\hline $23 c$ & $-0,074$ & 0,129 & $-0,097$ & 0,613 & 0,003 & 16 & 18 & 28 & 26 & 36 & 38 & 100 & 26 & 36 & 38 \\
\hline $24 i$ & $-0,086$ & 0,141 & $-0,114$ & 0,269 & 0,035 & 18 & 20 & 24 & 26 & 28 & 35 & 89 & 29 & 31 & 39 \\
\hline $27 \mathrm{~h}$ & $-0,224$ & 0,090 & 0,150 & 0,497 & 0,010 & 20 & 22 & 24 & 12 & 16 & 20 & 48 & 25 & 33 & 42 \\
\hline 30a1 & $-0,167$ & $-0,025$ & 0,109 & 0,578 & 0,005 & 8 & 7 & 9 & 8 & 7 & 5 & 20 & 40 & 35 & 25 \\
\hline $30 a 2$ & 0,117 & $-0,067$ & \begin{tabular}{|l|}
$-0,262$ \\
\end{tabular} & 0,597 & $-0,025$ & 7 & 9 & 12 & 4 & 6 & 7 & 17 & 24 & 35 & 41 \\
\hline $31 a$ & $-0,140$ & 0,027 & $-0,082$ & 0,588 & $-0,007$ & 10 & 12 & 15 & 7 & 13 & 7 & 27 & 26 & 48 & 26 \\
\hline 32e 2 & 0,337 & $-0,439$ & $-0,047$ & 0,644 & 0,010 & 12 & 18 & 17 & 16 & 20 & 24 & 60 & 27 & 33 & 40 \\
\hline $37 a$ & $-0,296$ & 0,050 & 0,245 & 0,307 & $-0,027$ & 14 & 15 & 19 & 12 & 16 & 12 & 40 & 30 & 40 & 30 \\
\hline $3 a 1$ & $-0,153$ & 0,012 & 0,081 & 0,601 & $-0,014$ & 26 & 28 & 29 & 26 & 32 & 56 & 114 & 23 & 28 & 49 \\
\hline $41 a 2$ & $-0,277$ & 0,164 & \begin{tabular}{|l|}
$-0,057$ \\
\end{tabular} & 0,409 & 0,000 & 22 & 26 & 32 & 34 & 44 & 6 & 84 & 40 & 52 & 7 \\
\hline $41 d 2$ & $-0,012$ & 0,082 & $-0,094$ & 0,237 & $-0,003$ & 28 & 32 & 35 & 14 & 30 & 18 & 62 & 23 & 48 & 29 \\
\hline $43 d$ & 0,135 & 0,085 & $-0,220$ & 0,366 & 0,000 & 10 & 12 & 14 & 4 & 12 & 8 & 24 & 17 & 50 & 33 \\
\hline $44 B$ & $-0,022$ & $-0,141$ & 0,004 & 0,415 & $-0,007$ & 15 & 18 & 16 & 6 & 5 & 20 & 31 & 19 & 16 & 65 \\
\hline 44D & $-0,549$ & 0,239 & 0,348 & 0,548 & $-0,023$ & 21 & 29 & 35 & 37 & 38 & 56 & 131 & 28 & 29 & 43 \\
\hline $45 G$ & 0,000 & $-0,059$ & $-0,054$ & 0,549 & 0,004 & 23 & 26 & 31 & 15 & 29 & 21 & 65 & 23 & 45 & 32 \\
\hline $45 \mathrm{H}$ & $-0,284$ & 0,116 & 0,147 & 0,512 & $-0,003$ & 22 & 24 & 27 & 16 & 17 & 15 & 48 & 33 & 35 & 31 \\
\hline $47 \mathrm{~A}$ & $-0,033$ & $-0,024$ & $-0,089$ & 0,423 & 0,016 & 17 & 18 & 23 & 29 & 30 & 38 & 97 & 30 & 31 & 39 \\
\hline $47 G$ & 0,540 & $-0,269$ & $-0,369$ & 0,824 & $-0,022$ & 19 & 22 & 25 & 12 & 21 & 18 & 51 & 24 & 41 & 35 \\
\hline $47 K$ & $-0,226$ & 0,085 & 0,114 & 0,563 & 0,003 & 25 & 28 & 32 & 37 & 43 & 45 & 125 & 30 & 34 & 36 \\
\hline $47 L$ & $-0,030$ & 0,046 & $-0,085$ & 0,400 & $-0,009$ & 16 & 18 & 21 & 32 & 41 & 39 & 112 & 29 & 37 & 35 \\
\hline $48 \mathrm{~A}$ & $-0,077$ & $-0,033$ & $-0,031$ & 0,573 & 0,001 & 20 & 22 & 24 & 44 & 33 & $?$ & & & & \\
\hline $48 C$ & $-0,051$ & $-0,073$ & 0,020 & 0,556 & 0,001 & 20 & 22 & 25 & 22 & 24 & 21 & 67 & 33 & 36 & 31 \\
\hline $48 \mathrm{D}$ & 0,522 & 0,651 & $-0,376$ & 0,067 & 0,011 & 25 & 26 & 30 & 26 & 38 & 26 & 90 & 29 & 42 & 29 \\
\hline $48 G$ & $-0,046$ & 0,056 & $-0,133$ & 0,427 & 0,017 & 16 & 18 & 20 & 22 & 24 & 25 & 71 & 31 & 34 & 35 \\
\hline $48 \mathrm{H}$ & $-0,036$ & 0,089 & $-0,177$ & 0,451 & $-0,006$ & 26 & 26 & 28 & 12 & 30 & 13 & 55 & 22 & 55 & 24 \\
\hline 481 & $-0,130$ & 0,130 & 0,091 & 0,224 & 0,006 & 26 & 32 & 30 & 40 & 58 & 39 & 137 & 29 & 42 & 28 \\
\hline 49D & 0,182 & $-0,079$ & $-0,020$ & 0,618 & $-0,004$ & 15 & 16 & 16 & 28 & 53 & 27 & 108 & 26 & 49 & 25 \\
\hline $49 E$ & $-0,728$ & 0,644 & 0,403 & 0,200 & $-0,013$ & 9 & 10 & 10 & 7 & 8 & 14 & 29 & 24 & 28 & 48 \\
\hline $49 P$ & $-0,231$ & 0,113 & 0,024 & 0,451 & $-0,007$ & 20 & 22 & 25 & 10 & 22 & 16 & 48 & 21 & 46 & 33 \\
\hline 4b3 & $-0,231$ & 0,186 & 0,171 & 0,193 & $-0,022$ & 24 & 27 & 31 & 28 & 42 & 29 & 99 & 28 & 42 & 29 \\
\hline $50 A$ & 0,052 & 0,089 & $-0,131$ & 0,261 & 0,010 & 20 & 24 & 24 & 20 & 26 & 16 & 62 & 32 & 42 & 26 \\
\hline $50 \mathrm{E}$ & 0,173 & $-0,027$ & $-0,268$ & 0,431 & $-0,003$ & 8 & 8 & 8 & 5 & 7 & 7 & 19 & 26 & 37 & 37 \\
\hline
\end{tabular}




\begin{tabular}{|c|c|c|c|c|c|c|c|c|c|c|c|c|c|c|c|}
\hline $50 \mathrm{~F}$ & 0,189 & 0,043 & $-0,192$ & 0,642 & $-0,003$ & 7 & 7 & 8 & 8 & 10 & 6 & 24 & 33 & 42 & 25 \\
\hline $51 B$ & $-0,014$ & 0,102 & $-0,332$ & 0,406 & $-0,001$ & 24 & 26 & 35 & 40 & 43 & 8 & 91 & 44 & 47 & 9 \\
\hline $52 \mathrm{~B}$ & $-0,195$ & $-0,090$ & 0,159 & 0,574 & 0,010 & 15 & 18 & 20 & 14 & 29 & 14 & 57 & 25 & 51 & 25 \\
\hline $53 \mathrm{~B}$ & 0,039 & $-0,073$ & $-0,075$ & 0,613 & $-0,008$ & 26 & 27 & 28 & 26 & 27 & 57 & 110 & 24 & 25 & 52 \\
\hline $53 \mathrm{E}$ & 0,110 & 0,266 & $-0,186$ & 0,310 & $-0,005$ & 34 & 37 & 43 & 25 & 30 & 14 & 69 & 36 & 43 & 20 \\
\hline $53 \mathrm{~K}$ & $-0,270$ & 0,016 & 0,163 & 0,653 & $-0,007$ & 18 & 21 & 24 & 26 & 38 & 32 & 96 & 27 & 40 & 33 \\
\hline $54 \mathrm{D}$ & $-0,212$ & $-0,075$ & 0,016 & 0,693 & 0,009 & 9 & 12 & 14 & 7 & 11 & 7 & 25 & 28 & 44 & 28 \\
\hline $54 \mathrm{E}$ & 0,042 & 0,161 & $-0,250$ & 0,421 & $-0,013$ & 18 & 23 & 30 & 14 & 22 & 23 & 59 & 24 & 37 & 39 \\
\hline 541 & $-0,071$ & 0,050 & $-0,032$ & 0,658 & $-0,020$ & 18 & 20 & 28 & 10 & 18 & 21 & 49 & 20 & 37 & 43 \\
\hline $54 \mathrm{~K}$ & $-0,203$ & 0,068 & 0,341 & 0,320 & $-0,026$ & 11 & 12 & 16 & 20 & 16 & 27 & 63 & 32 & 25 & 43 \\
\hline $54 \mathrm{M}$ & $-0,134$ & 0,134 & 0,015 & 0,276 & $-0,011$ & 26 & 28 & 34 & 20 & 18 & 15 & 53 & 38 & 34 & 28 \\
\hline $6 a$ & $-0,061$ & $-0,070$ & $-0,077$ & 0,425 & 0,002 & 18 & 18 & 22 & 19 & 30 & 44 & 93 & 20 & 32 & 47 \\
\hline $6 c 2$ & 0,019 & $-0,011$ & $-0,161$ & 0,555 & $-0,004$ & 18 & 30 & 40 & 92 & 90 & 57 & 239 & 38 & 38 & 24 \\
\hline $6 e$ & $-0,080$ & $-0,090$ & 0,020 & 0,397 & $-0,008$ & 20 & 20 & 20 & 6 & 8 & 18 & 32 & 19 & 25 & 56 \\
\hline $6 f$ & $-0,226$ & 0,137 & $-0,078$ & 0,333 & 0,004 & 24 & 29 & 32 & 27 & 32 & 28 & 87 & 31 & 37 & 32 \\
\hline $7 d$ & 0,012 & 0,088 & $-0,115$ & 0,308 & 0,008 & 24 & 27 & 40 & 44 & 52 & 60 & 156 & 28 & 33 & 38 \\
\hline Máximo & 0,540 & 0,651 & 0,403 & 0,824 & 0,038 & 38 & 44 & 46 & 92 & 90 & 64 & 239 & 44 & 55 & 65 \\
\hline Mínimo & $-0,728$ & $-0,439$ & $-0,376$ & 0,067 & $-0,027$ & 7 & 7 & 8 & 4 & 5 & 5 & 17 & 17 & 16 & 7 \\
\hline Mediana & $-0,061$ & 0,050 & $-0,053$ & 0,451 & $-0,002$ & 20 & 22 & 25 & 20 & 26 & 21 & 66 & 28 & 37 & 34 \\
\hline Promedio & $-0,068$ & 0,060 & $-0,032$ & 0,467 & $-0,001$ & 19 & 22 & 25 & 22 & 27 & 26 & 75 & 28 & 37 & 34 \\
\hline
\end{tabular}

G4 G9 16b

\begin{tabular}{|r|r|r|r|r|r|r|r|r|r|r|r|r|r|r|}
\hline$-1,571$ & 1,520 & $-0,223$ & 0,838 & 0,014 & 16 & 14 & 17 & 22 & 21 & 15 & 58 & 38 & 36 & 26 \\
\hline$-2,272$ & 1,562 & $-0,462$ & 1,632 & $-0,014$ & 10 & 11 & 11 & 6 & 7 & 3 & 16 & 38 & 44 & 19 \\
\hline$-0,858$ & 2,010 & $-1,746$ & 1,657 & 0,013 & 8 & 14 & 14 & 10 & 16 & 10 & 36 & 28 & 44 & 28 \\
\hline 0,000 & 3,152 & $-0,203$ & 1,340 & 0,038 & 9 & 10 & 14 & 7 & 12 & 5 & 24 & 29 & 50 & 21 \\
\hline$-2,457$ & 0,877 & $-0,036$ & 1,931 & $-0,003$ & 6 & 11 & 11 & 7 & 7 & 3 & 17 & 41 & 41 & 18 \\
\hline$-0,484$ & 1,171 & $-0,763$ & 1,620 & 0,034 & 6 & 9 & 13 & 5 & 9 & 4 & 18 & 28 & 50 & 22 \\
\hline$-0,575$ & 2,114 & $-0,948$ & 1,209 & $-0,002$ & 12 & 12 & 16 & 10 & 12 & 12 & 34 & 29 & 35 & 35 \\
\hline$-2,266$ & 1,699 & $-0,694$ & 0,953 & $-0,009$ & 12 & 16 & 20 & 64 & 50 & 40 & 154 & 42 & 32 & 26 \\
\hline 0,816 & 1,535 & $-2,842$ & 2,347 & $-0,009$ & 3 & 4 & 5 & 4 & 4 & 3 & 11 & 36 & 36 & 27 \\
\hline$-3,489$ & 1,713 & 0,024 & 1,635 & 0,018 & 8 & 10 & 11 & 11 & 10 & 3 & 24 & 46 & 42 & 13 \\
\hline$-1,697$ & 1,041 & $-0,329$ & 1,513 & 0,001 & 6 & 8 & 8 & 6 & 11 & 6 & 23 & 26 & 48 & 26 \\
\hline$-2,163$ & 0,860 & $-0,118$ & 1,552 & $-0,014$ & 5 & 6 & 9 & 10 & 9 & 10 & 29 & 34 & 31 & 34 \\
\hline 0,816 & 3,152 & 0,024 & 2,347 & 0,038 & 16 & 16 & 20 & 64 & 50 & 40 & 154 & 46 & 50 & 35
\end{tabular}




\begin{tabular}{|c|c|c|c|c|c|c|c|c|c|c|c|c|c|c|c|c|}
\hline \multirow[t]{5}{*}{ G10 } & 26k1 & $-1,335$ & 1,221 & $-0,036$ & 0,468 & $-0,015$ & 8 & 9 & 13 & 9 & 14 & 9 & 32 & 28 & 44 & 28 \\
\hline & $28 \mathrm{e}$ & $-2,045$ & 0,306 & 0,104 & 1,182 & $-0,028$ & 10 & 10 & 12 & 16 & 10 & 16 & 42 & 38 & 24 & 38 \\
\hline & $45 \mathrm{~L}$ & $-2,313$ & $-0,112$ & 0,167 & 0,996 & $-0,001$ & 22 & 24 & 25 & 25 & 32 & 31 & 88 & 28 & 36 & 35 \\
\hline & $8 a 1$ & $-3,597$ & $-1,560$ & 1,248 & 1,973 & $-0,023$ & 5 & 6 & 7 & 4 & 10 & 4 & 18 & 22 & 56 & 22 \\
\hline & $9 \mathrm{c1}$ & $-3,025$ & 0,394 & 0,638 & 0,866 & $-0,019$ & 22 & 24 & 24 & 40 & 39 & 21 & 100 & 40 & 39 & 21 \\
\hline & Máximo & $-1,335$ & 1,221 & 1,248 & 1,973 & $-0,001$ & 22 & 24 & 25 & 40 & 39 & 31 & 100 & 40 & 56 & 38 \\
\hline & Mínimo & $-3,597$ & $-1,560$ & $-0,036$ & 0,468 & $-0,028$ & 5 & 6 & 7 & 4 & 10 & 4 & 18 & 22 & 24 & 21 \\
\hline
\end{tabular}

G7 G11 $48 \mathrm{~K}$ \begin{tabular}{|l|l|l|l|l|l|}
\hline 0,958 & $-1,850$ & 0,017 & 1,845 & 0,008 \\
\hline
\end{tabular} \begin{tabular}{l|l|l|l|}
8 & 11 & 13 \\
\hline
\end{tabular} \begin{tabular}{|l|l|l|l|l|l|l|}
14 & 14 & 4 & 32 & 44 & 44 & 13 \\
\hline
\end{tabular}

\begin{tabular}{|c|c|c|c|c|c|c|c|c|c|c|c|c|c|c|c|}
\hline G11c G12a 10b & $-0,358$ & 0,137 & $-0,005$ & 0,739 & 0,025 & 20 & 24 & 32 & 16 & 24 & 16 & 56 & 29 & 43 & 29 \\
\hline $12 \mathrm{f} 2$ & 0,207 & $-0,090$ & $-0,267$ & 0,879 & $-0,002$ & 28 & 28 & 32 & 25 & 16 & 14 & 55 & 45 & 29 & 25 \\
\hline $13 c$ & $-0,123$ & $-0,052$ & 0,011 & 0,912 & $-0,011$ & 12 & 13 & 16 & 20 & 26 & 22 & 68 & 29 & 38 & 32 \\
\hline $19 b 2$ & $-0,444$ & 0,208 & 0,120 & 0,667 & 0,003 & 9 & 9 & 15 & 12 & 12 & 19 & 43 & 28 & 28 & 44 \\
\hline $19 c$ & $-0,430$ & 0,574 & 0,056 & 0,517 & 0,011 & 15 & 22 & 22 & 24 & 29 & 26 & 79 & 30 & 37 & 33 \\
\hline $24 d$ & 0,541 & 0,094 & $-0,731$ & 0,735 & 0,101 & 10 & 10 & 16 & 6 & 11 & 1 & 18 & 33 & 61 & 6 \\
\hline $24 j$ & $-0,202$ & 0,140 & $-0,046$ & 0,740 & $-0,012$ & 12 & 14 & 16 & 10 & 12 & 4 & 26 & 38 & 46 & 15 \\
\hline $31 d$ & 0,030 & 0,181 & $-0,145$ & 0,680 & 0,009 & 7 & 8 & 9 & 7 & 10 & 6 & 23 & 30 & 43 & 26 \\
\hline $31 f$ & 0,062 & 0,236 & $-0,179$ & 0,704 & 0,003 & 9 & 9 & 10 & 8 & 10 & 11 & 29 & 28 & 34 & 38 \\
\hline $36 b 2$ & $-0,486$ & $-0,263$ & 0,318 & 0,928 & 0,001 & 31 & 32 & 40 & 34 & 29 & 41 & 104 & 33 & 28 & 39 \\
\hline $42 c$ & 0,268 & $-0,050$ & $-0,304$ & 0,790 & 0,003 & 10 & 16 & 16 & 20 & $?$ & $?$ & & & & \\
\hline $44 \mathrm{~L}$ & 0,109 & $-0,010$ & $-0,243$ & 0,885 & 0,005 & 27 & 27 & 29 & 23 & 31 & 37 & 91 & 25 & 34 & 41 \\
\hline $45 B$ & $-0,191$ & 0,066 & 0,010 & 0,763 & 0,006 & 13 & 15 & 19 & 7 & 8 & 9 & 24 & 29 & 33 & 38 \\
\hline $46 \mathrm{~A}$ & 0,104 & 0,017 & $-0,286$ & 0,858 & 0,008 & 12 & 14 & 16 & 8 & 8 & 9 & 25 & 32 & 32 & 36 \\
\hline $46 N$ & $-0,182$ & 0,286 & $-0,099$ & 0,683 & 0,003 & 11 & 10 & 14 & 6 & 8 & 5 & 19 & 32 & 42 & 26 \\
\hline $49 \mathrm{~F}$ & $-0,297$ & $-0,174$ & 0,250 & 1,005 & $-0,006$ & 8 & 10 & 10 & 20 & 16 & 15 & 51 & 39 & 31 & 29 \\
\hline $50 B$ & 0,127 & 0,187 & $-0,193$ & 0,668 & 0,025 & 8 & 10 & 14 & 10 & 26 & 19 & 55 & 18 & 47 & 35 \\
\hline
\end{tabular}




\begin{tabular}{|c|c|c|c|c|c|c|c|c|c|c|c|c|c|c|}
\hline $50 M$ & $-0,250$ & 0,130 & 0,210 & 0,712 & $-0,023$ & 8 & \begin{tabular}{|l|l|}
10 & 11 \\
\end{tabular} & 7 & 15 & 8 & 30 & 23 & 50 & 27 \\
\hline $54 \mathrm{C}$ & $-0,348$ & 0,143 & 0,036 & 0,689 & 0,010 & 9 & \begin{tabular}{l|l|}
11 & 15 \\
\end{tabular} & 8 & 10 & 9 & 27 & 30 & 37 & 33 \\
\hline $5 d$ & $-0,236$ & $-0,102$ & 0,115 & 0,914 & $-0,015$ & 19 & \begin{tabular}{|l|l|}
22 & 29 \\
\end{tabular} & 11 & 20 & 16 & 47 & 23 & 43 & 34 \\
\hline $7 a 2$ & 0,075 & $-0,277$ & $-0,117$ & 0,973 & 0,003 & 16 & \begin{tabular}{l|l|}
18 & 22 \\
\end{tabular} & 21 & 21 & 17 & 59 & 36 & 36 & 29 \\
\hline Máximo & 0,541 & 0,574 & 0,318 & 1,005 & 0,101 & 31 & $\begin{array}{ll}32 & 40\end{array}$ & 34 & 31 & 41 & 104 & 45 & 61 & 44 \\
\hline Mínimo & $-0,486$ & $-0,277$ & $-0,731$ & 0,517 & $-0,023$ & 7 & 89 & 6 & 8 & 1 & 18 & 18 & 28 & 6 \\
\hline Mediana & $-0,182$ & 0,094 & $-0,046$ & 0,740 & 0,003 & 12 & 1416 & 11 & 16 & 15 & 45 & 30 & 37 & 33 \\
\hline Promedio & $-0,096$ & 0,066 & $-0,071$ & 0,783 & 0,007 & 14 & 1619 & 14 & 17 & 15 & 46 & 31 & 39 & 31 \\
\hline
\end{tabular}

G11: G12b 13g

$14 \mathrm{c} 2$

$16 \mathrm{~d} 3$

19a1

$22 \mathrm{~g}$

$23 \mathrm{~h}$

$26 \mathrm{~b}$

$26 \mathrm{k} 2$

$28 \mathrm{c}$

$29 f 2$

$28 \mathrm{~g}$

31d1

$31 \mathrm{e}$

$32 b$

$3 b 2$

$3 d$

$44 \mathrm{~F}$

$44 \mathrm{H}$

$44 \mathrm{M}$

45D

45J

$46 \mathrm{C}$

$46 \mathrm{H}$

$47 \mathrm{C}$

$48 \mathrm{~F}$

\begin{tabular}{|c|c|c|c|c|c|c|c|c|c|c|c|c|c|c|}
\hline$-0,005$ & 0,132 & $-0,447$ & 0,825 & 0,015 & 22 & 22 & 30 & 16 & 32 & 26 & 74 & 22 & 43 & 35 \\
\hline$-0,026$ & 0,015 & $-0,129$ & 0,946 & $-0,006$ & 10 & 13 & 15 & 9 & 10 & 0 & 19 & 47 & 53 & 0 \\
\hline$-0,131$ & 0,277 & $-0,266$ & 0,751 & $-0,028$ & 14 & 15 & 16 & 14 & 12 & 10 & 36 & 39 & 33 & 28 \\
\hline$-0,109$ & 0,143 & $-0,171$ & 0,818 & $-0,013$ & 6 & 9 & 13 & 6 & 10 & 6 & 22 & 27 & 45 & 27 \\
\hline 0,053 & 0,196 & $-0,385$ & 0,825 & 0,015 & 22 & 28 & 30 & 16 & 20 & 10 & 46 & 35 & 43 & 22 \\
\hline 0,215 & 0,228 & $-0,315$ & 0,870 & $-0,007$ & 20 & 28 & 28 & 17 & 17 & 24 & 58 & 29 & 29 & 41 \\
\hline$-0,651$ & 0,345 & 0,190 & 0,947 & $-0,007$ & 6 & 7 & 8 & 5 & 6 & 5 & 16 & 31 & 38 & 31 \\
\hline$-0,219$ & 0,141 & $-0,198$ & 0,875 & 0,006 & 10 & 12 & 16 & 13 & 17 & 9 & 39 & 33 & 44 & 23 \\
\hline$-0,035$ & 0,284 & $-0,427$ & 0,932 & $-0,016$ & 6 & 7 & 9 & 5 & 5 & 8 & 18 & 28 & 28 & 44 \\
\hline$-0,227$ & 0,239 & 0,064 & 0,817 & $-0,030$ & 7 & 8 & 8 & 6 & 9 & 7 & 22 & 27 & 41 & 32 \\
\hline$-0,162$ & 0,155 & $-0,247$ & 0,905 & $-0,001$ & 14 & 15 & 18 & 7 & 15 & 14 & 36 & 19 & 42 & 39 \\
\hline$-0,361$ & 0,050 & $-0,064$ & 1,098 & 0,015 & 6 & 6 & 10 & 2 & 13 & 5 & 20 & 10 & 65 & 25 \\
\hline 0,099 & 0,031 & $-0,491$ & 0,971 & $-0,003$ & 10 & 12 & 15 & 11 & 18 & 4 & 33 & 33 & 55 & 12 \\
\hline$-0,004$ & 0,111 & $-0,369$ & 0,959 & $-0,033$ & 10 & 8 & 12 & 13 & 13 & 10 & 36 & 36 & 36 & 28 \\
\hline 0,383 & $-0,182$ & $-0,610$ & 1,050 & 0,013 & 15 & 20 & 24 & 24 & 21 & 13 & 58 & 41 & 36 & 22 \\
\hline$-0,335$ & 0,122 & 0,048 & 0,851 & $-0,002$ & 9 & 8 & 11 & 6 & 10 & 7 & 23 & 26 & 43 & 30 \\
\hline$-0,037$ & 0,033 & $-0,268$ & 0,910 & 0,003 & 24 & 25 & 26 & 38 & 33 & 19 & 90 & 42 & 37 & 21 \\
\hline$-0,040$ & 0,042 & $-0,138$ & 0,933 & 0,003 & 24 & 25 & 26 & 31 & 32 & 27 & 90 & 34 & 36 & 30 \\
\hline$-0,281$ & 0,294 & $-0,088$ & 0,820 & 0,005 & 11 & 14 & 14 & 11 & 9 & 1 & 21 & 52 & 43 & 5 \\
\hline 0,026 & $-0,005$ & $-0,418$ & 0,925 & 0,002 & 23 & 28 & 33 & 23 & 40 & 34 & 97 & 24 & 41 & 35 \\
\hline$-0,193$ & 0,077 & $-0,312$ & 0,872 & $-0,003$ & 16 & 20 & 21 & 21 & 22 & 6 & 49 & 43 & 45 & 12 \\
\hline 0,337 & $-0,004$ & $-0,342$ & 1,045 & $-0,004$ & 8 & 9 & 11 & 9 & 6 & $?$ & & & & \\
\hline$-0,275$ & 0,092 & 0,080 & 0,876 & $-0,009$ & 10 & 12 & 16 & 10 & 20 & 15 & 45 & 22 & 44 & 33 \\
\hline 0,078 & $-0,027$ & $-0,263$ & 1,108 & $-0,011$ & 15 & 16 & 19 & 21 & 22 & 22 & 65 & 32 & 34 & 34 \\
\hline$-0,391$ & $-0,281$ & 0,086 & 1,076 & $-0,017$ & 18 & 20 & 28 & 10 & 14 & 9 & 33 & 30 & 42 & 27 \\
\hline
\end{tabular}




\begin{tabular}{|c|c|c|c|c|c|c|c|c|c|c|c|c|c|c|c|}
\hline 48J & $-0,074$ & \begin{tabular}{|l|l}
0,065 \\
\end{tabular} & $-0,141$ & \begin{tabular}{|c|}
0,983 \\
\end{tabular} & $-0,013$ & 12 & 13 & \begin{tabular}{|l|}
15 \\
\end{tabular} & 15 & 18 & 33 & 66 & 23 & 27 & 50 \\
\hline $48 \mathrm{~L}$ & 0,230 & 0,339 & $-0,359$ & 0,871 & $-0,015$ & 11 & 14 & 18 & 6 & 11 & 8 & 25 & 24 & 44 & 32 \\
\hline $48 \mathrm{M}$ & $-0,092$ & 0,079 & $-0,215$ & 0,935 & $-0,003$ & 20 & 26 & 28 & 28 & 26 & 32 & 86 & 33 & 30 & 37 \\
\hline $49 R$ & $-0,444$ & 0,286 & 0,028 & 0,895 & $-0,006$ & 12 & 14 & 13 & 5 & 32 & 14 & 51 & 10 & 63 & 27 \\
\hline $4 a 2$ & 0,054 & 0,414 & $-0,315$ & 0,730 & $-0,003$ & 24 & 26 & 32 & 34 & 44 & 16 & 94 & 36 & 47 & 17 \\
\hline $50 \mathrm{C}$ & 0,216 & 0,162 & $-0,472$ & 0,810 & $-0,028$ & 12 & 13 & 17 & 32 & 59 & 74 & 165 & 19 & 36 & 45 \\
\hline $50 \mathrm{~N}$ & $-0,023$ & 0,246 & $-0,263$ & 0,941 & $-0,007$ & 6 & 9 & 8 & 4 & 4 & 2 & 10 & 40 & 40 & 20 \\
\hline $53 \mathrm{D}$ & $-0,021$ & $-0,269$ & $-0,381$ & 1,124 & 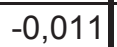 & 18 & 22 & 25 & 37 & 47 & 24 & 108 & 34 & 44 & 22 \\
\hline 531 & $-0,405$ & \begin{tabular}{|l|l|}
0,279 \\
\end{tabular} & $-0,156$ & 0,911 & $-0,001$ & 11 & 15 & 18 & 16 & 16 & 16 & 48 & 33 & 33 & 33 \\
\hline 53J & 0,196 & $-0,285$ & $-0,276$ & 1,128 & $-0,008$ & 14 & 16 & 25 & 15 & 28 & 12 & 55 & 27 & 51 & 22 \\
\hline $54 \mathrm{~N}$ & 0,179 & 0,113 & $-0,458$ & 0,901 & $-0,002$ & 8 & 11 & 15 & 9 & 10 & 8 & 27 & 33 & 37 & 30 \\
\hline $5 b$ & 0,259 & $-0,402$ & $-0,391$ & 1,260 & 0,000 & 14 & 16 & 20 & 17 & 27 & 27 & 71 & 24 & 38 & 38 \\
\hline 9a1 & $-0,413$ & 0,318 & 0,059 & 0,876 & $-0,001$ & 10 & 11 & 12 & 8 & 9 & 8 & 25 & 32 & 36 & 32 \\
\hline Máximo & 0,383 & 0,414 & 0,190 & 1,260 & 0,015 & 24 & 28 & 33 & 38 & 59 & 74 & 165 & 52 & 65 & 50 \\
\hline Mínimo & $-0,651$ & $-0,402$ & $-0,610$ & 0,730 & $-0,033$ & 6 & 6 & 8 & 2 & 4 & 0 & 10 & 10 & 27 & 0 \\
\hline Mediana & $-0,036$ & 0,118 & $-0,264$ & 0,910 & $-0,004$ & 12 & 14 & 17 & 13 & 17 & 10 & 45 & 32 & 41 & 30 \\
\hline Promedio & $-0,069$ & 0,101 & $-0,232$ & 0,931 & $-0,006$ & 13 & 16 & 19 & 15 & 20 & 15 & 51 & 31 & 41 & 28 \\
\hline G11kG12c 10c & 0,395 & 0,275 & $-0,493$ & 0,528 & 0,001 & 44 & 46 & 50 & 24 & 30 & 26 & 80 & 30 & 38 & 33 \\
\hline $11 b$ & $-0,189$ & 0,090 & $-0,098$ & 0,649 & 0,003 & 30 & 35 & 42 & 36 & 72 & 57 & 165 & 22 & 44 & 35 \\
\hline $11 d$ & $-0,244$ & 0,160 & $-0,215$ & 0,681 & $-0,001$ & 22 & 20 & 24 & 10 & 12 & 8 & 30 & 33 & 40 & 27 \\
\hline $1 \mathrm{~b} 1$ & 0,064 & $-0,033$ & $-0,336$ & 0,630 & \begin{tabular}{|l|}
$-0,027$ \\
\end{tabular} & 26 & 30 & 40 & 33 & 43 & 47 & 123 & 27 & 35 & 38 \\
\hline $1 c$ & $-0,305$ & 0,400 & $-0,209$ & 0,611 & $-0,007$ & 30 & 39 & 44 & 21 & 36 & 19 & 76 & 28 & 47 & 25 \\
\hline $22 \mathrm{a} 2$ & $-0,215$ & $-0,267$ & $-0,224$ & 0,958 & 0,000 & 10 & 10 & 14 & 6 & 9 & 2 & 17 & 35 & 53 & 12 \\
\hline $27 i$ & $-0,306$ & $-0,109$ & $-0,191$ & 0,859 & $-0,034$ & 16 & 17 & 20 & 23 & & & & & & \\
\hline $31 \mathrm{~g}$ & $-0,039$ & 0,187 & $-0,207$ & 0,496 & \begin{tabular}{|l|} 
\\
\end{tabular} & 14 & 16 & 17 & 10 & 12 & 16 & 38 & 26 & 32 & 42 \\
\hline $32 c$ & $-0,019$ & $-0,308$ & $-0,259$ & 1,000 & $-0,023$ & 9 & 10 & 11 & 8 & 18 & & & & & \\
\hline 32e 1 & $-0,237$ & 0,319 & $-0,199$ & 0,482 & 0,000 & 12 & 14 & 16 & 26 & 30 & 16 & 72 & 36 & 42 & 22 \\
\hline $44 \mathrm{E}$ & $-0,012$ & 0,104 & $-0,340$ & 0,631 & $-0,012$ & 25 & 27 & 29 & 28 & 43 & 23 & 94 & 30 & 46 & 24 \\
\hline $44 \mathrm{G}$ & $-0,213$ & 0,126 & $-0,263$ & |0,717 & 0,005 & 40 & 48 & 54 & 26 & 25 & 42 & 93 & 28 & 27 & 45 \\
\hline $45 C$ & $-0,162$ & 0,210 & $-0,270$ & |0,558 & 0,009 & 22 & 21 & 23 & 8 & 20 & 6 & 34 & 24 & 59 & 18 \\
\hline 451 & $-0,646$ & 0,036 & $-0,001$ & 0,764 & 0,020 & 14 & 17 & 20 & 17 & 27 & 18 & 62 & 27 & 44 & 29 \\
\hline $46 U$ & $-0,475$ & $-0,571$ & $-0,144$ & 1,161 & 0,019 & 10 & 10 & 10 & 4 & 7 & 2 & 13 & 31 & 54 & 15 \\
\hline $48 \mathrm{E}$ & $-0,251$ & 0,226 & $-0,038$ & 0,469 & $-0,007$ & 24 & 29 & 38 & 43 & 53 & 50 & 146 & 29 & 36 & 34 \\
\hline
\end{tabular}




\begin{tabular}{|c|c|c|c|c|c|c|c|c|c|c|c|c|c|c|}
\hline $53 \mathrm{~F}$ & $-0,052$ & 0,252 & $-0,314$ & 0,580 & 0,004 & 28 & \begin{tabular}{l|l|}
36 & 38 \\
\end{tabular} & 26 & 34 & 19 & 79 & 33 & 43 & 24 \\
\hline $54 \mathrm{H}$ & $-0,272$ & 0,222 & $-0,112$ & 0,570 & 0,001 & 14 & \begin{tabular}{l|l|}
16 & 25 \\
\end{tabular} & 14 & 18 & 28 & 60 & 23 & 30 & 47 \\
\hline $6 b$ & $-0,286$ & 0,323 & $-0,156$ & 0,591 & 0,026 & 22 & \begin{tabular}{|l|l|}
30 & 44 \\
\end{tabular} & 42 & 66 & 94 & 202 & 21 & 33 & 47 \\
\hline Máximo & 0,395 & 0,400 & $-0,001$ & 1,161 & 0,026 & 44 & 4854 & 43 & 72 & 94 & 202 & 36 & 59 & 47 \\
\hline Mínimo & $-0,646$ & $-0,571$ & $-0,493$ & 0,469 & $-0,034$ & 9 & 1010 & 4 & 7 & 2 & 13 & 21 & 27 & 12 \\
\hline Mediana & $-0,215$ & 0,160 & $-0,209$ & 0,630 & 0,000 & 22 & 2125 & 23 & 29 & 19 & 76 & 28 & 42 & 29 \\
\hline Promedio & $-0,182$ & 0,086 & $-0,214$ & 0,681 & $-0,002$ & 22 & $\begin{array}{ll}25 & 29\end{array}$ & 21 & 31 & 28 & 81 & 28 & 41 & 30 \\
\hline
\end{tabular}

\begin{tabular}{|c|c|c|c|c|c|c|c|c|c|c|c|c|c|c|c|}
\hline $\mathrm{G} 11 \in \mathrm{G} 12 \mathrm{~d} 17 \mathrm{~b}$ & 0,800 & $-0,033$ & $-0,524$ & 0,838 & $-0,005$ & 16 & 21 & 25 & 10 & 29 & 17 & 56 & 18 & 52 & 30 \\
\hline $30 c$ & 0,247 & $-0,063$ & $-0,157$ & 0,780 & 0,009 & 8 & 9 & 12 & 5 & 11 & 6 & 22 & 23 & 50 & 27 \\
\hline $44 \mathrm{~A}$ & 0,419 & $-0,440$ & $-0,300$ & 1,051 & 0,003 & 18 & 17 & 15 & 9 & 14 & 0 & 23 & 39 & 61 & 0 \\
\hline 47J & 0,289 & $-0,479$ & $-0,170$ & 1,253 & $-0,004$ & 14 & 17 & 19 & 20 & 23 & 18 & 61 & 33 & 38 & 30 \\
\hline $54 \mathrm{~L}$ & 0,513 & $-0,389$ & $-0,154$ & 0,992 & $-0,012$ & 24 & 25 & 28 & 14 & 16 & 43 & 73 & 19 & 22 & 59 \\
\hline Máximo & 0,800 & $-0,033$ & $-0,154$ & 1,253 & 0,009 & 24 & 25 & 28 & 20 & 29 & 43 & 73 & 39 & 61 & 59 \\
\hline Mínimo & 0,247 & $-0,479$ & $-0,524$ & 0,780 & $-0,012$ & 8 & 9 & 12 & 5 & 11 & 0 & 22 & 18 & 22 & 0 \\
\hline Mediana & 0,419 & $-0,389$ & $-0,170$ & 0,992 & $-0,004$ & 16 & 17 & 19 & 10 & 16 & 17 & 56 & 23 & 50 & 30 \\
\hline Promedio & 0,454 & $-0,281$ & $-0,261$ & 0,983 & $-0,002$ & 16 & 18 & 20 & 12 & 19 & 17 & 47 & 26 & 44 & 29 \\
\hline
\end{tabular}

\begin{tabular}{|c|c|c|c|c|c|c|c|c|c|c|c|c|c|c|c|}
\hline G9+1G12e $10 d 2$ & $-0,991$ & $-0,752$ & 0,005 & 1,029 & 0,001 & 24 & 24 & 27 & 30 & 33 & 36 & 99 & 30 & 33 & 36 \\
\hline $45 \mathrm{M}$ & $-0,602$ & 0,699 & $-0,122$ & 0,468 & $-0,004$ & 30 & 41 & 48 & 64 & 139 & 93 & 296 & 22 & 47 & 31 \\
\hline $48 B$ & $-1,253$ & $-0,666$ & $-0,010$ & 0,811 & $-0,007$ & 23 & 24 & 25 & 37 & 39 & 54 & 130 & 28 & 30 & 42 \\
\hline $49 C$ & 0,471 & $-0,329$ & $-0,919$ & 0,587 & $-0,021$ & 17 & 22 & 23 & 32 & 42 & 28 & 102 & 31 & 41 & 27 \\
\hline $5 c$ & $-0,949$ & 0,250 & $-0,009$ & 0,746 & $-0,007$ & 16 & 16 & 20 & $?$ & 16 & $?$ & & & & \\
\hline $8 b 2$ & 0,159 & 0,171 & $-0,955$ & 0,568 & $-0,019$ & 17 & 20 & 24 & 26 & 46 & 35 & 107 & 24 & 43 & 33 \\
\hline Máximo & 0,471 & 0,699 & 0,005 & 1,029 & 0,001 & 30 & 41 & 48 & 64 & 139 & 93 & 296 & 31 & 47 & 42 \\
\hline Mínimo & $-1,253$ & $-0,752$ & $-0,955$ & 0,468 & $-0,021$ & 16 & 16 & 20 & 26 & 16 & 28 & 99 & 22 & 30 & 27 \\
\hline Mediana & $-0,775$ & $-0,079$ & $-0,066$ & 0,667 & $-0,007$ & 20 & 23 & 25 & 32 & 41 & 36 & 107 & 28 & 41 & 33 \\
\hline Promedio & $-0,527$ & $-0,104$ & $-0,335$ & 0,701 & $-0,009$ & 21 & 25 & 28 & 38 & 53 & 49 & 147 & 27 & 39 & 34 \\
\hline
\end{tabular}

\begin{tabular}{|c|c|c|c|c|c|c|c|c|c|c|c|c|c|c|c|}
\hline G11£G12f $15 a$ & 0,770 & 0,683 & $-0,331$ & 0,578 & 0,014 & 16 & 22 & 25 & 3 & 24 & 15 & 42 & 7 & 57 & 36 \\
\hline $18 \mathrm{~b} 2$ & 0,584 & 0,643 & $-0,062$ & 0,405 & $-0,005$ & 28 & 33 & 36 & 35 & 36 & 53 & 124 & 28 & 29 & 43 \\
\hline $34 c$ & 0,243 & 0,996 & $-0,287$ & 0,492 & $-0,005$ & 11 & 16 & 18 & 31 & 45 & 86 & 162 & 19 & 28 & 53 \\
\hline $45 \mathrm{~A}$ & 0,485 & 0,665 & $-0,358$ & 0,562 & 0,021 & 20 & 23 & 28 & 6 & 34 & 19 & 59 & 10 & 58 & 32 \\
\hline 491 & 0,134 & 0,674 & 0,063 & 0,600 & 0,017 & 11 & 10 & 11 & 14 & 13 & 16 & 43 & 33 & 30 & 37 \\
\hline
\end{tabular}




\begin{tabular}{|r|r|r|r|r|r|r|r|rrr|r|r|r|r|r|}
\hline$-0,559$ & 0,089 & 0,609 & 0,999 & $-0,028$ & 9 & 9 & 8 & 5 & 14 & 8 & 27 & 19 & 52 & 30 \\
\hline 0,770 & 0,996 & 0,609 & 0,999 & 0,021 & 28 & 33 & 36 & 35 & 45 & 86 & 162 & 33 & 58 & 53 \\
$-0,559$ & 0,089 & $-0,358$ & 0,405 & $-0,028$ & 9 & 9 & 8 & 3 & 13 & 8 & 27 & 7 & 28 & 30 \\
0,364 & 0,669 & $-0,174$ & 0,570 & 0,005 & 14 & 19 & 22 & 10 & 29 & 18 & 51 & 19 & 41 & 36 \\
0,276 & 0,625 & $-0,061$ & 0,606 & 0,002 & 16 & 19 & 21 & 16 & 28 & 33 & 76 & 19 & 42 & 38 \\
\hline
\end{tabular}

Mediana

$\begin{array}{llllll}0,276 & 0,625 & -0,061 & 0,606 & 0,002\end{array}$

1921

10 